\title{
Interaktion des Frühsommer-Meningoenzephalitis- Virus mit antigenpräsentierenden Zellen
}

\author{
Dissertation \\ zur Erlangung des Doktorgrades \\ der Mathematisch-Naturwissenschaftlichen Fakultäten \\ der Georg-August-Universität zu Göttingen
}

vorgelegt von

Bastian Dörrbecker

aus Kassel

Göttingen 2011 
Anleiter:

Prof. Dr. Frank T. Hufert

Referent:

PD. Dr. Michael Hoppert

Koreferent:

Prof. Dr. Gerhard Hunsmann

Tag der mündlichen Prüfung:

17.03.2011 


\section{„Das Geheimnis des Könnens liegt im Wollen“"}

Giuseppe Mazzini 


\section{Inhaltsverzeichnis}

I. Inhaltsverzeichnis.......................................................................

II. Abkürzungsverzeichnis....................................................................V

III. Zusammenfassung.......................................................................XII

IV. Abstract....................................................................................III

1 Einleitung ....................................................................................... 1

1.1 Das Immunsystem .......................................................................

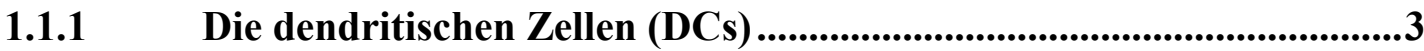

1.1.2 Die DC-Subpopulationen........................................................................3

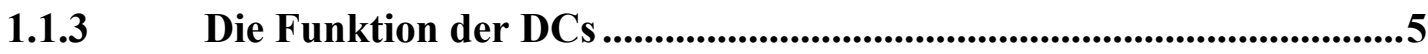

1.1.3.1 PAMP-Erkennung und PRR-vermittelte Aktivierung angeborener Immunmechanismen in DCs ......................................... 6

1.1.3.2 Das Typ I Interferonsystem und die Interferonantwort der

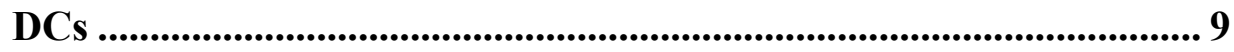

1.1.3.3 Antigenprozessierung und -präsentation.......................................... 11

1.1.4 Aktivierung der DCs und Migration ................................................12

1.1.5 Interaktion von DCs mit T-Zellen ......................................................13

1.2 Das Frühsommer-Meningoenzephalitis-Virus ............................15

1.2.1 Virusstruktur und Replikation ................................................................15

1.2.2 Viraler Übertragungszyklus und Wege der Infektion........................18

1.2.3 Der Krankheitsverlauf der FSME .....................................................20

1.2.4 Interaktionen des FSME-Virus mit dem Immunsystem der Säuger21

1.3 Ziele der Arbeit........................................................................................25

2 Material und Methoden ........................................................ 26

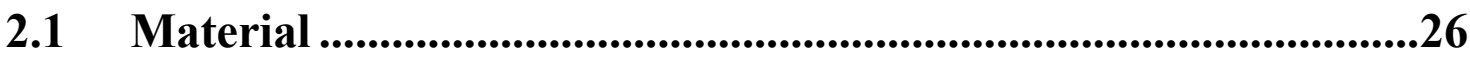

2.1.1 Chemikalien ......................................................................................................26

2.1.2 Materialien für die Zellkultur und andere Verbrauchswaren .........27

2.1.3 Gerätschaften ....................................................................................................32

2.1.4 Puffer, Medien und Lösungen...................................................35

2.1.5 Antikörper und Fluoreszensfarbstoffe..........................................38

2.1.6 Oligonukleotidprimer und Sonden .........................................................41

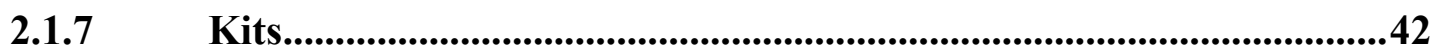

2.1.8 Datenanalyse und Software .........................................................43 
I Inhaltsverzeichnis $\quad$ II

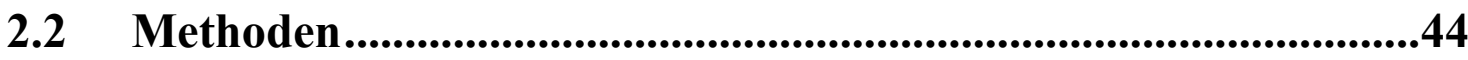

2.2.1 Zellisolation und Zellkultur .........................................................44

2.2.1.1 Bestimmung der Lebendzellzahl..................................................... 44

2.2.1.2 Kultivierung von etablierten Zelllinien ............................................ 45

2.2.1.2.1 Zelllinien .............................................................................................44

2.2.1.2.2 Subkultivierung / Zellpassage ......................................................45

2.2.1.3 Kryokonservierung und Auftauen von Zellen.....................................4 47

2.2.1.4 Isolation von PBMCs aus humanem Buffy-Coat ............................. 48

2.2.1.5 Isolation von einzelnen Zellpopulationen aus PBMCs ..................... 49

2.2.1.5.1 Isolation von mDCs aus PBMCs....................................................50

2.2.1.5.2 Isolation von pDCs aus PBMCs...............................................51

2.2.1.5.3 Isolation von T-Zellen aus PBMCs..........................................53

2.2.1.5.4 Kokultur von pDCs und T-Zellen...................................................54

2.2.2 Arbeiten mit Viren ...........................................................................55

2.2.2.1 Arbeiten unter S3-Bedingungen .......................................................... 55

2.2.2.2 Anzucht und Kultivierung von Viren.............................................. 55

2.2.2.3 Bestimmung des Virustiters ....................................................................5 56

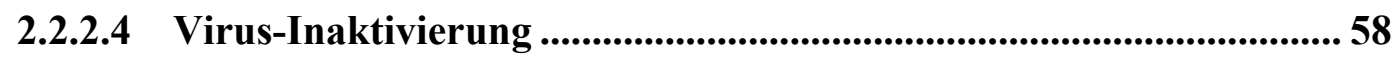

2.2.2.4.1 UV-Inaktivierung von Viren .........................................................58

2.2.2.4.2 Inaktivierung von Viren mittels PFA..........................................59

2.2.2.5 Virusinfektion von DCs und T-Zellen ...............................................5 59

2.2.3 Die polychromatische Durchflußzytometrie......................................61

2.2.4 Proliferationstest mittels CFSE .....................................................63

2.2.5 Konzentrationsbestimmung von Zytokinen mittels CBA ................65

2.2.6 Konzentrationsbestimmung von Interferon- $\alpha$ mittels ELISA ...........67

2.2.7 Zellviabilitätsmessung mittels MTT-Test ............................................68

2.2.8 Zellviabilitätsbestimmung mittels Lichtmikroskopie ........................70

2.2.9 Neutralisation des Interferonrezeptors (IFNAR)...............................70

2.2.10 Filtration von Zellkulturüberstände zur Entfernung von Zytokinen

2.2.11 Präparation und Nachweis von Nukleinsäuren...................................73

2.2.11.1 RNA Isolation ......................................................................................73

2.2.11.2 DNA Ausschluß / RNA Aufreinigung................................................... 74

2.2.11.3 Quantifizierung von RNA mittels Quant-iT RiboGreen RNA-

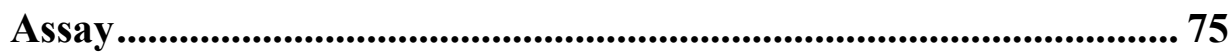

2.2.11.4 Die Polymerase-Ketten-Reaktion (PCR)................................................ 75

2.2.11.5 Die Reverse Transkriptase-PCR (RT-PCR) ................................... 77

2.2.11.6 Die GAPDH-RT-PCR ................................................................... 77

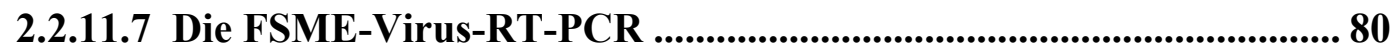

2.2.11.8 Die Agarose-Gelelektrophorese .................................................... 83

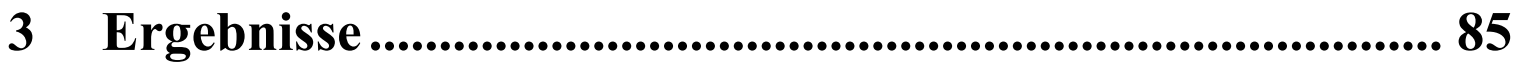

3.1 Die Immunantwort der DCs auf das FSME-Virus ..................86 
Isolation von DC-Subtypen .....................................................................86

3.1.1.1 Reinheitsanalyse der mDCs...............................................................8 86

3.1.1.2 Reinheitsanalyse der pDCs........................................................8 88

3.1.2 Das FSME-Virus beeinflusst die Expression von Oberflächenmolekülen der mDCs .........................................................89

3.1.3 Das FSME-Virus beeinflusst die Expression von Oberflächenmolekülen der pDCs ...................................................94

3.1.4 Das FSME-Virus induziert bei beiden DC-Subtypen eine IFN- $\alpha$ -

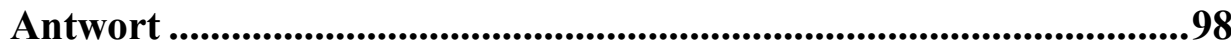

3.1.5 Das FSME-Virus induziert die Produktion proinflammatorischer Zytokine bei beiden DC-Subtypen..........................................................100

3.1.6 Replikation des FSME-Virus in den DC-Subtypen ...........................103

3.1.7 Replikation des FSME-Virus in mit IFNAR-Antikörper behandelten pDCs .......................................................................................106

3.1.7.1 Das FSME-Virus repliziert in den mit IFNAR-Antikörper behandelten pDCs .................................................................................. 107

3.1.7.2 Bestimmung der Zellviabilität nach FSME-Virusinfektion mittels MTT-Assay ........................................................................... 110

3.1.7.3 Der Nachweis von FSME-Virus RNA in infizierten DCs ................ 112

3.1.7.4 FSMEV-RT-PCR der pDCs ....................................................... 114

3.2 Die T-Zell-Antwort auf die FSME-Virusinfektion ..................116

3.2.1 Reinheitsbestimmung der isolierten T-Zellen ...................................117

3.2.2 Das FSME-Virus beeinflusst die Expression von Oberflächenmolekülen der T-Zellen .....................................................118

3.2.3 Zytokinantwort der T-Zellen nach FSME-Virusinfektion...............122

3.2.4 Das FSME-Virus repliziert nicht effizient in T-Zellen ......................123

3.2.4.1 Replikationsanalyse ........................................................................ 124

3.2.4.2 Zellviabilitätsanalyse mittels MTT-Assay ..................................... 126

3.2.5 Proliferation der T-Zellen nach FSME-Virusinfektion....................128

3.3 Infektion von Kokulturen aus pDCs und T-Zellen mit FSME-

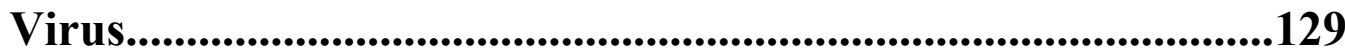

3.3.1 Das FSME-Virus beeinflusst die Expression von Oberflächenmolekülen der pDCs und T-Zellen in der gemeinsamen Kokultur.

3.3.2 Die Zytokinantwort in der pDC-T-Zell-Kokultur .........................132

4 Diskussion .................................................................135

4.1 Reaktion der DCs auf das FSME-Virus.....................................135

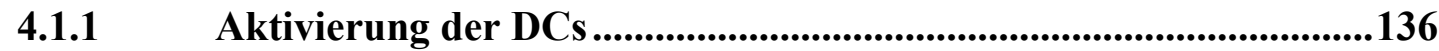

4.1.2 Interferonantwort der DCs auf die Infektion mit dem FSME-Virus

4.1.3 Zytokinantwort der DCs auf das FSME-Virus 
4.1.4 Hilft die Zytokinantwort der DCs dem Wirt oder dem FSME-Virus?

4.2 Einfluss der FSME-Virus-Infektion auf die T-Zellen................146

4.3 FSME-Virusreplikation in DCs oder T-Zellen als Ausbreitungsfaktor ................................................................................150

4.4 Mögliche Mechanismen der Immunmodulation durch das FSME-Virus

4.5 Einordnung der Ergebnisse und Ansatzpunkte für zukünftige Projekte

5 Literaturverzeichnis.................................................159

6 Anhang .....................................................................173

6.1 Abbildungsverzeichnis .............................................................173

6.2 Tabellenverzeichnis ..................................................................175

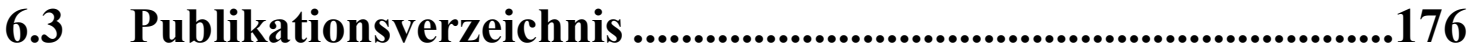

6.3.1 Publikationen mit persönlicher Beteiligung .......................................176

6.3.2 Aufführung der Präsentationen..................................................176

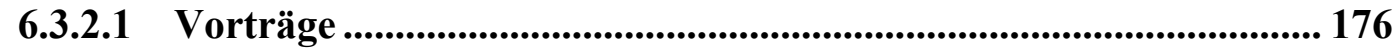

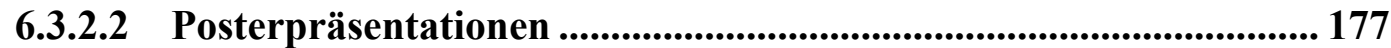

6.4 Danksagung...........................................................................................178

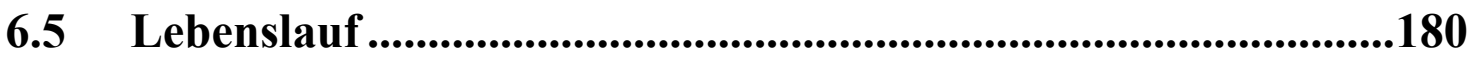




\section{Abkürzungsverzeichnis}

ADAR1

APC

APC

APC/Cy7

APOBEC

APRIL

BAFF

BDCA

BHS

BSA

BSL

CARD

CBA

CCL

CCR

CD

$\mathrm{CD}^{+}$T-Zellen

$\mathrm{CD}^{+}$T-Zellen

cDNA

CFSE

$\mathrm{CO}_{2}$

CPE
RNA spezifische Adenosindeaminase 1 (engl.: RNA-specific deaminase) antigenpräsentierende Zelle (engl.: antigen-presenting-cell)

Allophycocyanin

Allophycocyanin konjugiert mit dem Floureszenzfarbstoff Cy7 aus der Farbstoffgruppe der Cyanine

engl.: Apolipoprotein B RNA-editing Enzym

engl.: a proliferation inducing-ligand

engl.: B cell activating factor belonging to the TNF family

engl.: blood dendritic cell antigen

Blut-Hirn-Schranke

bovines Serumalbumin

Biosicherheitsstufe (engl.: bio safety level)

N-terminale Kaspase-Aktivierungs- und Rekrutierungsdomäne (engl.: N-terminal caspase-recruitment domain)

engl.: cytometric bead array

Chemokin (C-C Motiv) Ligand

Chemokin (C-C Motiv) Rezeptor

Unterscheidungsgruppe (engl.: cluster of differentiation)

CD4 positive T-Zellen

CD8 positive T-Zellen (CTLs)

komplementäre DNA (engl.: complementary DNA)

5(6)-Carboxyfluorescein di-Acetat N-Succinimidylester

Kohlendioxid

zytophatischer Effekt (engl.: cytopathic effect) 


\begin{tabular}{|c|c|}
\hline CTL & zytotoxische T-Zelle (engl.: cytotoxic T-Lymphocyte) \\
\hline \multirow[t]{2}{*}{$\mathrm{Cy}$} & Cyanine (Cy5, Cy7 floureszierende Farbstoffe der Cyanine- \\
\hline & Farbstoffgruppe) \\
\hline DC & dendritische Zelle (engl.: dendritic cell) \\
\hline DENV & Dengue-Virus \\
\hline DMEM & Zellkulturmedium, Dulbecco's Modified Eagle Medium \\
\hline DMSO & Dimethylsulfoxid \\
\hline DNA & Desoxyribonukleinsäure (engl. deoxyribonucleic acid) \\
\hline $\mathrm{Cp}$ & Schnittpunkt bei RT-PCR (engl.: crossing point) \\
\hline dsRNA & doppelsträngige RNA \\
\hline DTT & Dithiothreitol \\
\hline EDTA & Ethylendiamintetraacetat \\
\hline ELISA & enzymgekoppelter Immunadsorptionstest \\
\hline & (engl.: enzyme-linked immunosorbent assay) \\
\hline ER & endoplasmatisches Retikulum \\
\hline FACS & engl.: fluorescence activated cell sorting \\
\hline FAM & Carboxyfluorescein \\
\hline FITC & Fluoresceinisothiocyanat \\
\hline FKS & fötales Kälberserum \\
\hline FSC & Vorwärtsstreulicht (engl.: forward scatter) \\
\hline FSME & Frühsommer-Meningoenzephalitis \\
\hline FSME-Virus & Frühsommer-Meningoenzephalitis-Virus \\
\hline FSMEV & Frühsommer-Meningoenzephalitis-Virus (Benennung in Abbildungen) \\
\hline GAPDH & Glycerinaldehyd-3-phosphat-Dehydrogenase \\
\hline GM-CSF & engl.: granulocyte-macrophage colony stimulating factor \\
\hline GTP & Guanosintriphosphat \\
\hline HEPES & 2-(4-(2-Hydroxyethyl)-1-piperazinyl)-ethansulfonsäure \\
\hline
\end{tabular}




\begin{tabular}{|c|c|}
\hline HEV & der Lymphknoten (engl.: high endothelial venules) \\
\hline HRP & Meerrettich-Peroxidase (engl.: horseradish peroxidase) \\
\hline \multirow[t]{2}{*}{ ICAM } & interzelluläres Adhäsionsmolekül \\
\hline & (engl.: intercellular adhesion molecules) \\
\hline IFIT & engl.: interferon-induced protein with tetratricopeptide repeats \\
\hline IFN & Interferon \\
\hline IFNAR & Interferon- $\alpha / \beta$-Rezeptor \\
\hline Ig & Immunglobulin \\
\hline $\mathrm{I} \kappa \mathrm{B}$ & inhibitorisches kappa-B \\
\hline IKK- $\alpha$ & I $\kappa$ Kinase $\alpha$ (engl.: I $\kappa B$ kinases $\alpha)$ \\
\hline IL & Interleukin \\
\hline IPS-1 & engl.: interferon-beta promoter stimulator 1 \\
\hline IRAK & IL-1 Rezeptor-assoziierte Kinase (engl.: IL1 receptor associated kinase) \\
\hline IRF & Interferon regulatorischer Faktor (engl.: Interferon regulatory factor) \\
\hline ISG & IFN- $\alpha / \beta$-stimulierbares Gen \\
\hline ISG15 & engl.: IFN-stimulated protein of $15 \mathrm{kDa}$ \\
\hline ISGF3 & IFN-stimulierter Gen Faktor 3 \\
\hline ISRE & IFN-stimulierten Antwortelementen \\
\hline Jak & Janus Tyrosin Kinase \\
\hline JEV & Japan-B-Enzephalitis-Virus \\
\hline KFDV & Kyasanur-Wald-Fieber-Virus \\
\hline $\mathrm{LC}$ & Langerhans Zellen (engl.: Langerhans cell) \\
\hline LFA & engl:: lymphocyte function-associated antigen \\
\hline LGTV & Langat-Virus \\
\hline LIV & Louping Ill-Virus \\
\hline МФ & Makrophagen \\
\hline
\end{tabular}


MACS

MAPK

MAVS

MDA-5

$\mathrm{mDC}$

MEM

MHC

$\mathrm{MHz}$

MOI

mRNA

MTT

Mx1

MyD88

NAP1

$\mathrm{NF}-\kappa \mathrm{B}$

NIPC

NK-Zellen

NO

NOS

NS

NTPase

$\mathrm{OH}$

OHFV magnetische Zellseparation (engl.: magnetic activated cell sorting)

Mitogen-aktivierte Proteinkinase

(engl.: mitogen-activated protein kinase)

mitochondriales Adaptorprotein

engl.: melanoma-differentiation-associated gene 5

myeloide dendritische Zelle (engl.: myeloid dendritic cell)

Zellkulturmedium, Minimum Essential Medium

Haupthistokompatibilitätskomplex

(engl.: major histocompability complex)

Megahertz (Wellenlänge)

Multiplizität der Infektion (engl.: multiplicity of infection)

Boten-RNA (engl.: messenger RNA)

3-(4,4-Dimethylthiazol-2-yl)-2,5-diphenyl-tetrazoliumbromid

engl.: Myxovirus resistance 1

myeloides Differenzierungsgen der primären Antwort 88

(engl.: myeloid differentiation primary response gene 88)

engl.: NF- $\kappa B$-activating kinase-associated protein 1

engl.: nuclear factor kappa-B

natürliche Interferon-produzierende Zelle

(engl.: natural interferon-producing cell)

natürliche Killerzellen (engl.: natural killer cells)

Stickstoffmonoxid

Nitrit Oxid Synthetase

Nichtstrukturproteine

Nukleosid Triphosphatase

Hydroxygruppe

Omsker-Hämorrhagisches-Fieber-Virus 


\begin{tabular}{|c|c|}
\hline PAMP & $\begin{array}{l}\text { Pathogen-assoziiertes molekulares Muster } \\
\text { (engl.: Pathogen-associated molecular pattern) }\end{array}$ \\
\hline PBMC & $\begin{array}{l}\text { periphere mononukleare Blutzelle } \\
\text { (engl.: peripheral blood mononuclear cell) }\end{array}$ \\
\hline PBS & phosphatgepufferte Salzlösung (engl:: phosphate buffered saline) \\
\hline PCR & Polymerase-Kettenreaktion (engl:: polymerase chain reaction) \\
\hline $\mathrm{pDC}$ & plasmazytoide dendritische Zelle (engl.: plasmycytoid dendritic cell) \\
\hline $\mathrm{PE}$ & Phycoerythrin \\
\hline $\mathrm{PE} / \mathrm{Cy} 5$ & $\begin{array}{l}\text { Phycoerythrin konjugiert mit dem Floureszenzfarbstoff Cy5 aus der } \\
\text { Farbstoffgruppe der Cyanine }\end{array}$ \\
\hline $\mathrm{PE} / \mathrm{Cy} 7$ & $\begin{array}{l}\text { Phycoerythrin konjugiert mit dem Floureszenzfarbstoff } \mathrm{Cy} 7 \text { aus der } \\
\text { Farbstoffgruppe der Cyanine }\end{array}$ \\
\hline PerCP & Peridinin Chlorophyll a-Protein \\
\hline PerCP/Cy5.5 & $\begin{array}{l}\text { Peridinin Chlorophyll a-Protein konjugiert mit dem Floureszenzfarbstoff } \\
\text { Cy5 aus der Farbstoffgruppe der Cyanine }\end{array}$ \\
\hline PFA & Paraformaldehyd \\
\hline PHA & Phytohämagglutinin \\
\hline PKR & Proteinkinase $\mathrm{R}$ \\
\hline POWV & Powassan-Virus \\
\hline PPP & Triphosphat \\
\hline prM & Vorläufer des M Proteins beinhaltet, das auch als prM Protein \\
\hline Protein $\mathrm{C}$ & Kapsid-Protein bzw. Protein C (engl.: capsid), \\
\hline Protein E & Hüll-Protein bzw. Protein E (engl.: envelope) \\
\hline Protein $M$ & Matrix-Protein bzw. Protein M (engl.: matrix) \\
\hline PRR & mustererkennende Rezeptoren (engl.: Pattern-recognition-Receptors) \\
\hline $\operatorname{RdRp}$ & $\begin{array}{l}\text { RNA-abhängige RNA Polymerase } \\
\text { (engl.: RNA-dependent RNA polymerase) }\end{array}$ \\
\hline RIG-I & engl.: retinoid acid-inducible gene I \\
\hline
\end{tabular}




$\begin{array}{ll}\text { RIP } & \text { engl.: receptor interacting protein } \\ \text { RLR } & \text { RIG-I-artiger Rezeptor (engl.: RIG-I like receptor) } \\ \text { RNA } & \text { Ribonukleinsäure (engl.: ribonucleic acid) } \\ \text { RNA }^{+} & \text {RNA mit positiver Orientierung } \\ \text { RNaseL } & \text { Ribonuklease L } \\ \text { rpm } & \text { Umdrehungen pro Minute (engl.: revolutions per minute) } \\ \text { RPMI 1640 } & \text { Zellkulturmedium, Roswell Park Memorial Institute Medium } 1640 \\ \text { RT } & \text { Raumtemperatur } \\ \text { RT-PCR } & \text { Reverse Transkriptase PCR } \\ \text { SSC } & \text { Seitwärtsstreulicht (engl.: side scatter) } \\ \text { ssRNA } & \text { einzelsträngige RNA (engl.: single stranded RNA) } \\ \text { ssRNA } & \text { einzelsträngige RNA mit positiver Orientierung } \\ & \text { (engl.: single-stranded RNA) } \\ \text { STAT } & \text { engl.: signal transducer and activator of transcription } \\ \text { TAK1 } & \text { engl.: TGF-beta activated kinase 1 }\end{array}$

TAMRA Rhodamin

TAP Antigenpeptid-Transporter (engl.: Transporter associated with antigen processing)

TBE engl.: tick-borne encephalitis

TBEV engl.: tick-borne encephalitis virus

TBK1 engl.: TANK-binding kinase 1

$\mathrm{TCID}_{50} \quad$ Kulturinfektiösen-Dosis 50 (engl.: tissue-culture infectious dose $50 \%$ )

Th T-Helferzellen

Th1 CD4 positive T-Helferzellen Typ I

Th2 CD4 positive T-Helferzellen Typ II

TLR Toll-artige Rezeptoren (engl.: Toll-like receptor)

TMB 3,3',5,5-Tetramethylbenzidin (engl.: Tetramethyl-benzidine) 
TMR

TNF

TRAF

TRIF

Tyk

UK

USA

UV

WBC

WNV

YFV

ZNS
TAMRA

Tumornekrosefaktor (engl.: tumor necrosis factor)

Tumornekrosefaktor Rezeptor-assoziierter Faktor

(engl.: tumor necrosis factor receptor associated factor)

engl.: TIR domain-containing adaptor inducing IFN- $\beta$

Tyrosin Kinase

Vereinigtes Königreich (engl.: United Kingdom)

Vereinigte Staaten von Amerika (engl.: United States of America)

Ultraviolett

Leukozyten (engl.: white blood cells)

West-Nil-Fieber-Virus

Gelbfieber-Virus (engl.: yellow fever virus)

Zentralnervensystem 


\section{Zusammenfassung}

Das Frühsommer-Meningoenzephalitis-Virus (FSME-Virus) gehört zu der Familie der Flaviviren und ist innerhalb Europas das am weitesten verbreitete von Arthropoden übertragene Virus. Eine Infektion des Menschen mit dem FSME-Virus erfolgt zumeist über den Stich einer infizierten Zecke und kann im menschlichen Wirt zu schweren neurologischen Schäden führen. Die Pathogenese des FSME-Virus, die Mechanismen der FSME-Virus-WirtInteraktionen sowie der Neuroinvasion sind noch nicht vollständig geklärt. Die dendritischen Zellen (DCs) gehören zu den antigenpräsentierenden Zellen (APCs) und sind ein wichtiger Bestandteil des Immunsystems zur Erkennung, Prozessierung von Antigenen sowie der Aktivierung von T-Zellen. Darüber hinaus stellen die DCs die Schnittstelle zwischen der angeborenen- und erworbenen Immunantwort dar. Basierend auf funktionellen Eigenschaften können die DCs in zwei Hauptgruppen aufgeteilt werden, die myeloiden- und plasmazytoiden dendritischen Zellen (mDCs und pDCs). Während die mDCs die potenteren APCs sind, können die pDCs in Antwort auf eine virale Infektion binnen kurzer Zeit große Mengen an Typ I Interferonen produzieren, die dazu beitragen durch Etablierung eines antiviralen Status die Virusreplikation einzudämmen. Beide DC-Subtypen sind ein potentielles und frühes Ziel des FSME-Virus bei der Infektion des Menschen. In dieser Arbeit wurde untersucht, ob das FSME-Virus mit der Aktivierung von DCs und T-Zellen interferiert. Die DC-Subtypen und T-Zellen wurden dazu aus humanen Buffy-Coat isoliert, kultiviert und mit dem FSME-Virus infiziert. Anschließend wurde die Expression von Aktivierungsmarkern sowie die Produktion von proinflammatorischen Zytokinen und antiviral wirksamen IFN- $\alpha$ untersucht. Dabei konnte gezeigt werden, dass pDCs nach Infektion mit FSME-Virus aktiviert werden, während bei mDCs nur eine unvollständige Aktivierung zu beobachten war. Außerdem wird die Produktion der proinflammatorischen Zytokine TNF- $\alpha$, IL-6, IL-8 und dem IFN- $\alpha$ induziert, die bei den pDCs jedoch stärker ausfällt als bei den mDCs. Außerdem konnte gezeigt werden, dass das FSME-Virus im Gegensatz zu den pDCs in den mDCs repliziert. Dabei ist die Hemmung der FSME-Virusreplikation in den pDCs von der Funktion des IFNAR-Signalwegs abhängig. T-Zellen werden durch FSME-Virusinfektion nur unvollständig aktiviert und exprimieren verstärkt lediglich den Aktivierungsmarker CD69 nicht aber CD25 und MHC-II. Weiterhin ist die Zytokinantwort (IL-4, IL-5, IL-10, TNF- $\alpha$ und IFN- $\gamma$ ) relativ schwach ausgeprägt. Dennoch war eine effektive Replikation des FSME-Virus in den T-Zellen nicht zu beobachten. Damit spielen T-Zellen wie auch pDCs keine Rolle bei der Verbreitung des Virus im infizierten menschlichen Wirtsorganismus. Im Gegensatz hierzu sind mDCs, die die FSMEVirusreplikation unterstützen, potentielle Vehikel zur Virusverbreitung. 


\section{Abstract}

The tick-borne encephalitis virus (TBEV) belongs to the Flavivirus family and is the most prevalent arbovirus in Europe. Infection of humans with TBEV occurs mainly by bite of an infected tick and can lead to severe neurological disorders. But for TBEV humans are an accidental- and dead-end host. The pathogenesis of TBEV is still not completely understood, mechanisms of virus host response interaction and principles of neuroinvasion remain to be elucidated. Dendritic cells (DCs) belong to the antigen-presenting cells and are an important part of the innate immunity in context of recognition, processing and combat of viral pathogens. Moreover, they play an important role in linking the innate and adaptive immunity and are able to activate components of the adaptive immune systems like $\mathrm{T}$ cells. Corresponding to their function DCs are divided into two main subtypes: 1. myeloid dendritic cells (mDCs), which are the most potent antigen-presenting DC subtype and therefore play a decisive role in inducing the adaptive immune response. 2. plasmacytoid dendritic cells (pDCs), which are the main type I interferon-producing cells and therefore act as a link of innate and adaptive immune response. Both DC subtypes are potential and early targets of TBEV during the infection of the mammalian host. In this work the capability of TBEV to interfere with the activation of human DCs and T cells was analyzed. Therefore the DCsubtypes as well as $\mathrm{T}$ cells were isolated from human buffy coats, cultivated and subsequently infected with TBEV. Expression of activation markers and secretion of inflammatory cytokines as well as Interferon-alpha (IFN- $\alpha$ ) levels were determined. It could be demonstrated that pDCs were activated after infection with TBEV, while activation of mDCs was incomplete. TBEV infected pDCs produced high amounts of IFN- $\alpha$ as well as proinflammatory cytokines interleukin-6 (IL-6), IL-8 and tumor necrosis factor- $\alpha$ (TNF- $\alpha$ ). Moreover pDCs were capable to restrict TBEV replication. This restriction was dependent of a functional IFNAR signalling pathway. In contrast, $\mathrm{mDCs}$ supported TBEV replication and IFN- $\alpha$ production by TBEV infected mDCs was 10 -fold lower. Nevertheless TBEV-infected mDCs produced high amounts of IL-6, IL- 8 and TNF- $\alpha$. Activation of TBEV-infected T cells was incomplete since only the activation marker CD69 was upregulated while CD25 and MHC-II remained unchanged. Moreover, TBEV induce a modest cytokine response in $\mathrm{T}$ cells including IL-4, IL-5, IL-10, TNF- $\alpha$ and IFN- $\gamma$. Nevertheless, T cells do not support an effective replication of TBEV. Therefore, $\mathrm{T}$ cells and pDCs are probably not involved in the spreading of TBEV in infected humans. In contrast mDCs, which supported TBEV replication have to be considered as vehicles for virus dissemination. 


\section{Einleitung}

\subsection{Das Immunsystem}

Im Laufe des Lebens wird der menschliche Organismus mit einer Vielzahl an Fremdkörpern, wie toxischen oder nicht-toxischen Substanzen, Mikroorganismen, wie Bakterien, Pilze oder Parasiten sowie Viren konfrontiert, die den menschlichen Stoffwechsel gefährden oder sogar zerstören und im Extremfall zum Tod des Organismus führen können (46). Die Anforderungen an die Abwehrmechanismen in Form des Immunsystems bestehen darin diese Störfaktoren schnell $\mathrm{zu}$ erkennen und eine unverzügliche Informationsweiterleitung an Effektoren zu gewährleisten, die zum einen die betroffene Stelle lokalisieren und gegebenenfalls Verstärkung mobilisieren, die die Ausbreitung des Pathogens verhindern und eine effektive Bekämpfung des Pathogens einleiten, ohne dabei den eigenen Körper anzugreifen. Weiterhin müssen diese Mechanismen das Pathogen unschädlich machen oder gar vernichten und entsorgen, die Abwehr nach erfolgreicher Bekämpfung beenden, sowie ein Gedächtnis für dieses Pathogen anlegen, sodass eine erneute Infektion direkt bekämpft werden kann. Diesem ganzen Profil liegt ein komplexes Netzwerk aus Zellen und Botenstoffen zugrunde, das einer sehr genauen und effizienten Regulation bedarf. Im Laufe der Evolution haben sich bei den Säugetieren diverse Mechanismen zur Selbstverteidigung in Form eines komplexen Immunsystems ausgebildet (203).

Das Immunsystem der Vertebraten basiert auf drei Säulen, die eng miteinander verbunden sind $(99,192)$. Die erste Säule beinhaltet die anatomischen- und physikalischen Barrieren zwischen Umwelt und menschlichen Organismus, wie sie die Haut, die Schleimhaut, der Magen, der Darm, die Nase, die Atemwege und die Augen, sowie das saure Milieu im Magen, die Tränen, der Speichel und andere Sekrete darstellen (192). Sie bilden die erste Verteidigungslinie und verhindern dabei das Eindringen von sämtlichen Pathogenen und bietet Schutz gegen chemische- und physikalische Eingriffe, auf der anderen Seite verhindert sie zusätzlich den Verlust von Wasser und gelöster Substanzen (157).

Die beiden anderen Säulen beziehen sich auf die Immunantwort, die bezüglich der Spezifität, des Aufbaus und der Funktion in die angeborene- und die erworbene 
Immunantwort unterteilt werden kann. Im Gegensatz zu der angeborenen Immunität, die sich pränatal ausbildet und schon vor der Geburt vorhanden ist, reifen die Komponenten der erworbenen Immunität erst postnatal aus. Bei der angeborenen Immunantwort sind vor allem Zellen involviert, die Partikel durch Endozytose oder Phagozytose aufnehmen. Die Erkennung von eindringenden Pathogenen durch die Zellen erfolgt mittels einer eingeschränkten Anzahl an Keimbahn-kodierten Rezeptoren, die speziell hochkonservierte Muster der Pathogene erkennen (192). Nach der Erkennung werden Signalkaskaden in den Gang gesetzt, die zu einer Immunantwort der jeweiligen Zelle führen. Diese Immunantwort erfolgt unverzüglich, ist aber aufgrund der eingeschränkten Erkennung antigenunspezifisch (192). $\mathrm{Zu}$ den angeborenen Komponenten gehören Neutrophile, Granulozyten, natürliche Killerzellen (NK-Zellen), mononukleäre phagozytotisch aktive Zellen wie die Monozyten, Makrophagen und dendritischen Zellen (DCs), die eine Reihe von Botenstoffen, wie die Chemokine, Zytokine und Interferone produzieren, die unter anderem der Aktivierung des erworbenen Immunsystems sowie des Komplement-Systems dienen (99). Die erworbene Immunantwort hingegen basiert auf der Erkennung von Pathogenen durch antigenspezifische Rezeptoren (13). Die Ausbildung der Rezeptoren erfolgt über die somatische Rekombination der Erkennungsbereiche der Rezeptoren, wodurch ein mannigfaltiges Repertoire an Rezeptoren geschaffen wird. Diese Rezeptoren persistieren das ganze Leben innerhalb des Wirts und bilden eine Art immunologisches Gedächtnis, das im Falle einer Reinfektion mit dem Pathogen für eine weitaus schnellere Immunantwort sorgt. Die Ausbildung der erworbenen Immunantwort ist dagegen langwieriger und nimmt mehrere Tage in Anspruch. $\mathrm{Zu}$ der erworbenen Immunantwort gehören T-Helferzellen, zytotoxische T-Zellen und die B-Zellen (14).

Die angeborene- und erworbene Immunität sind sehr eng miteinander verbunden und ergänzen sich. Eine solche Art der Verbindung erfordert eine genaue Abstimmung der beteiligten Komponenten. Eine sehr wichtige Komponente des Immunsystems im Rahmen der Initiation und Modulation der angeborenen- sowie erworbenen Immunantwort stellen die DCs dar $(14,99)$. Sie gelten als Schnittstelle bzw. Verbindungsarm zwischen der erworbenen- und angeborenen Immunantwort (99, 130, 205). 


\subsubsection{Die dendritischen Zellen (DCs)}

Die dendritischen Zellen (engl.: dendritic cell (DC)) sind eine wichtige Komponente der angeborenen Immunantwort, die allerdings auch eine wichtige Rolle für die erworbenebzw. adaptive Immunantwort spielt. Bereits 1868 wurde eine Gruppe der DCs als Zellen mit langen Zellausläufern (Dendriten) in der Epidermis der menschlichen Haut entdeckt und aufgrund ihrer Morphologie von ihrem Entdecker Paul Langerhans als dendritische Zellen bezeichnet (110). Die Charakterisierung der DCs sowie die Entdeckung weiterer DC-Populationen begann allerdings erst über 100 Jahre später $(14,20)$.

Die DCs sind eine heterogene Gruppe, die sich aufgrund ihrer Morphologie, ihres Lebenszyklus, der Expression diverser Zelloberflächenmarker sowie ihrer Funktionen unterscheiden $(96,173,195)$. Basierend auf diesen Faktoren können die DCs in zwei Hauptgruppen, in die myeloiden dendritischen Zellen (mDCs) und die plasmazytoiden dendritischen Zellen (pDCs) eingeteilt werden (149, 164, 173). Beide Subtypen entwickeln sich aus $\mathrm{CD}^{+} 4^{+}$(Unterscheidungsgruppe bzw. engl.: c cluster of differentiation (CD)) Knochenmarksvorläuferzellen zu unreifen DCs. Dabei differenzieren diese hämatopoetischen Stammzellen entweder entlang der myeloiden Linie oder entlang der lymphoiden Linie. Neben den mDCs entstehen auch Erythrozyten, Granulozyten, Makrophagen, Monozyten und Thrombozyten aus der myeloiden Linie, während die pDCs und auch B-Zellen, NK-Zellen sowie T-Zellen aus der lymphoiden Linie entstehen (173). Die naiven DCs dringen in den Blutstrom ein, von dem aus sie in verschiedene lymphoide- und nicht-lymphoide Gewebe wandern und dort verweilen, bis sie auf ein Fremdantigen treffen $(63,149,180)$. Beide DC-Subtypen sind sehr rar und machen jeweils lediglich einen Anteil von weniger als $1 \%$ der peripheren mononukleären Blutzellen (engl.: peripheral blood mononuclear cells (PBMCs)) einer Person aus (69). Ein Schema zur Abstammung und Entwicklung von den humanen DCs ist in der Abbildung 1.1 dargestellt.

\subsubsection{Die DC-Subpopulationen}

Die mDCs können in weitere Subpopulationen aufgeteilt werden, wie den Langerhanszellen (engl.: Langerhans cell (LC)), den dermalen DCs und den interstitiellen DCs (130). In der Haut sind 3 Subpopulationen der mDCs lokalisiert, die LCs, die 
CD14 ${ }^{+}$-dermalen DCs und die $\mathrm{CD}^{+}{ }^{+}$dermalen DCs (193). Dagegen sind die interstitiellen DCs in Darm, Haut, Herz, Leber, Niere, Pankreas, Schilddrüse sowie Urogenitaltrakt, $\mathrm{zu}$ finden $(87,156)$. Die mDCs exprimieren neben den myeloiden

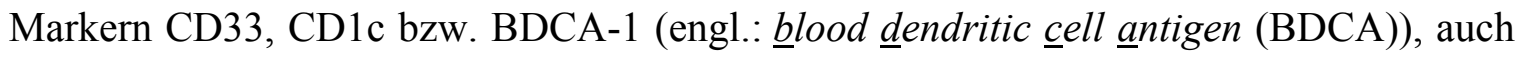
CD141 (BDCA-3) und CD11c.

Der Phänotyp der pDCs ist sehr speziell, da sie nicht die typischen Marker diverser Zelllinien exprimieren, wie die B-Zellen mit CD19 und CD21, die myeloiden Zellen mit CD13, CD14 und CD33 oder die T-Zellen mit CD3 und dem T-Zellrezeptor (17, 130). Eine charakteristische Eigenart der pDCs ist die starke Expression der IL-3-Rezeptor- $\alpha$ Kette (CD123) (17). Neben CD123 exprimieren sie auch das BDCA-2 bzw. CD303, ein C-Typ Transmembran Glykoprotein, das eine Rolle bei der Internalisierung von Liganden sowie bei deren Prozessierung und deren Repräsentation spielt, CD304 (BDCA-4, Neuropilin-1 $)^{+}, \mathrm{CD}^{+}$und CD45RA $(60,61)$. Im naiven Zustand bilden die pDCs eine Morphologie aus, die denen der Plasmazellen ähnelt und für konventionelle DCs bzw. mDCs ungewöhnlich ist. Die unreifen pDCs treten als große Zellen mit vielen Mitochondrien und offensichtlichen rauen endoplasmatischen Retikulum in Erscheinung (17). Aufgrund ihrer Ähnlichkeit zu den Plasmazellen wurden sie als „plasmazytoide“ Zellen beschrieben und durch das Fehlen von spezifischen Linienmarkern, sowie des vorwiegenden Vorkommens in den T-Zell-Zonen der lymphatischen Organe wurden sie auch als ,plasmazytoide T-Zellen” $(64,81)$ oder „plasmazytoide Monozyten“ bezeichnet (36). Weitere Aufenthaltsorte der pDCs sind neben dem Blut die Milz, Schleimhaut assoziierte lymphatische Gewebe, Thymus und Leber (185). Erst durch die Reifung im Zuge der Aktivierung nehmen sie die Morphologie von DCs an (14). Ein Schema zur Entwicklung und den ausgebildeten Phänotypen der DC-Subpopulationen ist in der Abbildung 1.1 dargestellt. 


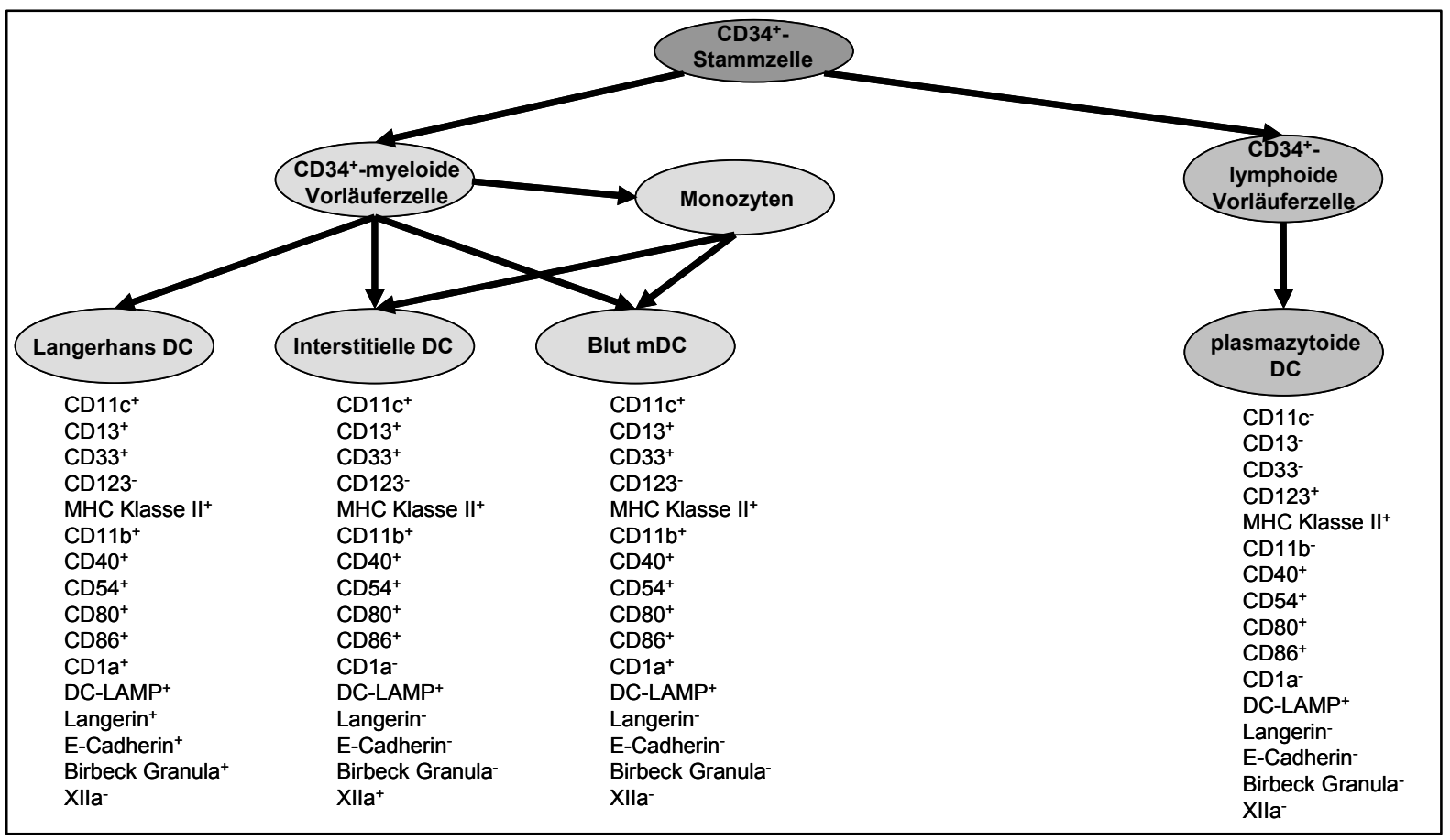

Abbildung 1.1: Schema zum Ursprung und der Entwicklung sowie zum ausgebildeten Phänotyp von humanen DCs (modifiziert nach (119)).

\subsubsection{Die Funktion der DCs}

Die DCs fungieren als eine Art Wächter in dem peripheren Gewebe, wo sie im Zuge einer Infektion in Kontakt mit eindringenden Pathogenen kommen (52). Neben den Monozyten und Makrophagen von der angeborenen Immunabwehr, sowie den B-Zellen als Teil der erworbenen Immunantwort gehören auch DCs zu der Gruppe der antigenpräsentierenden Zellen (engl.: antigen-presenting-çells (APCs)), wobei sich die Subtypen der DCs in der Fähigkeit Antigene zu präsentieren unterscheiden. Im Gegensatz zu den mDCs scheinen die pDCs bei der Antigenpräsentation eher eine untergeordnete Rolle zu spielen (84). Durch die hocheffiziente Aufnahme und Prozessierung von Antigenen, sowie deren Präsentation an der Zelloberfläche für Zellen des erworbenen Immunsystems, spielen die mDCs eine wichtige Rolle bei der Initiation des adaptiven Immunsystems.

Das einzigartige an den pDCs ist die Fähigkeit in Antwort auf diverse Stimuli binnen kurzer Zeit große Mengen an Typ I IFN zu produzieren, was ihnen auch den Beinamen der „natürlichen Interferon-produzierenden Zellen“ (engl.: “ñatural interferon-producing cells" (NIPCs)) eingebracht hat (70). Die pDCs produzieren den Hauptanteil an Typ I IFNs die von den PBMCs in Antwort auf virale Stimuli gebildet werden und sie 
können bis zu 1000-fach höhere Mengen an Typ I IFN produzieren als andere im Blut enthaltenen Zellen $(17,174)$. Dabei beeinflussen die Typ I IFNs viele Faktoren der angeborenen- wie auch der erworbenen Immunität. Sie spielen eine Schlüsselrolle bei der Induktion der angeborenen Immunantwort, daher werden sie auch als Bindeglied der angeborenen und erworbenen Immunität bezeichnet $(130,205)$.

\subsubsection{PAMP-Erkennung und PRR-vermittelte Aktivierung angeborener Immunmechanismen in DCs}

Ein sehr wichtiger Faktor für die Aktivierung des Immunsystems ist eine schnelle Erkennung von eindringenden Pathogenen. Als erste Säule in der Immunantwort erfolgt die primäre Detektion von Pathogenen durch das angeborene Immunsystem über so genannte Keimbahn-kodierte „mustererkennende Rezeptoren“ (engl.: Patternrecognition-Receptors (PRRs)), die entweder membranständig oder im Zytoplasma lokalisiert sind. Es gibt verschiedene PRRs, die spezielle Pathogen-spezifische Strukturen erkennen, die auch als Pathogen-assoziierte molekulare Muster (engl.: Pathogenassociated molecular patterns (PAMPs)) bezeichnet werden. Bei diesen molekularen Mustern handelt es sich um für Pathogene charakteristische und hochkonservierte Strukturen, die unabdingbar im Verlauf des Lebenszyklus des Pathogens sind. In Folge der Erkennung von PAMPs durch die PRRs wird eine Signalkaskade in den Gang gesetzt, die wiederum die Immunantwort einleitet. Die Erkennung von den allgemeinen konservierten Mustern der Pathogene durch Keimbahn-kodierte Rezeptoren des angeborenen Immunsystems erfolgt somit auf einer unspezifischen Ebene.

Naive DCs nehmen fortwährend Material aus ihrer Umgebung auf, allerdings ist die Präsentation der Antigene in diesem Zustand nicht sehr effektiv. Erkennt die Zelle mittels der Rezeptoren eindringende Pathogene, so kommt es zur Ausreifung der Zelle in einen aktivierten Zustand. Dieser aktivierte Zustand ist gekennzeichnet durch eine gesteigerte Aufnahme von Antigenen sowie deren Prozessierung und Präsentation (133). Die DCs agieren als die effizientesten APCs, da speziell die unreifen DCs verschiedene Fähigkeiten haben exogene Antigene aus der Peripherie aufzunehmen. Neben der Phagozytose bilden DCs auch große pinozytotische Partikel mit extrazellulärer Flüssigkeit und gelösten Stoffen aus, ein Prozess der auch als Makropinozytose bezeichnet wird. Weiterhin bilden die DCs Rezeptoren aus, die durch Adsorption mit 
äußeren Faktoren Endozytose auslösen, wie die C-Typ Lektin Rezeptoren, der Makrophagen Mannose Rezeptor oder DEC-205 wie auch der Fc $\gamma$ - und der Fce Rezeptor (14). In diesen Kompartimenten bilden sich die endosomalen PRRs aus und detektieren unterschiedliche Liganden.

Eine Gruppe solcher PRRs, die in vielen Immunzellen exprimiert werden, sind die Tollartigen Rezeptoren (engl.: toll-like receptors (TLRs)). Für die Säugetiere sind 11 unterschiedliche TLRs beschrieben, die sich aufgrund der Lokalisation und der jeweiligen PAMPs, die sie erkennen, unterscheiden. Die auf der Zelloberfläche lokalisierten TLRs, TLR1, TLR2, TLR4, TLR5, das Flagellin und TLR6, detektieren bakterielle Strukturen (186). Die endosomal lokalisierten TLRs, erkennen verschiedene Formen von Nukleinsäuren. Der TLR3 erkennt doppelsträngige RNA wie sie auch als Zwischenschritt bei der viralen Replikation vorhanden ist. Der TLR7 und TLR8 erkennen unterschiedliche Guanin- und Uracil-haltige einzelsträngige RNA oder poly-Uracil enthaltende einzelsträngige RNA und der TLR9 unmethylierte CpG Dinukleotide wie sie z. B. bei der bakteriellen DNA vorkommen (33). Die mDCs exprimieren eine große Bandbreite an TLRs, dazu gehören TLR2, TLR3, TLR4, TLR5, TLR6 und TLR8 (33). Die pDCs dagegen exprimieren nur die beiden endosomal lokalisierten TLR7 und TLR9 (33).

Durch die Bindung von viraler einzelsträngiger RNA an den TLR7 kommt es zu einer Rekrutierung des myeloiden Differenzierungsgens der primären Antwort 88 (engl.: $\underline{\text { myeloid }}$ differentiation primary response gene $\underline{88}$ (MyD88)), einem Adaptormolekül, das von vielen TLRs im Zuge der Aktivierung benutzt wird (s. Abbildung 1.2). Das aktivierte MyD88 bildet zusammen mit den IL-1 Rezeptorassoziierten Kinasen (engl.: IL1 receptor associated kinase (IRAK)) IRAK1, IRAK4, Tumornekrosefaktor Rezeptor-assoziierter Faktoren (engl.: tumor necrosis factor receptor associated factor (TRAF)) TRAF3, TRAF6, der IкB Kinase $\alpha$ (engl.: $\underline{\text { I }} B$ kinases $\underline{\alpha}$ $(\mathrm{IKK} \alpha)$ ), Interferon regulatorischen Faktoren (engl.: Interferon regulatory factor (IRF)) IRF5 und IRF7 einen Komplex, der auch als zytoplasmatischer TransduktionsTranslationsprozessor bezeichnet wird. Dieser Komplex führt zur Aktivierung von IRF7, was zu der Induktion der Expression von Typ I IFN-Genen führt. Das speziell in den pDCs konstitutiv exprimierte IRF7 ist dabei ein sehr wichtiger Faktor für die schnelle und umfangreiche Produktion der Typ I IFNs, die wiederum antiviral aktive Faktoren induzieren (84). Außerdem kommt es zur Aktivierung der Proteinkinase TAK1 
(engl.: $\underline{T} G F$-beta activated kinase 1 ). Die Aktivierung von TAK1 führt zur Aktivierung und nuklearen Translokation von NF- $\mathrm{kB}$ und Initiierung der Signalkette der Mitogenaktivierten Proteinkinasen (engl.: mitogen-activated protein kinases (MAPKs)) aktiviert. Weiterhin wird das IRF5 durch die Komplexbildung aktiviert. Die Aktivierung von NF-kB und IRF5 sowie die Induktion der MAPKs Signaltransduktionskette führt zur Expression von kostimulatorischen Molekülen sowie der Produktion von proinflammatorischen Zytokinen $(33,203)$. Der ebenfalls endosomal lokalisierte und auf den mDCs exprimierte TLR3 bildet nach Erkennung von viraler doppelsträngiger RNA auch einen Komplex. In diesem Komplex sind das Adaptormolekül TRIF (engl.: TIR domain-containing adaptor inducing IFN- $\beta$ ), RIP1 (engl.: receptor interacting protein) und NAP1 (engl.: $\underline{N} F-\kappa B$-activating kinase-associated protein) und bekannte Elemente aus der TLR7 Signalkette wie TRAF3, TRAF6 und TAK1, die ebenfalls NF- $\kappa$, aber auch IRF-3 aktivieren, die wiederum die Produktion von kostimulatorischen Molekülen, proinflammatorischen Zytokinen und von IFN- $\beta$ induzieren, beteiligt (203).

Eine weitere Gruppe der PRRs sind die so genannten RIG-I-artigen Rezeptoren (engl.: $\underline{R} I G-I$ like receptors (RLRs)). Zu der Familie der zytosolisch lokalisierten RLRs gehören neben dem RIG-I Rezeptor auch die MDA-5- und LGP-2-Rezeptoren (161). RIG-I und MDA-5 sind zytoplasmatische Helikasen, die virale RNA detektieren können (122) (s. Abbildung 1.2, Punkt A). RIG-I wird durch synthetische RNAs oder verschiedene virale RNAs induziert, die Modifikationen, wie ein 5'-PPP Ende oder eine „Pfannenstiel“-artige Konformation aufweisen. Der MDA-5 wird dagegen durch RNAs, denen eine 2-O-Methylierung in der Cap-Struktur fehlt, stimuliert (74). Die RLRs MDA-5 sowie RIG-I besitzen je zwei N-terminale Kaspase-Aktivierungs- und Rekrutierungsdomänen, so genannte CARDs, die mit dem mitochondrialen Adaptorprotein (MAVS), das eine CARD Domäne besitzt, interagieren. Das MAVS überträgt das Signal über eine Kaskade, die neben dem Stimulator des IFN- $\beta$-Promoters IPS-1 (engl.: interferon-beta promoter stimulator $\underline{1}$ ) auch das TBK1 (engl.: $\underline{T A N K}$ binding kinase $\underline{1}$ ) und IKK $\beta$ beinhaltet und zur Aktivierung der Transkriptionsfaktoren IRF-3, IRF-7 sowie das NF-kB aktivieren. Zu den Genen, deren Expression durch diese Transkriptionsfaktoren initiiert wird, gehören unter anderem auch die Gene der Typ I IFNs (169). Dabei wird die Produktion von IFN- $\beta$, proinflammatorischer Zytokine und die Expression von Aktivierungs- sowie Antigenpräsentationsmolekülen induziert 
(161). Das LPG-2 spielt hingegen eine inhibitorische Rolle bei der durch RIG-I und MDA-5 induzierten Induktion der Typ I IFNs (161). Die Induktion der Typ I IFNProduktion über den RIG-I-Signalweg scheint allerdings bei den pDCs im Gegensatz zu den konventionellen DCs entbehrlich zu sein (163).

\subsubsection{Das Typ I Interferonsystem und die Interferonantwort der DCs}

Von den Typ I IFNs, die auch als virale IFNs bezeichnet werden, sind speziell IFN- $\alpha$ und IFN- $\beta$ bei der Antwort auf eine Virusinfektion beteiligt (159). Die Typ I IFNs werden von mehreren Genen kodiert. Hierbei werden die IFN- $\alpha$ Subtypen beim Menschen von insgesamt 13 Genen kodiert (162), die eine 80-95\%ige Homologie auf Basis der Nukleinsäuren besitzen $(39,45,189)$, während IFN- $\beta$ dagegen nur von einem einzigen Gen kodiert wird (159). Basierend auf den Zeitpunkt der Expression können die IFN- $\alpha / \beta-G e n e$ in zwei Gruppen eingeteilt werden. $\mathrm{Zu}$ den Genen, die im Zuge der frühen Immunantwort exprimiert werden gehört neben dem IFN- $\beta$ das murine IFN- $\alpha 4$ Gen. Die Expression der später induzierten Gene, wie IFN- $\alpha 2,-5,-6$ und -8, ist von der Synthese und Wirkung der frühen IFNs abhängig (169). Bei einem gesunden Menschen sind unter normalen Umständen die Konzentrationen an IFN- $\alpha / \beta$ im Serum sehr gering oder nicht nachweisbar (26). Wie bereits im vorigen Abschnitt erwähnt, unterscheiden sich die DC-Subtypen hinsichtlich ihrer Typ I IFN Produktion: mDCs produzieren - ausgehend von der Aktivierung von TLR3, TLR8, RIG-I und MDA-5 als Virus-induziertes frühes Typ I IFN im wesentlichen IFN- $\beta$ (s. Abbildung 1.2; Abschnitt A), pDCs hingegen bilden nach Virusinfektion - ausgehend von der Aktivierung von TLR7 und TLR9 - große Mengen an IFN- $\alpha$ (s. Abbildung 1.2; Abschnitt B).

Die Virus-induzierten Typ I IFNs agieren auch als autokriner Überlebensfaktor der pDCs (130). Darüber hinaus sind die Typ I IFNs essentiell für die Aktivierung und Migration der pDCs in vivo (7). Die Typ I IFNs haben aber auch eine weitere autokrine Wirkung. Dabei stellen die Typ I IFNs selbst den Regulationsfaktor dar, der die eigene Produktion durch eine autokrine Feedback-Schleife stimuliert und somit die Typ I IFN-Antwort verstärkt (130) (s. Abbildung 1.2; Abschnitt C). Bei dieser Schleife binden die Typ I IFNs an den heterodimeren und hochaffinen IFN- $\alpha / \beta$-Rezeptor (IFNAR), durch die Bindung von Typ I IFN an den IFNAR kommt es zu einer Dimerisierung des Rezeptors, der wiederum die auto- und trans-Phosphorylierung der beiden IFNAR assoziierten Kinasen, 
der Tyrosin Kinase 2 (Tyk2) an der Untereinheit IFNAR1 und der Janus Protein Kinase 1 (Jak1), an der Untereinheit IFNAR2 induziert. Die Phosphorylierung der Janus Kinase führt zu einer Phosphorylierung der intrazellulären Domäne der Untereinheit IFNAR1 und zur Schaffung von einer Bindungsstelle für STAT2 (engl.: signal transducer and activator of transcription (STAT)). Durch die STAT2 Bindung an IFNAR1 wird eine Bindungsstelle geschaffen, an die STAT1 rekrutieren kann. Im Zuge der Bindung wird STAT1 phosphoryliert und bildet mit STAT2 Heterodimere. Die phosphorylierten Heterodimere STAT1/STAT2 dissoziieren von den IFNAR und assoziieren mit dem IFNregulatorischen Faktor 9 (IRF-9), wodurch der heterotrimere Komplex IFN-stimulierter Gen Faktor 3 (ISGF3) entsteht, der in den Kern transloziert. Dort bindet der ISGF3 an regulatorischen Konsensussequenzen der IFN- $\alpha / \beta$-stimulierbaren Gene (ISGs), den so genannten IFN-stimulierten Antwortelementen (ISREs) und initiiert die Transkription der ISGs. Die beschriebene Signalkaskade ruft die Induktion von über 300 ISGs hervor (47). $\mathrm{Zu}$ den ISGs gehören viele Genprodukte, die zur Ausbildung eines antiviralen Status der Zelle führen. Der antivirale Status ist geprägt durch die Expression vieler antiviraler wirksamer Moleküle, die eine Resistenz gegen virale Infektion fördern, sowie durch Induktion der Apoptose in den infizierten Zellen (185). Zu den antiviralen Effektoren gehören die Protein Kinase R (PKR), die die Translation hemmt, die RNA spezifische Adenosindeaminase 1 ADAR1 (engl.: RNA-specific deaminase ADAR1), die die RNAEditierung antreibt, die GTPase Mx1 (Myxovirus resistance 1), die virale Nukleoproteine sequestriert, die Ribonuklease L (RNaseL), die den Abbau der RNA fördert sowie die IFITs (engl.: interferon-induced protein with tetratricopeptide repeats), die ebenfalls als Translationshemmer fungieren. Die Typ I IFNs führen darüber hinaus zur gesteigerten Expression von den MHC-Molekülen sowie kostimulatorischer Moleküle wie CD40, CD80 und CD86 (189).

Die Typ I IFNs spielen auch eine Rolle bei der Einleitung der Apoptose. Die Apoptose bzw. der kontrollierte Zelltod ist ebenfalls ein Abwehrmechanismus, bei dem bei infizierten Zellen der Zelltod induziert wird, damit sich das Virus nicht weiter verbreiten kann. So führt eine IFN-induzierte Expression von PKR in Kombination mit doppelsträngiger RNA, die z. B. als Zwischenprodukt der viralen Replikation entsteht, zum Translationsstopp und damit zur Induktion der Apoptose (12). 


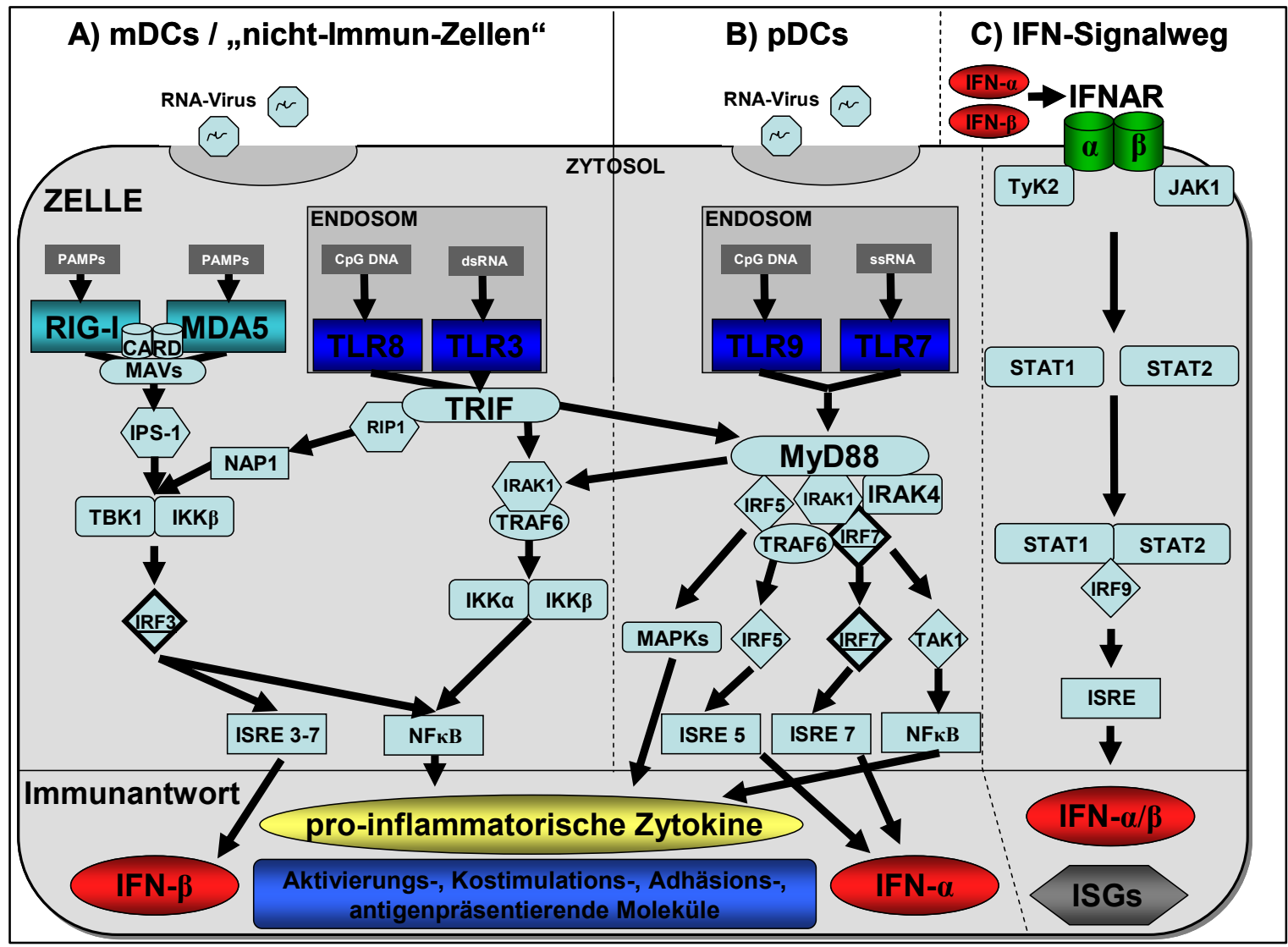

Abbildung 1.2: Schema zur Erkennung von PAMPs und Signalweiterleitung durch die PRRs sowie zur autokrinen Typ I IFN-Schleife.

a) IFN-Induktion in mDCs und ,nicht-Immun-Zellen b) IFN-Induktion in pDCs c) IFN-Signalweg und Induktion von ISGs.

\subsubsection{Antigenprozessierung und -präsentation}

Die Präsentation der Antigene findet durch spezielle Moleküle statt, die auch als Haupthistokompatibilitätskomplexe (MHCs) (engl.: major histocompability complexes) bezeichnet werden. Die beiden Hauptklassen der MHC-Komplexe unterscheiden sich unter anderem bezüglich ihrer Struktur, der Beschaffenheit ihrer Antigene, die sie präsentieren sowie der Lokalisation (196). Die MHC-I Moleküle sind im endoplasmatischen Retikulum (ER) lokalisiert und präsentieren vornehmlich endogene Antigene (wie z. B. virale Repliaktionsprodukte), im Gegensatz zu den MHC-II Molekülen, die in den Lysosomen lokalisiert sind und zumeist exogene Antigene präsentieren (196). Die MHC-I Moleküle bestehen aus einer Ig-artigen schweren Kette, die in der Membran verankert ist, und einer invarianten Kette, die auch als $\beta 2-$ Mikroglobulin bezeichnet wird. Im Gegensatz dazu bestehen die MHC-Klasse-II- 
Moleküle aus jeweils einer $\alpha$ - und $\beta$-Kette, die je zwei Ig-ähnliche Domänen und eine Transmembrandomäne besitzen.

Weiterhin besitzen die DCs die Fähigkeit zur so genannten Kreuzpräsentation, durch die exogene Antigene auch auf MHC-I Molekülen präsentiert werden können. Dabei besteht die Möglichkeit auch Spuren bzw. Peptidfragmente von Viren zu präsentieren, die die APCs nicht infizieren.

Bei einem weiteren Prozess der Antigenaufnahme, der auch für DCs nachgewiesen wurde, der Autophagozytose, werden so genannte Autophagosomen gebildet, die als Vakuolen mit einer Doppelmembran und sauren Milieu im inneren der Vakuole intrazelluläre Bestandteile wie fehlerhafte Makromoleküle oder zerstörte Organelle aufnehmen und im Zuge der Verschmelzung mit den Lysosomen in Peptidfragmente verdaut werden, mit denen ebenfalls die MHC-II Moleküle beladen werden. Die Autophagozytose stellt dabei eine Quelle für endogene Antigene dar, die mittels der MHC-II Komplexe an der Zelloberfläche präsentiert werden und kann für die Abwehr von Viren eine wichtige Rolle spielen $(25,112)$.

\subsubsection{Aktivierung der DCs und Migration}

Durch die Aktivierung der DCs durch die Aufnahme von Fremdantigenen und zusätzlicher Stimulation über CD40 wird die Expression von sämtlichen Molekülen induziert, die in der Immunantwort eine wichtige Rolle spielen. Die pDCs ändern sogar durch die Reifung ihre Morphologie (14). Im Zuge der Reifung der DCs kommt es zur Expression des Reifungsmarkers CD83 (130) und durch die Aktivierung von NF-кB, IRF5 und der MAPK kommt es zur erhöhten Expression der kostimulatorischen Moleküle CD40, CD80 sowie CD86, die im Zusammenspiel mit den MHC-Molekülen die T-Zellen aktivieren können. Im reifen Zustand ist die Aufnahme und Prozessierung der Antigene heruntergeregelt, während die Expression der MHC-Komplexe sowie der kostimulatorischen Molekülen zunimmt, wodurch eine gesteigerte Fähigkeit der Antigenpräsentation erreicht wird (206).

Weitere Moleküle, deren Expression durch die Aktivierung der DCs hochreguliert wird,

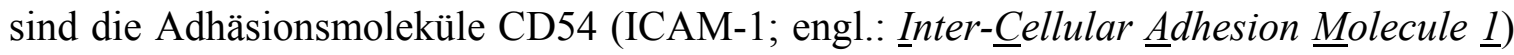
und CD58 (LFA-3; engl.: Lymphocyte function-associated antigen 3), die auch an der Interaktion mit den T-Zellen beteiligt sind (73). 
Der Fas-Rezeptor (CD95) spielt eine zentrale Rolle in der Regulation des programmierten Zelltods, der Apoptose. Durch die Stimulation durch den Fas-Liganden (CD95L) kommt es zur Initiation einer Signalkette, die Apoptose einleitet. Im Zuge der Apoptose kommt es zur gesteigerten Expression von CD95, sodass die Regulation der Fas (CD95)Expression auch als Kontrolle für die Fas-Antwort genutzt werden kann (197).

Im Zuge der Aktivierung kommt es bei den DCs zur Produktion proinflammatorischer Zytokine, wie TNF- $\alpha$ und IL-6 sowie IL-8 $(33,203)$.

Das TNF- $\alpha$ spielt eine Rolle bei der Reifung und Differenzierung der unreifen pDCs (130). Weiterhin induziert TNF- $\alpha$ die Expression von IL-6, wobei beide Zytokine Pyrogene und Fiebermediatoren sind. Die mDCs produzieren neben dem TNF- $\alpha$, IL-6 und IL-8 auch noch zusätzlich IL-1 $\beta$, ein weiteres Fieber induzierendes Pyrogen, sowie erhebliche Mengen von IL-12. Die proinflammatorischen Zytokine und Chemokine führen zur Rekrutierung von unreifen DCs oder anderen Immunzellen an den Ort der Entzündung (3).

Durch die Aktivierung der DCs wird deren Fähigkeit auf proinflammatorische Zytokine $\mathrm{zu}$ reagieren vermindert und die Wanderung $\mathrm{zu}$ den $\mathrm{T}$-Zellregionen in den peripheren Lymphknoten induziert (3).

\subsubsection{Interaktion von DCs mit T-Zellen}

In den Lymphknoten werden den naiven T-Zellen die Antigene präsentiert. Durch die Interaktion von Adhäsionsmolekülen wird zunächst ein Zell-Zell-Kontakt hergestellt. Auf Seiten der DCs sind die Adhäsionsmoleküle CD11c (mDCs), CD54 sowie CD58 involviert, die mit den Molekülen CD18, CD11 (LFA-1) und CD2 auf den T-Zellen interagieren. Die MHC-Moleküle präsentieren die Antigene an den T-Zellrezeptor, wodurch eine spezifische Bindung erfolgt. Die DCs sind in der Lage sowohl naive CD4 ${ }^{+}$als auch naive $\mathrm{CD}^{+} \mathrm{T}$-Zellen zu aktivieren (130). Dabei interagieren die mit einem Antigen beladenen MHC-I Moleküle auf den DCs mit dem T-Zellrezeptor der naiven $\mathrm{CD}^{+}$T-Zellen, während die beladenen MHC-II Moleküle mit dem T-Zellrezeptor der naiven $\mathrm{CD}^{+}$T-Zellen interagieren. Durch die Interaktion wird die Bindung der Adhäsionsmoleküle verstärkt $(58,59)$. Zur Aktivierung der T-Zellen kommt es allerdings erst durch eine weitere Interaktion von den kostimulatorischen Rezeptoren CD40, CD80 und CD86 auf Seiten der DCs mit den entsprechenden Liganden CD40L und CD28 auf 
Seiten der T-Zellen. Ohne die Kostimulation werden die T-Zellen nicht aktiviert und es wird die Apoptose eingeleitet (42).

Die naiven $\mathrm{CD}^{+}$T-Zellen differenzieren im Zuge der Aktivierung zu zytotoxischen Effektorzellen, die bei einem Aufeinandertreffen mit einer Zelle, die ein beladenes MHC-I Molekül trägt, was spezifisch an den T-Zellrezeptor bindet, den Zelltod dieser Zelle induziert oder es kommt zur Lyse der Zelle durch den gezielten Ausstoß von Perforin, durch das die Zellmembran der Zielzelle zerstört wird (95). Bei der Differenzierung der naiven $\mathrm{CD} 4^{+} \mathrm{T}$-Zellen spielen darüber hinaus auch noch die Zytokine eine große Rolle, die von den DCs während der Aktivierung sezerniert werden. Die Differenzierung von den naiven $\mathrm{CD}^{+}{ }^{+}$T-Zellen in $\mathrm{CD}^{+}$T-Helferzellen Typ 1 (Th1) oder in $\mathrm{CD}^{+}$T-Helferzellen Typ 2 (Th2) ist von den jeweiligen Zytokincocktail abhängig, der während der Aktivierung der T-Zellen sezerniert wird. Bei Vorhandensein von IL-12 kommt es zur Differenzierung von Th1-Zellen und bei der Anwesenheit von IL-4 und IL-6 erfolgt die Differenzierung zu Th2-Zellen (192). Die Th1-Zellen sezernieren TNF- $\alpha$, IL-2 und IFN- $\gamma$, wodurch Makrophagen zur Phagozytose stimuliert werden, sodass das eindringende Pathogen vernichtet werden kann. Dagegen sezernieren die Th2-Zellen IL-4, IL-5, IL-6, IL-10 und sind fähig die B-Zellen zur Antikörperproduktion zu stimulieren $(124,192)$. 


\subsection{Das Frühsommer-Meningoenzephalitis-Virus}

Das Frühsommer-Meningoenzephalitis-Virus (FSME-Virus) gehört zum Genus der Flaviviren, innerhalb der Familie der Flaviviridae, zu dem etwa 73 Viren gehören, und ist das in Europa am häufigsten vorkommende durch Arthropoden übertragene Virus (Kurzform Arbovirus, das vom englischen arthropod-borne virus abgeleitet ist) $(49,55)$. Andere Vertreter innerhalb der Flaviviren sind das Gelbfieber-Virus (YFV), das DengueVirus (DENV), das West-Nil-Fieber-Virus (WNV) und das Japan-B-Enzephalitis-Virus (JEV). Zum FSME-Virus-Serokomplex gehören neben dem FSME-Virus auch das Louping Ill-Virus (LIV), das Langat-Virus (LGTV), das Powassan-Virus (POWV), Omsker-Hämorrhaghisches-Fieber-Virus (OHFV) und das Kyasanur-Wald-Fieber-Virus (KFDV), sowie 12 weitere Flaviviren (79) (die Benennung der Viren in dieser Arbeit erfolgte nach dem „International Committee on Taxonomy of Viruses“ (ICTV) (93)). Basierend auf serologischen Analysen und Sequenzanalysen der Genome werden die FSME-Viren in drei Subtypen unterteilt, den europäischen Subtyp, den sibirischen Subtyp und den fernöstlichen Subtyp $(30,62)$.

Eine Infektion mit dem FSME-Virus kann zu Meningitis, Enzephalitis und Meningoenzephalomyelitis führen sowie schwere neurologische Schäden zur Folge haben $(28,125)$.

\subsubsection{Virusstruktur und Replikation}

FSME-Virionen sind runde behüllte Partikel (125). Dabei wird das virale Genom wird von einer Lipiddoppelmembran umgeben, die einen Durchmesser von 40-60 nm aufweist (117). Die Lipidhülle beinhaltet mit dem großen Hüll-Protein bzw. Protein E (E als Abkürzung für das englische Wort envelope) und dem Membran-Protein bzw. Protein M (engl.: matrix) zwei verschiedene Strukturproteine mit Membranankern (125). Das Protein E spielt eine wichtige Rolle als Ligand für den noch unbekannten Rezeptor auf der Wirtszelle und als Fusionsprotein (118). Durch die Interaktion des Glykoproteins E auf der Oberfläche des Virus mit zellulären Oberflächenrezeptoren bindet das Virion an die Wirtszelle und es kommt zur so genannten Adsorption bzw. Verschmelzung (Abbildung 1.4 (1.)). Durch die durch die Rezeptoren eingeleitete 
Endozytose bzw. Penetration werden die Virionen in Endosomen transportiert, in denen ein saures Milieu mit einem pH unter 6.6 vorherrscht (Abbildung 1.4 (2.)) (125). Der niedrige $\mathrm{pH}$ führt zu einer Konformationsänderung des Protein E, das dadurch nicht mehr in Dimeren, sondern in Trimeren auf dem Virion vorkommt. Durch diese Konformationsänderung wird die Verschmelzung der viralen Membran mit der endosomalen Membran eingeleitet, sodass das virale Nukleokapsid in das Zytoplasma gelangt. Nach der Freisetzung kommt es zum so genannten Uncoating bzw. Entpacken, bei dem das Kapsid die virale RNA in das Zytoplasma entlädt (Abbildung 1.4 (3.)).

Wie alle Flaviviren besitzt auch das FSME-Virus ein einzelsträngiges RNA-Genom mit einer positiven Orientierung (ssRNA ${ }^{+}$) und einer Länge von ca. 11000 Basen (88). Das virale RNA-Genom besitzt die gleiche Orientierung wie die mRNA und kann somit direkt ohne weitere Prozessierung oder Umschreibung translatiert werden. Durch Einbringen der viralen RNA kann daher der Repliaktionszyklus in Gang gesetzt werden, daher wird auch der Begriff „,infektiöse RNA“ verwendet $(118,126)$. Das Genom enthält einen einzigen langen offenen Leserahmen, der von jeweils einer nicht-kodierenden Region am 3'- und 5'-Ende flankiert wird. Das 5'-Ende besitzt ähnlich zellulärer mRNA eine CAP-Struktur, das 3'-Ende ist jedoch nicht polyadenyliert (s. Abbildung 1.3 oben) (37). Im Zuge der Translation entsteht ein einziges aus 3414 Aminosäuren bestehendes Polyprotein, das durch eine virale Serinprotease und zellulären Proteasen, wie einer Signalase und Furin oder Furin-artigen Proteasen, ko- und post-translational in drei Struktur- und sieben Nichtstrukturproteine prozessiert wird (Schnittstellen der Signalase (roter Pfeil) und zellulären Proteasen (blauer Pfeil) sind in der Abbildung 1.3 unten dargestellt) (89). Zu den drei Strukturproteinen gehören das Kapsid (C) Protein, das Membran (M) Protein sowie das Hüllprotein E. Die sieben Nichtstrukturproteine setzen sich zusammen aus den Proteinen NS1, NS2A, NS2B, NS3, NS4A, NS4B und NS5 (89). Die Nichtstrukturproteine besitzen unterschiedliche zum Teil noch ungeklärte Funktionen. Das Glykoprotein NS1 scheint zusammen mit dem Protein NS4A an der Replikation des viralen Genoms beteiligt zu sein $(116,123)$. Die beiden Proteine NS2A und NS2B fungieren als Proteasen. Das NS3 Protein kann mehrere Funktionen ausüben, während die Region um den C-Terminus sowohl Nukleosid Triphosphatase (NTPase) als auch Helikase Aktivität besitzt, fungiert die N-terminale Region des NS3 Proteins als Protease, die eine Rolle bei der Prozessierung des viralen Polyproteins spielt (127). Die Stellen, an 
der das NS3 Protein als Protease agiert und das Polyprotein prozessiert, sind in der Abbildung 1.3 unten mit kleinen hellblauen Dreiecken dargestellt. NS4A scheint eine Rolle als Kofaktor der NS3 Protease zu spielen (188).

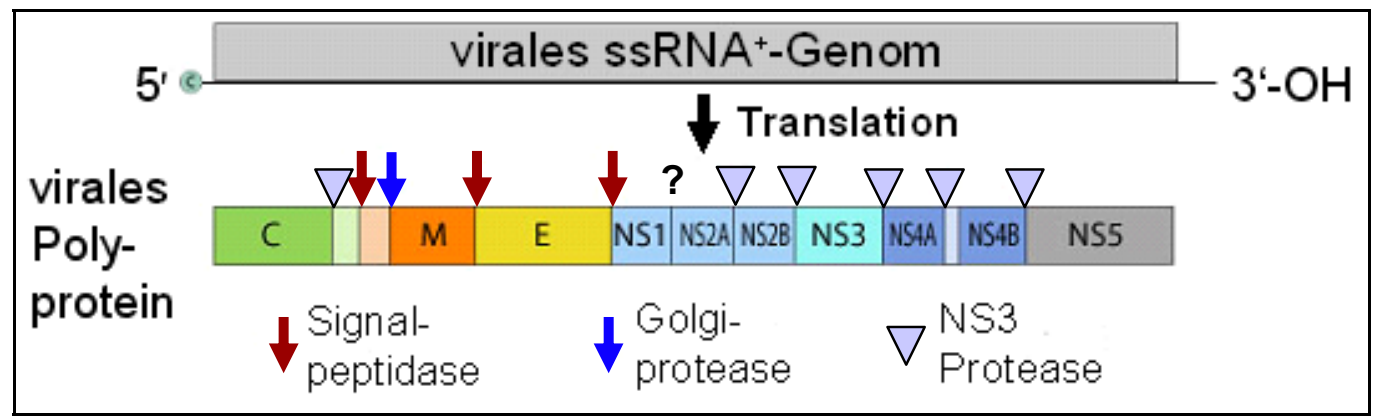

Abbildung 1.3: Aufbau des Genoms und Polyproteins der Flaviviren.

Oben ist das virale ssRNA-Genom mit den 5'- und 3'-Enden dargestellt. Unten ist das virale Polyprotein mit den einzelnen Prozessierungsstellen abgebildet (Abbildung modifiziert nach (92)).

Die Funktion des Proteins NS4B ist noch nicht aufgeklärt. Das NS5 Protein ist im Vergleich zu den anderen NS-Proteinen das größte und am stärksten konservierte Protein in der Reihe der Flaviviren (163). Das Protein NS5 ist multifunktional, mit der C-terminalen Region agiert es als RNA-abhängige RNA Polymerase (engl.: $\underline{R} N A$ dependent $\underline{R} N A$ polymerase $(\mathrm{RdRp}))$ und die N-terminale Region fungiert als Methyltransferase, die die CAP-Struktur am 5'-Ende methyliert (127).

Das virale Genom (ssRNA ${ }^{+}$) wird durch das Protein C in Nukleokapside auf der der zum Zytoplasma gewandten Seite der Membran des ER verpackt. Der Zusammenbau der Viren findet im ER statt und führt zunächst zu einem unreifen Virion, das neben den Proteinen $\mathrm{C}$ und $\mathrm{E}$ einen Vorläufer des M Proteins beinhaltet, das auch als prM Protein bezeichnet wird (Abbildung 1.4 (7.)) (37). Das prM-Protein wird im Zuge der zellulären Sekretion (Abbildung 1.4 (8.)) in dem sauren Milieu der Vesikel des trans-Golgi Netzwerkes durch die Protease Furin der Wirtszelle zum endgültigen M-Protein prozessiert (Abbildung 1.4 (9.)) (178). Die Prozessierung des M-Proteins führt zu einer Reorganisation des E-Proteins, sodass verschmelzungskompetente Homodimere entstehen. Nach Beendigung dieser Schritte ist ein reifes und infektiöses Virion entstanden, das durch die Verschmelzung der Transportvesikel mit der Plasmamembran die Zelle verlässt (Abbildung 1.4 (10.)) (199). 


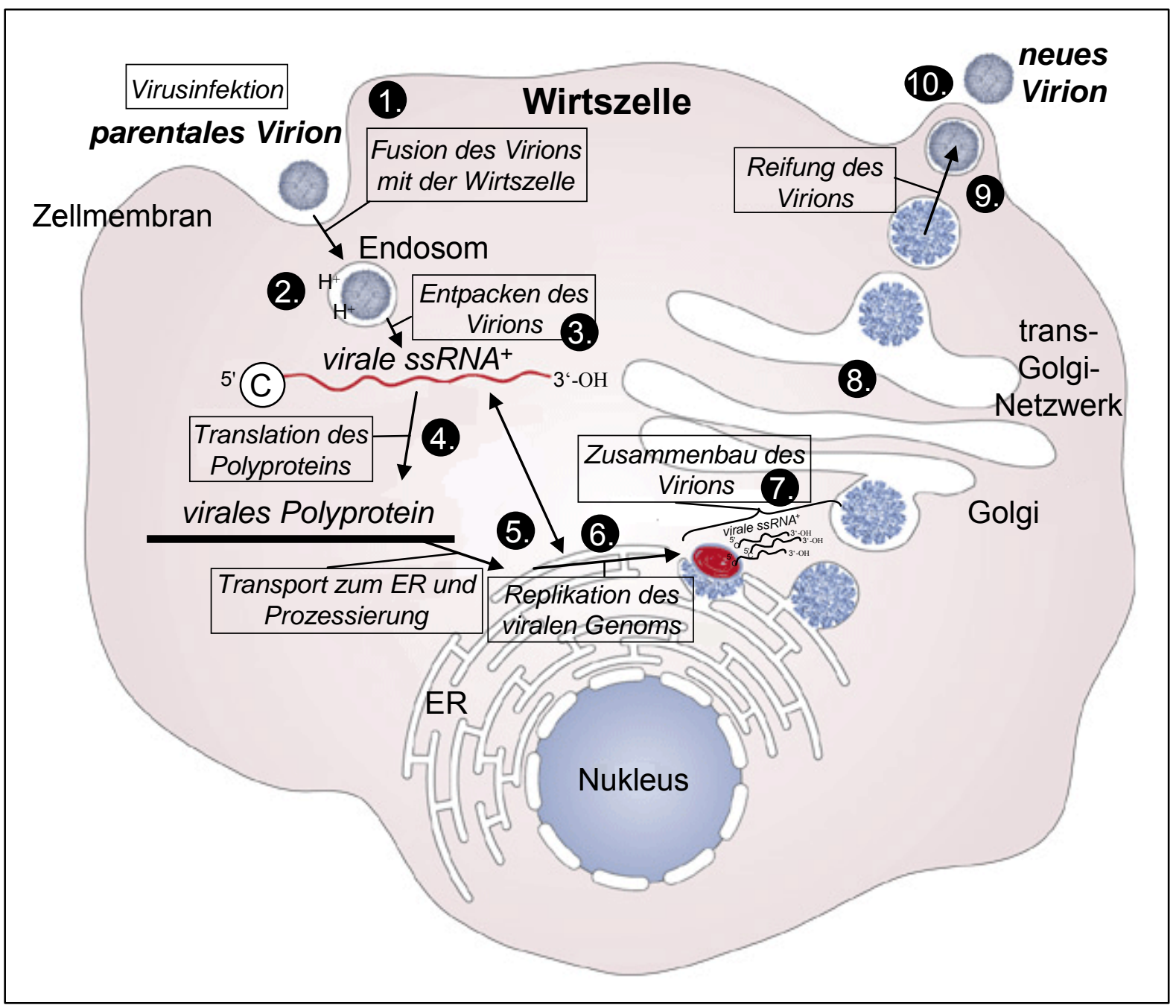

Abbildung 1.4: Replikationszyklus der Flaviviren (Abbildung modifiziert nach (139)).

\subsubsection{Viraler Übertragungszyklus und Wege der Infektion}

Der virale Übertragungszyklus des FSME-Virus umfasst neben Wirbeltiere auch Zecken als Nichtvertebraten. Die Zecken spielen im Übertragungszyklus der FSME-Viren eine wichtige Rolle als effektiver Vektor (163). Im Falle einer Infektion persistiert das FSMEVirus das lebenslang in den Zecken, sodass die Zecken nicht nur einen Vektor sondern auch ein Reservoir für das FSME-Virus darstellen $(57,127)$.

Das Hauptreservoir der FSME-Viren sind allerdings kleine Säugetiere, vornehmlich Nager (57). In diesen Wirten kann sich das FSME-Virus vermehren und mit großer Wahrscheinlichkeit durch einen Zeckenstich wieder auf den Vektor Zecke übertragen werden (183). Übertragungen unter Vertebraten sind bisher nicht nachgewiesen worden. 
Für das FSME-Virus stellt der Mensch wie auch viele andere größere Säugetiere einen Fehlwirt dar (s. Abbildung 1.5 rote Pfeile) (163). Es sind insgesamt drei Infektionswege von dem FSME-Virus auf den Menschen bekannt. Die am häufigsten vorkommende Variante der Übertragung stellt der Zeckenstich einer mit FSME-Virus infizierten Zecke dar (118). Die Übertragungsvariante via Zeckenstich unterliegt einer saisonalen Abhängigkeit, die auf die Aktivität der Zecken und dem jeweiligen Wetter der Jahreszeit zurückzuführen ist. Die Übertragung von FSME-Virus von Zecke auf den Menschen tritt von März bis Oktober auf, wobei sich die Fälle von FSME in den Zeiträumen von Juni bis Juli und von September bis Oktober gemäß der Aktivitätszunahme der Zecken in Abhängigkeit von dem Wetter häufen (16).

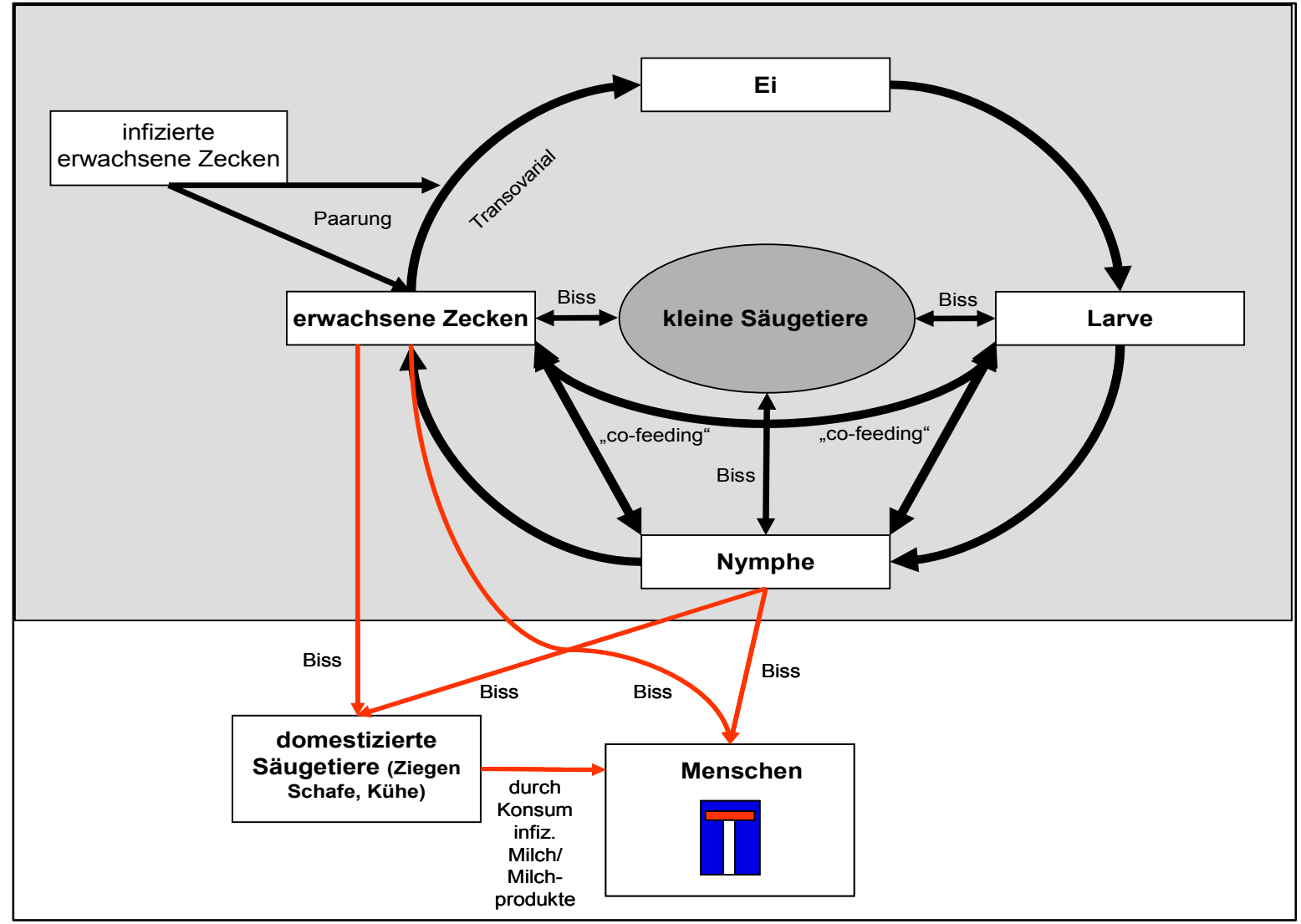

Abbildung 1.5: Viraler Übertragungszyklus des FSME-Virus (Abbildung modifiziert nach (127)).

Weitaus weniger häufig wird das FSME-Virus durch den Konsum von unpasteurisierter Milch oder Milchprodukten übertragen, die von FSME-Virus infizierten Ziegen, Schafen oder Kühen stammen. Dabei erfolgt der Übergang in die Milch während das Tier virämisch ist $(80,90,153)$. Das FSME-Virus übersteht auch Passagen saurer Milieus wie sie im Magen vorkommen, sodass es anschließend zur Infektion des Darmepithels 
kommt. Die dritte Übertragungsvariante stellt das Einatmen von FSME-Virus enthaltenen Aerosolen dar, wie sie z. B. bei der Ankonzentrierung von Virus mittels einer Zentrifuge entstehen können. Daher wird das FSME-Virus auch in die Kategorie der

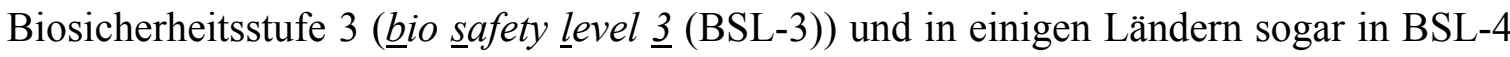
eingestuft (147).

\subsubsection{Der Krankheitsverlauf der FSME}

Der Krankheitsverlauf unterscheidet sich in Abhängigkeit von dem jeweiligen FSMEVirus-Subtyp. Die Infektion mit dem europäischen Subtyp verläuft in der Mehrzahl der Fälle asymptomatisch bzw. subklinisch (28). Der symptomatische Verlauf ist bei $72 \%$ der FSME-Patienten biphasisch $(57,97,118)$. Nach einer anfänglichen Inkubationszeit von gewöhnlich 7-14 Tagen folgt die erste, so genannte virämische Phase, die mit unspezifischen influenzaartigen Symptomen, wie Fieber, allgemeinen Unwohlsein, Muskelschmerzen, gastrointestinalen Symptomen, Leukozytopenie und Thrombozytopenie begleitet wird und bis zu 8 Tagen (gewöhnlich 2-4 Tage) andauern kann (54). Nach einem symptomfreien Intervall von bis zu einer Woche erfolgt der Ausbruch der zweiten so genannten enzephalitischen Phase, die vor allem von neurologischen Symptomen begleitet wird. Die dabei auftretenden schweren neurologischen Krankheiten reichen von Enzephalitis, Meningitis bis zur Meningoenzephalomyelitis oder Meningoenzephalo-radikulitis (28).

Dagegen verläuft die durch den fernöstlichen FSME-Virus Subtyp verursachte Krankheit bei $85 \%$ der Patienten monophasisch mit weitaus schwereren Symptomen, wie schweren Störungen des Zentralnervensystems (ZNS) und neurologische Schäden (57). Die Letalitätsrate des europäischen FSME-Virus Subtyps liegt bei bis zu 2\%, während die des fernöstlichen Subtyps bei bis zu 30\% liegt (62). FSME kann zu erheblichen gesundheitlichen Folge- und Langzeitschäden führen. Dabei kann es zu einem so genannten post-enzephalitisches FSME-Syndrom kommen, das eine dauerhafte Morbidität verursacht, die zu Einschränkungen der Lebensqualität des betroffenen Patienten führt $(57,85,91)$. $\mathrm{Zu}$ den Faktoren, die die Intensität des Krankheitsverlaufs beeinflussen, gehören die Dosis und die Virulenz auf der Seite des FSME-Virus und der Immunstatus auf der Seite des Wirts (166). Weiterhin scheint das Alter bei dem Krankheitsverlauf eine Rolle zu spielen. In der Literatur wird in einigen Fällen 
beschrieben, dass FSME im Kindesalter weitaus milder verläuft als in erwachsenen- oder fortgeschrittenen Altersgruppen (5). Allerdings sind auch FSME-Fälle bei Kindern bekannt, die zu neuropsychologischen Schäden oder Beeinträchtigungen der Lebensqualität geführt haben (106).

Aktuell gibt es keine antivirale Therapie gegen das FSME-Virus, allerdings ist eine effektive Impfung als Prävention verfügbar. Diese Impfung basiert auf mittels Paraformaldehyd inaktiviertes FSME-Virus, das bei $95 \%$ der geimpften Personen eine Immunität hervorruft $(22,105)$.

\subsubsection{Interaktionen des FSME-Virus mit dem Immunsystem der Säuger}

Die Interaktionen des FSME-Virus mit dem Immunsystem der Säugetiere sind in Abbildung 1.5 schematisch dargestellt. Bei dem häufigsten Übertragungsweg des FSMEVirus, durch den Stich einer infizierten Zecke, wird das Virus mittels des Zeckenspeichels, den die Zecke während des Stiches in die Stichstelle absondert, übertragen. Der Zeckenspeichel übernimmt dabei gleich mehrere Aufgaben. Zum einen vermehrt sich das FSME-Virus um bis zu das 100-fache im Speichel (2), zum anderen hat der Zeckenspeichel eine modulierende Wirkung auf die Immunzellen und spielt speziell bei der Schmerzunterdrückung während des Zeckenstiches eine wichtige Rolle. Die anti-hämostatischen, schmerzunterdrückenden-, antiinflammatorischen- und immunsupprimierenden Effekte des Zeckenspeichels beeinträchtigen die Reaktion der immunkompetenten Zellen, sodass eine Infektion von Zellen am Ort des Zeckenstichs mit dem FSME-Virus kommt $(147,148)$. Zu diesen Zellen in der Haut gehören neben LCs und Makrophagen vor allem Kreatinozyten, aber auch die DCs stellen einen frühen Angriffspunkt des FSME-Virus dar (163).

Für die Makrophagen konnte gezeigt werden, dass sie in Antwort auf eine Infektion mit dem FSME-Virus Stickstoffmonoxid produzieren, das inhibierend auf die virale Replikation wirkt und so die Ausbreitung des FSME-Virus einschränkt (103, 115). Allerdings wurde auch in Mausversuchen gezeigt, dass das FSME-Virus in den Makrophagen repliziert und sie so an der Ausbreitung des Virus beteiligt sind (1). Neutrophile, die aufgrund der hervorgerufenen Inflammation an die Infektionsstelle rekrutieren, können ebenfalls durch ihre primäre Funktion als phagozytotische Zellen und der Möglichkeit als Ort der FSME-Virusreplikation $\mathrm{zu}$ fungieren eine Rolle als 
Ausbreitungsfaktor für das FSME-Virus spielen (108). Bei den NK-Zellen konnte ein supprimierender Effekt der Aktivität durch die Infektion mit dem FSME-Virus sowie anderen Flaviviren wie dem WNV und dem LGTV gezeigt werden, sodass nahe liegt, dass die Flaviviren einen Mechanismus entwickelt haben der Antwort der NK-Zellen zu entgehen $(194,204)$. Welche Rolle die einzelnen DC-Subtypen allerdings genau während der Infektion mit dem FSME-Virus spielen ist jedoch unklar. Im Allgemeinen sollte eine Infektion der DCs mit dem FSME-Virus zu einer Erkennung durch die PRRs kommen und zur Ausreifung sowie einer Immunantwort der DCs führen. Speziell eine Typ I IFNAntwort, wie sie von den pDCs in Antwort auf virale Infektionen initiiert wird, hätte für das Virus weitreichende Folgen, da das FSME-Virus sowie andere Flaviviren sensitiv auf die Typ I IFNs reagieren (150), (65), (50), (44), (23). Eine Theorie besagt, dass das FSME-Virus die DCs in der Haut infiziert, dort repliziert und mit diesen Zellen über das lymphatische System zu den Lymphknoten transportiert wird (85). Bei der Übertragung des FSME-Virus durch infizierte Milch gelangt das FSME-Virus durch den Magen in den Darmtrakt, wo es ebenso auf DCs und Makrophagen trifft, die infiziert werden können und $\mathrm{zu}$ den Lymphknoten migrieren. Von dort aus breitet sich das FSME-Virus in die extra-neuralen Gewebe aus und es kommt zur Virämie. Das FSME-Virus dringt dabei hauptsächlich in das reticulo-endotheliale System ein, zu dem neben der Milz auch die Leber und das Knochenmark gehören (85). Im Serum von FSME-Patienten konnte neben den proinflammatorischen Zytokinen TNF- $\alpha$ und IL-6 auch IgM- und IgG-Antikörper nachgewiesen werden $(8,91,98,191)$. Während die $\operatorname{IgM}$ Antikörper nicht länger als 6-7 Wochen nachweisbar sind, bieten die IgG Antikörper einen Langzeitschutz (91). Inwieweit das FSME-Virus durch die Antikörper neutralisiert wird, hängt von der Antikörperproduktion ab. Eine schnelle und effektive humorale Immunantwort würde eine weitere Ausbreitung des FSME-Virus und somit eine Virämie verhindern (98). Das FSME-Virus ist neuroinvasiv und dringt mit Hilfe bis noch unbekannten Mechanismen durch die Blut-Hirn-Schranke (BHS) (125). Es gibt allerdings verschiedene Theorien, die eine mögliche Erklärung liefern wie das FSME-Virus die BHS passiert und in das ZNS vordringt (131).

Eine Theorie besagt, dass die inflammatorischen Zytokine TNF- $\alpha$ und IL-6 die Permeabilität der BHS beeinflussen und das FSME-Virus so durch die BHS gelangen könnte wie es auch für das WNV gezeigt wurde $(15,198)$. Eine weitere These sieht 
diverse Immunzellen wie T-Zellen, DCs oder Makrophagen als potentielles Shuttle für das FSME-Virus in einer Art „Trojanisches Pferd“-Mechanismus, wobei die infizierten Zellen die BHS passieren (101). Eine weitere These besagt, dass das FSME-Virus durch die Ausbreitung im Blut die Neuronen im Riechzentrum infiziert und sich durch Replikation weiter ausbreitet. Dieser Weg wird auch bei der Übertragung des FSMEVirus durch einatmen von FSME-Virus enthaltenen Aerosolen angenommen. Dabei kann das Virus ohne die BHS passieren zu müssen direkt in das ZNS gelangen (76). Im ZNS scheint das FSME-Virus unter anderem die antigenpräsentierenden Mikroglia Zellen zu infizieren, die neben der Antigenpräsentation auch die Produktion von inflammatorischen Zytokinen und Chemokinen initiieren (129). Durch die im Zuge der Inflammation produzierten Zytokine kommt es zur Einschleusung von Leukozyten aus der Peripherie in das ZNS, um die Immunantwort weiter zu verstärken (101). Die CD4 ${ }^{+}$T-Zellen scheinen verschiedene Rollen zu spielen, da sie zum einen die Inflammation im ZNS durch die Produktion inflammatorischer Zytokine verstärken und andererseits die Produktion des antiinflammatorischen Zytokins IL-10 die Immunantwort der Mikroglia Zellen hemmen. Eine hohe Konzentration von Neopterin im Hirnwasser deutet auf ein hohes Maß an T-Zell-Aktivität bei der FSME hin (83). Zu Beginn der enzephalitischen Phase konnten auch neutralisierende IgM- und IgG Antikörper nachgewiesen werden. Es konnte auch für das ZNS gezeigt werden, dass eine geringe Konzentration von neutralisierenden Antikörpern im Hirnwasser zur Folge hat, dass die akuten enzephalitischen Symptome heftiger verlaufen (85).

Im Zentralnervensystem scheinen die Neuronen die Zielzellen des FSME-Virus zu sein (125). Während der enzephalitischen Phase konnte keine RNA des FSME-Virus im Hirnwasser nachgewiesen werden, was darauf hindeutet, dass das FSME-Virus in den Neuronen lokalisiert ist und wohl von Zelle zu Zelle weitergegeben wird (82, 85, 158). Die zytotoxischen $\mathrm{CD}^{+}$T-Zellen leiten bei den infizierten Mikroglia Zellen und Neuronen den Zelltod ein, um eine weitere Ausbreitung des FSME-Virus zu verhindern. Die Zerstörung der Neuronen führt zu Schäden im ZNS $(77,167)$. 


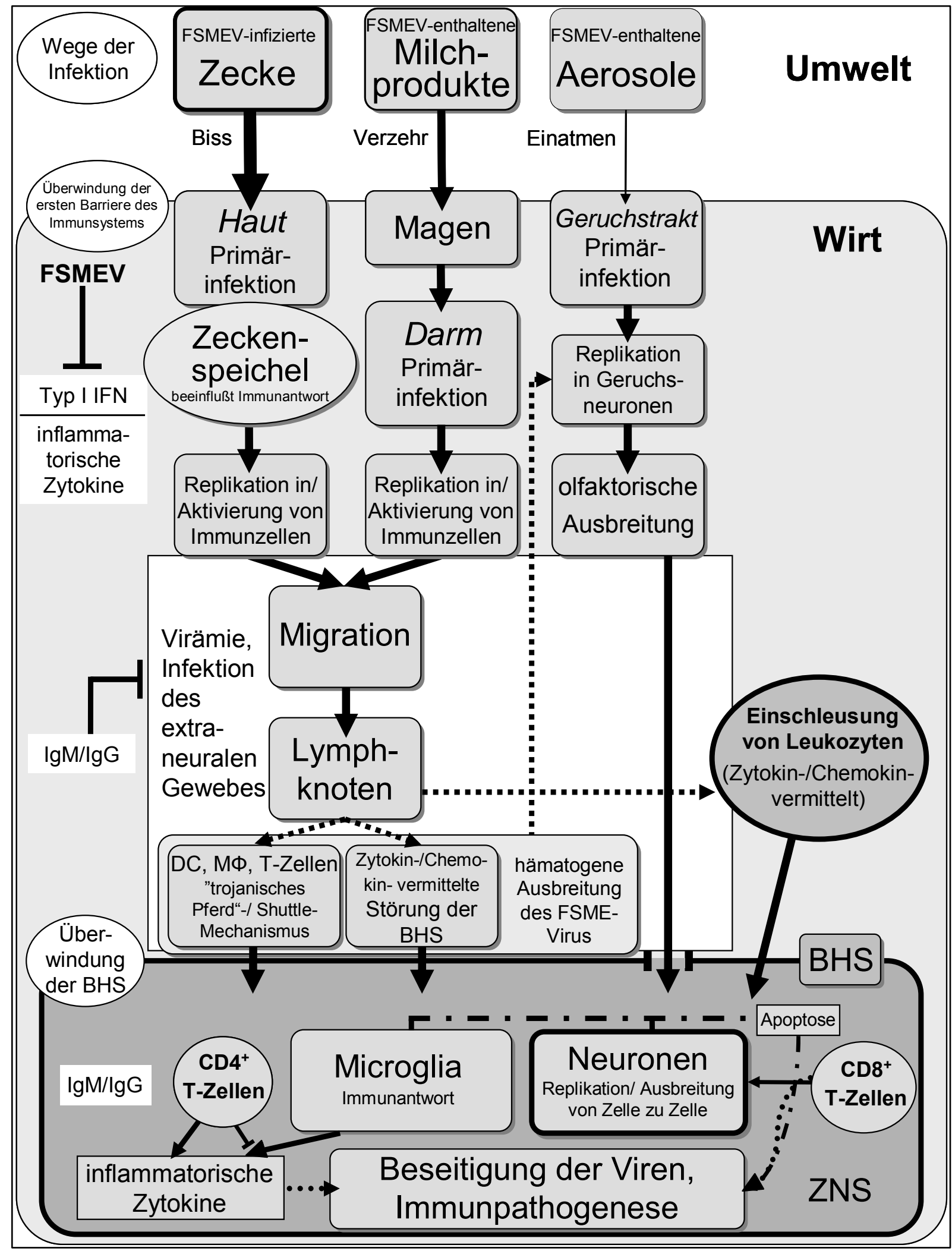

Abbildung 1.6: Interaktion von FSME-Virus mit dem Immunsystem der Säugetiere (Abbildung modifiziert nach (55)). 


\subsection{Ziele der Arbeit}

Aktuell sind viele Fragen im Rahmen der Pathogenese des FSME-Virus ungeklärt. Speziell die frühe Immunantwort nach der FSME-Virusinfektion ist noch weitgehend uncharakterisiert. Dabei stellen die DCs als APCs, die zum einen früh in der Infektion mit FSME-Virus in Kontakt kommen und zum anderen die Schnittstelle zwischen der angeborenen- und erworbenen Immunantwort darstellen, einen wichtigen Faktor dar.

Ziel der Arbeit ist es auf Ebene der verschiedenen DC-Subtypen die Interaktionen mit dem FSME-Virus zu untersuchen. Dies umfasst die Induktion pro- und antiinflammatorisch wirksamer Zytokine, sowie von antiviral wirksamen Typ I Interferon nach Kontakt von DCs mit dem FSME-Virus. In diesem Zusammenhang soll auch die Frage geklärt werden, ob DCs durch das FSME-Virus infizierbar sind und ob eine produktive Replikation des FSME-Virus in DCs stattfindet. Weiterhin soll untersucht werden, inwieweit es nach Kontakt mit FSME-Virus zur Aktivierung der ersten Schritte der adaptiven Immunität kommt, d. h. ob es zur Induktion von Reifungsmarkern, Adhäsionsmarkern, kostimulatorischen Molekülen und antigenpräsentierenden Molekülen kommt.

Darüber hinaus soll die Immunantwort der T-Zellen als wichtige Komponente des adaptiven Immunsystems analysiert werden. Dabei sollen Untersuchungen im Rahmen der Induktion von Aktivierungsmarkern und der Produktion von Zytokinen, sowie über eine produktive Replikation des FSME-Virus in den T-Zellen durchgeführt werden. Die pDCs sind in der Lage durch die Präsentation von Antigenen und durch die Produktion von IFN- $\alpha$ in Antwort auf virale Stimuli die T-Zellen effektiv zu aktivieren. Daher sollte auch die Immunantwort der T-Zellen in einer pDC-T-Zell-Kokultur im Rahmen der Expression von Aktivierungsmarkern und der Produktion von Zytokinen untersucht werden. 


\section{Material und Methoden}

\subsection{Material}

\subsubsection{Chemikalien}

Die in dieser Arbeit verwendeten Chemikalien sowie die jeweiligen Hersteller und der Verwendungszweck im Rahmen der Arbeit sind in der Tabelle 2.1 aufgeführt.

Tabelle 2.1: Verwendete Chemikalien.

\begin{tabular}{|c|c|c|}
\hline Chemikalie & Hersteller & Anwendung \\
\hline $\begin{array}{l}\text { 2-(4-(2-Hydroxyethyl)-1- } \\
\text { piperazinyl)-ethansulfonsäure } \\
\text { (HEPES) } 1 \mathrm{M}\end{array}$ & $\begin{array}{l}\text { cc-pro Gesellschaft für } \\
\text { Herstellung und Vertrieb } \\
\text { von Produkten für } \\
\text { Zellkulturen mbH, } \\
\text { Oberdorla, Deutschland }\end{array}$ & $\begin{array}{l}\text { Zellkultur } \\
\text { (Infektionsmedium) }\end{array}$ \\
\hline $\begin{array}{l}\text { 5(6)-Carboxyfluorescein di- } \\
\text { Acetat N-Succinimidylester } \\
\text { (CFSE) }\end{array}$ & $\begin{array}{l}\text { Sigma-Aldrich Chemie } \\
\text { GmbH, Steinheim, } \\
\text { Deutschland }\end{array}$ & $\begin{array}{l}\text { Färbung der PBMCs als } \\
\text { Proliferationstest }\end{array}$ \\
\hline $\begin{array}{l}\text { Bovines Serumalbumin } \\
\text { (BSA) }\end{array}$ & $\begin{array}{l}\text { Sigma-Aldrich Chemie } \\
\text { GmbH, Steinheim, } \\
\text { Deutschland }\end{array}$ & $\begin{array}{l}\text { Zusatz für } \\
\text { Aufreinigungspuffer für } \\
\text { DC-Aufreinigung }\end{array}$ \\
\hline Dimethylsulfoxid (DMSO) & $\begin{array}{l}\text { Carl-Roth GmbH \& Co } \\
\text { KG, Karlsruhe, } \\
\text { Deutschland }\end{array}$ & Einfriermedium \\
\hline Essigsäure (100 \%) & $\begin{array}{l}\text { Carl-Roth GmbH \& Co } \\
\text { KG, Karlsruhe, } \\
\text { Deutschland }\end{array}$ & $\begin{array}{l}\text { TAE-Puffer für die } \\
\text { Gelelektrophorese }\end{array}$ \\
\hline Ethanol (reinst) & $\begin{array}{l}\text { Carl-Roth GmbH \& Co } \\
\text { KG, Karlsruhe, } \\
\text { Deutschland }\end{array}$ & $\begin{array}{l}\text { RNA-Fällung, RNeasy-Kit } \\
\text { (Fa. Qiagen) }\end{array}$ \\
\hline Ethanol $99 \%$ vergällt & $\begin{array}{l}\text { CVH, Chemie Vertrieb } \\
\text { Hannover, Hannover, } \\
\text { Deutschland }\end{array}$ & Desinfektion \\
\hline
\end{tabular}




\begin{tabular}{|c|c|c|}
\hline Chemikalie & Hersteller & Anwendung \\
\hline $\begin{array}{l}\text { Ethylendiamintetraacetat } \\
\text { (EDTA)-dinatrium }\end{array}$ & $\begin{array}{l}\text { Serva Electrophoresis } \\
\text { GmbH, Heidelberg, } \\
\text { Deutschland }\end{array}$ & $\begin{array}{l}\text { Zusatz für } \\
\text { Aufreinigungspuffer für } \\
\text { DC-Aufreinigung }\end{array}$ \\
\hline L-Glutamin 200 mM (100x) & $\begin{array}{l}\text { cc-pro Gesellschaft für } \\
\text { Herstellung und Vertrieb } \\
\text { von Produkten für } \\
\text { Zellkulturen mbH, } \\
\text { Oberdorla, Deutschland }\end{array}$ & Zellkultur \\
\hline Paraformaldehyd (reinst) & $\begin{array}{l}\text { Carl-Roth GmbH \& Co } \\
\text { KG, Karlsruhe, } \\
\text { Deutschland }\end{array}$ & $\begin{array}{l}\text { Inaktivierung des FSME- } \\
\text { Virus }\end{array}$ \\
\hline Penicillin-Streptomycin & $\begin{array}{l}\text { cc-pro Gesellschaft für } \\
\text { Herstellung und Vertrieb } \\
\text { von Produkten für } \\
\text { Zellkulturen mbH, } \\
\text { Oberdorla, Deutschland }\end{array}$ & Zellkultur \\
\hline $\begin{array}{l}\text { Phosphatgepufferte } \\
\text { Salzlösung (PBS) }\end{array}$ & $\begin{array}{l}\text { cc-pro Gesellschaft für } \\
\text { Herstellung und Vertrieb } \\
\text { von Produkten für } \\
\text { Zellkulturen mbH, } \\
\text { Oberdorla, Deutschland }\end{array}$ & $\begin{array}{l}\text { Zellkultur, diverse } \\
\text { Waschschritte der Zellen }\end{array}$ \\
\hline Tris & $\begin{array}{l}\text { Carl-Roth GmbH \& Co } \\
\text { KG, Karlsruhe, } \\
\text { Deutschland }\end{array}$ & $\begin{array}{l}\text { TAE-Puffer für die } \\
\text { Gelelektrophorese }\end{array}$ \\
\hline $\begin{array}{l}\text { Trypsin/EDTA-Lösung } \\
0,25 \% / 0,02 \%(\mathrm{w} / \mathrm{v}) \text { in PBS } \\
(\mathrm{w} / \mathrm{o}) \mathrm{Ca}^{2+}, \mathrm{Mg}^{2+}\end{array}$ & $\begin{array}{l}\text { Biochrom AG, Berlin, } \\
\text { Deutschland }\end{array}$ & Zellkultur \\
\hline
\end{tabular}

\subsubsection{Materialien für die Zellkultur und andere Verbrauchswaren}

Die in dieser Arbeit verwendeten Materialien für die Zellkultur und weitere benutzte Verbrauchswaren sowie der jeweilige Hersteller und der Verwendungszweck im Rahmen der Arbeit sind in der Tabelle 2.2 dargestellt. 
Tabelle 2.2: Verwendete Materialien für die Zellkultur und Verbrauchswaren.

\begin{tabular}{|c|c|c|}
\hline Verbrauchsmaterial & Hersteller & Anwendung \\
\hline $\begin{array}{l}\text { Zellkulturmedium, } \\
\text { Dulbecco's Modified Eagle } \\
\text { Medium (DMEM) }\end{array}$ & $\begin{array}{l}\text { cc-pro Gesellschaft für } \\
\text { Herstellung und Vertrieb von } \\
\text { Produkten für Zellkulturen } \\
\text { mbH, Oberdorla, Deutschland }\end{array}$ & $\begin{array}{l}\text { Zellkulturmedium } \\
\text { (Infektionsmedium) }\end{array}$ \\
\hline $\begin{array}{l}\text { Zellkulturmedium, } \\
\text { Minimum Essential } \\
\text { Medium (MEM) }\end{array}$ & $\begin{array}{l}\text { cc-pro Gesellschaft für } \\
\text { Herstellung und Vertrieb von } \\
\text { Produkten für Zellkulturen } \\
\text { mbH, Oberdorla, Deutschland }\end{array}$ & $\begin{array}{l}\text { Zellkulturmedium } \\
\text { (Vero-B4) }\end{array}$ \\
\hline IL-2 & $\begin{array}{l}\text { Sigma-Aldrich Chemie } \mathrm{GmbH} \text {, } \\
\text { Steinheim, Deutschland }\end{array}$ & Zusatz für T-Zell-Medium \\
\hline IL-3 & $\begin{array}{l}\text { Sigma-Aldrich Chemie GmbH, } \\
\text { Steinheim, Deutschland }\end{array}$ & Zusatz für pDC-Medium \\
\hline IL-4 & $\begin{array}{l}\text { Miltenyi Biotec GmbH, } \\
\text { Bergisch Gladbach, } \\
\text { Deutschland }\end{array}$ & Zusatz für mDC-Medium \\
\hline GM-CSF & $\begin{array}{l}\text { Miltenyi Biotec GmbH, } \\
\text { Bergisch Gladbach, } \\
\text { Deutschland }\end{array}$ & Zusatz für mDC-Medium \\
\hline Phytohämagglutinin (PHA) & $\begin{array}{l}\text { Sigma-Aldrich Chemie GmbH, } \\
\text { Steinheim, Deutschland }\end{array}$ & Stimulanz für T-Zellen \\
\hline Ficoll Paque PLUS & $\begin{array}{l}\text { GE Healthcare Bio Sciences } \\
\text { AB, Uppsala, Schweden }\end{array}$ & $\begin{array}{l}\text { Gradientendichte- } \\
\text { zentrifugation }\end{array}$ \\
\hline Fötales Kälberserum (FKS) & $\begin{array}{l}\text { Invitrogen GmbH, Darmstadt, } \\
\text { Deutschland }\end{array}$ & Zellkultur \\
\hline $\begin{array}{l}\text { Fötales Kälberserum (FKS) } \\
\text { (endotoxinfrei) }\end{array}$ & $\begin{array}{l}\text { Invitrogen GmbH, Darmstadt, } \\
\text { Deutschland }\end{array}$ & Zellkultur (DCs) \\
\hline $\begin{array}{l}\text { Zellkulturmedium, Roswell } \\
\text { Park Memorial Institute } \\
\text { Medium } 1640 \text { (RPMI1640) }\end{array}$ & $\begin{array}{l}\text { cc-pro Gesellschaft für } \\
\text { Herstellung und Vertrieb von } \\
\text { Produkten für Zellkulturen } \\
\text { mbH, Oberdorla, Deutschland }\end{array}$ & Zellkulturmedium (DCs) \\
\hline Opti-MEM Gibco & $\begin{array}{l}\text { Invitrogen GmbH, Darmstadt, } \\
\text { Deutschland }\end{array}$ & Filtration \\
\hline
\end{tabular}




\begin{tabular}{|c|c|c|}
\hline Verbrauchsmaterial & Hersteller & Anwendung \\
\hline $\begin{array}{l}\text { Wasser für } \\
\text { Zellkulturzwecke } \\
\text { pyrogenfrei, steril }\end{array}$ & $\begin{array}{l}\text { cc-pro Gesellschaft für } \\
\text { Herstellung und Vertrieb von } \\
\text { Produkten für Zellkulturen } \\
\text { mbH, Oberdorla, Deutschland }\end{array}$ & Erythrozytenlyse \\
\hline shutdown solution & $\begin{array}{l}\text { BD Biosciences, Franklin } \\
\text { Lakes, NJ, USA }\end{array}$ & Durchflußzytometrie \\
\hline FACSFlow & $\begin{array}{l}\text { BD Biosciences, Franklin } \\
\text { Lakes, NJ, USA }\end{array}$ & Durchflußzytometrie \\
\hline FACSclean & $\begin{array}{l}\text { BD Biosciences, Franklin } \\
\text { Lakes, NJ, USA }\end{array}$ & Durchflußzytometrie \\
\hline 6 x DNA Loading Dye & $\begin{array}{l}\text { Fermentas, St. Leon-Rot, } \\
\text { Deutschland }\end{array}$ & Gelelektrophorese \\
\hline $\begin{array}{l}\text { DNA-Marker GeneRuler } \\
\text { Ultra Low Range DNA } \\
\text { Ladder } \\
(0.5 \mu \mathrm{g} / \mu \mathrm{l})\end{array}$ & $\begin{array}{l}\text { Fermentas, St. Leon-Rot, } \\
\text { Deutschland }\end{array}$ & Gelelektrophorese \\
\hline $\begin{array}{l}\text { Polystyrol } \\
\text { Rundbodenröhrchen } \\
5 \mathrm{ml}\end{array}$ & $\begin{array}{l}\text { BD Biosciences, Franklin } \\
\text { Lakes, NJ, USA }\end{array}$ & Durchflußzytometrie \\
\hline $\begin{array}{l}\text { Safe-lock Reaktionsgefäß } \\
1,5 \mathrm{ml}\end{array}$ & $\begin{array}{l}\text { Eppendorf AG, Hamburg, } \\
\text { Deutschland }\end{array}$ & Reaktionsgefäße \\
\hline $\begin{array}{l}\text { Standard Reaktionsgefäß } \\
1,5 \mathrm{ml}\end{array}$ & $\begin{array}{l}\text { Eppendorf AG, Hamburg, } \\
\text { Deutschland }\end{array}$ & Reaktionsgefäße \\
\hline $\begin{array}{l}\text { Pipette Reference } \\
0,5-10 \mu \mathrm{l}\end{array}$ & $\begin{array}{l}\text { Eppendorf AG, Hamburg, } \\
\text { Deutschland }\end{array}$ & Reaktionsgefäße \\
\hline $\begin{array}{l}\text { Pipette Reference } \\
100-1000 \mu 1\end{array}$ & $\begin{array}{l}\text { Eppendorf AG, Hamburg, } \\
\text { Deutschland }\end{array}$ & Reaktionsgefäße \\
\hline $\begin{array}{l}\text { Multikanalpipette Hat high } \\
\text { tech lab DV } 1000 \\
(100-1000 \mu \mathrm{l})\end{array}$ & PZ HTL S.A., Warschau, Polen & Pipettieren \\
\hline LightCycler Kapillaren & $\begin{array}{l}\text { Roche Diagnostics Deutschland } \\
\text { GmbH, Mannheim, } \\
\text { Deutschland }\end{array}$ & Kapillare für RT-PCR \\
\hline $\begin{array}{l}\text { serologische } \\
\text { Einmalpipetten } 1 \mathrm{ml}\end{array}$ & $\begin{array}{l}\text { Sarstedt AG \& CO., } \\
\text { Nümbrecht, Deutschland }\end{array}$ & Pipettieren \\
\hline
\end{tabular}




\begin{tabular}{|c|c|c|}
\hline Verbrauchsmaterial & Hersteller & Anwendung \\
\hline $\begin{array}{l}\text { serologische } \\
\text { Einmalpipetten } 5 \mathrm{ml}\end{array}$ & $\begin{array}{l}\text { Sarstedt AG \& CO., } \\
\text { Nümbrecht, Deutschland }\end{array}$ & Pipettieren \\
\hline $\begin{array}{l}\text { serologische } \\
\text { Einmalpipetten } 10 \mathrm{ml}\end{array}$ & $\begin{array}{l}\text { Sarstedt AG \& CO., } \\
\text { Nümbrecht, Deutschland }\end{array}$ & Pipettieren \\
\hline $\begin{array}{l}\text { serologische } \\
\text { Einmalpipetten } 25 \mathrm{ml}\end{array}$ & $\begin{array}{l}\text { Sarstedt AG \& CO., } \\
\text { Nümbrecht, Deutschland }\end{array}$ & Pipettieren \\
\hline $\begin{array}{l}\text { Schraubdeckelröhrchen } \\
2 \mathrm{ml}\end{array}$ & $\begin{array}{l}\text { Sarstedt AG \& CO., } \\
\text { Nümbrecht, Deutschland }\end{array}$ & $\begin{array}{l}\text { Aufbewahrung von } \\
\text { Flüssigkeiten }\end{array}$ \\
\hline Schraubröhre $15 \mathrm{ml}$ & $\begin{array}{l}\text { Sarstedt AG \& CO., } \\
\text { Nümbrecht, Deutschland }\end{array}$ & $\begin{array}{l}\text { Aufbewahrung von } \\
\text { Flüssigkeiten }\end{array}$ \\
\hline Schraubröhre $50 \mathrm{ml}$ & $\begin{array}{l}\text { Sarstedt AG \& CO., } \\
\text { Nümbrecht, Deutschland }\end{array}$ & $\begin{array}{l}\text { Aufbewahrung von } \\
\text { Flüssigkeiten }\end{array}$ \\
\hline $\begin{array}{l}\text { Pipettenfilterspitzen } \\
0,1-10 \mu 1\end{array}$ & $\begin{array}{l}\text { Tipone, StarLAB GmbH, } \\
\text { Ahrensburg, Deutschland }\end{array}$ & Pipettieren \\
\hline $\begin{array}{l}\text { Pipettenfilterspitzen } \\
1-20 \mu 1\end{array}$ & $\begin{array}{l}\text { Tipone, StarLAB GmbH, } \\
\text { Ahrensburg, Deutschland }\end{array}$ & Pipettieren \\
\hline $\begin{array}{l}\text { Pipettenfilterspitzen } \\
1-100 \mu 1\end{array}$ & $\begin{array}{l}\text { Tipone, StarLAB GmbH, } \\
\text { Ahrensburg, Deutschland }\end{array}$ & Pipettieren \\
\hline $\begin{array}{l}\text { Pipettenfilterspitzen } \\
1-200 \mu 1\end{array}$ & $\begin{array}{l}\text { Tipone, StarLAB GmbH, } \\
\text { Ahrensburg, Deutschland }\end{array}$ & Pipettieren \\
\hline $\begin{array}{l}\text { Pipettenfilterspitzen } \\
101-1000 \mu 1\end{array}$ & $\begin{array}{l}\text { Tipone, StarLAB GmbH, } \\
\text { Ahrensburg, Deutschland }\end{array}$ & Pipettieren \\
\hline Glasware & $\begin{array}{l}\text { Brand GmbH \& CO KG, } \\
\text { Wertheim, Deutschland }\end{array}$ & Behälter \\
\hline $\begin{array}{l}\text { Gewebekulturplatte mit } 96 \\
\text { Vertiefungen }\end{array}$ & $\begin{array}{l}\text { Nunc GmbH \& Co, } \\
\text { Langenselbold, Deutschland }\end{array}$ & Zellkultur, TCID 50 \\
\hline $\begin{array}{l}\text { Gewebekulturplatte mit } \\
6 \text { Vertiefungen }\end{array}$ & $\begin{array}{l}\text { Nunc GmbH \& Co, } \\
\text { Langenselbold, Deutschland }\end{array}$ & Zellkultur \\
\hline $\begin{array}{l}\text { Gewebekulturplatte mit } \\
24 \text { Vertiefungen }\end{array}$ & $\begin{array}{l}\text { Nunc GmbH \& Co, } \\
\text { Langenselbold, Deutschland }\end{array}$ & Zellkultur \\
\hline $\begin{array}{l}\text { CELLSTAR Zellkultur } \\
\text { Flaschen } 50 \mathrm{ml}, 25 \mathrm{~cm}^{2}\end{array}$ & $\begin{array}{l}\text { Greiner Bio-One GmbH, } \\
\text { Solingen-Wald, Deutschland }\end{array}$ & Zellkultur \\
\hline $\begin{array}{l}\text { CELLSTAR Zellkultur } \\
\text { Flaschen } 250 \mathrm{ml}, 75 \mathrm{~cm}^{2}\end{array}$ & $\begin{array}{l}\text { Greiner Bio-One GmbH, } \\
\text { Solingen-Wald, Deutschland }\end{array}$ & Zellkultur \\
\hline
\end{tabular}




\begin{tabular}{|c|c|c|}
\hline Verbrauchsmaterial & Hersteller & Anwendung \\
\hline $\begin{array}{l}\text { CELLSTAR Zellkultur } \\
\text { Flaschen } 550 \mathrm{ml}, 175 \mathrm{~cm}^{2}\end{array}$ & $\begin{array}{l}\text { Greiner Bio-One GmbH, } \\
\text { Solingen-Wald, Deutschland }\end{array}$ & Zellkultur \\
\hline Neubauer-Zählkammer & $\begin{array}{l}\text { Madaus GmbH, Köln, } \\
\text { Deutschland }\end{array}$ & Zellzahlbestimmung \\
\hline LD-Säulen & $\begin{array}{l}\text { Miltenyi Biotec GmbH, } \\
\text { Bergisch Gladbach, } \\
\text { Deutschland }\end{array}$ & $\begin{array}{l}\text { Isolation von } \mathrm{pDCs} \text { und } \\
\mathrm{mDCs}\end{array}$ \\
\hline LS-Säulen & $\begin{array}{l}\text { Miltenyi Biotec GmbH, } \\
\text { Bergisch Gladbach, } \\
\text { Deutschland }\end{array}$ & Isolation von T-Zellen \\
\hline MS-Säulen & $\begin{array}{l}\text { Miltenyi Biotec GmbH, } \\
\text { Bergisch Gladbach, } \\
\text { Deutschland }\end{array}$ & $\begin{array}{l}\text { Isolation von pDCs und } \\
\text { T-Zellen }\end{array}$ \\
\hline \multicolumn{3}{|l|}{ Arbeitssicherheit } \\
\hline $\begin{array}{l}\text { Antifect FD10 } \\
\text { Flächendesinfektions-mittel }\end{array}$ & $\begin{array}{l}\text { Schülke \& Mayr GmbH, } \\
\text { Norderstedt, Deutschland }\end{array}$ & $\begin{array}{l}\text { Flächendesinfektion } \\
\text { Verwendung 3\%ig im S3- } \\
\text { Bereich und 2\%ig im S2- } \\
\text { Bereich }\end{array}$ \\
\hline $\begin{array}{l}\text { gynäkologische } \\
\text { Handschuhe }\end{array}$ & $\begin{array}{l}\text { Lohmann \& Rauscher GmbH \& } \\
\text { Co. KG, Neuwied, Deutschland }\end{array}$ & Handschutz \\
\hline $\begin{array}{l}\text { Handschuhe, } \\
\text { Latexhandschuhe SATIN } \\
\text { PLUS }\end{array}$ & $\begin{array}{l}\text { Kimberly-Clark Europe Ltd., } \\
\text { Surrey, UK }\end{array}$ & Handschutz \\
\hline $\begin{array}{l}\text { Jupiter HAT-101 } \\
(045-00-59 \mathrm{P})\end{array}$ & $\begin{array}{l}\text { 3M Deutschland GmbH, Neuss, } \\
\text { Deutschland }\end{array}$ & Schutz der Atemwege \\
\hline $\begin{array}{l}\text { Korsolex basic } \\
\text { Instrumentendesinfektions- } \\
\text { mittel }\end{array}$ & $\begin{array}{l}\text { Bode Chemie GmbH \& Co, } \\
\text { Hamburg, Deutschland }\end{array}$ & $\begin{array}{l}\text { Desinfektionsmittel für } \\
\text { Instrumente, Tauchbäder } \\
\text { 3\%ig im S3 eingesetzt }\end{array}$ \\
\hline $\begin{array}{l}\text { Schutzbrille Bacou-Dalloz } \\
\text { Pulsafe }\end{array}$ & Roissy CDG, Frankreich & Augenschutz \\
\hline
\end{tabular}




\subsubsection{Gerätschaften}

Die in dieser Arbeit verwendeten Gerätschaften sowie der jeweilige Hersteller und der Verwendungszweck im Rahmen der Arbeit sind in der Tabelle 2.3 aufgeführt.

Tabelle 2.3: Verwendete Gerätschaften.

\begin{tabular}{|c|c|c|c|}
\hline Gerät & Name des Geräts & Hersteller & Anwendung \\
\hline Brutschrank & HERAsafe KS18 & $\begin{array}{l}\text { Thermo Scientific, } \\
\text { Langenselbold, } \\
\text { Deutschland }\end{array}$ & $\begin{array}{l}\text { Inkubation bei } \\
\text { Zellkultur }\end{array}$ \\
\hline Desinfektionsbad & $\begin{array}{l}\text { Instrumenten- } \\
\text { Desinfektionswan- } \\
\text { ne } 101\end{array}$ & $\begin{array}{l}\text { Bode Chemie GmbH } \\
\text { \& Co., Hamburg, } \\
\text { Deutschland }\end{array}$ & Virus-Inaktivierung \\
\hline Drucker & Epson Fx-850 & $\begin{array}{l}\text { EPSON Deutschland } \\
\text { GmbH, Meerbusch, } \\
\text { Deutschland }\end{array}$ & Drucken \\
\hline Drucker & $\begin{array}{l}\text { HP Buisness incjet } \\
2300\end{array}$ & $\begin{array}{l}\text { Hewlett-Packard } \\
\text { GmbH, Böblingen, } \\
\text { Deutschland }\end{array}$ & Drucken \\
\hline $\begin{array}{l}\text { Durchfluß- } \\
\text { zytometer }\end{array}$ & BD FACSCanto II & $\begin{array}{l}\text { BD Biosciences, } \\
\text { Franklin Lakes, NJ, } \\
\text { USA }\end{array}$ & $\begin{array}{l}\text { Durchfluß- } \\
\text { zytometrie }\end{array}$ \\
\hline ELISA-Reader & $\begin{array}{l}\text { Thermomax } \\
\text { microplate reader }\end{array}$ & $\begin{array}{l}\text { Molecular Devices } \\
\text { inc., USA }\end{array}$ & $\begin{array}{l}\text { Auslesen des } \\
\text { ELISA-Tests }\end{array}$ \\
\hline Feinwaage & $\begin{array}{l}\text { Satorius MC1 } \\
\text { Research RC2105 }\end{array}$ & $\begin{array}{l}\text { Satorius AG, } \\
\text { Göttingen, } \\
\text { Deutschland }\end{array}$ & Abwiegen \\
\hline $\begin{array}{l}\text { Gefrierschränke: } \\
-20{ }^{\circ} \mathrm{C}\end{array}$ & Liebherr Premium & $\begin{array}{l}\text { Liebherr-International } \\
\text { Deutschland GmbH, } \\
\text { Biberach an der Riss, } \\
\text { Deutschland }\end{array}$ & $\begin{array}{l}\text { Einfrieren und } \\
\text { Lagerung der } \\
\text { Medien, Antikörper, } \\
\text { etc. }\end{array}$ \\
\hline $\begin{array}{l}\text { Gefrierschränke: } \\
-80^{\circ} \mathrm{C}\end{array}$ & $\begin{array}{l}-85 \text { Ultra low } \\
\text { freezer } 457052\end{array}$ & $\begin{array}{l}\text { New Brunswick } \\
\text { Scientific, Edison, NJ, } \\
\text { USA }\end{array}$ & $\begin{array}{l}\text { Einfrieren und } \\
\text { Lagerung der Viren } \\
\text { und Überstände }\end{array}$ \\
\hline $\begin{array}{l}\text { Gefriertruhe: } \\
-140^{\circ} \mathrm{C}\end{array}$ & $\begin{array}{l}\text { HFC 10140TOP- } \\
\text { M21 }\end{array}$ & $\begin{array}{l}\text { Thermo scientific, } \\
\text { Langenselbold, } \\
\text { Deutschland }\end{array}$ & Lagerung von Zellen \\
\hline
\end{tabular}




\begin{tabular}{|c|c|c|c|}
\hline Gerät & Name des Geräts & Hersteller & Anwendung \\
\hline $\begin{array}{l}\text { Geldokumenta- } \\
\text { tionseinheit }\end{array}$ & ChemiDoc XRS & $\begin{array}{l}\text { Bio-Rad Laboratories } \\
\text { GmbH, München, } \\
\text { Deutschland }\end{array}$ & $\begin{array}{l}\text { Dokumentation von } \\
\text { Agarosegelen }\end{array}$ \\
\hline $\begin{array}{l}\text { Gelelektropho- } \\
\text { reseeinheit }\end{array}$ & $\begin{array}{l}\text { Gibco BRL } \\
\text { Horizontal Gel } \\
\text { Electrophoresis } \\
\text { Apparatus }\end{array}$ & $\begin{array}{l}\text { Life Technologies } \\
\text { Corporation, Carlsbad, } \\
\text { California, USA }\end{array}$ & Gelelektrophorese \\
\hline $\begin{array}{l}\text { Gerät für die } \\
\text { Konzentartions- } \\
\text { bestimmung von } \\
\text { Nukleinsäuren }\end{array}$ & $\begin{array}{l}\text { FLUOstar } \\
\text { OPTIMA }\end{array}$ & $\begin{array}{l}\text { BMG LABTECH } \\
\text { GmbH, Offenburg, } \\
\text { Deutschland }\end{array}$ & $\begin{array}{l}\text { RNA } \\
\text { Konzentrationsbe- } \\
\text { stimmung }\end{array}$ \\
\hline $\begin{array}{l}\text { Kühlschränke: } \\
+4{ }^{\circ} \mathrm{C}\end{array}$ & Liebherr Comfort & $\begin{array}{l}\text { Liebherr-International } \\
\text { Deutschland GmbH, } \\
\text { Biberach an der Riss, } \\
\text { Deutschland }\end{array}$ & $\begin{array}{l}\text { Lagerung der } \\
\text { Medien, Antikörper, } \\
\text { etc. }\end{array}$ \\
\hline Lichtmikroskop & $\begin{array}{l}\text { Eclipse TS100 } \\
\text { inverted } \\
\text { Microscope }\end{array}$ & $\begin{array}{l}\text { Nikon Corporation, } \\
\text { Tokio, Japan }\end{array}$ & Mikroskopie \\
\hline $\begin{array}{l}\text { Light Cycler } \\
\text { Kapillarenzentri- } \\
\text { fuge }\end{array}$ & $\begin{array}{l}\text { LC Carousel } \\
\text { Centrifuge } 2.0\end{array}$ & $\begin{array}{l}\text { Roche Diagnostics } \\
\text { Deutschland GmbH, } \\
\text { Mannheim, } \\
\text { Deutschland }\end{array}$ & RT-PCR \\
\hline Magnet & $\begin{array}{l}\text { MiniMACS } \\
\text { Magnet für MS- } \\
\text { Säulen }\end{array}$ & $\begin{array}{l}\text { Miltenyi Biotec } \\
\text { GmbH, Bergisch } \\
\text { Gladbach, } \\
\text { Deutschland }\end{array}$ & $\begin{array}{l}\text { Isolation von } \\
\text { Zellpopulationen }\end{array}$ \\
\hline Magnet & $\begin{array}{l}\text { MidiMACS } \\
\text { Magnet für } \\
\text { LD-/LS-Säulen }\end{array}$ & $\begin{array}{l}\text { Miltenyi Biotec } \\
\text { GmbH, Bergisch } \\
\text { Gladbach, } \\
\text { Deutschland }\end{array}$ & $\begin{array}{l}\text { Isolation von } \\
\text { Zellpopulationen }\end{array}$ \\
\hline Magnetrührer & IKAMAG REO & $\begin{array}{l}\text { Janke \& Kunkel } \\
\text { GmbH \& Co KG; IKA } \\
\text { Labortechnik, Staufen, } \\
\text { Deutschland }\end{array}$ & $\begin{array}{l}\text { Anrühren von } \\
\text { Lösungen und } \\
\text { Puffer }\end{array}$ \\
\hline
\end{tabular}




\begin{tabular}{|c|c|c|c|}
\hline Gerät & Name des Geräts & Hersteller & Anwendung \\
\hline Magnetständer & $\begin{array}{l}\text { MACS Multi } \\
\text { Stand }\end{array}$ & $\begin{array}{l}\text { Miltenyi Biotec } \\
\text { GmbH, Bergisch } \\
\text { Gladbach, } \\
\text { Deutschland }\end{array}$ & $\begin{array}{l}\text { Magnethalter für } \\
\text { Zellisolationen }\end{array}$ \\
\hline $\begin{array}{l}\text { Mikroskop- } \\
\text { Display }\end{array}$ & $\begin{array}{l}\text { Digital Sight DS- } \\
\text { L1 }\end{array}$ & $\begin{array}{l}\text { Nikon Corporation, } \\
\text { Tokio, Japan }\end{array}$ & Dokumentation \\
\hline Mikrowelle & $\begin{array}{l}\text { NE1027 } \\
\text { Microwave }\end{array}$ & $\begin{array}{l}\text { Panasonic } \\
\text { Deutschland GmbH, } \\
\text { Hamburg, } \\
\text { Deutschland }\end{array}$ & $\begin{array}{l}\text { Zubereitung von } \\
\text { Agarosegelen }\end{array}$ \\
\hline $\begin{array}{l}\text { Netzgerät für die } \\
\text { Gelelektropho- } \\
\text { reseeinheit }\end{array}$ & $\begin{array}{l}\text { Electrophoresis } \\
\text { supply EPS301 }\end{array}$ & $\begin{array}{l}\text { Amersham, GE } \\
\text { Healthcare Bio } \\
\text { Sciences AB, Uppsala, } \\
\text { Schweden }\end{array}$ & $\begin{array}{l}\text { Gelelektrophorese- } \\
\text { zubehör }\end{array}$ \\
\hline Pipettierhilfe & Pipetus & $\begin{array}{l}\text { Hirschmann } \\
\text { Laborgeräte GmbH \& } \\
\text { Co. KG, Eberstadt, } \\
\text { Deutschland }\end{array}$ & $\begin{array}{l}\text { Pipettierhilfe für } \\
\text { serologische } \\
\text { Pipetten }\end{array}$ \\
\hline RT-PCR Cycler & LightCycler 2.0 & $\begin{array}{l}\text { Roche Diagnostics } \\
\text { Deutschland GmbH, } \\
\text { Mannheim, } \\
\text { Deutschland }\end{array}$ & RT-PCR \\
\hline Sterilbank & $\begin{array}{l}\text { Kendro Hera Safe } \\
\text { Typ: KS18 }\end{array}$ & $\begin{array}{l}\text { Kendro, Thermo } \\
\text { scientific, } \\
\text { Langenselbold, } \\
\text { Deutschland }\end{array}$ & steriles Arbeiten \\
\hline Sterilbank & $\begin{array}{l}\text { BioGARD Hood } \\
\text { ClassII Type A }\end{array}$ & $\begin{array}{l}\text { The Baker Company } \\
\text { inc., Sanford, Maine, } \\
\text { USA }\end{array}$ & steriles Arbeiten \\
\hline Thermoblock & $\begin{array}{l}\text { Whatman TB2 } \\
\text { Thermoblock }\end{array}$ & $\begin{array}{l}\text { Biometra GmbH, } \\
\text { Göttingen, } \\
\text { Deutschland }\end{array}$ & Auftauen der Viren \\
\hline Thermomixer & $\begin{array}{l}\text { Thermomixer } \\
\text { compact }\end{array}$ & $\begin{array}{l}\text { Eppendorf AG, } \\
\text { Hamburg, } \\
\text { Deutschland }\end{array}$ & $\begin{array}{l}\text { Beheizen und } \\
\text { Schütteln von } \\
\text { Reaktionsgefäßen }\end{array}$ \\
\hline
\end{tabular}




\begin{tabular}{|c|c|c|c|}
\hline Gerät & Name des Geräts & Hersteller & Anwendung \\
\hline Tischzentrifuge & Centrifuge 5418 & $\begin{array}{l}\text { Eppendorf AG, } \\
\text { Hamburg, } \\
\text { Deutschland }\end{array}$ & Zentrifugation \\
\hline UV-Lampe & $\begin{array}{l}\text { Micro UVIS } \\
\text { Typ131200 }\end{array}$ & $\begin{array}{l}\text { Desaga GmbH, } \\
\text { Heidelberg, } \\
\text { Deutschland }\end{array}$ & $\begin{array}{l}\text { UV-Inaktivierung } \\
\text { der Viren }\end{array}$ \\
\hline Vortexer & Grant-bio PV1 & $\begin{array}{l}\text { Grant Instruments } \\
\text { (Cambridge) Ltd., } \\
\text { Cambridgeshire, UK }\end{array}$ & $\begin{array}{l}\text { Mixen von } \\
\text { Lösungen }\end{array}$ \\
\hline Wasserbad & type 3048 & $\begin{array}{l}\text { Kottermann } \\
\text { Labortechnik GmbH } \\
\text { \& Co. KG, Uetze- } \\
\text { Häringsen, } \\
\text { Deutschland }\end{array}$ & $\begin{array}{l}\text { Vorwärmen von } \\
\text { Medien für die } \\
\text { Zellkultur, } \\
\text { Herstellung PBS + } \\
3 \% \text { PFA }\end{array}$ \\
\hline Wasserbad & Julabo SW22 & $\begin{array}{l}\text { Julabo Labortechnik } \\
\text { GmbH, Seelbach, } \\
\text { Deutschland }\end{array}$ & $\begin{array}{l}\text { Vorwärmen von } \\
\text { Medien für die } \\
\text { Zellkultur, } \\
\text { Herstellung PBS + } \\
3 \% \text { PFA }\end{array}$ \\
\hline Zentrifuge & Multifuge 3 L-R & $\begin{array}{l}\text { Thermo Scientific, } \\
\text { Langenselbold, } \\
\text { Deutschland }\end{array}$ & Zentrifugation \\
\hline Zentrifuge & Megafuge $1.0 \mathrm{R}$ & $\begin{array}{l}\text { Thermo Scientific, } \\
\text { Langenselbold, } \\
\text { Deutschland }\end{array}$ & Zentrifugation \\
\hline
\end{tabular}

\subsubsection{Puffer, Medien und Lösungen}

Die in dieser Arbeit verwendeten Puffer, Medien und Lösungen sowie die jeweilige Zusammensetzung und der Verwendungszweck im Rahmen der Arbeit sind in der Tabelle 2.4 dargestellt. 
Tabelle 2.4: Verwendete Puffer, Medien und Lösungen.

\begin{tabular}{|c|c|}
\hline \multicolumn{2}{|l|}{ Medien } \\
\hline Verwendung für die Kultivierung von & Zusammensetzung des Mediums \\
\hline \multirow[t]{5}{*}{ Vero-B4 Zellen } & Eagles MEM-Medium \\
\hline & $10 \%$ FKS \\
\hline & 2 mM L-Glutamin \\
\hline & $100 \mathrm{mg} / \mathrm{ml}$ Penicillin \\
\hline & $100 \mathrm{mg} / \mathrm{ml}$ Streptomycin \\
\hline \multirow[t]{5}{*}{ PBMCs } & RPMI 1640 \\
\hline & $10 \% \mathrm{FKS}$ \\
\hline & 2 mM L-Glutamin \\
\hline & $100 \mathrm{mg} / \mathrm{ml}$ Penicillin \\
\hline & $100 \mathrm{mg} / \mathrm{ml}$ Streptomycin \\
\hline \multirow[t]{7}{*}{ mDCs } & RPMI 1640 \\
\hline & $10 \%$ FKS endotoxinfrei \\
\hline & 2 mM L-Glutamin \\
\hline & $100 \mathrm{mg} / \mathrm{ml}$ Penicillin \\
\hline & $100 \mathrm{mg} / \mathrm{ml}$ Streptomycin \\
\hline & $500 \mathrm{U} / \mathrm{ml} \mathrm{IL-4}$ \\
\hline & $50 \mathrm{ng} / \mathrm{ml} \mathrm{GM}-\mathrm{CSF}$ \\
\hline \multirow[t]{6}{*}{ pDCs } & RPMI 1640 \\
\hline & $10 \%$ FKS endotoxinfrei \\
\hline & 2 mM L-Glutamin \\
\hline & $100 \mathrm{mg} / \mathrm{ml}$ Penicillin \\
\hline & $100 \mathrm{mg} / \mathrm{ml}$ Streptomycin \\
\hline & $100 \mu \mathrm{g} / \mathrm{ml} \mathrm{IL}-3$ \\
\hline
\end{tabular}




\begin{tabular}{|c|c|}
\hline \multicolumn{2}{|l|}{ Medien } \\
\hline Verwendung für die Kultivierung von & Zusammensetzung des Mediums \\
\hline \multirow[t]{5}{*}{ T-Zellen } & RPMI 1640 \\
\hline & $10 \%$ FKS endotoxinfrei \\
\hline & 2 mM L-Glutamin \\
\hline & $100 \mathrm{mg} / \mathrm{ml}$ Penicillin \\
\hline & $100 \mathrm{mg} / \mathrm{ml}$ Streptomycin \\
\hline \multirow[t]{6}{*}{$\begin{array}{l}\text { Infektionsmedium (Anzucht von Viren } \\
\text { auf Vero-B4 Zellen) }\end{array}$} & DMEM \\
\hline & $2 \% \mathrm{FKS}$ \\
\hline & 2 mM L-Glutamin \\
\hline & 2 mM HEPES \\
\hline & $100 \mathrm{mg} / \mathrm{ml}$ Penicillin \\
\hline & $100 \mathrm{mg} / \mathrm{ml}$ Streptomycin \\
\hline \multirow[t]{3}{*}{ Einfriermedium } & 60 \% RPMI 1640 \\
\hline & $30 \% \mathrm{FKS}$ \\
\hline & $10 \%$ DMSO \\
\hline Puffer & Zusammensetzung des Puffers \\
\hline \multirow[t]{3}{*}{$\begin{array}{l}\text { Aufreinigungspuffer für dendritische } \\
\text { Zellen }\end{array}$} & Phosphatgepufferte Salzlösung (PBS) \\
\hline & $0,5 \%$ Bovines Serumalbumin (BSA) \\
\hline & $200 \mathrm{mM}$ Ethylendiamintetraacetat (EDTA) \\
\hline \multirow{4}{*}{$\begin{array}{l}50 \text { x TAE-Puffer }(\mathrm{pH} 8,3) \\
\text { für die Gelelektrophorese }\end{array}$} & \\
\hline & $800 \mathrm{mM}$ Tris \\
\hline & 950 mM Essigsäure (100 \%) \\
\hline & 50 mM EDTA $(\mathrm{pH} 8,0)$ \\
\hline
\end{tabular}




\begin{tabular}{||l|l||}
\hline \hline Lösungen & Zusammensetzung der Lösung \\
\hline \multicolumn{2}{|l||}{} \\
\hline Trypanblaulösung & $0,25 \mathrm{~g}[\mathrm{w} / \mathrm{v}]$ in $100 \mathrm{ml} \mathrm{PBS}$ \\
\hline \multicolumn{2}{|l||}{} \\
\hline Fixierungslösung & PBS \\
\cline { 2 - 3 } & $3 \%$ Paraformaldehyd (PFA) \\
\hline
\end{tabular}

\subsubsection{Antikörper und Fluoreszensfarbstoffe}

Die in dieser Arbeit verwendeten Antikörper und die jeweiligen Fluoreszenzfarbstoffe sowie der jeweilige Hersteller und der Verwendungszweck im Rahmen der Arbeit sind in der Tabelle 2.5 dargestellt.

Tabelle 2.5: Verwendete Antikörper und Fluoreszenzfarbstoffe.

\begin{tabular}{|c|c|c|c|}
\hline Antigen & $\begin{array}{l}\text { Fluoreszenz- } \\
\text { farbstoff }\end{array}$ & Isotyp & Hersteller \\
\hline $\mathrm{CD} 1 \mathrm{c}$ & FITC & $\begin{array}{l}\text { Maus Anti- } \\
\text { Mensch IgG2a }\end{array}$ & $\begin{array}{l}\text { BD Biosciences, Franklin } \\
\text { Lakes, NJ, USA }\end{array}$ \\
\hline $\mathrm{CD} 2$ & PE & $\begin{array}{l}\text { Maus Anti- } \\
\text { Mensch IgG2a }\end{array}$ & $\begin{array}{l}\text { BD Biosciences, Franklin } \\
\text { Lakes, NJ, USA }\end{array}$ \\
\hline CD3 & APC & 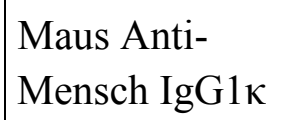 & $\begin{array}{l}\text { BD Biosciences, Franklin } \\
\text { Lakes, NJ, USA }\end{array}$ \\
\hline CD3 & PerCP & 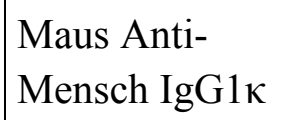 & $\begin{array}{l}\text { BD Biosciences, Franklin } \\
\text { Lakes, NJ, USA }\end{array}$ \\
\hline CD3 & Pacific Blue & 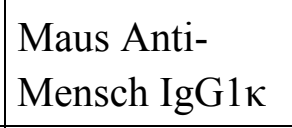 & $\begin{array}{l}\text { BioLegend, San Diego, CA, } \\
\text { USA }\end{array}$ \\
\hline CD4 & $\mathrm{APC} / \mathrm{Cy} 7$ & $\begin{array}{l}\text { Maus Anti- } \\
\text { Mensch IgG1к }\end{array}$ & $\begin{array}{l}\text { BD Biosciences, Franklin } \\
\text { Lakes, NJ, USA }\end{array}$ \\
\hline CD8 & $\mathrm{PE} / \mathrm{Cy} 7$ & 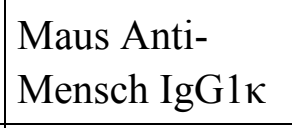 & $\begin{array}{l}\text { BD Biosciences, Franklin } \\
\text { Lakes, NJ, USA }\end{array}$ \\
\hline CD11c & $\mathrm{PE} / \mathrm{Cy} 7$ & $\begin{array}{l}\text { Maus Anti- } \\
\text { Mensch IgG1к }\end{array}$ & $\begin{array}{l}\text { BioLegend, San Diego, CA, } \\
\text { USA }\end{array}$ \\
\hline
\end{tabular}




\begin{tabular}{|c|c|c|c|}
\hline Antigen & $\begin{array}{l}\text { Fluoreszenz- } \\
\text { farbstoff }\end{array}$ & Isotyp & Hersteller \\
\hline CD14 & FITC & $\begin{array}{l}\text { Maus Anti- } \\
\text { Mensch IgG2a }\end{array}$ & $\begin{array}{l}\text { BD Biosciences, Franklin } \\
\text { Lakes, NJ, USA }\end{array}$ \\
\hline CD14 & PerCP & $\begin{array}{l}\text { Maus Anti- } \\
\text { Mensch IgG2a }\end{array}$ & $\begin{array}{l}\text { BD Biosciences, Franklin } \\
\text { Lakes, NJ, USA }\end{array}$ \\
\hline CD19 & $\mathrm{PE}$ & 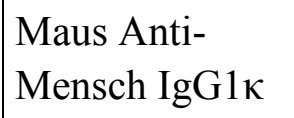 & $\begin{array}{l}\text { BD Biosciences, Franklin } \\
\text { Lakes, NJ, USA }\end{array}$ \\
\hline CD25 & PE & 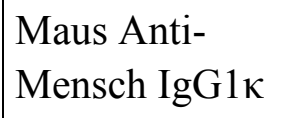 & $\begin{array}{l}\text { BD Biosciences, Franklin } \\
\text { Lakes, NJ, USA }\end{array}$ \\
\hline CD40 & PE & 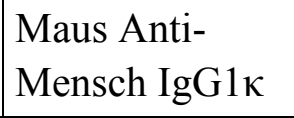 & $\begin{array}{l}\text { BD Biosciences, Franklin } \\
\text { Lakes, NJ, USA }\end{array}$ \\
\hline CD54 & PE & 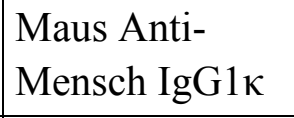 & $\begin{array}{l}\text { BD Biosciences, Franklin } \\
\text { Lakes, NJ, USA }\end{array}$ \\
\hline CD58 & FITC & $\begin{array}{l}\text { Maus Anti- } \\
\text { Mensch IgG2aא }\end{array}$ & $\begin{array}{l}\text { BD Biosciences, Franklin } \\
\text { Lakes, NJ, USA }\end{array}$ \\
\hline CD69 & FITC & $\begin{array}{l}\text { Maus Anti- } \\
\text { Mensch IgG2aא }\end{array}$ & $\begin{array}{l}\text { BD Biosciences, Franklin } \\
\text { Lakes, NJ, USA }\end{array}$ \\
\hline CD80 & FITC & 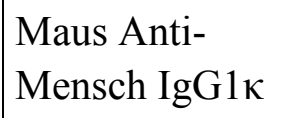 & $\begin{array}{l}\text { BD Biosciences, Franklin } \\
\text { Lakes, NJ, USA }\end{array}$ \\
\hline CD83 & PE & $\begin{array}{l}\text { Maus Anti- } \\
\text { Mensch IgG1к }\end{array}$ & $\begin{array}{l}\text { BD Biosciences, Franklin } \\
\text { Lakes, NJ, USA }\end{array}$ \\
\hline CD86 & APC & 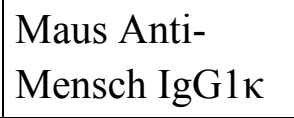 & $\begin{array}{l}\text { BD Biosciences, Franklin } \\
\text { Lakes, NJ, USA }\end{array}$ \\
\hline CD95 & FITC & 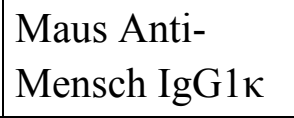 & $\begin{array}{l}\text { BD Biosciences, Franklin } \\
\text { Lakes, NJ, USA }\end{array}$ \\
\hline CD123 & PerCP/Cy5.5 & $\begin{array}{l}\text { Maus Anti- } \\
\text { Mensch IgG2aא }\end{array}$ & $\begin{array}{l}\text { BD Biosciences, Franklin } \\
\text { Lakes, NJ, USA }\end{array}$ \\
\hline CD303 & APC & 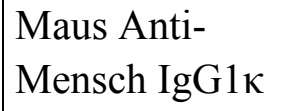 & $\begin{array}{l}\text { BD Biosciences, Franklin } \\
\text { Lakes, NJ, USA }\end{array}$ \\
\hline $\begin{array}{l}\text { MHC-I } \\
(\text { HLA-A,B,C) }\end{array}$ & Pacific Blue & $\begin{array}{l}\text { Maus Anti- } \\
\text { Mensch IgG2aא }\end{array}$ & $\begin{array}{l}\text { BioLegend, San Diego, CA, } \\
\text { USA }\end{array}$ \\
\hline $\begin{array}{l}\text { MHC-II } \\
\text { (HLA-DR) }\end{array}$ & Pacific Blue & $\begin{array}{l}\text { Maus Anti- } \\
\text { Mensch IgG2aא }\end{array}$ & $\begin{array}{l}\text { BioLegend, San Diego, CA, } \\
\text { USA }\end{array}$ \\
\hline
\end{tabular}




\begin{tabular}{|c|c|c|c|}
\hline Antigen & $\begin{array}{l}\text { Fluoreszenz- } \\
\text { farbstoff }\end{array}$ & Isotyp & Hersteller \\
\hline $\begin{array}{l}\text { MHC-II } \\
\text { (HLA-DR) }\end{array}$ & $\mathrm{PE} / \mathrm{Cy} 7$ & 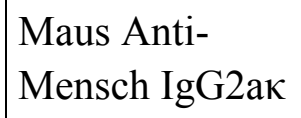 & $\begin{array}{l}\text { BioLegend, San Diego, CA, } \\
\text { USA }\end{array}$ \\
\hline \multicolumn{4}{|l|}{ Isotypenkontrollen } \\
\hline Antigen & $\begin{array}{l}\text { Fluoreszenz- } \\
\text { farbstoff }\end{array}$ & Isotyp & Hersteller \\
\hline $\begin{array}{l}\text { Isotypenkontrolle, } \\
\text { Maus, Klon: } \\
\text { MOPC-21 }\end{array}$ & APC/Cy7 & Maus IgG2 $2 \kappa$ & $\begin{array}{l}\text { BioLegend, San Diego, CA, } \\
\text { USA }\end{array}$ \\
\hline $\begin{array}{l}\text { Isotypenkontrolle, } \\
\text { Maus, Klon: } \\
\text { MOPC-21 }\end{array}$ & FITC & 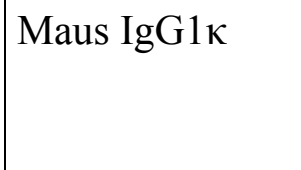 & $\begin{array}{l}\text { BioLegend, San Diego, CA, } \\
\text { USA }\end{array}$ \\
\hline $\begin{array}{l}\text { Isotypenkontrolle, } \\
\text { Maus, Klon: } \\
\text { MOPC-21 }\end{array}$ & $\mathrm{PE} / \mathrm{Cy} 7$ & Maus IgG1к & $\begin{array}{l}\text { BioLegend, San Diego, CA, } \\
\text { USA }\end{array}$ \\
\hline $\begin{array}{l}\text { Isotypenkontrolle, } \\
\text { Maus, Klon: } \\
\text { MOPC-21 }\end{array}$ & APC & 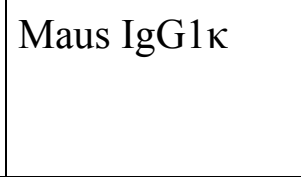 & $\begin{array}{l}\text { BioLegend, San Diego, CA, } \\
\text { USA }\end{array}$ \\
\hline $\begin{array}{l}\text { Isotypenkontrolle, } \\
\text { Maus, Klon: } \\
\text { MOPC-173 }\end{array}$ & Pacific Blue & Maus IgG2aк & $\begin{array}{l}\text { BioLegend, San Diego, CA, } \\
\text { USA }\end{array}$ \\
\hline $\begin{array}{l}\text { Isotypenkontrolle, } \\
\text { Maus, Klon: } \\
\text { MOPC-21 }\end{array}$ & PE & 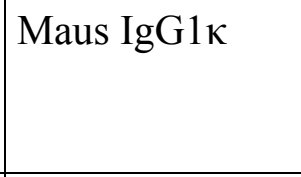 & $\begin{array}{l}\text { BioLegend, San Diego, CA, } \\
\text { USA }\end{array}$ \\
\hline $\begin{array}{l}\text { Isotypenkontrolle, } \\
\text { Maus, Klon: } \\
\text { MOPC-21 }\end{array}$ & PE/Cy5 & 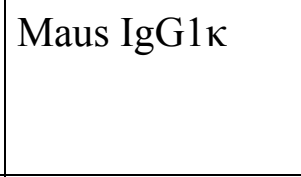 & $\begin{array}{l}\text { BioLegend, San Diego, CA, } \\
\text { USA }\end{array}$ \\
\hline $\begin{array}{l}\text { Isotypenkontrolle, } \\
\text { Maus, Klon: } \\
\text { MOPC-21 }\end{array}$ & PerCP/Cy5.5 & 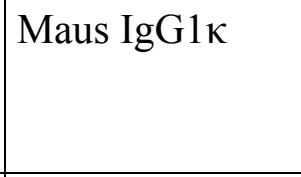 & $\begin{array}{l}\text { BioLegend, San Diego, CA, } \\
\text { USA }\end{array}$ \\
\hline $\begin{array}{l}\text { Isotypenkontrolle, } \\
\text { Maus, Klon: } \\
\text { MOPC-21 }\end{array}$ & PerCP & Maus IgG1к & $\begin{array}{l}\text { BioLegend, San Diego, CA, } \\
\text { USA }\end{array}$ \\
\hline
\end{tabular}




\begin{tabular}{||l|l|l|l||}
\hline Antigen & Isotyp & Hersteller & Anwendung \\
\hline Maus & humanen & PBL, Biomedical & Neutralisierung des \\
monoklonaler & Interferon- $\alpha /-\beta$ & Laboratories, & Interferon- $\alpha /-\beta$ Rezeptors \\
Antikörper gegen & Rezeptor Kette 2, & Piscataway, NJ, & \\
humanen & IgG2a & USA & \\
Interferon- $\alpha /-\beta$ & & & \\
Rezeptor Kette 2 & & & \\
\hline \hline
\end{tabular}

\subsubsection{Oligonukleotidprimer und Sonden}

Die in dieser Arbeit verwendeten Oligonukleotidprimer und Sonden sowie der jeweilige Hersteller und der Verwendungszweck im Rahmen der Arbeit sind in der Tabelle 2.6 aufgeführt.

Tabelle 2.6: Verwendete Oligonukleotidprimer und Sonden.

\begin{tabular}{|c|c|c|c|c|}
\hline $\begin{array}{l}\text { Name/ } \\
\text { Bezeichnung }\end{array}$ & $\begin{array}{l}\text { Publikation/ } \\
\text { Quelle }\end{array}$ & Sequenz $\left(5^{\prime}-3^{\prime}\right)$ & Hersteller & $\begin{array}{l}\text { Verwendungs- } \\
\text { zweck }\end{array}$ \\
\hline $\begin{array}{l}\text { huGAPDH } \\
\text { _for }\end{array}$ & $(132)$ & $\begin{array}{l}\text { GGAAGCTCAC } \\
\text { TGGCATGGC }\end{array}$ & \multirow{3}{*}{$\begin{array}{l}\text { Sigma-Aldrich } \\
\text { Chemie } \\
\text { GmbH, } \\
\text { Steinheim, } \\
\text { Deutschland }\end{array}$} & $\begin{array}{l}\text { Vorwärts- } \\
\text { primer der } \\
\text { GAPDH-RT- } \\
\text { PCR }\end{array}$ \\
\hline $\begin{array}{l}\text { huGAPDH } \\
\text { _rev }\end{array}$ & (132) & $\begin{array}{l}\text { TAGACGGCAG } \\
\text { GTCAGGTCCA }\end{array}$ & & $\begin{array}{l}\text { Rückwärts- } \\
\text { primer der } \\
\text { GAPDH-RT- } \\
\text { PCR }\end{array}$ \\
\hline $\begin{array}{l}\text { huGAPDH } \\
\text { probe }\end{array}$ & $(132)$ & $\begin{array}{l}\text { [6FAM]CCCCA } \\
\text { CTGCCAACGT } \\
\text { GTCAGTG[TAM] }\end{array}$ & & $\begin{array}{l}\text { Sonde der } \\
\text { GAPDH-RT- } \\
\text { PCR }\end{array}$ \\
\hline TBE FP4 & $\begin{array}{l}\text { erhalten von } \\
\text { M. Weidmann }\end{array}$ & $\begin{array}{l}\text { TTTТTССТССТ } \\
\text { CСТАТАCWAA } \\
\text { АТTCC }\end{array}$ & $\begin{array}{l}\text { TIB MolBiol } \\
\text { Syntheselabor } \\
\text { GmbH, Berlin, } \\
\text { Deutschland }\end{array}$ & $\begin{array}{l}\text { Vorwärts- } \\
\text { primer der } \\
\text { FSMEV-RT- } \\
\text { PCR }\end{array}$ \\
\hline
\end{tabular}




\begin{tabular}{|c|c|c|c|c|}
\hline TBE RP4 & $\begin{array}{l}\text { erhalten von } \\
\text { M. Weidmann }\end{array}$ & $\begin{array}{l}\text { gTCACWCATCA } \\
\text { CCTCCTTgTCAg } \\
\text { AC }\end{array}$ & \multirow{2}{*}{$\begin{array}{l}\text { TIB MolBiol } \\
\text { Syntheselabor } \\
\text { GmbH, Berlin, } \\
\text { Deutschland }\end{array}$} & $\begin{array}{l}\text { Rückwärts- } \\
\text { primer der } \\
\text { FSMEV-RT- } \\
\text { PCR }\end{array}$ \\
\hline TBE P4 & $\begin{array}{l}\text { erhalten von } \\
\text { M. Weidmann }\end{array}$ & $\begin{array}{l}\text { [6FAM]TTCTTgT } \\
\text { TCTCCCTgAgCC } \\
\text { ACCATCAC[TMR] }\end{array}$ & & $\begin{array}{l}\text { Sonde der } \\
\text { FSMEV-RT- } \\
\text { PCR }\end{array}$ \\
\hline
\end{tabular}

\subsubsection{Kits}

Die in dieser Arbeit verwendeten Kits sowie der jeweilige Hersteller und der Verwendungszweck im Rahmen der Arbeit sind in der Tabelle 2.7 dargestellt.

Tabelle 2.7: Verwendete Kits.

\begin{tabular}{|c|c|c|}
\hline Kit / Bezeichnung & Hersteller & Anwendung \\
\hline $\begin{array}{l}\text { Ambion Turbo DNA-free } \\
\text { Kit }\end{array}$ & $\begin{array}{l}\text { AB Applied Biosystems, } \\
\text { Carlsbad, CA, USA }\end{array}$ & Entfernung von DNA \\
\hline $\begin{array}{l}\text { CellTiter } 96 \text { Non- } \\
\text { Radioactive Cell } \\
\text { Proliferation Assay }\end{array}$ & $\begin{array}{l}\text { Promega Corporation, } \\
\text { Madison, WI, USA }\end{array}$ & Zellviabilitätsmessung \\
\hline $\begin{array}{l}\text { Cytometric Bead Array } \\
\text { (CBA) Human Inflam- } \\
\text { matory Cytokine Kit }\end{array}$ & $\begin{array}{l}\text { BD Biosciences, Franklin } \\
\text { Lakes, NJ, USA }\end{array}$ & $\begin{array}{l}\text { Konzentrationsbestimmung } \\
\text { von Zytokinen }\end{array}$ \\
\hline $\begin{array}{l}\text { Cytometric Bead Array } \\
\text { (CBA) Human Th1/Th2 } \\
\text { Cytokine Kit }\end{array}$ & $\begin{array}{l}\text { BD Biosciences, Franklin } \\
\text { Lakes, NJ, USA }\end{array}$ & $\begin{array}{l}\text { Konzentrationsbestimmung } \\
\text { von Zytokinen }\end{array}$ \\
\hline $\begin{array}{l}\text { Diamond Plasmacytoid } \\
\text { Dendritic Cell Isolation } \\
\text { Kit }\end{array}$ & $\begin{array}{l}\text { Miltenyi Biotec GmbH, } \\
\text { Bergisch Gladbach, } \\
\text { Deutschland }\end{array}$ & Isolation von $\mathrm{pDCs}$ \\
\hline Interferon- $\alpha$ ELISA & $\begin{array}{l}\text { PBL, Biomedical Laboratories, } \\
\text { Piscataway, NJ, USA }\end{array}$ & $\begin{array}{l}\text { IFN- } \alpha \\
\text { Konzentrationsbestimmung }\end{array}$ \\
\hline $\begin{array}{l}\text { LightCycler } 480 \text { RNA } \\
\text { Master Hydrolysis Probes }\end{array}$ & $\begin{array}{l}\text { Roche Diagnostics } \\
\text { Deutschland GmbH, } \\
\text { Mannheim, Deutschland }\end{array}$ & RT-PCR \\
\hline
\end{tabular}




\begin{tabular}{||l|l|l||}
\hline Kit / Bezeichnung & Hersteller & Anwendung \\
\hline $\begin{array}{l}\text { LightCycler FastStart } \\
\text { DNA Master HybProbe }\end{array}$ & $\begin{array}{l}\text { Roche Diagnostics } \\
\text { Deutschland GmbH, } \\
\text { Mannheim, Deutschland }\end{array}$ & PCR \\
\hline $\begin{array}{l}\text { Myeloid Dendritic Cell } \\
\text { Isolation Kit }\end{array}$ & $\begin{array}{l}\text { Miltenyi Biotec GmbH, } \\
\text { Bergisch Gladbach, } \\
\text { Deutschland }\end{array}$ & Isolation von mDCs \\
\hline $\begin{array}{l}\text { Pan T Cell Isolation } \\
\text { Kit II }\end{array}$ & $\begin{array}{l}\text { Miltenyi Biotec GmbH, } \\
\text { Bergisch Gladbach, } \\
\text { Deutschland }\end{array}$ & Isolation von T-Zellen \\
\hline $\begin{array}{l}\text { Quant-iT RiboGreen RNA } \\
\text { Reagent and Kit }\end{array}$ & $\begin{array}{l}\text { Invitrogen GmbH, Darmstadt, } \\
\text { Deutschland }\end{array}$ & $\begin{array}{l}\text { RNA } \\
\text { Konzentrationsbestimmung }\end{array}$ \\
\hline RNeasy Mini Kit & $\begin{array}{l}\text { QIAGEN GmbH, Hilden, } \\
\text { Deutschland }\end{array}$ & $\begin{array}{l}\text { Isolierung von RNA aus } \\
\text { humanen Zellen und } \\
\text { Zellkulturüberständen }\end{array}$ \\
\hline \hline
\end{tabular}

\subsubsection{Datenanalyse und Software}

Die in dieser Arbeit verwendeten Programme zur Datenanalyse, Datenauswertung, Literaturrecherche und Textbearbeitung sowie der jeweilige Hersteller und der Verwendungszweck im Rahmen der Arbeit sind in der Tabelle 2.8 aufgeführt.

Tabelle 2.8: Verwendete Programme zur Datenanalyse, Literaturrecherche und Textverarbeitung.

\begin{tabular}{||l|l|l||}
\hline \hline Programm & Hersteller & Anwendung \\
\hline EndNote X & $\begin{array}{l}\text { Thomson ISI ResearchSoft, } \\
\text { Stamford, USA }\end{array}$ & $\begin{array}{l}\text { Literaturrecherche und } \\
\text {-verwaltung }\end{array}$ \\
\hline FACSDiva 6.0 & $\begin{array}{l}\text { BD Biosciences, Franklin Lakes, } \\
\text { NJ, USA }\end{array}$ & $\begin{array}{l}\text { Bedien- und } \\
\text { Analysesoftware für } \\
\text { Durchflußzytometer }\end{array}$ \\
\hline FCAPArray v1.0 & $\begin{array}{l}\text { Soft Flow Hungary Ltd., Pécs, } \\
\text { Ungarn }\end{array}$ & $\begin{array}{l}\text { Auswertungssoftware für } \\
\text { CBA }\end{array}$ \\
\hline FlowJo & Tree Star Inc., USA & $\begin{array}{l}\text { Auswertungssoftware für } \\
\text { Durchflußzytometrie }\end{array}$ \\
\hline
\end{tabular}




\begin{tabular}{|l|l|l||}
\hline Programm & Hersteller & Anwendung \\
\hline $\begin{array}{l}\text { Fluostar Reader Control } \\
\text { and Data Analysis } \\
\text { Software }\end{array}$ & $\begin{array}{l}\text { BMG LABTECH GmbH, } \\
\text { Offenburg, Deutschland }\end{array}$ & $\begin{array}{l}\text { Bedien- und } \\
\text { Analysesoftware Fluostar }\end{array}$ \\
\hline $\begin{array}{l}\text { LightCycler Probe } \\
\text { Design Software 2.0 }\end{array}$ & $\begin{array}{l}\text { Roche Diagnostics Deutschland } \\
\text { GmbH, Mannheim, Deutschland }\end{array}$ & $\begin{array}{l}\text { Bedien- und } \\
\text { Analysesoftware RT-PCR } \\
\text { (LC 2.0) }\end{array}$ \\
\hline Microsoft Office XP & Microsoft Inc., USA & $\begin{array}{l}\text { Text- und } \\
\text { Datenverarbeitung }\end{array}$ \\
\hline Quantity One & $\begin{array}{l}\text { Bio-Rad Laboratories GmbH, } \\
\text { München, Deutschland }\end{array}$ & $\begin{array}{l}\text { Bedien- und } \\
\text { Analysesoftware von 1D- } \\
\text { Elektrophorese Gelen }\end{array}$ \\
\hline
\end{tabular}

\subsection{Methoden}

In dem Methodenteil werden für jede Sektion diverse Gerätschaften, Arbeitsmittel, Arbeitsmittel aus vorhergegangenen Schritten sowie Software unter den Punkt Material aufgeführt. Auf eine zusätzliche Aufführung von den im alltäglichen Gebrauch benötigten Kunststoff- oder Verbrauchswaren wird abgesehen, da diese in einem jeden Labor vorhanden sein sollten. Diese Waren sind aber auch in dem vorangegangenen Kapitel (2.1. Material) aufgeführt.

\subsubsection{Zellisolation und Zellkultur}

\subsubsection{Bestimmung der Lebendzellzahl}

Um die Zellzahl der vitalen Zellen nach Isolation oder in der Zellkultur zu ermitteln, wurden die Zellen mit Trypanblau angefärbt. Bei Trypanblau handelt es sich um einen Vitalfarbstoff, der in nekrotisierte Zellen mit beschädigter Membran eindringt und sie somit blau anfärbt. Bei den lebenden Zellen dagegen dringt das Trypanblau nicht in die Zellen ein, sodass diese nicht angefärbt werden und sich so sichtbar von den toten Zellen abheben und zählen lassen. 
Material:

- Neubauer-Zählkammer (Fa. Madaus, Köln, Deutschland)

- Trypanblau-Lösung $(0,25 \%$ in PBS) (beides Fa. cc-pro GmbH, Oberdorla, Deutschland)

Protokoll:

Für die Zellzahlbestimmung wurden $10 \mu 1$ einer Zellsuspension mit $10 \mu 1$ TrypanblauLösung vermischt. Von dieser Lösung wurden $10 \mu \mathrm{l}$ in eine Neubauer-Zählkammer $(0,0025 \mathrm{~mm} \times 0,0025 \mathrm{~mm} \times 0,1 \mathrm{~mm})$ gegeben und mit Hilfe des Lichtmikroskops ausgezählt. Mit Einbeziehung des Kammerfaktors (1 $\mathrm{x} \quad 10^{4}$ Zellen/ml) und des Verdünnungsfaktors (1:2) konnte anschließend die Lebendzellzahl bestimmt werden (Anzahl der gezählten Zellen pro Großquadrat x $2 \times 10^{4}$ Zellen/ml) und die Zellsuspension auf die gewünschte Zellzahl verdünnt und eingesetzt werden.

\subsubsection{Kultivierung von etablierten Zelllinien}

\subsection{Zelllinien}

Bei den Vero-B4 Zellen handelt es sich um eine Zelllinie, die aus Nierenzellen von Grünen Meerkatzen (Chlorocebus aethiops) isoliert wurde (202). Die Vero-B4 Zellen sind diploid, besitzen 60 Chromosomen und weisen eine fibroblastenähnliche Morphologie auf (202). Weiterhin sind sie für eine Vielzahl von Viren anfällig und können daher als Zellen für die Anzucht von Viren sowie Replikationsstudien, Plaqueassays und als Indikatorzellen benutzt werden. Die Vero-B4 Zellen wachsen adhärent und haben eine Verdopplungszeit von etwa $25 \mathrm{~h}$ (48). Die in dieser Arbeit benutzte Vero-B4 Zelllinie stammte aus der Deutschen Sammlung von Mikroorganismen und Zellkulturen GmbH (DSMZ) aus Braunschweig.

\subsection{Subkultivierung / Zellpassage}

Bei den Monolayerkulturen, die in Zellkulturflaschen wachsen, ist es notwendig für das uneingeschränkte Wachstum und zur Vitalitätserhaltung der Zellen einen regelmäßigen Austausch des Zellkulturmediums vorzunehmen. Außerdem muss bei zunehmendem Wachstum der Zellen ein vollständiges Zuwachsen bzw. eine vollständige Konfluenz der Zellen vermieden werden, indem man die Zellen subkultiviert bzw. passagiert. Bei der 
Passage der Zellen werden die adhärenten Zellen zunächst mit Trypsin abgelöst. Dabei spaltet das Trypsin, das als Peptidase agiert, äußere Proteine der Zellen, die am Adhäsionsvorgang beteiligt sind. Allerdings darf die Inkubation mit dem Trypsin nicht zu lange dauern, da es sonst zu Schäden an den Zellen kommen kann. Der Trypsinzellsuspension wird nach der Inkubation Medium zugeführt und die Zellzahl bestimmt. Schließlich wird die Zellsuspension auf das jeweilige Mengenverhältnis eingestellt und wieder in die Kulturflasche oder in verschiedene Typen von Gewebekulturplatten ausgesät.

\section{Material:}

- Zellkulturflaschen, Gewebekulturplatten (Nunc, Langenselbold, Deutschland)

- Vero-B4 Zellkulturmedium (s. 2.1.4 Puffer, Medien und Lösungen)

- Trypsin/EDTA (Biochrom AG, Berlin, Deutschland)

- PBS (cc-pro GmbH, Oberdorla, Deutschland)

\section{Protokoll:}

Das alte Zellkulturmedium wurde für die Zellpassage komplett abgenommen und die adhärenten Vero-B4 Zellen mit PBS gewaschen. Danach wurde die Trypsin-EDTALösung zugesetzt und die Zellen bei $37{ }^{\circ} \mathrm{C}$ und $5 \% \mathrm{CO}_{2}$-Atmosphäre in den Brutschrank für ca. 5 min inkubiert. Die Zellen befanden sich durch die Trypsinbehandlung zumeist in Lösung, aber durch klopfen mit der Hand an der Flasche konnten die letzten noch adhärenten Zellen von der Flasche abgelöst werden. Anschließend wurde eine definierte Menge an Zellkulturmedium zugegeben und die Zellzahl bestimmt. Danach wurde die Zellsuspension entsprechend mit Zellkulturmedium verdünnt. Für die Virustitration mittels TCID $_{50}$ (s. 2.2.2.3 Bestimmung des Virustiters) sowie für den MTT-Assay (s. 2.2.7 Zellviabilitätsmessung mittels des MTT-Assays) wurden $2 \times 10^{4}$ Zellen pro Vertiefung in eine Zellkulturplatte mit 96 Vertiefungen ausgesät. Die Zellkulturflaschen sowie die Gewebekulturplatten mit der Vero-B4 Zellsuspension wurden bei $37^{\circ} \mathrm{C}$ und $5 \% \mathrm{CO}_{2}$-Atmosphäre im Brutschrank inkubiert.

Bei einem Wechsel des Zellkulturmediums wurde das Zellkulturmedium komplett abgenommen und die Zellen mit PBS gewaschen. Anschließend wurde zu der Zellkultur 
wieder entsprechendes Medium zugegeben und die Zellkulturflasche bei $37^{\circ} \mathrm{C}$ und $5 \%$ $\mathrm{CO}_{2}$-Atmosphäre im Brutschrank inkubiert.

\subsubsection{Kryokonservierung und Auftauen von Zellen}

Für die Aufbewahrung und Konservierung der Vero-B4 Zellen über eine längere Zeit wurden die Zellen bei $-140^{\circ} \mathrm{C}$ gelagert. Damit die Zellen in eine derart niedrige Temperatur überführt werden können ohne dabei zu lysieren bedarf es einer speziellen Prozedur. Um die Zellen bei $-70^{\circ} \mathrm{C}$ oder $-140{ }^{\circ} \mathrm{C} \mathrm{zu}$ lagern, wird ein spezielles Einfriermedium benötigt, in das die Zellen überführt werden, bevor sie in Schraubdeckelröhrchen aliquotiert und anschließend in ein isopropanolhaltigen Kryogefäß bei $-70^{\circ} \mathrm{C}$ aufbewahrt werden. Durch die Überführung der Zellen in ein isopropanolhaltiges Kryogefäß bei $-70{ }^{\circ} \mathrm{C}$ sinkt die Temperatur um $1{ }^{\circ} \mathrm{C}$ pro min in den Schraubdeckelröhrchen ab, sodass die Zellen keinen Kälteschock erfahren und lysieren.

\section{$\underline{\text { Material: }}$}

- Cryo $1{ }^{\circ} \mathrm{C}$ freezing container (Nalgene, Hereford, England)

- Einfriermedium (cc-pro GmbH, Oberdorla, Deutschland)

- Vero-B4 Zellkulturmedium (cc-pro GmbH, Oberdorla, Deutschland)

\section{Protokoll:}

\section{Einfrierprozedur}

Für die Kryokonservierung von Vero-B4 Zellen wurde zunächst die Zellzahl der kultivierten Zellen bestimmt und die Zellzahl je nach Bedarf der Aufbewahrung eingestellt. Anschließend wurden die Zellen mit der gewünschten Zellzahl für 10 min bei $300 \mathrm{xg}$ und $4{ }^{\circ} \mathrm{C}$ zentrifugiert, der Überstand verworfen und das Zellpellet mit $10^{7}$ Zellen / $1 \mathrm{ml}$ Einfriermedium resuspendiert und in Schraubdeckelröhrchen aliquotiert. Die Schraubdeckelröhrchen mit den Zellen wurden anschließend für eine Nacht in einem isopropanolhaltigen Kryogefäß bei $-70{ }^{\circ} \mathrm{C}$ gelagert. Nach ca. $24 \mathrm{~h}$ wurden die Schraubdeckelgefäße mit der Zellsuspension für die längere Aufbewahrung in eine $-140{ }^{\circ} \mathrm{C}$ Gefriertruhe überführt. 


\section{Auftauprozedur}

Zum Auftauen der Zellen wurden die Schraubdeckelgefäße mit den gefrorenen Zellen in einem $37^{\circ} \mathrm{C}$ warmen Wasserbad angetaut und in eine $15 \mathrm{ml}$ Schraubröhre mit $10 \mathrm{ml}$ VeroB4- Zellkulturmedium überführt. Anschließend wurde die $15 \mathrm{ml}$ Schraubröhre mit der Zellsuspension bei 300 x g für 5 min zentrifugiert und der Überstand verworfen. Das Zellpellet wurde in frischem Vero-B4 Zellkulturmedium resuspendiert und in eine $25 \mathrm{~cm}^{3}$ Zellkulturflasche ausgesät.

\subsubsection{Isolation von PBMCs aus humanem Buffy-Coat}

Die Isolation von humanen peripheren mononuklearen Blutzellen (PBMCs) aus Leukozytenkonzentraten (Buffy-Coats) erfolgte mittels Dichtegradientenzentrifugation $(145,146)$. Für die Dichtegradientenzentrifugation wurde Ficoll Hypaque als Trennlösung eingesetzt. Bei Ficoll handelt es sich um ein neutrales, zahlreich verzweigtes, hydrophiles Polymer, das eine Dichte von $1,077 \mathrm{~g} / \mathrm{cm}^{3}$ aufweist. Bei der Dichtegradientenzentrifugation wird das Ficoll (bzw. die Trennlösung) mit verdünnten Blut vorsichtig überschichtet. Bei der anschließenden Zentrifugation erfolgt eine Auftrennung der Blut-Zell-Populationen auf Basis ihres Gradienten. Die Erythrozyten $\left(1,09-1,1 \mathrm{~g} / \mathrm{cm}^{3}\right)$ und Granulozyten $\left(1,08-1,09 \mathrm{~g} / \mathrm{cm}^{3}\right)$ haben eine größere Dichte als das Ficoll und setzen sich nach Zentrifugation als Pellet am Boden ab (141). Die Monozyten (Dichte ca. 1,08 g/ $\mathrm{cm}^{3}$ ) und Lymphozyten $\left(1,06-1,08 \mathrm{~g} / \mathrm{cm}^{3}\right)(141)$ haben eine geringere Dichte als das Ficoll und setzen sich als weiße bis milchige Interphase zwischen der klaren Ficoll Phase und der Serumphase ab. In der obersten Phase, der Plasmaphase, verbleiben die Thrombozyten $\left(1.04-1.06 \mathrm{~g} / \mathrm{cm}^{3}\right)$ aufgrund ihrer geringen Dichte.

Material:

- Buffy-Coat (Blutspendedienst des Deutschen Roten Kreuz, Springe, Deutschland) ${ }^{1}$

- Ficoll-Hypaque Plus, (GE Healthcare Bio Sciences AB, Uppsala, Schweden)

- PBS (cc-pro GmbH, Oberdorla, Deutschland)

- Aqua dest. (cc-pro GmbH, Oberdorla, Deutschland)

- PBMC-Medium (s. 2.1.4 Puffer, Medien und Lösungen) 
${ }^{1}$ Die Buffy-Coats wurden vom Blutspendedienst des Deutschen Roten Kreuz der Landesverbände Niedersachsen, Sachsen-Anhalt, Thüringen, Oldenburg und Bremen gGmbH (NSTOB) des DRK in Springe bezogen. Die Buffy-Coats hatten ein Volumen von ca. 60 - $70 \mathrm{ml}$ und enthielten 99,9 \% der Zellen der Vollblutspende (CPD-stabilisiert, $450 \mathrm{ml}$ - $500 \mathrm{ml}$ ). Der Hämatokrit-Wert betrug ca. $45 \%$ (Quelle der Angaben: Dr. Volgmann, Produktionsleiter NSTOB Springe).

\section{Protokoll:}

Das Ausgangsmaterial in Form von Buffy-Coats wurde 1:5 mit PBS verdünnt. Von diesem Gemisch wurden $35 \mathrm{ml}$ langsam und vorsichtig auf $15 \mathrm{ml}$ Ficoll Hypaque Plus, das in eine $50 \mathrm{ml}$ Schraubröhre vorgelegt wurde, geschichtet, sodass zwei Phasen entstanden. Nach der darauf folgenden Zentrifugation $\left(300 \mathrm{xg} ; 20 \mathrm{~min} ; 4{ }^{\circ} \mathrm{C}\right) \mathrm{mit}$ verringerter Bremskraft bei der Verzögerung der Zentrifuge, um ein Vermischen der Phasen $\mathrm{zu}$ vermeiden, wurde die milchige Interphase, bei der es sich um die ankonzentrierten PBMCs handelt, abgenommen und anschließend in zwei weiteren Waschschritten mit jeweils $50 \mathrm{ml}$ PBS aufgereinigt. Die Erythrozyten, die noch in der Zellsuspension vorhanden waren; wurden mittels einer Erythrozytenlyse entfernt. Dabei wurden die Erythrozyten mit $10 \mathrm{ml}$ Zellkulturwasser (Aqua dest.) für $25 \mathrm{~s}$ lysiert und anschließend die Zellsuspension mit PBS auf ein Endvolumen von $50 \mathrm{ml}$ aufgefüllt, um eine Lyse der anderen Zellen zu vermeiden. Nach der erfolgten Isolation der PBMCs wurde die Zellzahl ermittelt und anschließend erfolgte entweder eine Weiterverarbeitung, bei der verschiedene DC-Subtypen isoliert wurden (s. 2.2.1.5 Isolation von einzelnen Zellpopulationen aus PBMCs), die CFSE-Färbung (s. 2.2.4 Proliferationstest mittels CFSE) oder eine direkte Kultivierung in PBMC-Medium (s. 2.1.4 Puffer, Medien und Lösungen), wobei $1 \times 10^{6}$ Zellen in $150 \mu$ PBMC-Medium aufgenommen und in je einer Vertiefung einer Gewebekulturplatte mit 96 Vertiefungen gegeben wurden. Die Inkubation erfolgte bei $37^{\circ} \mathrm{C}$ in einer $5 \%$ igen $\mathrm{CO}_{2}$-Atmosphäre.

\subsubsection{Isolation von einzelnen Zellpopulationen aus PBMCs}

Die beiden DC-Subtypen (mDCs und pDCs) sind sehr rar und machen lediglich einen Anteil von weniger als $1 \%$ der PBMCs aus (69). Der Anteil der T-Lymphozyten an den PBMCs ist mit $75 \%$ deutlich höher. Um die jeweiligen Zellsubtypen mit einer möglichst 
hohen Reinheit aus den PBMCs, die mittels Ficoll-Gradientendichtezentrifugation aus den Buffy-Coats isoliert wurden (s. 2.2.1.4 Isolation von PBMCs aus humanen BuffyCoat), zu separieren bedarf es daher einer geeigneten Technik. In dieser Arbeit wurden die mDCs, pDCs sowie die T-Zellen mittels magnetischer Zellseparation (engl.: magnetic activated cell sorting (MACS)) isoliert (134). Das Prinzip der magnetischen Zellseparation liegt darin, dass spezifische Antikörper an metallischen Partikel (Beads) gekoppelt sind. Bei der Bindung der an die metallischen Beads gekoppelten Antikörper an die jeweiligen Zielzellen können diese markierten Zellen durch ein magnetisches Feld zurückgehalten werden. Durchlaufen diese markierten Zielzellen eine spezielle Säule, die einem magnetischen Feld ausgesetzt ist, so werden diese in der Matrix der Säule zurückgehalten. Durch wiederholtes Waschen der Säule werden Zellen ohne BeadAntikörper von der Säule eluiert, sodass eine höhere Reinheit der Zielzellen erreicht wird. Erst wenn das magnetische Feld aufgehoben wird, können die Beads samt Antikörper und Zellen von der Säule eluiert werden. Bei dieser Prozedur handelt es sich um eine positive Selektion. Umgekehrt kann auch eine unerwünschte Zellpopulation oder Zellpopulationen mit spezifischen an Beads gekoppelten Antikörpern markiert werden und durch das magnetische Feld über die Säule von der nicht-markierten Population getrennt werden. Bei diesem Vorgang spricht man von einer negativen Selektion.

\subsection{Isolation von mDCs aus PBMCs}

Bei der Isolation von mDCs mit Hilfe des Myeloid Dendritic Cell Isolation Kits der Firma Miltenyi Biotec GmbH (Bergisch Gladbach, Deutschland) werden die Zellen auf Basis der negativen Selektion von den restlichen PBMCs separiert. Dabei wird zu den isolierten PBMCs (s. 2.2.1.4 Isolation von PBMCs aus humanen Buffy-Coat) zuerst ein Cocktail von Biotin konjugierten Antikörpern gegeben, die gegen spezifische Marker der restlichen PBMCs, der so genannten nicht-mDCs, gerichtet sind. In einem zweiten Schritt wird ein Anti-Biotin Antikörper, der mit Beads konjugiert ist, zugegeben. Der zweite Antikörper bindet das Biotin der Primärantikörper und macht die markierten Zellen anfällig für das magnetische Feld. Durch die Passage einer speziellen Säule (LD-Säulen), die in einem Magneten (MidiMACS) steht und somit einem starken magnetischen Feld ausgesetzt ist, bleiben die mit den Beads versehenen „nicht-mDCs“ an der Matrix der Säule hängen, während die mDCs die Säule passieren und entsprechend aufgefangen 
werden können. Durch Wiederholung des Schrittes kann die Reinheit der mDCs erhöht werden.

\section{$\underline{\text { Material: }}$}

- PBMCs (s. 2.2.1.4 Isolation von PBMCs aus humanen Buffy-Coat)

- Myeloid Dendritic Cell Isolation Kit (Miltenyi Biotec GmbH, Bergisch Gladbach, Deutschland)

- LD-Säulen (Miltenyi Biotec GmbH, Bergisch Gladbach, Deutschland)

- Magnet: MidiMACS (für LD-Säulen) (Miltenyi Biotec GmbH, Bergisch Gladbach, Deutschland)

- Magnetständer: MACS Multi Stand (Miltenyi Biotec GmbH, Bergisch Gladbach, Deutschland)

- DC-Puffer (s. 2.1.4 Puffer, Medien und Lösungen)

- $\quad$ mDC-Medium (s. 2.1.4 Puffer, Medien und Lösungen)

\section{Protokoll:}

Die Isolation der mDCs wurde gemäß der Beschreibung aus dem Dendritic Cell Isolation Kits der Firma Miltenyi Biotec GmbH (Bergisch Gladbach, Deutschland) ohne weitere Änderung durchgeführt. Die Reinheit der isolierten mDCs wurde mittels der Durchflußzytometrie analysiert (s. 2.2.3 Durchflußzytometrie). Die mDCs wurden mit einer Dichte von $2 \times 10^{5}$ Zellen pro Vertiefung einer Gewebekulturplatte mit 24 Vertiefungen in je $1 \mathrm{ml} \mathrm{mDC}$-Medium ausgesät. Die ausgesäten Zellen wurden bei $37{ }^{\circ} \mathrm{C}$ und einer 5\%igen $\mathrm{CO}_{2}$-Atmosphäre inkubiert.

\subsection{Isolation von pDCs aus PBMCs}

Um die pDCs aus den humanen PBMCs, die mittels FicollGradientendichtezentrifugation aus Buffy-Coat isoliert wurden (s. 2.2.1.4 Isolation von PBMCs aus humanen Buffy-Coat), zu separieren, wurde das Diamond Plasmacytoid Dendritic Cell Isolation Kit der Firma Miltenyi Biotec GmbH (Bergisch Gladbach, Deutschland) verwendet.

Die Aufreinigungsmethode von pDCs aus PBMCs mittels des Diamond Plasmacytoid Dendritic Cell Isolation Kits der Firma Miltenyi Biotec GmbH (Bergisch Gladbach, Deutschland) basiert auf einer gekoppelten negativen- und positiven Selektion, bei der in 
einem ersten Schritt via negativer Selektion die „nicht-pDCs“ von den PBMCs entfernt werden und in einem zweiten Schritt mittels einer positiven Selektion speziell die pDCs aus dem Rest der verbliebenen PBMC-Suspension isoliert werden. Von den PBMCs werden in einem ersten Schritt die nicht-pDCs, wie T-Zellen, B-Zellen, NK-Zellen, mDCs, Monozyten, Granulozyten und Erythrozyten mittels eines Anti-Biotin Antikörpercocktails markiert. Dieser Antikörpercocktail enthält an Beads gekoppelte Antikörper, die gegen eine Reihe von entsprechenden Markern der Zelllinien gerichtet sind. Durch den Lauf über eine im magnetischen Feld befindlichen Säule werden die über die Antikörper mit Beads gekoppelten „nicht-pDCs“ angezogen und verbleiben in der Säule. Die pDCs dagegen sind nicht über die Antikörper an Beads gekoppelt und laufen durch die sich im magnetischen Feld befindende Säule durch. Die Reinheit der pDCs ist nach diesem Selektionsschritt allerdings gering. Nach mehreren Waschschritten der pDCSuspension erfolgt der zweite Separationsschritt. Dabei werden die Zellen mit einem Anti-CD304 Antikörper behandelt, der an Beads gekoppelt ist. CD304 (BDCA-4/Neuropilin-1) ist ein spezifischer Marker der pDCs. Außerdem konnte gezeigt werden, dass der CD304 Antikörper keinen Effekt auf den Aktivierungszustand der pDCs sowie auf die Interferon Produktion hat. Durch die spezifische Bindung der gekoppelten CD304 Antikörper an die pDCs können diese bei einer weiteren Passage des Magnets positiv selektiert werden. Demnach bleiben die mit den Beads und den pDCs versehenen Antikörper an dem Magneten hängen, während die restlichen nicht-pDCs durch mehrere Waschschritte ausgewaschen werden. Durch die anschließende Aufhebung des magnetischen Felds können die pDCs schließlich aus der Säule gewaschen werden. Durch die Kombination von den beiden Selektionsschritten kann eine hohe Reinheit der isolierten pDCs erreicht werden.

\section{Material:}

- PBMCs (s. 2.2.1.4 Isolation von PBMCs aus humanen Buffy-Coat)

- Diamond Plasmacytoid Dendritic Cell Isolation Kit der Firma Miltenyi Biotec GmbH (Bergisch Gladbach, Deutschland)

- LD-Säulen, MS-Säulen (beides Miltenyi Biotec GmbH, Bergisch Gladbach, Deutschland) 
- Magnete: MidiMACS (für LD-Säulen) und MiniMACS (für MS-Säulen) (beide Miltenyi Biotec GmbH, Bergisch Gladbach, Deutschland)

- Magnetständer: MACS Multi Stand (Miltenyi Biotec GmbH, Bergisch Gladbach, Deutschland)

- DC-Puffer (s. 2.1.4 Puffer, Medien und Lösungen)

- $\quad$ pDC-Medium (s. 2.1.4 Puffer, Medien und Lösungen)

\section{Protokoll:}

Die Isolation der pDCs wurde gemäß der Beschreibung aus dem Diamond Plasmacytoid Dendritic Cell Isolation Kit der Firma Miltenyi Biotec GmbH (Bergisch Gladbach, Deutschland) ohne weitere Änderung durchgeführt. Die Reinheit der isolierten pDCs wurde mittels der Durchflußzytometrie analysiert (s. 2.2.3 Durchflußzytometrie). Die pDCs wurden mit einer Dichte von $2 \times 10^{5}$ Zellen pro Vertiefung einer Gewebekulturplatte mit 24 Vertiefungen in je $1 \mathrm{ml}$ pDC-Medium ausgesät. Die ausgesäten Zellen wurden bei $37^{\circ} \mathrm{C}$ und in einer $5 \%$ igen $\mathrm{CO}_{2}$-Atmosphäre inkubiert.

\subsection{Isolation von T-Zellen aus PBMCs}

Die Isolation der T-Zellen erfolgte mit dem Pan T Cell Isolation Kit II der Firma Miltenyi Biotec GmbH (Bergisch Gladbach, Deutschland). Das Prinzip der T-Zell-Separation mit dem Pan T Cell Isolation Kit II basiert dabei auf einer negative Selektion, bei der die „nicht-T-Zellen“ aus den isolierten PBMCs (s. 2.2.1.4 Isolation von PBMCs aus humanen Buffy-Coat) depletiert werden. Dabei werden die „nicht-T-Zellen“ zunächst mit Hilfe eines Biotin-konjugierten Antikörpercocktail, der gegen spezifische Marker der „nichtT-Zellen“ gerichtet ist, markiert. Dann erfolgt die Bindung eines weiteren Antikörpers, der mit metallischen Beads konjugiert ist und gegen das Biotin des ersten Antikörpers gerichtet ist. Durch die Passage einer Säule (LS-Säulen), die in einem Magneten (MidiMACS) steht und somit einem starken magnetischen Feld ausgesetzt ist, bleiben die mit den Beads versehenen „nicht-T-Zellen“ in der Säule, während lediglich die unmarkierten T-Zellen die Säule passieren und isoliert werden können.

\section{Material:}

- PBMCs (s. 2.2.1.4 Isolation von PBMCs aus humanen Buffy-Coat) 
- Pan T Cell Isolation Kit II (Miltenyi Biotec GmbH, Bergisch Gladbach, Deutschland)

- LS-Säulen (Miltenyi Biotec GmbH, Bergisch Gladbach, Deutschland)

- Magnet: MidiMACS (für LS-Säulen) (Miltenyi Biotec GmbH, Bergisch Gladbach, Deutschland)

- Magnetständer: MACS Multi Stand (Miltenyi Biotec GmbH, Bergisch Gladbach, Deutschland)

- DC-Puffer (s. 2.1.4 Puffer, Medien und Lösungen)

- $\quad$ T-Zell-Medium (s. 2.1.4 Puffer, Medien und Lösungen)

Protokoll:

Die Isolation der T-Zellen wurde gemäß der Beschreibung aus dem Pan T Cell Isolation Kit II der Firma Miltenyi Biotec GmbH (Bergisch Gladbach, Deutschland) ohne weitere Änderung durchgeführt. Die Reinheit der isolierten T-Zellen wurde mittels der Durchflußzytometrie analysiert (s. 2.2.3 Durchflußzytometrie). Die T-Zellen wurden mit einer Dichte von $2 \times 10^{5}$ Zellen pro Vertiefung einer Gewebekulturplatte mit 24 Vertiefungen in je $1 \mathrm{ml}$ T-Zell-Medium ausgesät. Die ausgesäten Zellen wurden bei $37^{\circ} \mathrm{C}$ und in einer $5 \%$ igen $\mathrm{CO}_{2}$-Atmosphäre inkubiert.

\subsection{Kokultur von pDCs und T-Zellen}

Um zu anlaysieren, in wie weit die pDCs die T-Zellen aktivieren und die T-Zellen auf eine eventuelle Aktivierung in Hinblick auf die Differenzierung, Expression von diversen Rezeptoren sowie Zytokinproduktion reagieren, wurden pDCs und T-Zellen separat isoliert, kokultiviert und schließlich mit FSME-Virus infiziert. Für die Kokultivierung von pDCs und T-Zellen wurden beide Zellpopulationen aus jeweils dem selben BuffyCoat isoliert, sodass es sich dabei um eine autologe Kokultivierung der beiden Zellpopulationen handelte.

Material:

- T-Zellen (s. 2.2.1.5.3 Isolation von T-Zellen aus PBMCs)

- pDCs (s. 2.2.1.5.2 Isolation von pDCs aus PBMCs)

- DC-Medium (s. 2.1.4 Puffer, Medien und Lösungen) 
Protokoll:

Dazu wurden zunächst die PBMCs aus den humanen Buffy-Coat isoliert (s. 2.2.1.5 Isolation von PBMCs aus humanen Buffy-Coat). Die pDCs wurden mit Hilfe des Diamond Plasmacytoid Dendritic Cell Isolation Kit und die T-Zellen mittels des Pan T Cell Isolation Kit II (beide von Miltenyi Biotec GmbH, Bergisch Gladbach, Deutschland) von den PBMCs separiert (s. 2.2.1.5.3 Isolation von T-Zellen aus PBMCs und 2.2.1.5.2 Isolation von pDCs aus PBMCs). Für die Kokultivierung wurden die beiden Zellpopulationen vereint. Das Mischungsverhältnis der pDCs zu den T-Zellen betrug dabei 1 : 10). Dabei wurden pro Vertiefung einer Gewebekulturplatte mit 24 Vertiefungen $1 \times 10^{5}$ pDCs mit $9 \times 10^{5}$ T-Zellen in DC-Medium ohne weitere Zusätze ausgesät und bei $37^{\circ} \mathrm{C}$ und in einer $5 \%$ igen $\mathrm{CO}_{2}$-Atmosphäre inkubiert.

\subsubsection{Arbeiten mit Viren}

\subsubsection{Arbeiten unter S3-Bedingungen}

In vielen Teilen der Welt ist das FSME-Virus als Virus der Biosicherheitsklasse (BSL)-3 oder BSL-4 deklariert (18). Problematisch bei dem FSME-Virus ist, dass es auch über Aerosole, wie sie bei der Aufkonzentrierung oder Zentrifugation der Virussuspension entstehen, übertragen werden können. Aus diesem Grund fanden die Arbeiten mit aktivem Virus in einem BSL-3-Labor unter entsprechenden Sicherheitsvorkehrungen statt.

\subsubsection{Anzucht und Kultivierung von Viren}

In dieser Arbeit wurde mit dem FSME-Virus Stamm Hypr gearbeitet. Der FSME-Virus Stamm Hypr stammt ursprünglich aus Brünn in der Tschechischen Republik, wo er 1953 aus dem Blut eines FSME-Patienten isoliert wurde (155). Bei dem Stamm handelt es sich um einen hoch virulenten Vertreter des europäischen FSME-Virus Subtyps (62). Für die Anzucht von FSME-Viren wurden konfluente Vero-B4 mit durch das Auftauen der kryokonservierten FSME-Viren erhaltene Virussuspension infiziert. Die infizierten Zellen wurden bei $37^{\circ} \mathrm{C}$ in einer 5\%igen $\mathrm{CO}_{2}$-Atmosphäre inkubiert, bis ein deutlicher zytophatischer Effekt (engl.: cytopathic effect (CPE)) zu erkennen war. In diesem Zustand wurde der Virusüberstand geerntet und bei $-80{ }^{\circ} \mathrm{C}$ konserviert und bis zum Gebrauch gelagert. 
Material:

- $25 \mathrm{~cm}^{3}$ Zellkulturflasche mit konfluenten Vero-B4 Zellen (s. 2.2.1.2.2 Subkultivierung / Zellpassage)

- $\quad$ PBS (cc-pro GmbH, Oberdorla, Deutschland)

- Infektionsmedium (s. 2.1.4 Puffer, Medien und Lösungen)

\section{Protokoll:}

Bei der $25 \mathrm{~cm}^{3}$ Zellkulturflasche mit den konfluenten Vero-B4 Zellen wurde erst das komplette Medium entfernt und die Zellen mit PBS gewaschen. Nach dem Entfernen des PBS wurden $500 \mu 1$ der aufgetauten FSME-Virussuspension auf die konfluenten Vero-B4 Zellen gegeben. Anschließend wurden die Zellen mit der Virussuspension bei $37{ }^{\circ} \mathrm{C}$ und $5 \%$ iger $\mathrm{CO}_{2}$-Atmosphäre für $1 \mathrm{~h}$ inkubiert. Nach der Inkubationszeit wurde die Flasche mit Infektionsmedium aufgefüllt und bei $37^{\circ} \mathrm{C}$ und $5 \%$ iger $\mathrm{CO}_{2}$-Atmosphäre inkubiert, bis ein deutlicher CPE sichtbar war. Zusätzlich wurde bei jeder Infektion eine Wachstumskontrolle mitgeführt. Dazu wurden bei einer $25 \mathrm{~cm}^{3}$ Zellkulturflasche mit konfluenten Vero-B4 Zellen das Medium abgenommen, die Zellen mit PBS gewaschen und anschließend die Flasche mit Infektionsmedium aufgefüllt. Bei der Ernte des Virusüberstandes sowie des Überstandes der Wachstumskontrolle wurde das Infektionsmedium von den infizierten oder nicht-infizierten Zellen entfernt und bei $300 \mathrm{xg}$ für $10 \mathrm{~min}$ zentrifugiert. Danach wurde der Virusüberstand oder Zellkulturüberstand abgenommen, zu $1 \mathrm{ml}$ in $2 \mathrm{ml}$ Kryogefäße aliquotiert und bei $-80{ }^{\circ} \mathrm{C}$ gelagert.

\subsubsection{Bestimmung des Virustiters}

Die Titer der angezogenen Viren und der virusenthaltenden Überstände wurden anhand der Kulturinfektiösen-Dosis 50 (engl.: tissue-çulture infectious $\underline{\text { dose }} \underline{50} \%\left(\mathrm{TCID}_{50}\right)$ ) quantifiziert.

Die $\mathrm{TCID}_{50}$ gibt dabei im Allgemeinen die Verdünnung einer virushaltigen Lösung an, die noch ausreicht, um die Hälfte einer Zellkultur zu infizieren bzw. entspricht die letzte Verdünnung, bei der 50 \% der Zellkulturen einen zytopathischen Effekt aufweisen.

Dazu wurden mit den geernteten Virusüberständen serielle Verdünnungsreihen in $1: 10$ Verdünnungsschritten mit dem Infektionsmedium angesetzt, die in mehreren 
Parallelansätzen auf die Vero-B4 Zellen gegeben wurden, die anschließend bei $37^{\circ} \mathrm{C}$ und in einer 5\%igen $\mathrm{CO}_{2}$-Atmosphäre inkubiert wurden. Die Auswertung des Zustands der Zellen bzw. für die Abschätzung eines CPEs bei den Zellen in den einzelnen Vertiefungen der Gewebekulturplatte wurde mittels eines Lichtmikroskops durchgeführt.

Die Kalkulation des Virustiters wurde mit Hilfe der folgenden Formel von Spearmann und Kärber (56) durchgeführt:

$$
\begin{aligned}
\log _{\mathrm{TCID} 50} & =\log \mathrm{D}-\left(\left(\log \mathrm{D}_{0}\right) / 2\right)+\log \mathrm{D}_{0} \times(\Sigma(\mathrm{n} / \mathrm{p})) \\
& =\log \mathrm{D}+\log \mathrm{D}_{0} \times(\Sigma(\mathrm{n} / \mathrm{p}))-\left(\log \mathrm{D}_{0} / 2\right) \\
\operatorname{TCID}_{50} & =\mathrm{D} \times\left(\mathrm{D}_{0} \times 10^{\Sigma(\mathrm{n} / \mathrm{p})}\right) /\left(\mathrm{D}_{0} \times 10^{1 / 2}\right) \\
& =\mathrm{D} \times 10^{\Sigma(\mathrm{n} / \mathrm{p})} / 10^{1 / 2} \\
& =\mathrm{D} \times 10^{\Sigma(\mathrm{n} / \mathrm{p})-1 / 2}
\end{aligned}
$$

$\mathrm{TCID}_{50} / \mathrm{ml}=\left(\mathrm{D} \times 10^{\Sigma(\mathrm{n} / \mathrm{p})-1 / 2}\right) / \mathrm{V}$

$\mathrm{D}=$ Verdünnungsfaktor

$\mathrm{D}_{0}=$ Verdünungsintervall

$\mathrm{n}=$ Anzahl der Vertiefungen mit sichtbarem CPE in der Gewebekulturplatte

$\mathrm{p}=$ Anzahl der Parallelbestimmungen auf der Zellkulturplatte

$\Sigma(\mathrm{n} / \mathrm{p})=$ Summe der $\mathrm{n} / \mathrm{p}$ Quotienten beginnend mit der letzten Verdünnungsstufe mit $\mathrm{n} / \mathrm{p}=1$ und endend mit der letzten Verdünnungsstufe mit $\mathrm{n} / \mathrm{p}>0$

$\mathrm{V}=$ eingesetztes Volumen in $\mathrm{ml}$

\section{Material:}

- $\quad$ Vero-B4 Zellen (s. 2.2.1.2.2 Subkultivierung und Zellpassage)

- Infektionsmedium (s. 2.1.4 Puffer, Medien und Lösungen)

- PBS (cc-pro GmbH, Oberdorla, Deutschland)

- Lichtmikroskop (Nikon Corporation, Tokio, Japan)

\section{Protokoll:}

Für die Virustiterbestimmung via TCID $_{50} / \mathrm{ml}$ wurden Vero-B4 Zellen mit einer Dichte von $2 \times 10^{4}$ Zellen pro Vertiefung in eine Gewebekulturplatte mit 96 Vertiefungen 
ausgesät und anschließend für $24 \mathrm{~h}$ bei $37^{\circ} \mathrm{C}$ und in einer $5 \%$ igen $\mathrm{CO}_{2}$-Atmosphäre inkubiert. Nach den 24 h Inkubationszeit wurden mit den jeweiligen Virusüberständen serielle Verdünnungsreihen in 1:10 Verdünnungsschritten mit Infektionsmedium angesetzt. Bevor jeweils $25 \mu \mathrm{l}$ der verdünnten Virusüberstände parallel in 8 Vertiefungen auf die Zellen in der Gewebekulturplatte mit 96 Vertiefungen gegeben wurden, wurde bei den Vero-B4 Zellen in den Gewebekulturplatten das Zellkulturmedium abgenommen, die Vertiefungen mit PBS gewaschen und mit jeweils $100 \mu$ Infektionsmedium aufgefüllt. In jeweils 2 Vertiefungen einer Reihe wurden anstatt der verdünnten Virusüberstände $25 \mu 1$ von dem Infektionsmedium als Wachstumskontrolle zugegeben. Anschließend wurden die Platten bei $37^{\circ} \mathrm{C}$ und in einer 5\%igen $\mathrm{CO}_{2}$-Atmosphäre inkubiert. Nach etwa 3-5 Tagen konnte die Anzahl der Vertiefungen der Gewebekulturplatte mit den Vero-B4 Zellen, die einen CPE aufwiesen mittels des Lichtmikroskops bestimmt werden und anhand der Formel nach Spearman und Kärber konnte der Titer berechnet werden.

\subsubsection{Virus-Inaktivierung}

\subsection{UV-Inaktivierung von Viren}

Als Kontrolle bei sämtlichen Versuchen wurde neben dem aktiven FSME-Virus auch UV-inaktiviertes FSME-Virus auf die Zellen gegeben. Durch die UV-Inaktivierung sind die Viruspartikel noch intakt, aber sie können nicht mehr replizieren.

\section{Material:}

- Gewebekulturplatte mit 6 Vertiefungen (Nunc GmbH \& Co, Langenselbold, Deutschland)

- UV-Lampe (312 $\mathrm{nm}$ bei $12 \mathrm{~W})$

\section{Protokoll:}

Für die UV-Inaktivierung des FSME-Virus wurden $300 \mu \mathrm{l}$ des Virusisolats in eine Gewebekulturplatte mit 6 Vertiefungen gegeben und anschließend für 20 min unter die UV-Lampe in einem Abstand von etwa $5 \mathrm{~cm}$ gestellt. Die Suspension mit dem UVinaktivierten Virus konnte anschließend direkt für die Kokultivierung mit entsprechenden 
Zellen genutzt werden. Um mögliche negative Effekte durch das Einfrieren zu vermeiden, wurde bei Bedarf ohne einfrieren das Virus inaktiviert und benutzt.

\subsection{Inaktivierung von Viren mittels PFA}

Um das FSME-Virus zu inaktivieren, wurde zu den Zellpellets sowie zu den inkubierten CBA-Beads PBS zugegeben, das einen Paraformaldehydanteil von $3 \%$ enthielt. Durch das Paraformaldehyd wird das FSME-Virus inaktiviert. Die Aldehyde haben bakterizide, fungizide und viruzide Wirkung. Die Wirkweise der Aldehyde beruht dabei auf das Zustandekommen einer Methylenbrückenbindung zwischen diversen Aminogruppen der Proteine (102). Aber das Formaldehyd kann auch zu Veränderungen an den Nukleinsäuren führen, wodurch das morphologisch intakte Virus vollständig inaktiviert wird (177). Die Reaktionszeit für die Inaktivierung hängt von der Konzentration des eingesetzten Paraformaldehyds ab (135).

\section{Material:}

- $\quad$ Paraformaldehyd 3 \% (w/v) (Carl-Roth GmbH \& Co KG, Karlsruhe, Deutschland)

- PBS (cc-pro GmbH, Oberdorla, Deutschland)

- Wasserbad (Julabo Labortechnik GmbH, Seelbach, Deutschland)

\section{Protokoll:}

Für die PFA Inaktivierung der FSME-Virus enthaltenen Lösungen wurde zunächst $3 \%$ PFA in PBS gelöst. Da das PFA bei $20^{\circ} \mathrm{C}$ in Wasser nur sehr schwer löslich ist, wurde das PBS mit dem enthaltenen PFA für $6 \mathrm{~h}$ bei $70{ }^{\circ} \mathrm{C}$ im Wasserbad unter Schütteln gelöst und anschließend für den zeitnahen Gebrauch bei $4{ }^{\circ} \mathrm{C}$ oder für maximal 1 Monat bei $-20{ }^{\circ} \mathrm{C}$ gelagert. Für die Inaktivierung von potentiell infektiösen Proben wurde auf die Zellpellets oder Beads jeweils PBS mit 3 \% Paraformaldehyd zugegeben und für 15 min bei $4{ }^{\circ} \mathrm{C}$ im Kühlschrank inkubiert.

\subsubsection{Virusinfektion von DCs und T-Zellen}

Um die DCs, T-Zellen oder die Kokultur aus pDCs und T-Zellen zu infizieren, wurde zu den jeweiligen ausgesäten Kulturen das FSME-Virus zugegeben. Die Infektion der Zellen erfolgte dabei mit einer Multiplizität der Infektion (engl.: multiplicity of infection (MOI)) 
von 10. Das bedeutet, dass bei dieser Kultur pro einzelner Zelle 10-fach so viele infektiöse Partikel vorhanden sind.

Zusätzlich zu den mit Virus infizierten Zellen wurde auch zu einer Charge der Zellen das gleiche Volumen an Überstand der VeroB4-Zellen aus der Wachstumskontrolle (s. 2.2.2.2 Anzucht und Kultivierung von Viren) als uninfizierte bzw. Mock-Kontrolle zugegeben und wie die infizierten Zellen behandelt. Eine weitere Kontrolle wurde mit der Kokultivierung von UV-inaktivierten, replikationsunfähigen FSME-Virus durchgeführt. Dafür wurden zu einer weiteren Zellcharge ein identisches Volumen an UV-inaktivierten FSME-Virus zugesetzt.

Neben der Infektion der Zellen wurde parallel die Restinfektiosität der verwendeten Virussupension ermittelt. Hierzu wurde ein Aliquot der verwendeten Virussuspension in zellfreier Umgebung über den identischen Zeitraum wie die infizierten Zellen inkubiert.

\section{$\underline{\text { Material: }}$}

- Zellen (mDCs, pDCs, T-Zellen oder Kokultur aus pDCs und T-Zellen) in einer Gewebekulturplatte mit 24 Vertiefungen (s. Kapitel 2.2.1.5.1-4)

- FSME-Virusüberstand (s. 2.2.2.2 Anzucht und Kultivierung von Viren)

- Überstand der Vero-B4-Zellen aus der Wachstumskontrolle (s. 2.2.2.2 Anzucht und Kultivierung von Viren)

- UV-inaktivierter FSME-Virusüberstand (s. 2.2.2.4.1 UV-Inaktivierung von Viren)

\section{Protokoll:}

Für die Virusinfektion der DCs, T-Zellen oder von Kokulturen wurden zu den jeweiligen Zellkulturen FSME-Virus mit einer MOI von 10 zugegeben. Für die Mock-Kontrolle wurden in die jeweiligen Vertiefungen mit den Zellen das gleiche Volumen an Überstand der VeroB4-Zellen aus der Wachstumskontrolle (s. 2.2.2.2 Anzucht und Kultivierung von Viren) und für die Kontrolle mit dem UV-inaktivierten FSME-Virus wurde das identische Volumen an UV-inaktivierten FSME-Virus (s. 2.2.2.4.1 UV-Inaktivierung von Viren) zugegeben. Die infizierten bzw. behandelten Zellkulturen wurden bei $37{ }^{\circ} \mathrm{C}$ und in einer 5\%igen $\mathrm{CO}_{2}$-Atmosphäre inkubiert. Zur Bestimmung der Restinfektiosität wurde die identische Menge an Virus zu dem identischen Volumen an Medium zugegeben, um den 
Verdünnungsfaktor zu wahren. Die verdünnte Virussuspension wurde anschließend für die gleiche Zeit wie die Zellen bei $37{ }^{\circ} \mathrm{C}$ und in einer $5 \%$ igen $\mathrm{CO}_{2}$-Atmosphäre inkubiert.

\subsubsection{Die polychromatische Durchflußzytometrie}

Die Durchflußzytometrie ist eine Methode zur quantitativen Analyse von Partikeln, wie sie zum Beispiel Zellen oder Beads darstellen, sowie zur Untersuchung von deren Charakteristika auf molekularer Ebene. Die Partikel müssen sich dabei in einer Suspension befinden und eine Größe von 0,2-150 $\mu \mathrm{m}$ aufweisen. Bei der Messung dieser Partikel mittels eines Durchflußzytometers, wird die Suspension langsam in das Gerät befördert. Dabei passieren die in der zu messenden Probe enthaltenen Partikel einzeln mittels eines laminaren Flüssigkeitsstroms die Messzelle des Durchflußzytometers. In dieser Messzelle werden die Partikel mit Laserlicht von verschiedenen definierten Wellenlängen nacheinander bestrahlt. Erreicht z. B. eine Zelle die Messzelle, dann wird sie von einem initialen Laserstrahl mit einer Wellenlänge von $488 \mathrm{~nm}$ bestrahlt. Das Licht des Lasers wird, wenn es auf die Zelle trifft, aufgrund diverser Eigenschaften der Zelle gestreut. $\mathrm{Zu}$ diesen Eigenschaften gehören die Größe der Zelle bzw. die Querschnittsfläche, der Refraktionsindex, die Beschaffenheit der Membran (Faltungen in der Zellmembran oder Ausbildung von Dendriten etc.), intrazelluläre Granularität, Komplexizität der Zelle, etc. Das gestreute Licht wird von verschiedenen Detektoren eingefangen. Durch einen frontal angebrachten Lichtdetektor, dem so genannten Forward-Scatter (FSC)-Detektor, wird das diffraktionierte Licht in einem Winkel von 1-10 $0^{\circ}$ aufgefangen. Anhand dieser Ablenkung können Rückschlüsse auf die Größe und Zelloberfläche der Zelle gezogen werden. Ein weiterer Detektor, der Side-Scatter (SSC)Detektor, ist seitlich in einem Winkel von $90^{\circ} \mathrm{zu}$ dem eintreffenden Laserstrahl angebracht und misst das reflektierte und gebrochene Licht. Mittels der Messwerte der Reflektion und Lichtbrechung können wiederum Rückschlüsse auf die Granularität und Komplexizität der Zelle gezogen werden. Je stärker der Laserstrahl reflektiert oder gebrochen wird, desto granulärer und komplexer ist die untersuchte Zelle.

Neben der Streuung des Lichtes kann auch die Fluoreszenz gemessen werden, die von den durch Laserlicht angeregten Fluorchromen (die an Antikörper gekoppelt sind) ausgestrahlt werden. Durch die Verwendung von Fluorochrom-gekoppelten Antikörpern, die gegen verschiedene Moleküle auf der Zelloberfläche oder innerhalb der Zelle 
gerichtet sind, kann die Expression dieser Moleküle analysiert werden. Durch die Bestrahlung mit Laserlicht werden die Fluorochrome angeregt und emittieren Licht einer anderen Wellenlänge. Diese Fluoreszenz der Fluorochrome wird zu entsprechenden Detektoren geleitet. Die Fluoreszenz der Fluorochrome sowie das seitwärts gestreute Licht haben allerdings eine sehr geringe Intensität und werden deshalb durch Photodetektoren aufgefangen, die die schwachen Lichtsignale verstärken. Die detektierten Lichtsignale werden durch ein elektronisches System in elektronische Signale konvertiert, die wiederum mit einem Computer und der entsprechenden Software dargestellt und bearbeitet werden können.

Die Signalhöhe wird dabei auf 16384 Ebenen und die Signalfrequenz mit einer $10 \mathrm{MHz}-$ Rasterung gemessen. Aus diesen beiden Parametern können die Signalfläche sowie der Zeitverlauf des Signals bestimmt werden.

In dieser Arbeit wurde das Durchflußzytometer FACSCantoII der Firma BD Biosciences verwendet. Die Anregung der Fluoreszenz erfolgte über drei verschiedene Laser: Einem blauen Laser, der eine Wellenlänge von $488 \mathrm{~nm}$ ausstrahlt, einem roten Laser, der Licht mit einer Wellenlänge von $633 \mathrm{~nm}$ ausstrahlt, und einem violetten Laser, der Licht mit einer Wellenlänge von $405 \mathrm{~nm}$ ausstrahlt.

Bei einem Multicolor-Ansatz ist es von Bedeutung bei der Auswahl der Fluochromgekoppelten Antikörper darauf zu achten, dass sich die Anregungsspektren der einzelnen Fluochrome überlagern und die Emissionsspektren sich möglichst unterscheiden sollten, wobei sich eine Überlappung nicht ganz ausschließen lässt.

Aus diesem Grund ist es wichtig vor einer Versuchsreihe eine Kompensation durchzuführen, bei der die diversen Überlappungen durch die Messung der einzelnen an Bead-gekoppelten Fluorochrome durch die Kompensationselektronik der Software FACSDiva 6.0 (Fa. BD Biosciences, Franklin Lakes, NJ, USA) das Signal in allen Detektoren ermittelt wird und der Anteil der Überlappung elektronisch subtrahiert wird. Die Helligkeit der Fluoreszenzsignale entspricht der Menge an gebundenen Antikörpern. Je heller das Fluoreszenzsignal, desto mehr Antikörper haben an der Zelle gebunden. 
Material:

- Fluorochrom-gekoppelte Antikörper (s. 2.1.5 Antikörper und Fluoreszenzfarbstoffe)

- Durchflußzytometer (FACSCantoII der Firma BD Biosciences)

- PBS (cc-pro GmbH, Oberdorla, Deutschland)

- $\quad$ Fixierungslösung: PBS mit 3 \% PFA (s. 2.1.4 Puffer, Medien und Lösungen)

\section{Protokoll:}

Für die Färbung der Zellen mit Fluorochrom-gekoppelten Antikörpern wurden spezifische Antikörpersets zusammengestellt. Nach der Zugabe der Antikörper der jeweiligen Sets wurden die Zellen 15 min bei $4{ }^{\circ} \mathrm{C}$ im Kühlschrank inkubiert. Nach der Inkubationszeit wurden die Zellen mit PBS gewaschen. Da die Arbeiten zumeist mit infektiösem FSMEVirus in einem BSL-3-Labor durchgeführt wurden und das Durchflußzytometer örtlich getrennt in einem BSL-1-Labor untergebracht war, wurden die Proben mit Paraformaldehyd behandelt, um das FSME-Virus zu inaktivieren. Dabei wurde PBS mit einem Anteil von 3\% Paraformaldehyd auf die Zellen gegeben und die Zellen anschließend für 15 min bei $4{ }^{\circ} \mathrm{C}$ inkubiert. Nach der Inkubation wurden die Zellen nochmals mit PBS gewaschen und mit ca. $300 \mu$ PBS aufgefüllt. Vor der Überführung zum Durchflußzytometer wurden die Röhrchen für 5 min mit Korsolex desinfiziert.

Die anschließende durchflußzytometrische Analyse wurde mit einem FACSCantoII Zytometer der Firma BD Biosciences durchgeführt und die Auswertung der Daten erfolgte anhand der FlowJo Software der Firma Tree Star.

\subsubsection{Proliferationstest mittels CFSE}

Das Prinzip des Proliferationstest mittels der Carboxyfluorescein-succinimidyl-Ester(CFSE) Färbung beruht auf der Aufnahme des CFSEs von Zellen, die durch die Zellteilung einen Verdünnungseffekt des CFSE hervorrufen. Dieser Verdünnungseffekt kann mittels des Durchflußzytometers untersucht werden. Das CFSE ist eine fluoreszierende Substanz, die als Lebendfarbstoff keine Zytotoxizität besitzt. Durch die Zugabe von CFSE zu Zellen, nehmen diese den Farbstoff durch Diffusion auf. In den Zellen bindet das CFSE an Aminogruppen der Proteine, sodass das CFSE nicht mehr aus der Zelle diffundieren kann und somit im Zellplasma verweilt. Im Zuge einer Zellteilung 
werden die Proteine mit dem CFSE, die in der Mutterzelle vorhanden sind, auf die Tochterzellen aufgeteilt. Somit enthalten die Tochterzellen ebenfalls Proteine, die am CFSE gebunden sind, aber durch die Aufteilung im Zuge der Zellteilung ist die Konzentration an CFSE in den Tochterzellen geringer, als es bei der Mutterzelle bzw. Ausgangszelle der Fall war. Dadurch wird allerdings auch das Fluoreszenzsignal, das durch das CFSE in den Tochterzellen hervorgerufen wird, schwächer. Teilen sich die Tochterzellen weiter, so wird das Fluoreszenzsignal durch den Verdünnungseffekt der Teilung immer geringer. Als Proliferationskontrolle wurde Phytohämagglutinin (PHA) benutzt, das die Proliferation von T-Zellen induziert.

Material:

- $\quad 2 \times 10^{7}$ humane PBMCs (s. 2.2.1.4 Isolation von PBMCs aus humanen Buffy-Coats)

- CFSE (Sigma-Aldrich Chemie GmbH, Steinheim, Deutschland)

- $\quad$ PBS (cc-pro GmbH, Oberdorla, Deutschland)

- FKS (Invitrogen GmbH, Darmstadt, Deutschland)

- Phytohämagglutinin (PHA) (Sigma-Aldrich Chemie GmbH, Steinheim, Deutschland)

- $\quad$ PBMC-Medium (s. 2.1.4 Puffer, Medien und Lösungen)

\section{Protokoll:}

Für den Proliferationstest wurden $2 \times 10^{7}$ isolierte humane PBMCs mit $1 \mu \mathrm{M}$ Carboxyfluorescein in $1 \mathrm{ml}$ PBS für 15 min bei $37{ }^{\circ} \mathrm{C}$ und $5 \% \mathrm{CO}_{2}$ inkubiert und dabei gelegentlich geschwenkt. Danach erfolgten die Zugabe von $100 \mu \mathrm{l}$ FKS und ein Zentrifugationsschritt für $10 \mathrm{~min}$ bei $350 \mathrm{x}$ g. Der Überstand wurde verworfen und das Zellpellet wurde in $1 \mathrm{ml}$ PBMC-Medium aufgenommen und für $30 \mathrm{~min}$ bei $37^{\circ} \mathrm{C}$ und $5 \% \mathrm{CO}_{2}$-Atmosphäre inkubiert. Nach der Inkubationszeit wurden die Zellen dreimal mit $2 \%$ FKS enthaltendem PBS gewaschen und mit einer Dichte von $2 \times 10^{6}$ Zellen pro Vertiefung einer Gewebekulturplatte mit 96 Vertiefungen in $200 \mu 1$ PBMC-Medium ausgesät. Im Anschluss wurde je eine Vertiefung der Gewebekulturplatte mit den PBMCs mit dem FSME-Virus, mit dem UV-inaktivierten FSME-Virus, mit dem Stimulanz Phytohämagglutinin (PHA) $(20 \mu \mathrm{g} / \mathrm{ml})$ und mit Medium als Mock-Kontrolle kokultiviert bzw. stimuliert. Die Zellkultur erfolgte bei $37^{\circ} \mathrm{C}$ und $5 \% \mathrm{CO}_{2}$ Zufuhr für 3 und 5 Tage. 
Nach der Inkubationszeit von 3 und 5 Tagen wurden die Zellen geerntet und mit PBS gewaschen. Nach der Waschprozedur erfolgte die Färbung mit spezifischen Fluochromgekoppelten Antikörpern. Nach einer anschließenden Inkubationszeit für 15 min bei $4{ }^{\circ} \mathrm{C}$ erfolgte ein weiterer Waschschritt mit PBS und die Fixierung mit 3 \% PFA enthaltendem PBS für 15 min bei $4{ }^{\circ} \mathrm{C}$. Darauf erfolgte ein letzter Waschschritt mit PBS. Danach wurden die Proben mit ca. $300 \mu 1$ PBS aufgefüllt. Vor der Überführung zum Durchflußzytometer wurden die Röhrchen für 5 min mit Korsolex desinfiziert. Die Proben wurden anschließend mit dem Durchflußzytometer analysiert und die aufgenommenen Daten mittels der FlowJo Software der Firma Tree Star ausgewertet.

\subsubsection{Konzentrationsbestimmung von Zytokinen mittels CBA}

Die Bestimmung von verschiedenen Zytokinen wurde mit Hilfe des cytometric $\underline{\text { bead }}$ arrays (CBA) der Firma BD Biosciences durchgeführt $(137,187)$. Der CBA ist im Allgemeinen eine Methode, um die Konzentration an löslichen Proteinen, wie es die Zytokine sind, zu analysieren. Das Prinzip des CBA ähnelt dabei dem des SandwichELISAs. Der CBA besteht aus verschiedenen Bead-Populationen, die zum einen untereinander eine verschiedenen Fluoreszenzintensität besitzen und zum anderen untereinander an verschiedene Antikörper gekoppelt sind, die je nach Population spezifisch gegen ein anderes Zytokin gerichtet sind. Die Beads sind somit in der Lage die einzelnen je nach Bead-Population verschiedenen Zytokine aus der zu messenden Probe zu fangen. Bei dem Human inflammation kit der Firma BD Biosciences, das in dieser Arbeit benutzt wurde, werden 6 verschiedene Parameter bzw. Zytokine untersucht, sodass 6 verschiedene Bead-Populationen zusammengegeben werden. Diese Bead-Populationen werden zunächst in die Vertiefungen einer Gewebekulturplatte mit 96 Vertiefungen vorgelegt. Danach werden die Proben, bzw. die Zellkulturüberstände hinzu gegeben, deren Zytokin Konzentrationen bestimmt werden sollen. In einem weiteren Schritt werden verschiedene Antikörperpopulationen hinzu gegeben, die je nach Population gegen die unterschiedlichen Zytokine gerichtet sind. Die Antikörperpopulationen sind alle an identische Fluorochrome (PE) gekoppelt.

Nach einer dreistündigen Inkubationszeit können die Proben mittels eines Durchflußzytometers analysiert werden. Die Bead-Populationen haben zwar die gleiche Größe, sie können aber aufgrund ihrer unterschiedlichen Fluoreszenzintensität 
voneinander unterschieden werden und somit auch die daran gebundenen Zytokine. Je mehr Zytokine von den Beads gebunden wurden, desto mehr von dem spezifischen Fluorochrom-gekoppelten Antikörper können an die Zytokine binden, sodass das Fluoreszenzsignal der Antikörper intensiver wird. Neben den Proben werden auch Standards mit definierten Mengen an den entsprechenden Zytokinen mitgeführt. Durch die Gegenüberstellung der Fluoreszenz, die von den Beads ausgeht, zu der Fluoreszenz, die von den Antikörpern ausgeht, können zum einen die jeweiligen Zytokine unterschieden werden und zum anderen die durch die Intensität der Fluoreszenz der Antikörper können anhand der Standardkurven die Konzentration der Zytokine ermittelt werden.

In diesem Fall wurde die Konzentration der proinflammatorischen Zytokinen IL-1 $\beta$, IL-6, IL-8, TNF- $\alpha$ und IL-12p40 sowie des antiinflammatorischen Zytokins IL-10 mittels dem Human inflammation kit der Firma BD Biosciences bestimmt. Die Zytokinantwort der T-Zellen und Kokulturen von pDCs und T-Zellen wurde dagegen mit dem Human Th1/Th2Cytokine kit der Firma BD Biosciences bestimmt. Anhand des Human Th1/Th2Cytokine kit werden die Konzentrationen der Zytokine IL-2, IL-4, IL-5, IL-10 TNF- $\alpha$ und IFN- $\gamma$ analysiert. Die Analyse der Zytokine wurde mittels des Durchflußzytometers FACSCanto II der Firma BD Biosciences durchgeführt. Für die Analyse der Gewebekulturplatte mit 96 Vertiefungen wird ein HTS-Modul benötigt. Dabei handelt es sich um einen speziellen Probenaufnehmer, der die Proben aus der Gewebekulturplatte mit 96 Vertiefungen entnehmen kann. Die Erstellung der Standardkurven sowie die Auswertung der Daten erfolgten mit dem Programm FCAP Array v1.0 der Firma Softlow.

\section{Material:}

- Zellkulturüberstände (mDCs, pDCs, T-Zellen und Kokultur von pDCs und T-Zellen)

- CBA (BD Biosciences, Franklin Lakes, NJ, USA)

- PBS (cc-pro GmbH, Oberdorla, Deutschland)

- Durchflußzytometer (FACSCantoII) (BD Biosciences, Franklin Lakes, NJ, USA) (s. 2.2.3 Durchflußzytometrie) 
Protokoll:

Die Messung der Zytokin-Konzentrationen in Zellkulturüberstände von mDCs und pDCs wurden mittels des Human inflammation kit der Firma BD Biosciences durchgeführt. Die Konzentration der Zytokine in den T-Zellkulturüberständen und den Überständen der Kokultur wurde mit dem Human Th1/Th2Cytokine kit der Firma BD Biosciences durchgeführt. Die Prozedur, sowie die Erstellung der Standards und Kompensation des Durchflußzytometers (FACSCanto II der Firma BD Biosciences) erfolgte dabei gemäß der Beschreibung des Herstellers. Die Standardkurven, sowie die zu bestimmenden Konzentrationsdaten wurden mittels des Programms FCAP Array v1.0 der Firma Softflow ausgewertet.

\subsubsection{Konzentrationsbestimmung von Interferon- $\alpha$ mittels ELISA}

Um zum einen nachzuweisen, ob die mDCs und pDCs das Typ I IFN, IFN- $\alpha$, produzieren und zum anderen um Aussagen über die Menge des produzierten IFN- $\alpha$ zu machen, wurden die IFN- $\alpha$-Konzentrationen der mDC- und pDC-Zellkulturüberstände mittels des Interferon- $\alpha$ Enzyme-linked-immunosorbent-assays (ELISA) der Firma PBL, Biomedical Laboratories (Piscataway, NJ, USA) analysiert. Bei dem in dieser Arbeit verwendeten IFN- $\alpha$ ELISA handelt es sich um einen so genannten Sandwich-ELISA. Dazu werden spezifische gegen das zu messende Antigen (in diesem Fall das IFN- $\alpha$ ) gerichtete Antikörper adsorptiv oder kovalent an einen festen Körper (z. B. die Oberflächen der Kavitäten von Mikrotiterplatten mit 96 Vertiefungen) gekoppelt. Dieser Antikörper kann nun aus zugefügten Zellkulturüberständen oder anderen IFN- $\alpha$ enthaltenden Lösungen das IFN- $\alpha$ binden. Nach der Inkubationszeit, die für eine vollständige Bindung notwendig ist, können durch mehrmaliges Auswaschen der einzelnen Vertiefungen der ELISA-Platte alle anderen Substanzen entfernt werden. Bei diesem Kit erfolgt nach der Waschprozedur die Zugabe eines Sekundärantikörpers, der auch spezifisch gegen das Antigen (also IFN- $\alpha$ ) gerichtet ist, aber an andere Epitope des Antigens bindet als der gebundene Antikörper. Nach der Zugabe erfolgt eine weitere Inkubationsphase und mehrere Waschschritte, durch die der Anteil an ungebundenen Antikörper entfernt wird.

In einem weiteren Schritt wird ein Detektionsantikörper zugegeben, der gegen den Sekundärantikörper gerichtet ist. Dieser Detektionsantikörper trägt darüber hinaus einen Marker, in diesem Fall das Enzym Meerrettich-Peroxidase (engl.: horseradish peroxidase 
(HRP)). Nach der Inkubation mit Detektionsantikörper und erneutem Waschen erfolgt die Zugabe des Substrates 3,3',5,5-Tetramethylbenzidin (engl.: Tetramethyl- $\underline{b} e n z i d i n e$ (TMB)), das von der HRP in ein farbiges Endprodukt umgewandelt wird. Nach Zugabe einer Stopplösung, die die Aktivität der HRP hemmt, kann die Absorption des farbigen Endprodukts bei einer Wellenlänge von $450 \mathrm{~nm}$ mittels ELISA-Reader gemessen werden. Dabei gilt, je mehr Antikörper mit HRP vorhanden sind desto höher ist die Enzymaktivität und dementsprechend kann mehr TMB in das farbige Endprodukt umgewandelt werden, wodurch die Absorption der Probe erhöht wird. Damit kann indirekt nachgewiesen werden, ob IFN- $\alpha$ in der Probe vorhanden ist. Um die Konzentration des IFN- $\alpha$ in den gemessenen Proben $\mathrm{zu}$ bestimmen, muss eine entsprechende IFN- $\alpha$-Standardkurve parallel zu den Proben erstellt und gemessen werden.

\section{Material:}

- Zellkulturüberstände (mDCs, pDCs, T-Zellen und Kokultur von pDCs und T-Zellen)

- Interferon- $\alpha$ ELISA (PBL, Biomedical Laboratories, Piscataway, NJ, USA)

- Zellkulturwasser (cc-pro GmbH, Oberdorla, Deutschland)

- ELISA-Reader (Molecular Devices inc., USA)

\section{Protokoll:}

Die Messung der IFN- $\alpha$-Konzentrationen wurde anhand der Zellkulturüberstände der mDCs und pDCs mittels des Interferon- $\alpha$ ELISA-Kits der Firma PBL Biomedical Laboratories durchgeführt. Die Prozedur erfolgte ohne weitere Modifikation gemäß der Beschreibung des Herstellers.

\subsubsection{Zellviabilitätsmessung mittels MTT-Test}

Um die Zellviabilität von den als Indikatorzellen eingesetzten Vero-B4 Zellen, die mit FSME-Viren oder verschiedenen Zellkulturüberständen infiziert oder kokultiviert wurden, zu analysieren, wurde der CellTiter 96 Non-Radioactive Cell Proliferation Assay der Firma Promega Corporation (Madison, WI, USA) benutzt. Das Prinzip der Methode basiert auf dem MTT-Test, bei dem zu den Zellen der einzelnen Versuchsreihen das Substrat MTT, (3-(4,4-Dimethylthiazol-2-yl)-2,5-diphenyl-tetrazoliumbromid), 
zugegeben wird und eine anschließende Inkubation erfolgt. Innerhalb der Inkubationszeit wird das MTT durch die Aktivität mitochondrialer Dehydrogenasen, die nur in lebenden Zellen aktiv sind, zu einem wasserunlöslichen Produkt, dem Formazan, reduziert. Nach der Inkubationszeit wird eine Stopplösung zugegeben, die zum einen die Zellen lysiert und zum anderen das Formazan solubilisiert. Die Absorption des Formazans (dessen Absorptionsmaximum bei $570 \mathrm{~nm}$ liegt) kann mit einem ELISA-Reader bestimmt werden. Die Höhe der Absorption ist proportional zu der Anzahl an lebenden Zellen.

\section{Material:}

- Gewebekulturplatte mit 96 Vertiefungen mit den Ansätzen der TCID $_{50}$-Titration (s. 2.2.2.3 Bestimmung des Virustiters)

- CellTiter 96 Non-Radioactive Cell Proliferation Assay (Promega Corporation, Madison, WI, USA)

- ELISA-Reader (Molecular Devices inc., USA)

\section{Protokoll:}

Für die Bestimmung der Zellviabilität von Vero-B4 Zellen, die mit dem FSME-Virus, UV-inaktivierten FSME-Virus, Zellkulturüberstand (Mock), Inputvirus, Überstände aus Zellkultur von pDCs, die mit IFNAR-Antikörper behandelt wurden, infiziert oder koinkubiert wurden, wurde der MTT-Assay benutzt. Dafür wurde in jede Vertiefung der Gewebekulturplatte mit 96 Vertiefungen $15 \mu \mathrm{l}$ der Dye solution, die eine Tetrazol Komponente enthält, zugegeben und die Platte anschließend bei $37{ }^{\circ} \mathrm{C}$ und $5 \% \mathrm{CO}_{2}$ Atmosphäre für $4 \mathrm{~h}$ inkubiert. Innerhalb der Inkubationszeit wird durch die Mitochondrien das Tetrazol in Formazan umgewandelt. Nach der Inkubationszeit wurde in jede Vertiefung der Gewebekulturplatte $100 \mu 1$ des Stopp-Mix hinzu gegeben, der das Formazan solubilisiert, und über Nacht bei Raumtemperatur inkubiert. Am nächsten Tag wurde die Absorption der einzelnen Vertiefungen bei $570 \mathrm{~nm}$ mittels eines ELISAReaders (Molecular Devices, USA) ausgelesen. 


\subsubsection{Zellviabilitätsbestimmung mittels Lichtmikroskopie}

Für die Auswertung der TCID $_{50}$-Analysen wurden die einzelnen Vertiefungen der Gewebekulturplatte mittels Lichtmikroskop (Nikon Corporation, Tokio, Japan) begutachtet und auf das Vorhandensein von CPEs der als Indikatorzellen verwendeten Vero-B4 Zellen kontrolliert. Das Lichtmikroskop verfügte dabei über drei Objektive mit einer $10 \mathrm{x}, 20 \mathrm{x}$ und $40 \mathrm{x}$ Vergrößerung und einem Okular mit einer $10 \mathrm{x}$ Vergrößerung. Die Vergrößerung des Mikroskops setzt sich aus dem Produkt der beiden Faktoren Vergrößerung des Objektivs und Vergrößerung des Okulars zusammen. Demzufolge konnten die Zellen mit 100 x, $200 \mathrm{x}$ und $400 \mathrm{x}$ Vergrößerung betrachtet und dokumentiert werden. Die jeweiligen Vertiefungen mit den Zellen auf den Gewebekulturplatten wurden anhand des Mikroskop-Display (Nikon Corporation, Tokio, Japan) dokumentiert.

\section{Material:}

- Zellkulturüberstände (mDCs, pDCs, T-Zellen und Kokultur von pDCs und T-Zellen)

- Lichtmikroskop (Nikon Corporation, Tokio, Japan)

- Mikroskop-Display (Nikon Corporation, Tokio, Japan)

\section{Protokoll:}

Für die Auswertung des $\mathrm{TCID}_{50}$ und zur Bestimmung des Virustiters der jeweilige Überstände wurden die einzelnen Vertiefungen der Gewebekulturplatte mittels eines Lichtmikroskops (Nikon Corporation, Tokio, Japan) untersucht. Dabei wurde geschaut, bis zu welcher Verdünnungsstufe des Überstandes auf den Indikatorzellen (Vero-B4) noch ein CPE zu erkennen war. Die einzelnen Vertiefungen mit den Zellen auf der Gewebekulturplatte mit 96 Vertiefungen wurden schließlich mit dem Mikroskop-Display (Nikon Corporation, Tokio, Japan) dokumentiert.

\subsubsection{Neutralisation des Interferonrezeptors (IFNAR)}

Um zu untersuchen, ob die positive Typ I IFN Feedback-Schleife dazu beiträgt die Replikation des FSME-Virus in den pDCs zu unterdrücken, wurde der IFNAR durch einen Antikörper neutralisiert. Dabei wurde ein monoklonaler Antikörper verwendet, der 
gegen die Interferon- $\alpha /-\beta$ Rezeptor Kette 2 gerichtet ist, sodass die Typ I IFNs, die aus dem ersten Signalweg produziert wurden sind, nicht die positive Schleife der autokrinen- und parakrinen Induktion über den IFNAR aktivieren können und somit eine erhöhte Typ I IFN-Produktion hervorrufen. Die Neutralisation erfolgte nach einer Methode von Colamunici und Domanski (38).

\section{Material:}

- $\quad$ humane pDCs (s. 2.2.1.5.2 Isolation von pDCs aus PBMCs)

- IFNAR-Antikörper (Maus monoklonaler Antikörper gegen humanen Interferon- $\alpha /-\beta$ Rezeptor Kette 2) (PBL, Biomedical Laboratories, Piscataway, NJ, USA)

\section{Protokoll:}

Für die Neutralisation des IFNAR bei den pDCs, wurden von frisch isolierten humanen pDCs (s. 2.2.1.5.2 Isolation von pDCs aus PBMCs) die Hälfte der Zellen ( 3 x $10^{5}$ Zellen) in pDC-Puffer für $2 \mathrm{~h}$ bei $4{ }^{\circ} \mathrm{C}$ im Kühlschrank gelagert. $\mathrm{Zu}$ dem anderen Anteil der pDCs wurde der IFNAR-Antikörper zugegeben und die Zellen ebenfalls für $2 \mathrm{~h}$ bei $4{ }^{\circ} \mathrm{C}$ inkubiert. Nach der Inkubationszeit wurden zu den Zellen jeweils $3 \mathrm{ml}$ pDC-Medium zugeführt und die Zellen in einer Gewebekulturplatte mit 24 Vertiefungen in einer Dichte von $1 \times 10^{5}$ Zellen pro Vertiefung ausgesät. Jeweils eine Vertiefung der pDCs mit und ohne Antikörperbehandlung wurde mit FSME-Virus (MOI 10) infiziert, in einem weitere Vertiefung wurden jeweils gleiche Volumen an Überstand der VeroB4-Zellen aus der Wachstumskontrolle (s. 2.2.2.2 Anzucht und Kultivierung von Viren) und für die Kontrolle mit dem UV-inaktivierten FSME-Virus wurde das identische Volumen an UVinaktivierten FSME-Virus (s. 2.2.2.4.1 UV-Inaktivierung von Viren) zugegeben. Die infizierten bzw. behandelten Zellkulturen wurden bei $37^{\circ} \mathrm{C}$ und in einer $5 \%$ igen $\mathrm{CO}_{2^{-}}$ Atmosphäre inkubiert.

\subsubsection{Filtration von Zellkulturüberstände zur Entfernung von Zytokinen}

Die Zytokine können viele verschieden Effekte auf die Zellen haben (s. Kapitel 1). Um mögliche störende Effekte der antiviraler und proinflammatorischer Zytokine oder Chemokine auszuschließen, wurden die Zellkulturüberstände zusätzlich mittels eines 
speziellen Filtersystems filtriert. Die Größe der meisten proinflammatorischen Zytokine liegt unter $30 \mathrm{kDa}$. Das Molekulargewicht der humanen Typ I IFNs reicht von 17,5 kDa bis $27 \mathrm{kDa}$ (IFN- $\alpha$ : 17,5-27 kDa und IFN- $\beta$ : $20 \mathrm{kDa}$ ) (21) und das Molekulargewicht von IL-6 ist abhängig von der Glykosylierung und reicht von $21 \mathrm{kDa}$ bis $28 \mathrm{kDa}(19)$. Das in dieser Arbeit benutzte Filtersystem Amicon Ultra-4 Centrifugal Filter Devices 30K der Firma Millipore Corporation beruht auf einer Membran mit einer Ausschlussgröße von $30 \mathrm{kDa}$, sodass die meisten proinflammatorischen Zytokine ausgefiltert werden.

\section{Material:}

- Zellkulturüberstände (pDCs und pDCs mit IFNAR-Antikörper behandelt (s. 2.2.9 Neutralisation des Interferonrezeptors (IFNAR)))

- Amicon Ultra-4 Centrifugal Filter Devices 30K (Millipore Corporation, Billerica, Massachusetts, USA)

- Opti-MEM Gibco (Invitrogen GmbH, Darmstadt)

- $\quad$ PBS (cc-pro GmbH, Oberdorla, Deutschland)

\section{Protokoll:}

Bevor die eigentliche Filtration der Zellkulturüberstände erfolgte, wurden die Filtereinheiten Amicon Ultra-4 Centrifugal Filter Devices 30K der Firma Millipore Corporation zunächst gewaschen. Dazu wurden die Filter mit $4 \mathrm{ml}$ PBS befüllt und bei $4000 \mathrm{x} \mathrm{g}$ und $4{ }^{\circ} \mathrm{C}$ für $10 \mathrm{~min}$ zentrifugiert. Anschließend erfolgten die Beladung der Filter mit den Zellkulturüberständen (jeweils $1 \mathrm{ml}$ ) und ein weiterer Zentrifugationsschritt bei $4000 \mathrm{x}$ g und $4{ }^{\circ} \mathrm{C}$ für $10 \mathrm{~min}$. Darauf wurden jeweils $4 \mathrm{ml}$ Opti-MEM auf die Membran gegeben und die Säulen bei 4000 x g und $4{ }^{\circ} \mathrm{C}$ für $10 \mathrm{~min}$ zentrifugiert. Die Membran wurde anschließend mit jeweils $1 \mathrm{ml}$ PBS beladen und dieses mehrfach sorgfältig mit einer Pipette aufgenommen. Mit den Proben wurden zum einen anschließend TCID $_{50}$-Analysen angesetzt, um den Virustiter zu überprüfen, und zum anderen wurden die Proben mit RLT-Lysepuffer (aus dem RNeasy Mini Kit der Firma Qiagen) für die RNA-Isolation versetzt und bei $-80^{\circ} \mathrm{C}$ gelagert. 


\subsubsection{Präparation und Nachweis von Nukleinsäuren}

\subsubsection{RNA Isolation}

Zur Isolation der gesamt-RNA aus pDCs sowie aus deren Zellkulturüberstände wurde das RNeasy Mini Kit der Firma Qiagen GmbH (Hilden, Deutschland) verwendet. Diese Methode basiert auf der selektiven Bindung der RNA an eine Silikagelmembran. Dazu wurden die Zellen bzw. Zellkulturüberstände mit RLT-Puffer versetzt und die Zellen zusätzlich mittels des QIAshredder (Fa. Qiagen $\mathrm{GmbH}$, Hilden, Deutschland) zur Homogenisierung und Trennung der Zellreste von der RNA behandelt. Anschließend wurden die Proben mit Ethanol versetzt. Das Ethanol trägt dazu bei, dass zwischen der RNA und den OH-Atomen des Silikats der Silikagelmembran Wasserstoffbrückenbindungen ausgebildet werden, sodass die RNA selektiv an die Silikagelmembran in den Säulen bindet. Ein darauf folgender Waschschritt entfernt die nicht-gebundenen Bestandteile von der Silikagelmembran der Säule. Anschließend erfolgt eine Behandlung mit DNase I, bei der noch vorhandene genomische DNA in den Proben abgebaut wird. Nach der DNase-Behandlung erfolgen mehrere Zentrifugationsschritte und Waschschritte mit Waschpufferlösungen, bei denen Salze, Proteine und andere zelluläre Bestandteile, die noch in der Probe vorhanden sein können, von der Silikagelmembran entfernt werden. Die RNA-Moleküle können nach der Waschprozedur mit RNase-freiem Wasser von der Silikagelmembran eluiert werden. Damit der Abbau der RNA während der Extraktionsprozedur verhindert wird, müssen die Arbeiten an einem speziell gereinigten RNase-freiem Arbeitsplatz stattfinden. Bei den benutzten Gerätschaften handelte es sich um steriles RNase- und DNase-freies Einmalmaterial. Die Lagerung der gereinigten RNA erfolgte bei $-80^{\circ} \mathrm{C}$.

\section{Material:}

- Zellen oder Überstände aus der Zellkultur (pDCs und pDCs mit IFNAR-Antikörper behandelt (s. 2.2.9 Neutralisation des Interferonrezeptors (IFNAR)))

- $\quad$ RNeasy Mini Kit (Qiagen GmbH, Hilden, Deutschland)

- Ethanol (reinst) (Carl-Roth GmbH \& Co KG, Karlsruhe, Deutschland) 
Protokoll:

Um die RNA zunächst aus den Zellen zu extrahieren, wurden 1 x $10^{5}$ Zellen mittels RLTPuffer lysiert und anschließend mit dem QIAshredder der Firma Qiagen GmbH nach dem Protokoll des Herstellers homogenisiert. Als Ausgangsvolumen der Zellkulturüberstände wurden jeweils $700 \mu$ l eingesetzt. Die RNA Extraktion erfolgte nach dem Protokoll des Herstellers für das Mini Kit der Firma Qiagen GmbH. Die auf der Silikagelmembran gebundene RNA wurde nach der Waschprozedur mit $50 \mu 1$ RNase-freiem Wasser eluiert und direkt bei $-80{ }^{\circ} \mathrm{C}$ gelagert.

\subsubsection{DNA Ausschluß / RNA Aufreinigung}

Nach der RNA-Isolation ist die isolierte RNA (s. 2.3.1 RNA-Isolation) meistens noch mit einem großen Anteil an DNA kontaminiert. Um aus den RNA-Proben diese Verunreinigung durch die DNA zu beseitigen, wurde das Ambion Turbo DNA-free Kit der Firma AB Applied Biosystems (Carlsbad, CA, USA) benutzt. Das Prinzip dieser Aufreinigungsmethode liegt darin, dass die DNA in den RNA-Proben durch die Behandlung mit einer speziellen DNase depolymerisiert wird. Die so genannte TURBO DNase, die bei der Prozedur des Ambion Turbo DNA-free Kit (AB Applied Biosystems, Carlsbad, CA, USA) zum Einsatz kommt, hat eine bis zu 50-fach größere Aktivität als die konventionelle DNase I. Anschließend wird die DNase und die divalenten Kationen aus den Proben entfernt, sodass die RNA-Proben frei von der DNA Kontamination und anderen Störfaktoren sein sollte. Die Reinheit der RNA-Proben wurde anschließend mittels einer GAPDH-RT-PCR kontrolliert (s. Kapitel 2.2.11.6).

\section{Material:}

- $\quad$ RNA-Proben (s. 2.3.1 RNA-Isolation)

- Ambion Turbo DNA-free Kit (AB Applied Biosystems, Carlsbad, CA, USA)

- Thermomixer compact (Eppendorf AG, Hamburg, Deutschland)

\section{Protokoll:}

Die RNA-Aufreinigung mittels des Ambion Turbo DNA-free Kit erfolgte ohne weitere Modifikationen nach den Angaben des Herstellers (AB Applied Biosystems, Carlsbad, CA, USA). Die aufgereinigten RNA-Proben wurden bei $-80^{\circ} \mathrm{C}$ gelagert. 


\subsubsection{Quantifizierung von RNA mittels Quant-iT RiboGreen RNA-Assay}

Um den Erfolg der durchgeführten RNA-Isolation (s. 2.3.1 RNA-Isolation) zu kontrollieren und die isolierte RNA zu quantifizieren, wurden die Konzentrationen der RNA-Proben mittels des Quant-iT RiboGreen RNA Reagent und Kit der Firma Invitrogen GmbH (Darmstadt, Deutschland) quantifiziert. Das Prinzip dieser Quantifizierung basiert auf einem Detektionsreagenz (RiboGreen RNA quantitation reagent), das an Ribonukleinsäuren bindet, dessen Absorption bei einer Wellenlänge von $530 \mathrm{~nm}$ gemessen werden kann. Der Vorteil dieser Prozedur im Vergleich zu einer Quantifizierung der RNA durch die Messung der RNA-Absorption bei einer Wellenlänge von $260 \mathrm{~nm}$ liegt darin, dass eine Beeinflussung der Absorption bei einer Wellenlänge von $530 \mathrm{~nm}$ durch z. B. Proteine oder freie Einzelnukleotide vermieden wird.

\section{$\underline{\text { Material: }}$}

- $\quad$ RNA-Proben (s. 2.3.1 RNA-Isolation)

- Quant-iT RiboGreen RNA Reagent und Kit (Invitrogen GmbH, Darmstadt, Deutschland)

- FLUOstar OPTIMA (BMG LABTECH GmbH, Offenburg, Deutschland)

Protokoll:

Die RNA-Quantifizierung mittels des Quant-iT RiboGreen RNA Reagent und Kit erfolgte ohne weitere Modifikationen nach den Angaben des Herstellers (Invitrogen $\mathrm{GmbH}$, Darmstadt, Deutschland). Für die Bestimmung der Standardkurve wurde der High-Range Standard parallel angesetzt. Die Absorption der Proben wurde mit dem FLUOstar OPTIMA (BMG LABTECH GmbH, Offenburg, Deutschland) bei einer Wellenlänge von $530 \mathrm{~nm}$ gemessen und die Konzentrationen anhand der Standardkurve berechnet.

\subsubsection{Die Polymerase-Ketten-Reaktion (PCR)}

Die Polymerase-Ketten-Reaktion (PCR) ist eine Methode zur Amplifikation von spezifischen DNA-Fragmenten. Dabei erfolgt die Vervielfältigung der DNA-Stränge mittels Polymerasen. 
Das Prinzip der PCR beruht auf einer periodisch sich wiederholenden Abfolge von drei Schritten, durch die spezifische DNA-Fragmente mittels Polymerasen amplifiziert werden. In einem ersten Schritt wird die doppelsträngige DNA denaturiert, sodass sie einzelsträngig vorliegt. Dieser Denaturierungsschritt findet bei Temperaturen um die $95{ }^{\circ} \mathrm{C}$ statt. In einem darauf folgenden Schritt lagern sich die spezifischen Oligonukleotidmoleküle (Primer) am 5'- und 3'-Ende des zu amplifizierenden DNA Fragments an. Die Temperatur, die bei dem so genannten Annealing der Primer benötigt wird, hängt von der Schmelztemperatur des jeweiligen eingesetzten Primerpaares ab. In einem weiteren Schritt werden die Primerpaare durch eine DNA-abhängige Polymerase verlängert, in dem die Polymerase freie Desoxynukleosid-Triphosphate komplementär zur Matrize einbaut. Die Temperatur, die für die so genannte Elongation der Primerpaare benötigt wird, ist von der DNA-Polymerase abhängig und die benötigte Zeit von der Länge der zu amplifizierenden Matrize sowie der Aktivität der Polymerase. Nach der Elongation erfolgt ein weiterer Denaturierungs- und Elongationsschritt, bei dem zum einen die neu gebildeten doppelsträngigen DNA-Fragmente von den DNA-Matrizen getrennt werden und durch Anlagerung der Primerpaare nun selbst als DNA-Matrize fungieren. Auf das Annealing folgt wieder ein Elongationsschritt. Wie oft sich diese Abfolge bzw. diese Zyklen wiederholen ist davon abhängig, wie viel Kopien benötigt werden. In der Regel werden 25-30, maximal 50 Zyklen durchgeführt. Nach den Zyklen erfolgt ein finaler Extensionsschritt, bei dem unvollständig verlängerte Produkte vervollständigt werden.

Bei der Real-Time-PCR kann der Amplifikationsstatus direkt abgelesen werden. Dabei bindet während des Annealing-Schritts neben den beiden sequenzspezifischen Primern auch eine sequenzspezifische Fluoreszenzsonde an die Zielsequenz der DNA, die als Reporter fungiert. Bei dieser Fluoreszenzsonde handelt es sich um ein komplementäres Oligonukleotid, das am 5'-Ende mit einen Fluoreszenzfarbstoff markiert ist. Am 3'-Ende der Fluoreszenzsonde ist ein Quencher angefügt, der die Fluoreszenz des Farbstoffs unterdrückt. Durch die Synthese des neuen DNA-Stranges durch die Taq-Polymerase wird durch die 5'-3'-Exonukleaseaktivität der Polymerase die Fluoreszenzsonde in kleine Fragmente geschnitten, sodass der Fluoreszenzfarbstoff vom Quencher getrennt wird und die Reporterfluoreszenz freigesetzt werden kann. Diese Fluoreszenzemission ist durch den Real-Time-PCR-Cycler detektierbar. Dabei ist die Intensität des Fluoreszenzsignals 
proportional $\mathrm{zu}$ der Gesamtmenge an amplifizierter DNA. Die Messung der Fluoreszenzemissionen erfolgt einmal pro Zyklus während des Annealings. Bei den hier verwendeten Sonden handelte es sich um Oligonukleotide, die am 5'-Ende mit dem Fluoreszenzfarbszoff Fluorescein (FAM) und am 3'-Ende mit dem Quencher Rhodamin (TAMRA) markiert waren.

\subsubsection{Die Reverse Transkriptase-PCR (RT-PCR)}

Eine Methode für die Vervielfältigung von mRNA und viraler RNA ist die Reverse Transkriptase PCR (RT-PCR). Im Prinzip sind bei der RT-PCR zwei Methoden vereinigt, da durch eine initial ablaufenden reverse Transkription die RNA in DNA umgeschrieben wird und in einem zweiten Schritt die umgeschriebene DNA mittels der PCR amplifiziert wird.

Dabei wird in einem ersten Reaktionsschritt die RNA oder mRNA durch die reverse Transkriptase in komplementäre DNA (engl.: complementary DNA (cDNA)) umgeschrieben. Nach der Reverse-Transkriptase-Reaktion erfolgt in einem weiteren Schritt eine PCR, bei der die durch die reverse Transkriptase hergestellte cDNA mittels DNA-Primer amplifiziert wird. In einem nächsten Schritt werden spezielle Teile der durch den RT-Schritt hergestellten cDNA durch die PCR mit sequenzspezifischen Primern vervielfältigt. In dieser Arbeit wurden die RT-PCRs als Ein-Schritt-PCR durchgeführt, sodass beide Reaktionsschritte mit einem Puffer in einem Reaktionsgefäß nacheinander vollzogen wurden. Für die RT-PCR wurde das LightCycler 480 RNA Master Hydrolysis Probes Kit der Firma Roche Diagnostics verwendet.

\subsubsection{Die GAPDH-RT-PCR}

Um zu kontrollieren, dass die RNA-Proben nach der Aufarbeitung mit dem Turbo DNAfree Kit (AB Applied Biosystems, Carlsbad, CA, USA) (s. Kapitel 2.2.11.2) frei von DNA Kontaminationen waren, wurden eine RT-PCR mit Primern durchgeführt, die spezifisch für ein so genanntes housekeeping Gen als Referenzgen waren. Bei den Referenz-Genen handelt es sich um Gene, die konstitutiv und unabhängig von dem Zelltyp, dem Zellstadium und anderen äußeren Einflüssen exprimiert werden und für Enzyme kodieren, die eine wichtige unabkömmliche Funktion für die Zelle haben. Aus diesem Grund werden diese Gene auch als so genannte housekeeping-Gene bezeichnet. Das Enzym Glycerinaldehyd-3-phosphat-Dehydrogenase (GAPDH) wird durch ein 
solches housekeeping-Gen kodiert. Die GAPDH ist für den Stoffwechsel der Lebewesen unverzichtbar und wird daher relativ unabhängig von dem Zellstadium oder äußeren Einflüssen exprimiert. Daher ist die GAPDH-RT-PCR auch eine geeignete Kontrolle, um RNA-Proben auf DNA-Kontaminationen zu untersuchen. Darüber hinaus wird aufgrund dieser Eigenschaften die Expression des GAPDH-Gens häufig auch als Referenz für die relative Quantifizierung von nicht-konstitutiv exprimierten RNAs verwendet.

Material:

- GAPDH-Primer (huGAPDH_for; huGAPDH_rev) (Sigma-Aldrich Chemie GmbH, Steinheim, Deutschland), (s. 2.1.6 Oligonukleotidprimer und Sonden)

- TBEV-Sonde (TBE P4) (TIB MolBiol Syntheselabor GmbH, Berlin, Deutschland) (s. 2.1.6 Oligonukleotidprimer und Sonden)

- LightCycler 2.0 (Roche Diagnostics Deutschland GmbH, Mannheim, Deutschland)

- LC Carousel Centrifuge 2.0 (Roche Diagnostics Deutschland GmbH, Mannheim, Deutschland)

- LightCycler Capillaries (Roche Diagnostics Deutschland GmbH, Mannheim, Deutschland)

- LightCycler 480 RNA Master Hydrolysis Probes (Roche Diagnostics Deutschland GmbH, Mannheim, Deutschland)

\section{Protokoll:}

Der Ansatz für die Real Time-RT-PCR mittels dem LightCycler 480 RNA Master Hydrolysis Probes Kit der Firma Roche Diagnostics wurde nach den Angaben des Herstellers zusammengestellt. Als Primer für die Amplifikation der durch den RT-Schritt entstandenen cDNA wurden die in den Tabellen angegebenen Primer und Sonden verwendet (s. 2.1.6 Oligonukleotidprimer und Sonden). Das Protokoll für den Reaktionsansatz der GAPDH-RT-PCR ist in der Tabelle 2.9 dargestellt. Die Komponenten wurden an einem sterilen Platz als Mastermix zusammen pipettiert, um RNA und DNA Kontaminationen zu vermeiden. Der Mastermix wurde in Volumina von $19 \mu 1$ in spezielle Kapillare für den Lightcycler vorgelegt (LightCycler Capillaries der Firma Roche Diagnostics). Danach erfolgte an einem gesonderten sterilen DNA- und 
RNA-freien Ort die Zugabe der Proben. Weiterhin wurde eine Probe, die statt cDNA nur Wasser enthielt, als Negativkontrolle der PCR und Indikator für Kontaminationen mitgeführt.

Tabelle 2.9: Reaktionsansatz für die GAPDH RT-PCR mittels dem LightCycler 480 RNA Master Hydrolysis Probes Kit.

\begin{tabular}{|l|c|c||}
\hline \hline Reagenzien & Volumen $(\mathbf{2 0} \boldsymbol{\mu l}$ Reaktionsansatz) & Endkonzentration \\
\hline LC-RNA-Master $(2.7 \mathrm{x})$ & $7,5 \mu 1$ & $1 \mathrm{x}$ \\
\hline Activator & $1,3 \mu 1$ & - \\
\hline Wasser & $6,8 \mu 1$ & - \\
\hline Enhancer $(20 \mathrm{x})$ & $1,0 \mu \mathrm{l}$ & $1 \mathrm{x}$ \\
\hline huGAPDH_for $(10 \mu \mathrm{M})$ & $1,0 \mu 1$ & $500 \mathrm{nM}$ \\
\hline huGAPDH_rev $(10 \mu \mathrm{M})$ & $1,0 \mu 1$ & $500 \mathrm{nM}$ \\
\hline huGAPDH_probe $(10 \mu \mathrm{M})$ & $0,4 \mu 1$ & $200 \mathrm{nM}$ \\
\hline \hline Probe & $1,0 \mu 1$ & - \\
\hline
\end{tabular}

Als weitere Kontrolle wurden in zwei Ansätzen DNA-Proben mitgeführt, bei denen es sich um Gesamt-DNA Proben handelte, die aus pDCs einer Mock-Kontrolle isoliert (s. Kapitel 2.2.11.1) und keiner weiteren Aufreinigung unterzogen wurden. Die befüllten Kapillaren wurden in einer speziellen Zentrifuge (LC Carousel Centrifuge 2.0 der Firma Roche Diagnostics) abzentrifugiert und anschließend in das PCR-Gerät, dem LightCycler 2.0 der Firma Roche Diagnostics, eingelegt. Das Programm der RT-PCR, mit dem der LightCycler 2.0 programmiert wurde ist in der Tabelle 2.10 dargestellt.

Tabelle 2.10: Programm für die GAPDH-RT-PCR.

\begin{tabular}{||l|c|c|c||}
\hline Programm & Temperatur & Zeit & Zyklus / Zyklen \\
\hline Reverse Transkriptase-Schritt & $63^{\circ} \mathrm{C}$ & $5 \mathrm{~min}$ & $(1)$ \\
\hline Aktivierung & $95^{\circ} \mathrm{C}$ & $5 \mathrm{~min}$ & $(1)$ \\
\hline \multirow{2}{*}{ PCR } & $95^{\circ} \mathrm{C}$ & $15 \mathrm{~s}$ & \multirow{2}{*}{45 Zyklen } \\
\cline { 2 - 4 } & $60^{\circ} \mathrm{C}$ & $1 \mathrm{~min}$ & $(1)$ \\
\hline Kühlung & $40^{\circ} \mathrm{C}$ & $30 \mathrm{~s}$ & \\
\hline
\end{tabular}


Die Bedienung des LightCycler 2.0 der Firma Roche Diagnostics und die Auswertung der FSMEV-RT-PCR wurde mit Hilfe des Programms LightCycler Probe Design Software 2.0 der Firma Roche Diagnostics durchgeführt. Um die Ergebnisse der GAPDHRT-PCR weiterhin zu kontrollieren und die Reinheit zu dokumentieren, wurde mit den PCR-Produkten eine Agarose-Gelelektrophorese durchgeführt (s. Kapitel 2.2.11.8).

\subsubsection{Die FSME-Virus-RT-PCR}

Um die RNA des FSME-Virus in den pDCs und im Zellkulturüberstand der pDCs nachzuweisen und darüber hinaus zu quantifizieren, wurde eine FSME-Virus RT-PCR mit diesen RNA-Proben durchgeführt. Dazu wurden für das FSME-Virus spezifische Primer für die Amplifikation der durch den RT-Schritt bei der RT-PCR hergestellten cDNA eingesetzt. Um eine Quantifizierung der viralen RNA vornehmen zu können, wurde ein FSME-Virus-RNA-Standard mitgeführt. Bei dem FSME-Virus-Standard handelte es sich um RNA-Moleküle des FSME-Virus, die mit einer definierten Molekülzahl / ml eingesetzt wurde. Insgesamt wurden 7 Verdünnungen des FSMEVRNA-Standards mitgeführt, die eine Konzentration von 1 x $10^{7}$ Molekülen / $\mathrm{ml}$ in Verdünnungsschritten um den Faktor 10 bis 1 x $10^{1}$ Molekülen / $\mathrm{ml}$ enthielten. Der FSME-Virus-RNA-Standard wurde bei jeder FSMEV-RT-PCR als Probe mitgeführt. Der in dieser Arbeit verwendete FSME-Virus-RNA-Standard wurde von der Frau Andrea Koch aus der Arbeitsgruppe des Herrn Dr. Manfred Weidmann hergestellt und u. a. für diese Arbeit zur Verfügung gestellt. Um darüber hinaus zu gewährleisten, dass gleiches Ausgangsmaterial an RNA aus den Zellen und Zellkulturüberständen eingesetzt wurde, um so die unterschiedlichen Mengen an Virus-RNA in den Überständen bestimmen zu können, wurde bei dem Material au den Zellen je 1 ng RNA eingesetzt und bei dem Material aus den Überständen das gleiche Volumen ( $1 \mu \mathrm{l})$. Für die Auswertung wurde mit Hilfe des Programms LightCycler Probe Design Software 2.0 der Firma Roche Diagnostics für jede Probe ein so genannter Cp-Wert (engl.: crossing point $(\mathrm{Cp})$ ) ermittelt. Dieser Cp-Wert gibt den Zyklus an, bei dem die gemessene Fluoreszenz der Probe die Hintergrund-Fluoreszenz signifikant übersteigt und ein konstantes Fluoreszenzniveau erreicht. Bei einer optimal verlaufenden PCR beträgt die Effizienz $100 \%$ und in jedem Zyklus verdoppelt sich die Menge an DNA und somit auch das Fluoreszenzsignal, da die Fluoreszenz proportional zur DNA-Menge ist. Dabei entspricht eine Einheit des CP-Wertes der doppelten Menge an eingesetzter Startmenge an RNA. 
Ein niedriger $\mathrm{Cp}$-Wert der FSMEV-RT-PCR geht einher mit einer großen Menge an viraler RNA, die in der Probe enthalten war. Bezogen auf die pDCs, aus denen die RNA als Ausgangsmaterial isoliert wurde, ist eine große Menge an gemessener RNA gleichbedeutend mit einer großen Menge an viraler RNA, die in den Zellen oder in den Zellkulturüberständen enthalten waren. Anhand des FSME-Virus-Standards konnte durch die Bildung des Verhältnisses von $\mathrm{Cp}$-Wert zur enthaltenen viralen Kopienzahl eine Standardkurve erstellt werden, mit der die Kopienzahl / $\mathrm{ml}$ in den einzelnen RNA-Proben bestimmt werden konnte.

Material:

- FSME-Virus-Primer (TBE FP4; TBE RP4) (TIB MolBiol Syntheselabor GmbH, Berlin, Deutschland) (s. 2.1.6 Oligonukleotidprimer und Sonden)

- FSMEV-Sonde (TBE P4) (TIB MolBiol Syntheselabor GmbH, Berlin, Deutschland) (s. 2.1.6 Oligonukleotidprimer und Sonden)

- FSME-Virus-RNA-Standard mit Konzentrationen von 1 x $10^{7}$ Molekülen / $\mathrm{ml}$ in Verdünnungsschritten um den Faktor 10 bis 1 x $10^{3}$ Molekülen / $\mathrm{ml}$

- LightCycler 2.0 (Roche Diagnostics Deutschland GmbH, Mannheim, Deutschland)

- LC Carousel Centrifuge 2.0 (Roche Diagnostics Deutschland GmbH, Mannheim, Deutschland)

- LightCycler Capillaries (Roche Diagnostics Deutschland GmbH, Mannheim, Deutschland)

- LightCycler 480 RNA Master Hydrolysis Probes (Roche Diagnostics Deutschland GmbH, Mannheim, Deutschland)

\section{Protokoll:}

Der Ansatz für die Real Time-RT-PCR mittels dem LightCycler 480 RNA Master Hydrolysis Probes Kit der Firma Roche Diagnostics wurde nach den Angaben des Herstellers zusammengestellt. Als Primer für die Amplifikation der durch den RT-Schritt entstandenen cDNA wurden die in den Tabellen angegebenen Primer und Sonden verwendet (s. 2.1.6 Oligonukleotidprimer und Sonden). Das Protokoll für den Reaktionsansatz der FSME-Virus-RT-PCR ist in der Tabelle 2.11 dargestellt. 
Die Komponenten wurden an einem sterilen Platz als Mastermix zusammen pipettiert, um RNA und DNA Kontaminationen zu vermeiden. Der Mastermix wurde in Volumina von $19 \mu 1$ in spezielle Kapillare für den Lightcycler vorgelegt (LightCycler Capillaries der Firma Roche Diagnostics). Danach erfolgte an einem gesonderten sterilen DNA- und RNA-freien Ort die Zugabe der Proben. Weiterhin wurde eine Probe, die statt cDNA nur Wasser enthielt, als Negativkontrolle der PCR und Indikator für Kontaminationen mitgeführt.

Außerdem wurden für die Quantifizierung der FSME-Virus-RNA Proben der FSMEVirus-Standardreihe mitgeführt, die in Verdünnungstufen mit dem Faktor 10 Konzentration von $1 \times 10^{3}$ bis $1 \times 10^{7}$ Kopien / ml enthielten. Die befüllten Kapillaren wurden in einer speziellen Zentrifuge (LC Carousel Centrifuge 2.0 der Firma Roche Diagnostics) abzentrifugiert und anschließend in das PCR-Gerät, dem LightCycler 2.0 der Firma Roche Diagnostics, eingelegt.

Tabelle 2.11: Reaktionsansatz für die FSMEV-RT-PCR mittels dem LightCycler 480 RNA Master Hydrolysis Probes Kit.

\begin{tabular}{||l|c|c||}
\hline \hline Reagenzien & Volumen $(\mathbf{2 0} \boldsymbol{\mu l}$ Reaktionsansatz) & Endkonzentration \\
\hline LC-RNA-Master $(2.7 \mathrm{x})$ & $7,5 \mu \mathrm{l}$ & $1 \mathrm{x}$ \\
\hline Activator & $1,3 \mu \mathrm{l}$ & - \\
\hline Wasser & $6,8 \mu \mathrm{l}$ & - \\
\hline Enhancer $(20 \mathrm{x})$ & $1,0 \mu \mathrm{x}$ \\
\hline TBE FP4 $(10 \mu \mathrm{M})$ & $1,0 \mu \mathrm{l}$ & $500 \mathrm{nM}$ \\
\hline TBE RP4 $(10 \mu \mathrm{M})$ & $1,0 \mu 1$ & $500 \mathrm{nM}$ \\
\hline TBE P4 $(10 \mu \mathrm{M})$ & $0,4 \mu \mathrm{l}$ & $200 \mathrm{nM}$ \\
\hline \hline Probe/Standard & $1,0 \mu 1$ & - \\
\hline
\end{tabular}

Das Programm der RT-PCR, mit dem der LightCycler 2.0 programmiert wurde ist in der Tabelle 2.13 dargestellt. Die Bedienung des LightCycler 2.0 der Firma Roche Diagnostics und die Erstellung der Standardkurve sowie die Auswertung der FSMEV-RT-PCR wurde mit Hilfe des Programms LightCycler Probe Design Software 2.0 der Firma Roche Diagnostics durchgeführt. 
Tabelle 2.12: Programm für die FSMEV-RT-PCR.

\begin{tabular}{||l|c|c|c||}
\hline \hline Programm & Temperatur & Zeit & Zyklus / Zyklen \\
\hline \multicolumn{3}{||}{} \\
\hline Reverse Transkriptase-Schritt & $63^{\circ} \mathrm{C}$ & $5 \mathrm{~min}$ & $(1)$ \\
\hline Aktivierung & $95^{\circ} \mathrm{C}$ & $5 \mathrm{~min}$ & $(1)$ \\
\hline \multirow{2}{*}{ PCR } & $95^{\circ} \mathrm{C}$ & $15 \mathrm{~s}$ & \multirow{2}{*}{45 Zyklen } \\
\cline { 2 - 4 } & $60^{\circ} \mathrm{C}$ & $1 \mathrm{~min}$ & $(1)$ \\
\hline Kühlung & $40^{\circ} \mathrm{C}$ & $30 \mathrm{~s}$ & \multirow{2}{*}{}
\end{tabular}

\subsubsection{Die Agarose-Gelelektrophorese}

Um zu kontrollieren, ob die PCR erfolgreich war und die gewünschten bzw. ungewünschten DNA-Fragmente entstanden sind, wurden die PCR-Produkte mittels der Gelelektrophorese der Größe nach aufgetrennt und analysiert. Mittels der Gelelektrophorese können DNA-Moleküle gemäß ihrer Größe aufgetrennt werden. Dabei wird die DNA in ein Agarosegel gefüllt und einem elektrischen Feld ausgesetzt. Da das Grundgerüst der DNA negativ geladen ist, durchwandert die DNA aufgrund des elektrischen Feldes das Agarosegel in Richtung der positiven Ladung, wobei kleine DNA Fragmente das Agarosegel schneller durchdringen können als große DNA Fragmente. Dabei spielt auch die Porengröße der Agarose eine wichtige Rolle, da durch sie die Beweglichkeit der Nukleinsäuren beeinflusst wird. Je höher der Anteil der Agarose im Gel, desto langsamer durchdringt die Nukleinsäure das Gel. Durch die Färbung mit Ethidiumbromid, das interkalierend auf die DNA wirkt, kann die DNA in dem Agarosegel durch die Bestrahlung von UV-Licht mit einer Wellenlänge von $254 \mathrm{~nm}$ sichtbar gemacht werden. Dabei regt das UV-Licht das Ethidiumbromid, das sich an der DNA angelagert hat, an und bringt es zum fluoreszieren, sodass man die Bande der DNA deutlich im Gel erkennen kann.

Für die Abschätzung der Längen der Nukleinsäuren, werden bei den Läufen meistens Marker mitgeführt, die DNA-Fragmente mit definierten Längen haben. 
Material:

- 6 x Ladepuffer (6 x DNA Loading Dye der Firma Fermentas, St. Leon-Rot, Deutschland)

- Marker (GeneRuler Low Range DNA Ladder der Firma Fermentas, St. Leon-Rot, Deutschland)

- $\quad$ TAE-Puffer (s. 2.1.4 Puffer, Medien und Lösungen)

- Gibco BRL Horizontal Gel Electrophoresis Apparatus (Life Technologies Corporation, Carlsbad, California, USA)

- Electrophoresis supply EPS301 (Amersham, GE Healthcare Bio Sciences AB, Uppsala, Schweden)

- ChemiDoc XRS (Bio-Rad Laboratories GmbH, München, Deutschland)

- Quantity One (Bio-Rad Laboratories GmbH, München, Deutschland)

\section{Protokoll:}

Für die Gelelektrophorese wurden 2\%ige Agarosegele hergestellt. Dazu wurden $2 \%$ Agar in TAE-Puffer in einer Mikrowelle erwärmt, bis keine Polymere bzw. optische Schlieren in der Lösung zu erkennen waren. Daraufhin wurde das Gel auf mit der Gibco BRL Horizontal Gel Electrophoresis Apparatus Apperatur der Firma Life Technologies Corporation gegossen. Nachdem das Gel polymerisiert und abgekühlt war, wurde die Apparatur mit TAE-Puffer aufgefüllt. Von den DNA-Proben wurden jeweils $10 \mu \mathrm{lmit}$ $2 \mu 1$ des 6 x Ladepuffers der Firma Fermentas versetzt und in die Taschen des Gels aufgetragen. Zur Abschätzung der Längen wurden zwei Geltaschen mit einem Marker, dem GeneRuler Low Range DNA Ladder der Firma Fermentas, der DNA-Fragmenten bekannter Größe enthielt, aufgetragen. Bei dem Marker handelte es sich um den „GeneRuler 100 bp DNA Ladder“ der Firma Fermentas. Der Lauf des Gels erfolgte bei 100 V, bis der DNA-Farbmarker etwa im unteren Drittel des Gels zu sehen war. Danach wurden die Gele unter UV-Licht mit einer Wellenlänge von $254 \mathrm{~nm}$ mittels eines ChemiDoc XRS der Firma Bio-Rad Laboratories betrachtet und dokumentiert. Die Bedienung und Aufnahme des Gels erfolgte über die Quantity One Software der Firma Bio-Rad Laboratories. 


\section{Ergebnisse}

In dieser Arbeit wurde die Interaktion des FSME-Virus mit plasmazytoiden- und konventionellen DCs sowie T-Zellen als wichtige Komponenten der angeborenen- bzw. adaptiven Immunantwort auf unterschiedlichen Ebenen untersucht. In der ersten Versuchsreihe wurden die Interaktionen des FSME-Virus mit primären konventionellenund plasmazytoiden DCs, die einen wichtigen Teil des adaptiven Immunsystems sowie die Schnittstelle zwischen der angeborenen und erworbenen Immunität darstellen, untersucht. Dazu wurden beide DC-Subtypen einzeln aus humanen Buffy-Coats isoliert und mit dem FSME-Virus infiziert. Die Immunantwort der DC-Subtypen wurde über die Zeit von drei Tagen zum einen durch die Analyse der Expression kostimulatorischer und antigenpräsentierender Moleküle sowie von Aktivierungs-, Reifungs-, Adhäsions- und Apoptose Markern mittels der Durchflußzytometrie und zum anderen durch die Analyse der Produktion von IFN- $\alpha$ und pro- bzw. antiinflammatorischen Zytokinen untersucht. Weiterhin wurde untersucht, ob in den einzelnen DC-Subtypen die Replikation von FSME-Virus stattfindet. Die Ergebnisse der ersten Versuchsreihe sind in dem Kapitel 3.1 dargestellt.

In der zweiten Versuchsreihe wurden die Interaktionen des FSME-Virus mit den T-Zellen als wichtige Komponente der adaptiven Immunantwort untersucht. Dazu wurde die Expression verschiedener Aktivierungsmarker, sowie die Produktion von Zytokinmustern nach Infektion von T-Zellen mit FSME-Virus analysiert. Zusätzlich wurde auch die Fähigkeit des FSME-Virus in den T-Zellen zu replizieren getestet. Die Ergebnisse zur Interaktion des FSME-Virus mit den T-Zellen sind im Kapitel 3.2 aufgeführt.

In einer dritten Versuchsreihe wurden die pDCs als Komponente der angeborenen Immunantwort und die T-Zellen als Teil der adaptive Immunantwort kokultiviert und diverse Interaktionen mit dem FSME-Virus von der Expression sämtlicher Oberflächenmoleküle bis hin zur Zytokinproduktion untersucht. Die Ergebnisse der dritten Versuchsreihe sind in Kapitel 3.3 dargestellt. 


\subsection{Die Immunantwort der DCs auf das FSME-Virus}

\subsubsection{Isolation von DC-Subtypen}

Die DCs wurden aus humanen Buffy-Coats wie unter 2.2.1.5.1 (mDCs) und 2.2.1.5.2. (pDCs) beschrieben isoliert und anschließend mittels der Durchflußzytometrie (s. Kapitel 2.2.3) auf ihre Reinheit überprüft. Eine möglichst hohe Reinheit der isolierten Zellen ist von großer Bedeutung, da eine Kontamination mit anderen Zellen die Ergebnisse beeinflussen könnten. Die Reinheitskontrolle erfolgte mittels spezifischer Fluorchrom-gekoppelter Antikörper, mit denen die jeweiligen DC-Subtypen markiert wurden, und einer anschließenden durchgeführten durchflußzytometrischen Analyse (s. Kapitel 2.2.3). Die Ergebnisse der Reinheitskontrollen der DC-Subtypen sind in den Kapiteln 3.1.1.1 (mDCs) und 3.1.1.2 (pDCs) dargestellt.

\subsubsection{Reinheitsanalyse der mDCs}

Für die Reinheitskontrolle der aus humanen Buffy-Coats isolierten mDCs wurden die Zellen direkt nach der Isolation mit Fluorochrom-gekoppelten Antikörpern gegen spezifische Marker der mDCs sowie gegen spezifische Marker anderer Zelllinien als Negativkontrolle behandelt und mittels der Durchflußzytometrie untersucht. Als spezifische Marker der mDCs wurde die Expression von CD11c und CD1c mittels Fluorochrom-gekoppelter Antikörper nachgewiesen. Dazu wurden die Antikörper CD1c-APC, CD11c-Pe-Cy7 benutzt. Als Negativkontrolle und Indikator einer möglicherweise fehlgeschlagenen Isolation der mDCs wurden die Marker CD14 (FITC) für die Monozyten und Makrophagen sowie CD19 (Pe) für die B-Zellen mittels Fluorochrom-gekoppelter Antikörper untersucht. Die Reinheitsanalyse ist in der Abbildung 3.1 dargestellt. Im Abschnitt A der Abbildung 3.1 sind Dot-Plot-Diagramme der isolierten mDCs abgebildet. Auf der linken Seite unter Punkt A sind die mDCs in einem Dot-Plot-Diagramm dargestellt, bei dem die Stärke der Vorwärtsstreuung (FSC) (Ordinate) gegen die Stärke der Seitwärtsstreuung (SSC) (Abszisse) aufgetragen ist. In dem rechten Diagramm sind die Fluoreszenzintensitäten der spezifischen Antikörper CD11c gegen CD1c als Dot-Plot aufgetragen. Wie der Abbildung entnommen werden kann, ergaben die durchflußzytometrischen Analysen, dass die isolierte mDCZellpopulation eine Reinheit von über $90 \%$ besaß (CD1c und CD11c doppelt-positive Zellen (s. Abbildung 3.1 unter Punkt A, rechts)). 


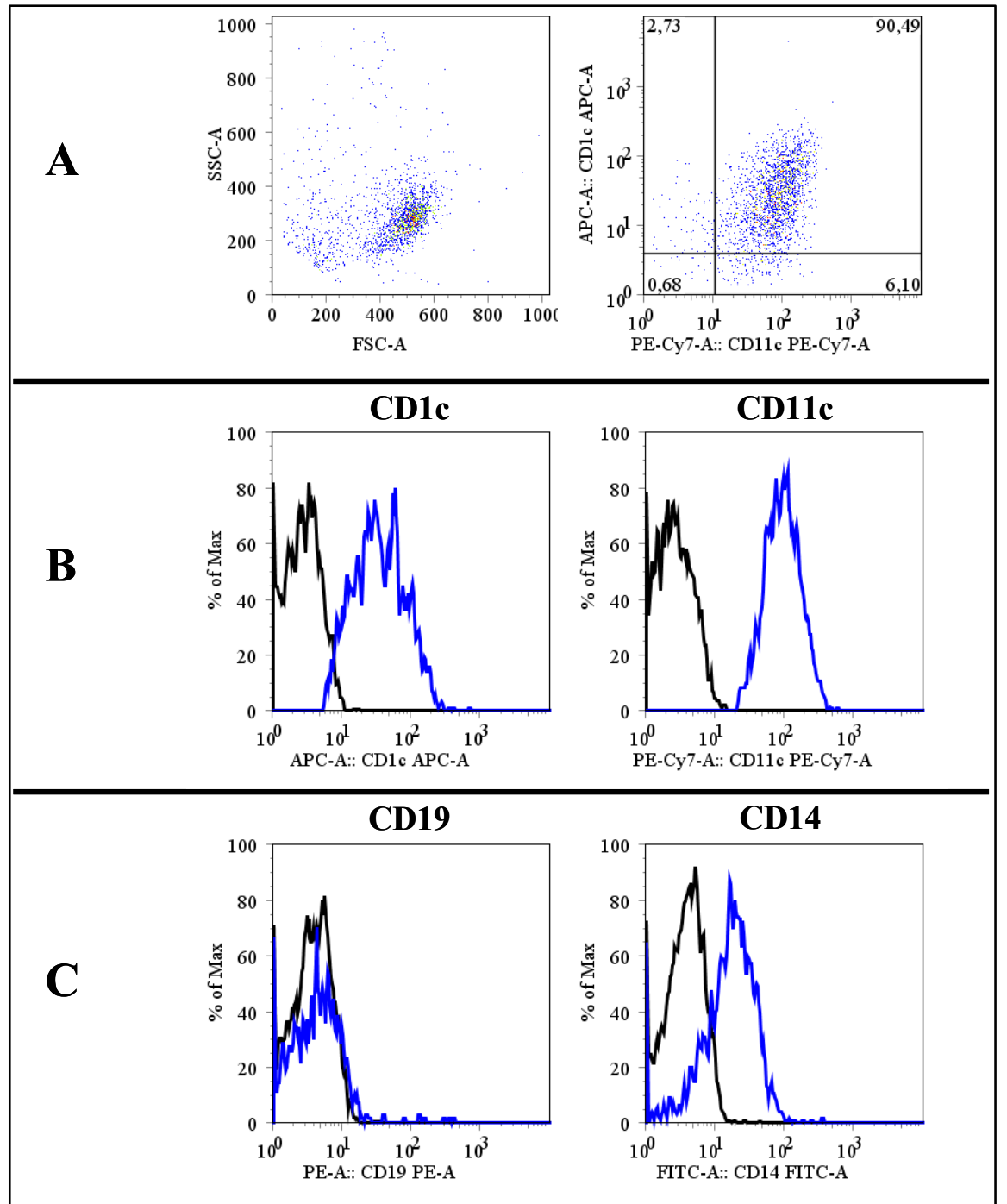

\section{Abbildung 3.1: Reinheitsanalyse der isolierten mDCs.}

Unter Punkt A sind die mDCs als Dot-Plot-Diagramme dargestellt. Die linke Graphik zeigt die mDCs in der FSC (Abszisse)-SSC (Ordinate)-Darstellung und die rechte Graphik die Auftragung der Fluoreszenzen der CD1c- (Abszisse)- zu den CD11c-Antikörpern (Ordinate). Unter Punkt B sind die Histogramme der Fluoreszenzintensität der spezifischen Antikörper CD1c (links) und CD11c (rechts) dargestellt, die Isotypenkontrollen sind als schwarze Linien und die jeweiligen Marker als blaue Linien aufgeführt. Unter Punkt C sind die Histogramme der Fluoreszenzintensität des B-Zell-spezifischen Antikörpers CD19 (links) und des Monozyten- und Makrophagen-spezifischen Antikörpers CD14 (rechts) dargestellt.

In den Histogrammen, die unter den Punkten B und C aufgeführt werden, ist die relative Zellzahl (Ordinate) gegen die Fluoreszenzintesität (Abszisse) aufgetragen. Je stärker das Fluoreszenzsignal ist, desto weiter rechts auf der Abszisse liegt der Scheitelwert in der Graphik und desto mehr wird von diesem Marker, gegen den sich der Fluorochromgekoppelte Antikörper richtet, auf der Zelloberfläche exprimiert. In Abbildung 3.1 unter Punkt B ist die Expression der mDC-spezifischen Marker CD1c (links, blaue Linie) und CD11c (rechts, blaue Linie) im Vergleich zur Isotypenkontrolle (Negativkontrolle) 
(schwarze Linien) dargestellt. Unter Punkt C sind die beiden Negativkontrollen in Form der für die mDCs unspezifischen Marker CD19 (B-Zellen) (links) und CD14 (Makrophagen und Monozyten) rechts) aufgeführt. Aus den Expressionsprofilen lässt sich schließen, dass die gewonnene mDC-Population weitgehend frei von B-Zellen ist, jedoch einen gewissen Anteil an CD14-positiven Zellen (Makrophagen bzw. Monozyten, möglicherweise auch CD14-positive mDC-Vorläuferzellen) enthält.

\subsubsection{Reinheitsanalyse der pDCs}

Wie bei den mDCs wurde auch die Aufreinigung der pDCs aus humanen Buffy-Coats durchflußzytometrisch auf ihre Reinheit kontrolliert. Dazu wurden die isolierten pDCs direkt nach der Aufreinigung auf die Expression der pDC-spezifischen Marker CD123 und CD303 mit Hilfe von Fluorochrom-gekoppelten Antikörpern (PerCP-Cy5-antiCD123 bzw. APC-anti-CD303) untersucht. Als Negativkontrolle und Indikator einer möglicherweise fehlgeschlagenen Isolation der pDCs wurden die isolierten pDCs auf Expression von CD14 (Monozyten und Makrophagen) sowie CD19 (B-Zellen) mittels Fluorochrom-gekoppelter Antikörper (FITC-anti-CD14 bzw. Pe-anti-CD19) untersucht. Die Ergebnisse der Reinheitsanalyse sind in der Abbildung 3.2 dargestellt.

Auf der linken Seite unter Punkt A sind die pDCs in einem Dot-Plot-Diagramm dargestellt, bei dem die Stärke der Vorwärtsstreuung (FSC) (Ordinate) gegen die Stärke der Seitwärtsstreuung (SSC) (Abszisse) aufgetragen ist. In dem rechten Diagramm sind die Fluoreszenzintensitäten der spezifischen Antikörper CD303 gegen CD123 als DotPlot aufgetragen. Wie der Abbildung 3.2 entnommen werden kann, ergaben die durchflußzytometrischen Analysen, dass die isolierte pDC-Zellpopulation eine Reinheit von über $90 \%$ besaß.

In Abbildung 3.2 unter Punkt B ist die Expression der pDC-spezifischen Marker CD123 (links, blaue Linie) und CD303 (rechts, blaue Linie) im Vergleich zur Isotypenkontrolle (Negativkontrolle) (schwarze Linien) dokumentiert. Unter Punkt C sind die beiden Negativkontrollen in Form der für die pDCs unspezifischen Marker CD19 (B-Zellen) (links) und CD14 (Makrophagen und Monozyten) (rechts) dargestellt. Aus den Expressionsprofilen lässt sich schließen, dass die gewonnene pDC-Population weitgehend frei von B-Zellen, Makrophagen und Monozyten ist. 


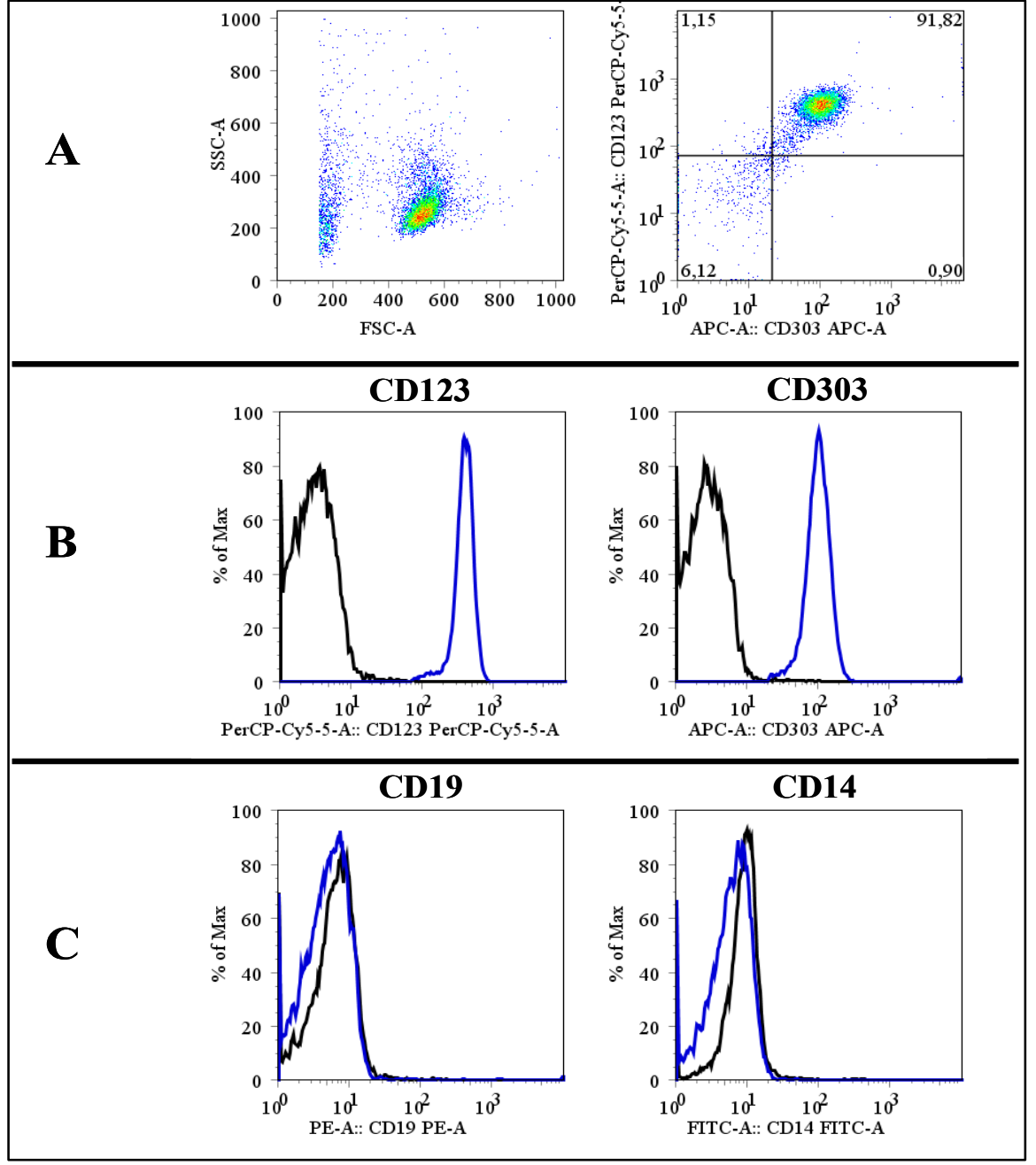

Abbildung 3.2: Reinheitsanalyse der isolierten pDCs.

Unter Punkt A sind die pDCs als Dot-Plot-Diagramme dargestellt. Die linke Graphik zeigt die pDCs in der FSC (Abszisse)-SSC (Ordinate)-Darstellung und die rechte Graphik die Auftragung der Fluoreszenzen der spezifischen Marker CD123 (Abszisse)- zu den CD303 (Ordinate). In Abschnitt B sind die Histogramme der Fluoreszenzintensität der spezifischen Antikörper CD123 (links) und CD303 (rechts) dargestellt, die Isotypenkontrollen sind als schwarze Linien und die jeweiligen Marker als blaue Linien aufgeführt. Unter Punkt C sind die Histogramme der Fluoreszenzintensität des B-Zell-spezifischen Antikörpers CD19 (links) und des Monozyten- und Makrophagen-spezifischen Antikörpers CD14 (rechts) dargestellt.

\subsubsection{Das FSME-Virus beeinflusst die Expression von Oberflächenmolekülen der mDCs}

Um die Reaktion der mDCs auf eine Infektion mit dem FSME-Virus sowie dem UVinaktivierten FSME-Virus zu untersuchen, wurde die Expression spezieller Moleküle analysiert, die aufgrund einer Aktivierung oder Reifung der mDCs verstärkt exprimiert werden oder die bei der Interaktion mit T-Zellen beteiligt sind. Im Rahmen dieser Arbeit wurden die Expression des Reifungsmarkers CD83, der kostimulatorischen Moleküle CD40, CD80 und CD86, der Adhäsionsmoleküle CD54 und CD58 sowie die Expression 
der antigenpräsentierenden Moleküle MHC-I und MHC-II untersucht. Außerdem wurde die Expression des Apoptose Markers CD95 analysiert. Um den Verlauf der Expression der verschiedenen Oberflächenmoleküle zu untersuchen, wurden nach 12 h, 24 h, 48 h und $72 \mathrm{~h}$ jeweils mDCs geerntet, die mit FSME-Virus infiziert worden waren oder mit UV-inaktivierten FSME-Virus oder Medium als Mock-Kontrolle kokultiviert wurden (s. Kapitel 2.2.2.5). Anhand dieser Kinetik sollten mögliche Einflüsse des FSME-Virus auf die Expression der Oberflächenmoleküle der mDCs analysiert werden. Die mDCs wurden mit spezifischen Fluorochrom-gekoppelten Antikörpern gegen die entsprechenden Oberflächenmoleküle behandelt und mittels der durchflußzytometrischen Analyse untersucht (s. Kapitel 2.2.3). Die Ergebnisse sind für die Spezifitätsmarker und antigenpräsentierenden Moleküle in der Abbildung 3.3 für die Kostimulations-, Aktivierungs- und Reifungsmarker in der Abbildung 3.4 und für die Adhäsionsmoleküle sowie dem Apoptosemarker in der der Abbildung 3.6 dargestellt.

In der Abbildung 3.3 ist zu erkennen, dass es sich bei den analysierten Zellen über die Zeit hinweg um mDCs gehandelt hat, die sowohl CD1c als auch CD11c als spezifische Marker exprimieren. Weiterhin ist ersichtlich, dass die Expression des antigenpräsentierenden Moleküls MHC-I bei den mDCs, die mit dem aktiven als auch mit dem UV-inaktivierten Virus infiziert bzw. inkubiert wurden, gegenüber der MockKontrolle 24 h - 72 h nach Infektion leicht erhöht ist, wobei die Unterschiede 48 h nach Infektion am deutlichsten $\mathrm{zu}$ erkennen waren. Dagegen ist bei dem antigenpräsentierenden Molekül MHC-II nur $12 \mathrm{~h}$ und $24 \mathrm{~h}$ nach Infektion eine sehr leicht erhöhte Expression gegenüber der Mock-Kontrolle zu erkennen. Das bedeutet, dass die mDCs in Antwort auf das FSME-Virus die Präsentation von Antigenen über den untersuchten Zeitraum von $72 \mathrm{~h}$ nach der Infektion leicht oder im Falle des MHC-IIMoleküls nur bis $48 \mathrm{~h}$ nach Infektion verstärken. In der Abbildung 3.4 kann man erkennen, dass sich die Expression der kostimulatorischen Moleküle CD40, CD80 und CD86 in Antwort auf die Infektion mit dem FSME-Virus oder dem UV-inaktivierten Virus im Vergleich zur Mock-Kontrolle nur wenig ändert. 


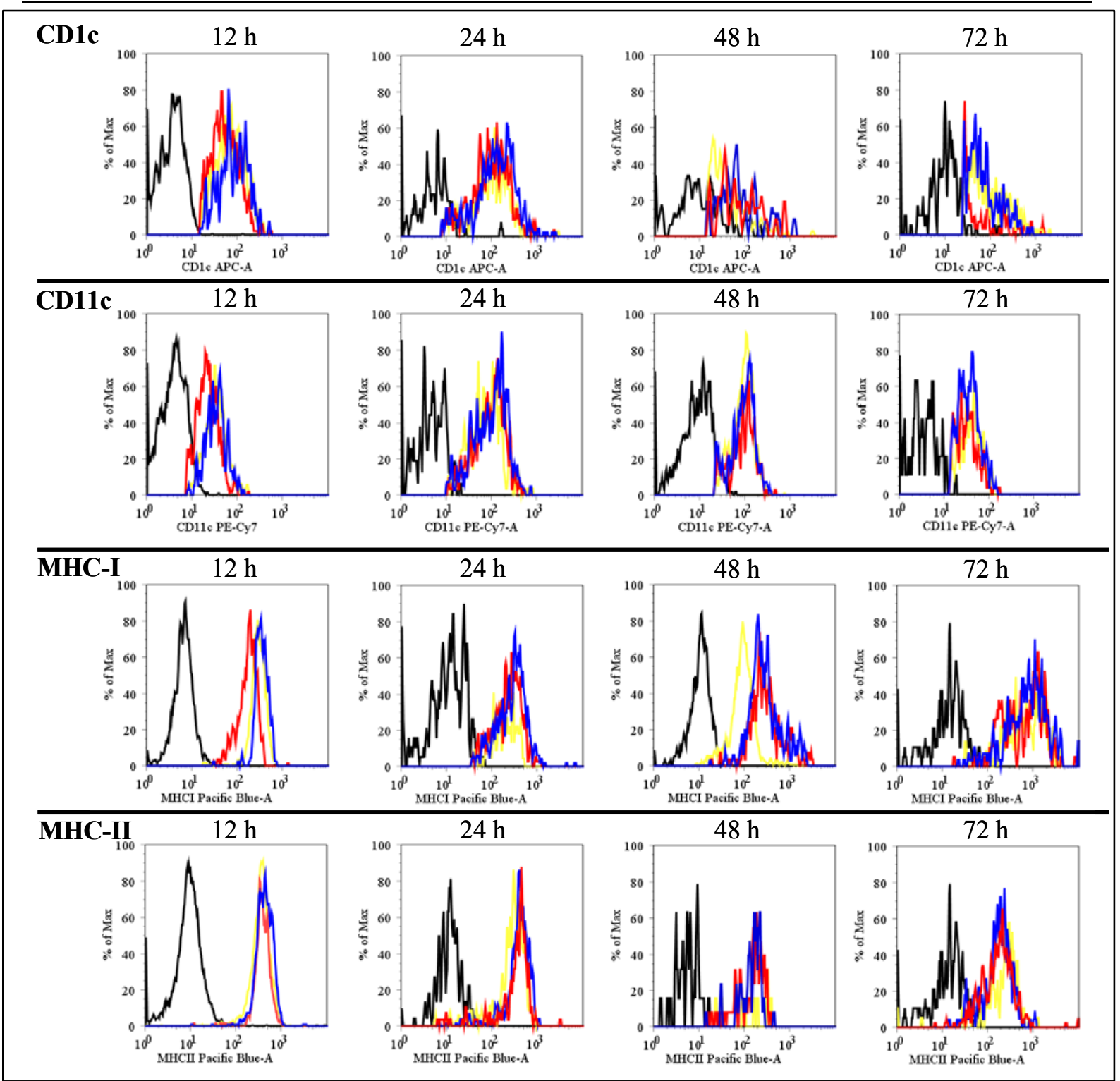

Abbildung 3.3: Durchflußzytometrische Analyse der Expression von spezifischen und antigenpräsentierenden Molekülen der mDCs.

In der Abbildung sind die Expressionsmuster der spezifischen mDC-Marker CD1c sowie CD11c und der antigenpräsentierenden Moleküle MHC-I und MHC-II im Zeitraum von $12 \mathrm{~h}, 24 \mathrm{~h}, 48 \mathrm{~h}$ und $72 \mathrm{~h}$ nach Infektion aufgeführt. Die mDCs, die mit dem aktiven FSME-Virus infiziert wurden, sind als blaue Linie, die mit dem UV-inaktivierten Virus kokultivierten mDCs sind als rote Linie, die Mock-Kontrolle ist als gelbe Linie und die Isotypenkontrolle ist als schwarze Linie dargestellt.

Bei dem CD40-Molekül ist erst nach 24 h eine leichte Aktivierung zu sehen, während bei dem Aktivierungsmarker CD86 bereits nach $12 \mathrm{~h}$ eine Veränderung im Expressionsmuster der infizierten mDCs zu sehen ist. Bei dem kostimulatorischen CD80Molekül ist lediglich nach $72 \mathrm{~h}$ eine leicht erhöhte Expression der mit dem FSME-Virusinfizierten mDCs $\mathrm{zu}$ erkennen. $\mathrm{Zu}$ den anderen Zeitpunkten kann kein Unterschied zwischen infizierten und nicht-infizierten Zellen ausgemacht werden. Auch bei dem 
Reifungsmarker CD83 ist die Expression über den Zeitraum von $72 \mathrm{~h}$ bei den infizierten Zellen nur wenig verändert, wobei eine deutlichere Erhöhung der Expression von CD83 nur $48 \mathrm{~h}$ nach Infektion zu erkennen ist. Demnach kommt es nicht zu einer ausgeprägten Reifung und Aktivierung der mDCs in Antwort auf eine Infektion mit dem FSME-Virus.

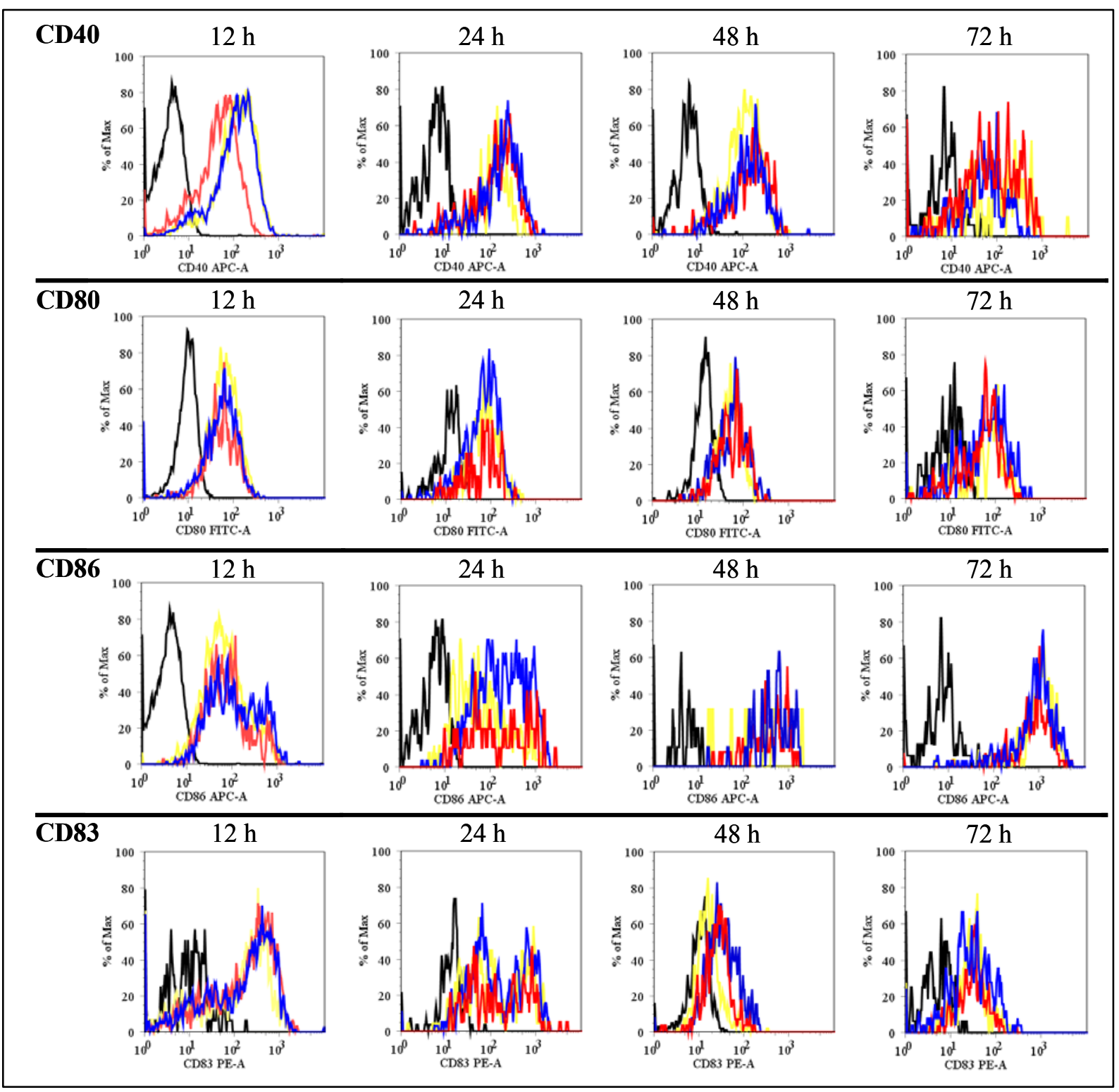

Abbildung 3.4: Durchflußzytometrische Analyse der Expression von kostimulatorischen-, Aktivierungs- und Maturierungsmarken der mDCs.

In der Abbildung sind die Expressionsmuster der kostimulatorischen- und Aktivierungsmarker CD40, CD80, CD86 und dem Maturationsmarker CD83 im Zeitraum von 12 h, 24 h, 48 h und 72 h nach Infektion aufgeführt. Die mDCs, die mit dem aktiven FSME-Virus infiziert wurden, sind als blaue Linie, die mit dem UV-inaktivierten Virus kokultivierten mDCs sind als rote Linie, die Mock-Kontrolle ist als gelbe Linie und die Isotypenkontrolle ist als schwarze Linie dargestellt. 


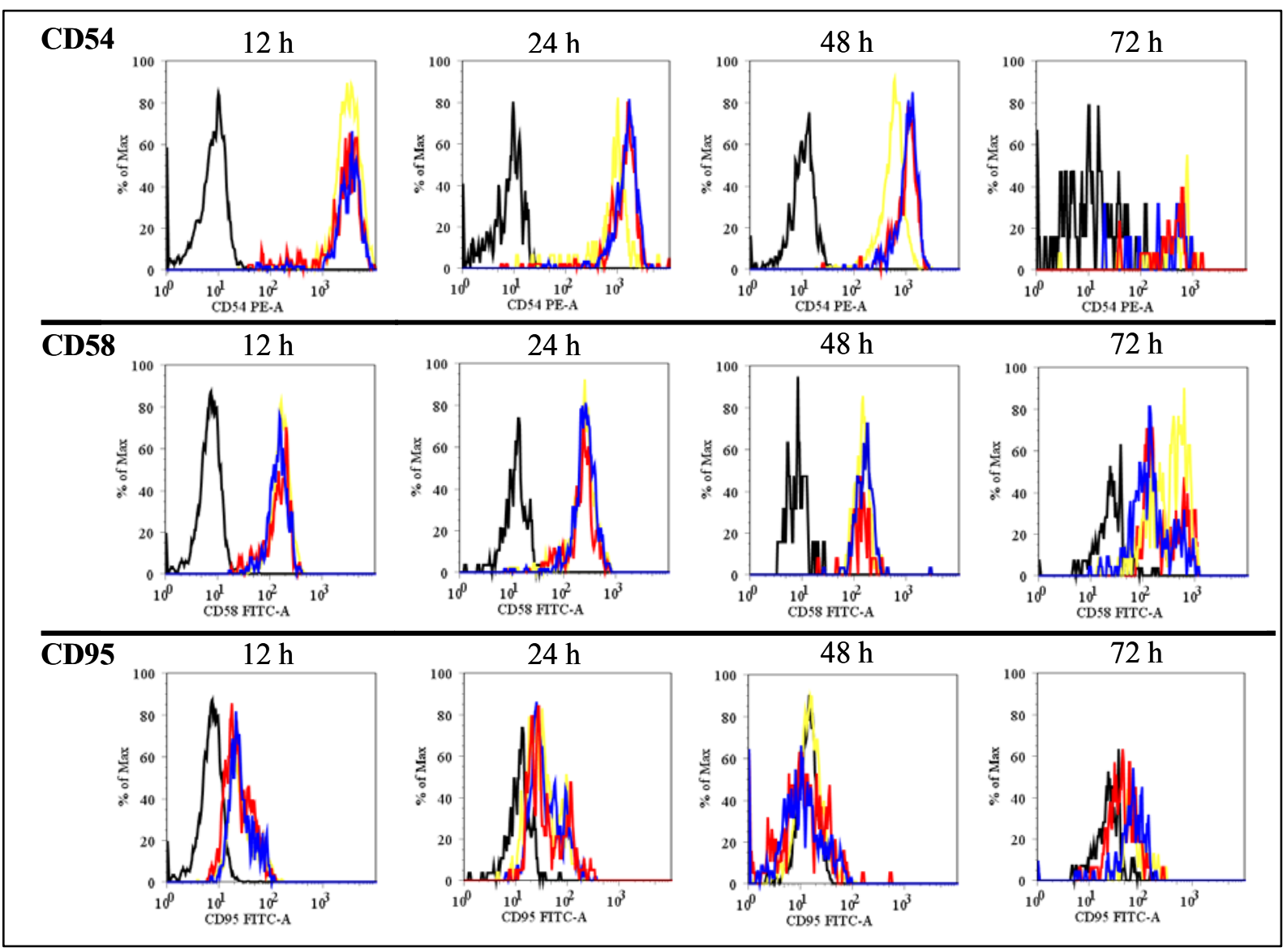

Abbildung 3.5: Durchflußzytometrische Analyse der Expression von Adhäsions- und ApoptoseMarkern der mDCs.

In der Abbildung sind die Expressionsmuster der Adhäsionsmoleküle CD54 und CD58 sowie des Apoptosemarkers CD95 im Zeitraum von 12 h, 24 h, 48 h und $72 \mathrm{~h}$ nach Infektion aufgeführt. Die mDCs, die mit dem aktiven FSME-Virus infiziert wurden, sind als blaue Linie, die mit dem UV-inaktivierten Virus kokultivierten mDCs sind als rote Linie, die Mock-Kontrolle ist als gelbe Linie und die Isotypenkontrolle ist als schwarze Linie dargestellt

In der Abbildung 3.5 sind die Expressionsmuster der Adhäsionsmoleküle CD54 und CD58 sowie des Apoptosemarkers CD95 dargestellt. Bei den mDCs konnte nur für das Adhäsionsmolekül CD54 eine verstärkte Expression im Zeitraum zwischen $24 \mathrm{~h}$ und $48 \mathrm{~h}$ nach Infektion in Antwort auf das replikationskompetente und UV-inaktivierte FSMEVirus festgestellt werden. Für das zweite Adhäsionsmolekül CD58 sowie für den Apoptosemarker CD95 konnte keine Veränderung bezüglich der Expression gegenüber der Mock-Kontrolle gezeigt werden. 


\subsubsection{Das FSME-Virus beeinflusst die Expression von Oberflächenmolekülen der pDCs}

Um den Einfluss des FSME-Virus auf die Expression der Oberflächenmoleküle der pDCs über einen Zeitraum von $72 \mathrm{~h} \mathrm{zu}$ untersuchen, wurden pDCs mit FSME-Virus infiziert und die Expression verschiedener Oberflächenmoleküle 12 h, 24 h, 48 h und 72 h nach Infektion untersucht. Analog zur Analyse der FSME-Virus infizierten mDCs wurde auch bei den pDCs die Expression des Reifungsmarkers CD83, der kostimulatorischen Moleküle CD40, CD80 und CD86, der Adhäsionsmoleküle CD54 und CD58, der antigenpräsentierenden Moleküle MHC-I und MHC-II sowie des Apoptosemarkers CD95 über einen Zeitraum von $72 \mathrm{~h}$ analysiert. Ähnlich wie bei den mDCs wurden Kokultivierungen mit UV-inaktivierten FSME-Virus oder Medium als Kontrollen durchgeführt (s. Kapitel 2.2.2.5). Die pDCs wurden anschließend mit spezifischen Fluorochrom-gekoppelten Antikörpern gegen die entsprechenden Oberflächenmoleküle behandelt und mittels der durchflußzytometrischen Analyse untersucht (s. Kapitel 2.2.3). Die Ergebnisse sind für die spezifischen und antigenpräsentierenden Moleküle in der Abbildung 3.6, für die Kostimulations-, Aktivierungs- und Reifungsmarker in der Abbildung 3.7 und für die Adhäsionsmoleküle sowie dem Apoptosemarker in der Abbildung 3.8 dargestellt.

In der Abbildung 3.6 ist zu sehen, dass der spezifische Marker der pDCs, das CD123, über den Zeitraum von $72 \mathrm{~h}$ unverändert stark exprimiert wird. Außerdem wird ersichtlich, dass die beiden antigenpräsentierenden Moleküle MHC-I und MHC-II bereits nach $12 \mathrm{~h}$ in Antwort auf das aktive FSME-Virus verstärkt exprimiert werden. Diese verstärkte Antigenpräsentation im Zuge der Infektion mit dem FSME-Virus geht für MHC-I über den Beobachtungszeitraum aber wieder auf den Wert der Mock-Kontrolle zurück, während für MHC-II auch nach $48 \mathrm{~h}$ und $72 \mathrm{~h}$ nach Infektion mit replikationskompetentem FSME-Virus eine leichte Erhöhung der MHC-II-Expression zu beobachten war. 


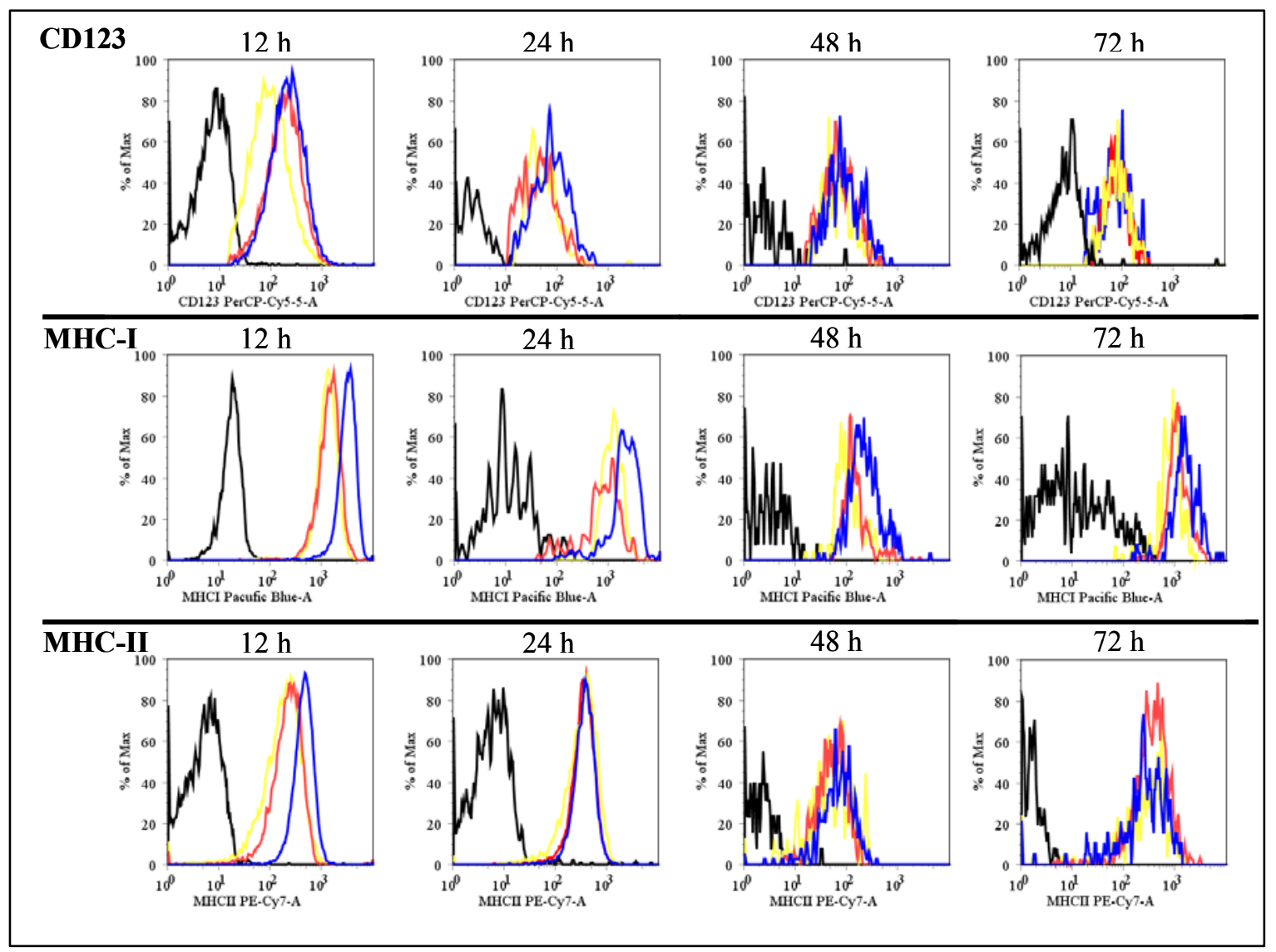

Abbildung 3.6: Durchflußzytometrische Analyse der Expression von spezifischen und antigenpräsentierenden Molekülen der pDCs.

In der Abbildung sind die Expressionsmuster des spezifischen pDC-Markers CD123 und der antigenpräsentierenden Moleküle MHC-I und MHC-II im Zeitraum von 12 h, 24 h, 48 h und 72 h nach Infektion aufgeführt. Die pDCs, die mit dem aktiven FSME-Virus infiziert wurden, sind als blaue Linie, die mit dem UV-inaktivierten Virus kokultivierten pDCs sind als rote Linie, die Mock-Kontrolle ist als gelbe Linie und die Isotypenkontrolle ist als schwarze Linie dargestellt.

In der Abbildung 3.7 kann man erkennen, dass bereits $12 \mathrm{~h}$ nach der Infektion der pDCs mit dem FSME-Virus eine verstärkte Expression der kostimulatorischen Moleküle CD40, CD80 und CD86 sowie des Reifungsmarkers CD83 in Antwort auf das aktive FSMEVirus induziert wird. Diese verstärke Expression nimmt allerdings über den Zeitraum von $72 \mathrm{~h}$ hinweg wieder ab. Nach $72 \mathrm{~h}$ ist kein Unterschied mehr im Bezug der Expression dieser Marker zwischen den FSME-Virus-infizierten pDCs, den mit UV-inaktivierten Virus kokultivierten pDCs sowie der Mock-Kontrolle zu beobachten. Eine Infektion mit FSME-Virus induziert die Reifung der pDCs. Die verstärkte Expression dieser Moleküle ist allerdings zeitlich begrenzt und nach $72 \mathrm{~h}$ ist kein Unterschied $\mathrm{zu}$ nicht-infizierten pDCs erkennbar. 


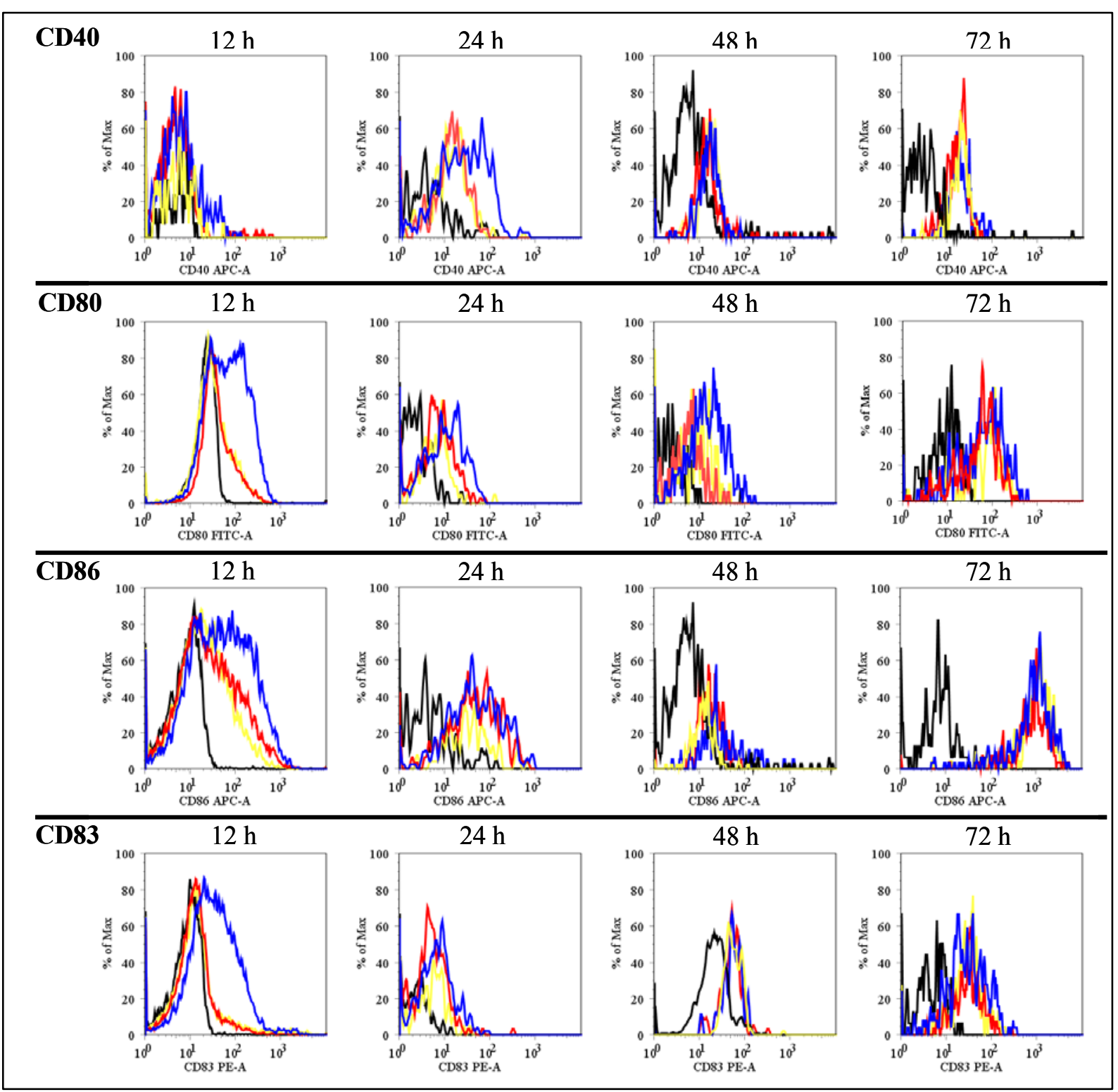

Abbildung 3.7: Durchflußzytometrische Analyse der Expression von kostimulatorischen-, Aktivierungs- und Maturierungsmarken der pDCs.

In der Abbildung sind die Expressionsmuster der kostimulatorischen- und Aktivierungsmarker CD40, CD80, CD86 und dem Maturationsmarker CD83 im Zeitraum von 12 h, 24 h, 48 h und 72 h nach Infektion aufgeführt. Die pDCs, die mit dem aktiven FSME-Virus infiziert wurden, sind als blaue Linie, die mit dem UV-inaktivierten Virus kokultivierten pDCs sind als rote Linie, die Mock-Kontrolle ist als gelbe Linie und die Isotypenkontrolle ist als schwarze Linie dargestellt.

Die Expressionsmuster der Adhäsionsmoleküle CD54 und CD58 sowie des Apoptosemarkers CD95 sind in der Abbildung 3.8 dargestellt. 


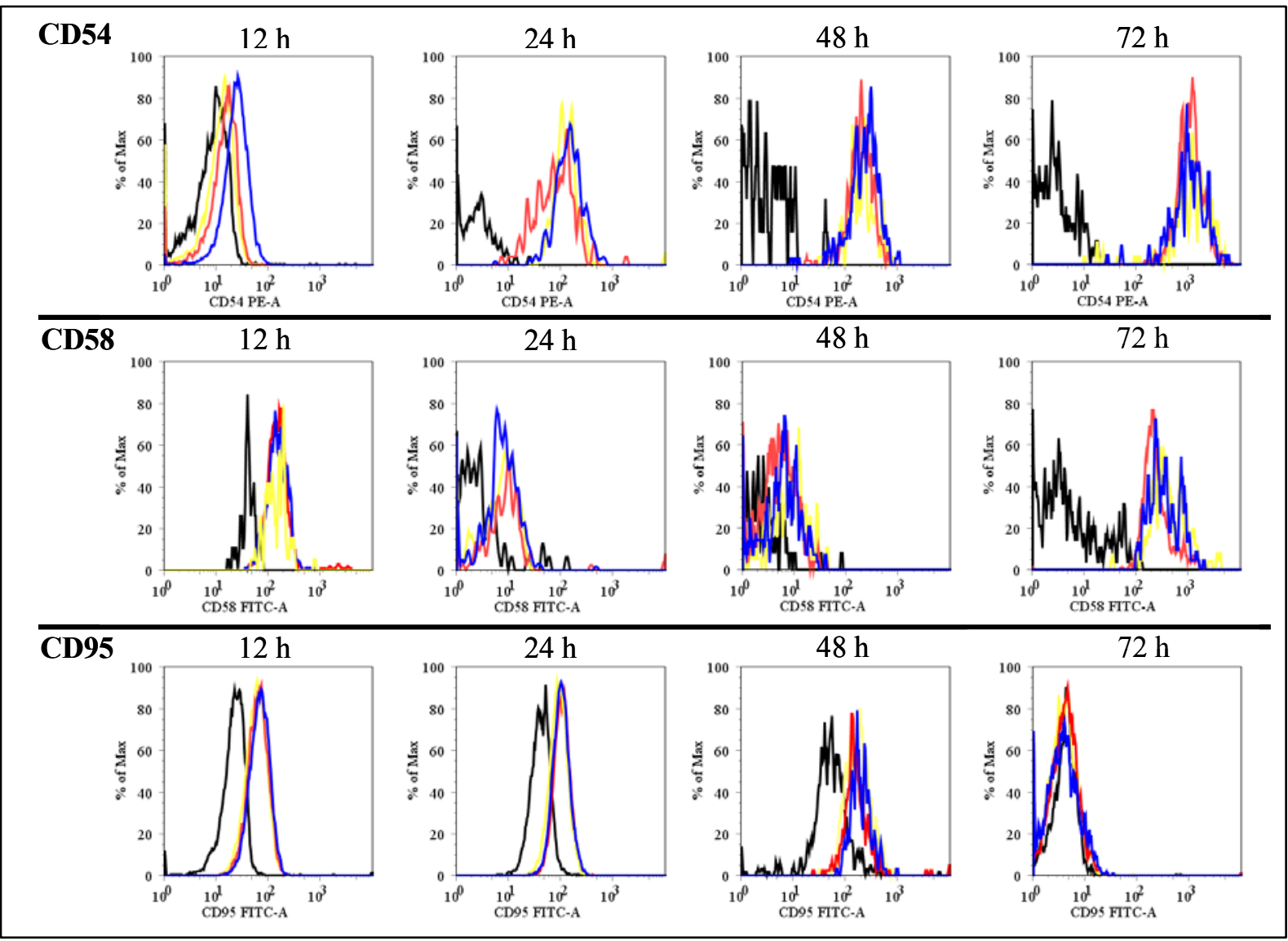

Abbildung 3.8: Durchflußzytometrische Analyse der Expression von Adhäsions- und ApoptoseMarkern der pDCs.

In der Abbildung sind die Expressionsmuster der Adhäsionsmoleküle CD54 und CD58 sowie des Apoptosemarkers CD95 im Zeitraum von 12 h, 24 h, 48 h und 72 h nach Infektion aufgeführt. Die pDCs, die mit dem aktiven FSME-Virus infiziert wurden, sind als blaue Linie, die mit dem UV-inaktivierten Virus kokultivierten pDCs sind als rote Linie, die Mock-Kontrolle ist als gelbe Linie und die Isotypenkontrolle ist als schwarze Linie dargestellt

Bei den Adhäsionsmolekülen kann ähnlich wie bei den Aktivierungs- und Reifungsmarkern eine verstärkte Expression der Moleküle nachgewiesen werden, die allerdings über die Zeit hinweg abnimmt, sodass nach $72 \mathrm{~h}$ kein Unterschied zwischen der Mock-Kontrolle und FSME-Virus infizierten pDCs erkennbar ist. Die Expression des Apotosemarkers ist über den Zeitraum von $72 \mathrm{~h}$ gering, wobei kein Unterschied zwischen der Mock-Kontrolle und den pDCs, die mit dem aktiven oder UV-inaktivierten Virus inkubiert wurden auszumachen ist. Nach $72 \mathrm{~h}$ konnte keine Expression des Apoptosemarkers festgestellt werden. 


\subsubsection{Das FSME-Virus induziert bei beiden DC-Subtypen eine IFN- $\alpha$-Antwort}

Beide DC-Subtypen können als Antwort auf einen viralen Stimulus IFN- $\alpha$ produzieren, das wiederum die Expression von Komponenten des angeborenen Immunsystems induziert, die eine antivirale Wirkung haben und darüber hinaus wichtige Teile des adaptiven Immunsystems aktivieren kann (s. Kapitel 1.1.4-5). Darüber hinaus konnte gezeigt werden, dass einige Flaviviren und darunter auch das das FSME-Virus, sensitiv bezüglich der antiviralen Wirkung der Komponenten sind, die durch das IFN- $\alpha$ induziert werden (FSME-Virus (150), DENV (65); (50), JEV (44) und LGTV (23)). Speziell die pDCs sind in der Lage innerhalb kurzer Zeit große Mengen an IFN- $\alpha$ zu produzieren (17, 174). Aus diesem Grund sollte untersucht werden, ob das FSME-Virus auch die Produktion von IFN- $\alpha$ in den beiden DC-Subtypen induziert oder ob das FSME-Virus in der Lage ist die Produktion von IFN- $\alpha$ zu hemmen oder über die Zeit hinweg zu beeinflussen.

Um die Konzentration des von den DCs produzierten IFN- $\alpha$ zu messen, wurden beide DC-Subtypen jeweils mit dem FSME-Virus Stamm Hypr infiziert (MOI 10) (s. Kapitel 2.2.2.5). Weiterhin wurden die DC-Subtypen als Kontrolle auch mit dem UVinaktivierten, replikationsunfähigen FSME-Virus kokultiviert sowie im nicht-infizierten Zustand als Mock-Kontrolle kultiviert. Um den Verlauf der Produktion des IFN- $\alpha$ zu analysieren, wurden nach $12 \mathrm{~h}, 24 \mathrm{~h}, 48 \mathrm{~h}$ und $72 \mathrm{~h}$ jeweils DC-Zellkulturüberstände geerntet und die IFN- $\alpha$ Konzentration mittels IFN- $\alpha$-ELISA bestimmt (s. Kapitel 2.2.6).

Die Ergebnisse der Kinetik der IFN- $\alpha$-Produktion der mDCs und der pDCs sind in der Abbildung 3.9 dargestellt (mDCs A und pDCs B). Es ergab sich, dass das FSME-Virus in beiden DC-Subtypen eine IFN- $\alpha$-Antwort induziert, die sich allerdings in ihrem zeitlichen Verlauf und in der Qualität unterscheidet (Abbildung 3.9). Die Produktion von IFN- $\alpha$ durch die mDCs als Antwort auf repliaktionskompetentes (Abbildung 3.9 A, blaue Linie) und UV-inaktiviertes (Abbildung 3.9 A, rote Linie) FSME-Virus erreicht $12 \mathrm{~h}$ bis $24 \mathrm{~h}$ nach der Infektion mit Werten um die $300 \mathrm{pg} / \mathrm{ml}$ ihr Maximum. Nach $48 \mathrm{~h}$ bis $72 \mathrm{~h}$ nimmt die Konzentration fast um die Hälfte ab und erreicht 140 bzw. 120 pg / ml. Das aktive FSME-Virus induziert dagegen bei den pDCs eine sehr starke IFN- $\alpha$-Produktion (Abbildung 3.9 B, blaue Linie). 


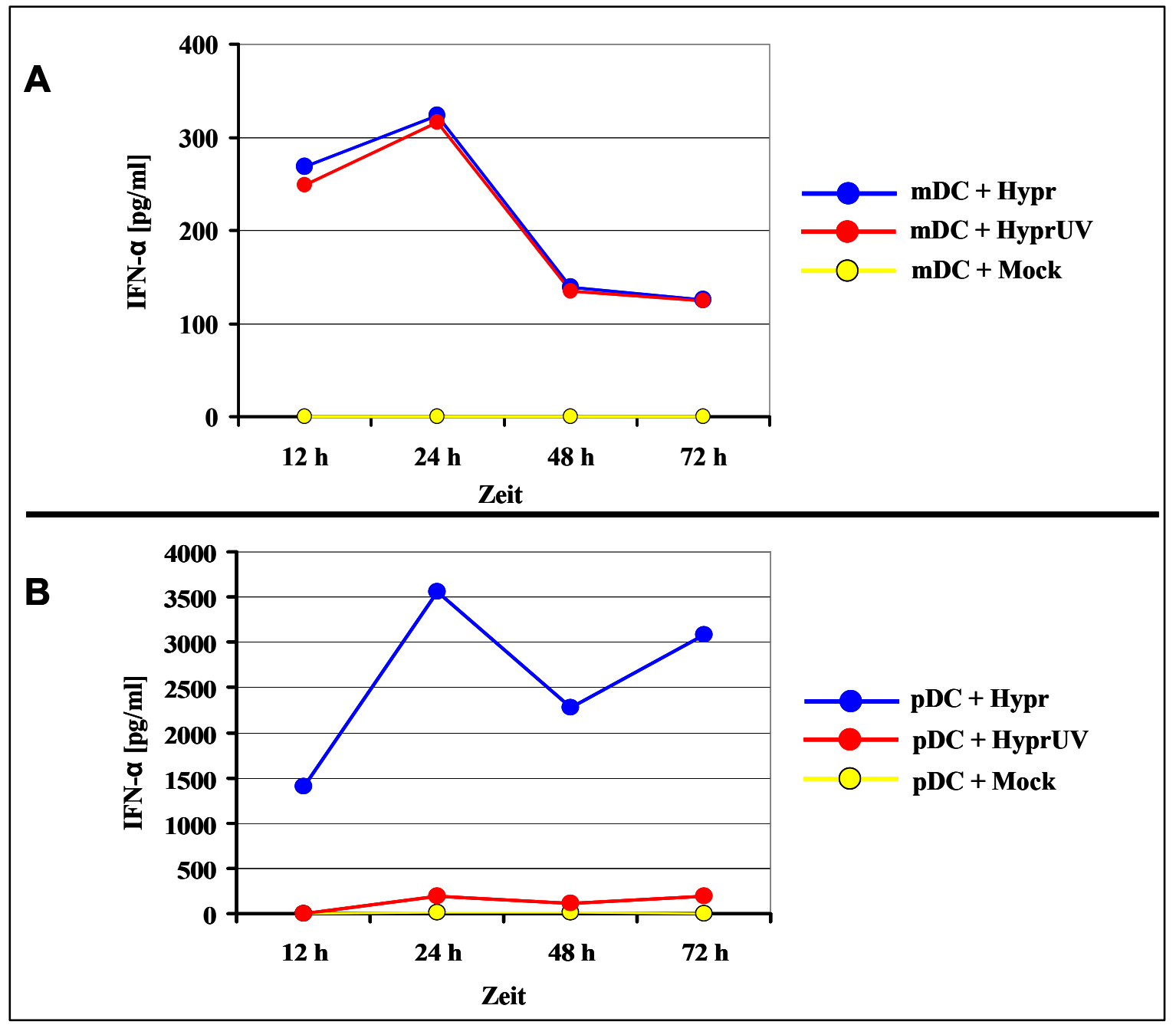

Abbildung 3.9: Darstellung des zeitlichen Verlaufs der IFN- $\alpha$-Produktion der mDCs und pDCs.

Im oberen Teil der Abbildung unter Punkt A sind die Ergebnisse des IFN- $\alpha$-ELISAs der Zellkulturüberstände der mDCs aufgeführt und im unteren Teil der Abbildung unter Punkt B sind die Ergebnisse des IFN- $\alpha$-ELISAs der Zellkulturüberstände der pDCs dargestellt, die für die Zeitpunkte $12 \mathrm{~h}$, $24 \mathrm{~h}, 48 \mathrm{~h}$ und $72 \mathrm{~h}$ bestimmt wurden. Auf der Abszisse sind die Zeitpunkte aufgetragen, an denen die Proben entnommen wurden und auf der Ordinate die jeweiligen IFN- $\alpha$-Konzentrationen, die in den Proben gemessen wurden. Die blaue Linie repräsentiert die IFN- $\alpha$-Konzentrationen der DCs, die mit dem FSMEVirus infiziert wurden, die roten Linien die IFN- $\alpha$-Konzentrationen der DCs, die mit dem UV-inaktivierten FSME-Virus inkubiert wurden, und die gelben Linien die jeweilige Mock-Kontrollen.

Bereits nach $12 \mathrm{~h}$ liegt die IFN- $\alpha$-Konzentration in dem Zellkulturüberstand der FSMEVirus infizierten pDCs bei annähernd $1500 \mathrm{pg} / \mathrm{ml}$. Die Werte erreichen nach $24 \mathrm{~h}$ ein Maximum von über $3500 \mathrm{pg} / \mathrm{ml}$. Im Vergleich zu den mDCs fällt die IFN- $\alpha$-Antwort bei den pDCs damit um den Faktor 10 stärker aus. Die IFN- $\alpha$-Konzentration bleibt bei den pDCs auch $72 \mathrm{~h}$ nach Infketion erhöht. Im Gegensatz zu mDCs fällt die InterferonAntwort der pDCs auf das UV-inaktivierte FSME-Virus (Abbildung 3.9, Punkt B, rote Linie) im Vergleich zu replikationskompetentem FSME-Virus deutlich schwächer 
aus und liegt um den Faktor 10 unter den IFN- $\alpha$-Konzentrationen, die durch die pDCs in Antwort auf das aktive FSME-Virus produziert werden. Dennoch wird auch hier eine IFN- $\alpha$-Produktion in den pDCs induziert, die von der Größenordnung her denen der mDCs auf das UV-inaktivierte, sowie auf das aktive FSME-Virus entspricht. Allerdings bleibt die Konzentration des IFN- $\alpha$ über die Zeit hinweg erhöht und fällt nicht wie bei den mDCs wieder ab. Bei beiden DC-Subtypen konnte erwartungsgemäß in den MockKontrollen kein IFN- $\alpha$ nachgewiesen werden (Abbildung 3.9, Punkte A und B, gelbe Linien).

Somit konnte gezeigt werden, dass das FSME-Virus bei beiden DC-Subtypen eine IFN- $\alpha$ Antwort induziert. Die IFN- $\alpha$-Antwort fällt bei den pDCs, die auch als Typ I IFNproduzierende Zellen bezeichnet werden, um den Faktor 10 größer aus als bei den mDCs. Weiterhin fällt auf, dass die IFN- $\alpha$-Produktion in $\mathrm{mDCs}$ zu späteren Zeitpunkten nach Infektion wieder abfällt, während bei pDCs die IFN- $\alpha$-Produktion anhält.

\subsubsection{Das FSME-Virus induziert die Produktion proinflammatorischer Zytokine bei beiden DC-Subtypen}

Wie schon im Kapitel 3.1.2 gezeigt werden konnte, werden im Rahmen der FSMEVirusinfektion die mDCs nur unvollständig aktiviert. Dagegen werden die pDCs als Antwort auf eine Infektion mit dem FSME-Virus aktiviert und steigern die Expression diverser Aktivierungs-, Reifungs- und Adhäsionsmarker sowie die Expression kostimulatorischer- und antigenpräsentierender Moleküle (s. Kapitel 3.1.3). Außerdem konnte in dieser Arbeit gezeigt werden, dass durch die Infektion mit dem FSME-Virus bei beiden DC-Subtypen die IFN- $\alpha$-Produktion induziert wurde (s. Kapitel 3.1.4). Im aktivierten Zustand sind die DCs darüber hinaus in der Lage in Antwort auf virale Stimuli weitere Zytokine zu produzieren, die verschiedene Funktionen haben. Diese Zytokine sind an der Aktivierung anderer Zellen beteiligt, sie können Fieber induzieren, zur Rekrutierung von anderen Immunzellen führen oder aber auch die proinflammatorischen Immunantwort inhibieren und somit eine antiinflammatorische Wirkung haben. In dieser Arbeit wurde Produktion einer Auswahl an Zytokinen der DC-Subtypen untersucht. Dazu gehörten neben den proinflammatorischen Zytokinen IL-1 $\beta$, TNF- $\alpha$, IL-6 und IL-8 auch das antiinflammatorische Zytokin IL-10 sowie das Zytokin IL-12p40. Nach Infektion der DC-Subtypen mit dem FSME-Virus mit einer MOI von 10 wurden nach jeweils $12 \mathrm{~h}$, 
$24 \mathrm{~h}, 48 \mathrm{~h}$ und $72 \mathrm{~h}$ die Konzentrationen der Zytokine IL-1 $\beta$, IL-6, IL-8, IL-10, IL-12p40 und TNF- $\alpha$ in den DC-Zellkulturüberständen mittels eines CBAs analysiert (s. Kapitel 2.2.5). Als Kontrolle wurden die DCs auch mit dem UV-inaktivierten, replikationsunfähigen FSME-Virus kokultiviert und im nicht-infizierten Zustand als Mock-Kontrolle kultiviert. Die erhaltenen Ergebnisse sind für die mDCs in der Abbildung 3.10 und für die pDCs in der Abbildung 3.11 dargestellt.

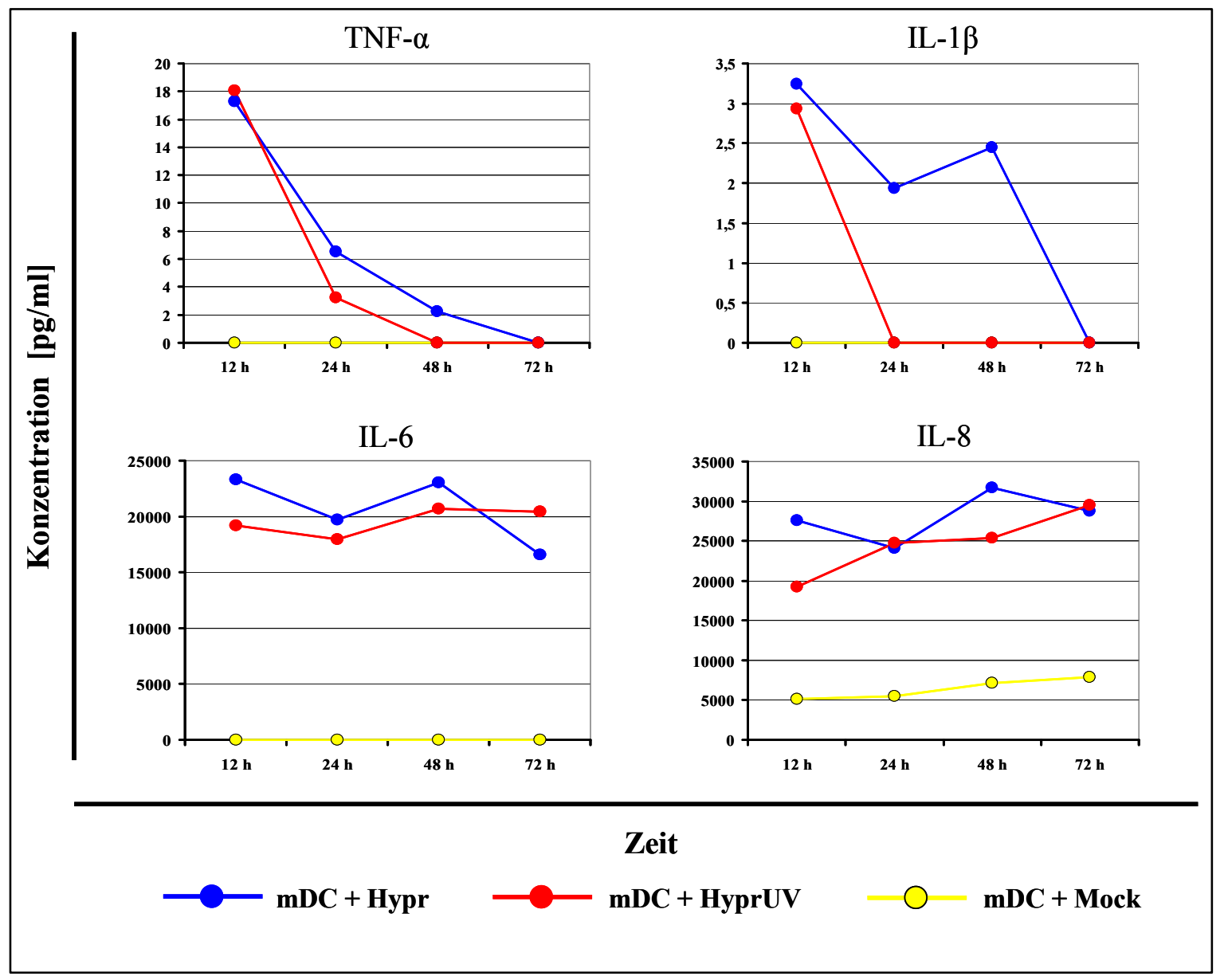

\section{Abbildung 3.10: Messung der inflammatorischen Zytokine der mDCs mittels CBA.}

In der Abbildung sind die Ergebnisse des CBAs der Zellkulturüberstände der mDCs dargestellt, die für die Zeitpunkte $12 \mathrm{~h}, 24 \mathrm{~h}, 48 \mathrm{~h}$ und $72 \mathrm{~h}$ bestimmt wurden. Auf der Abszisse sind die Zeitpunkte aufgetragen, an denen die Proben entnommen wurden und auf der Ordinate die jeweiligen Konzentrationen des jeweiligen Zytokins, die in den Zellkulturüberständen vorhanden waren. Die blaue Linie repräsentiert die Zytokin-Konzentrationen der mDCs, die mit dem FSME-Virus infiziert wurden, die roten Linien die Zytokin-Konzentrationen der mDCs, die mit dem UV-inaktivierten FSME-Virus inkubiert wurden, und die gelben Linien die jeweiligen Mock-Kontrollen.

Das FSME-Virus induziert in mDCs die Produktion der proinflammatorischen Zytokine IL-1 $\beta$, TNF- $\alpha$, IL-6 und IL-8. Das antiinflammatorische IL-10 sowie das Zytokin IL-12p40 konnten nicht in den Zellkulturüberständen der mDCs nachgewiesen werden. 
Die frühen proinflammatorischen Zytokine IL-1 $\beta$ und TNF- $\alpha$ sind $12 \mathrm{~h}$ nach der Infektion mit dem FSME-Virus in geringen Konzentrationen von $27 \mathrm{bzw} .17 \mathrm{pg} / \mathrm{ml}$ in den Zellkulturüberständen der mDCs vorhanden. $72 \mathrm{~h}$ nach der Infektion waren beide Zytokine nicht mehr nachweisbar. Schon $12 \mathrm{~h}$ nach Infektion werden große Mengen an IL-6 und IL-8 von den mDCs in Antwort auf das FSME-Virus produziert. Die Konzentrationen des IL-6 erreichen dabei Werte um die $20000 \mathrm{pg} / \mathrm{ml} \mathrm{zu}$ allen gemessenen Zeitpunkten. Die Konzentrationen des Zytokins IL-8 liegen noch etwas höher, wobei $72 \mathrm{~h}$ nach Infektion noch fast $30000 \mathrm{pg} / \mathrm{ml}$ nachweisbar waren. Die Zytokinantwort der mDCs auf das UV-inaktivierte FSME-Virus entspricht in etwa der, die durch das aktive Virus induziert wird. Lediglich die frühen proinflammatorischen Zytokine IL-1 $\beta$ und TNF- $\alpha$ sind bereits nach $24 \mathrm{~h}$ bzw. $48 \mathrm{~h}$ nicht mehr nachweisbar. Bei der Mock-Kontrolle wurde ausschließlich die Produktion des Zytokins IL-8 induziert, wobei die Konzentrationen über die Zeit von 72 h deutlich unter der 10000 pg / ml-Marke liegen.

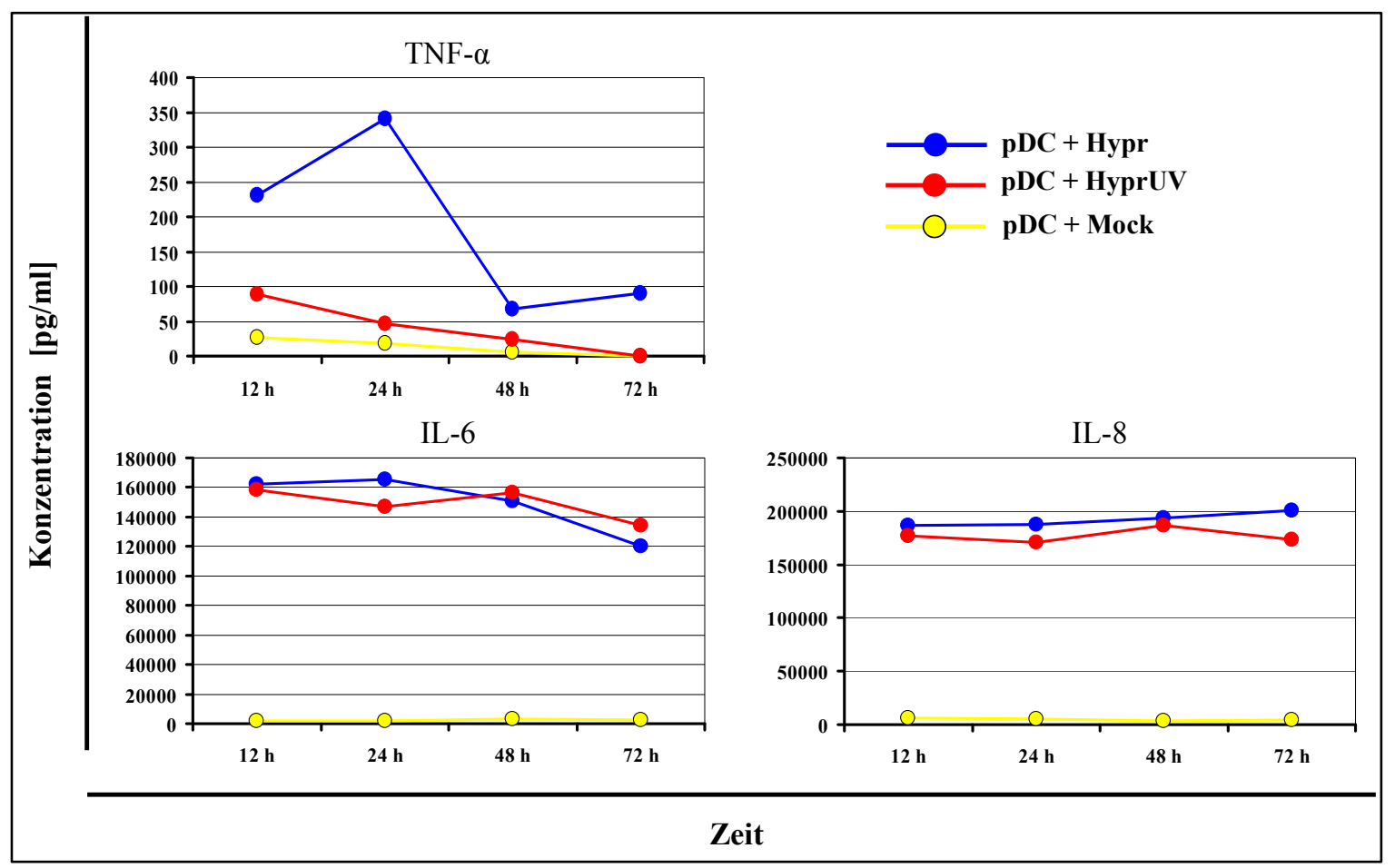

Abbildung 3.11: Messung der inflammatorischen Zytokine der pDCs mittels CBA.

In der Abbildung sind die Ergebnisse des CBAs der Zellkulturüberstände der pDCs dargestellt, die für die Zeitpunkte 12 h, 24 h, 48 h und 72 h bestimmt wurden. Auf der Abszisse sind die Zeitpunkte aufgetragen, an denen die Proben entnommen wurden und auf der Ordinate die jeweiligen Konzentrationen des jeweiligen Zytokins, die in den Zellkulturüberständen vorhanden waren. Die blaue Linie repräsentiert die Zytokin-Konzentrationen der pDCs, die mit dem FSME-Virus infiziert wurden, die roten Linien die Zytokin-Konzentrationen der pDCs, die mit dem UV-inaktivierten FSME-Virus inkubiert wurden und die gelben Linien die jeweiligen Mock-Kontrollen. 
In den Zellkulturüberständen der mit dem FSME-Virus infizierten pDCs konnten die Zytokine TNF- $\alpha$, IL-6 und IL-8 nachgewiesen werden. Bereits $12 \mathrm{~h}$ nach der Infektion konnte eine Konzentration von $230 \mathrm{pg} / \mathrm{ml}$ des frühen proinflammatorischen Zytokins TNF- $\alpha$ nachgewiesen werden. Nach 24 h konnten 340 pg / ml an TNF- $\alpha$ nachgewiesen werden, wobei im weiteren zeitlichen Verlauf sich die Mengen verringerten und nach $72 \mathrm{~h}$ um die $100 \mathrm{pg} / \mathrm{ml}$ in den Zellkulturüberstände vorhanden waren. Die Konzentrationen der beiden Zytokine IL-6 und IL-8 liegen deutlich über denen des TNF- $\alpha$ und den Werten, die bei den mDCs gemessen wurden. Bereits nach $12 \mathrm{~h}$ konnten über $150000 \mathrm{pg} / \mathrm{ml}$ in den Überständen der infizierten pDCs nachgewiesen werden. Die hohen Konzentrationen der beiden Zytokine waren über den Zeitraum von $72 \mathrm{~h}$ relativ konstant. Die Zytokinantwort der pDCs auf das UV-inaktivierte FSME-Virus ist fast identisch zu der Zytokinantwort auf die Infektion mit dem aktiven Virus. In den Überständen der Mock-Kontrolle waren geringe Konzentrationen der Zytokine IL-6 und IL-8 vorhanden, wobei die Werte deutlich unter den Werten der Überstände der mit den Virus infizierten pDCs lagen.

Zusammenfassend konnte gezeigt werden, dass das FSME-Virus in beiden DC-Subtypen eine proinflammatorische Antwort induziert, die bereits nach $12 \mathrm{~h}$ mit erhöhten Konzentrationen an proinflammatorischen Zytokine aktiv ist. Dabei induziert das FSMEVirus bei beiden DC-Subtypen die Produktion der proinflammatorischen Zytokine TNF- $\alpha$, IL-6 und IL-8, wobei die Konzentrationen der einzelnen Zytokine, die durch die infizierten pDCs produziert wurden, deutlich über denen der mDCs liegt. Dagegen konnte die Produktion des frühen proinflammatorischen Zytokins IL-1 $\beta$ lediglich bei den mDCs nachgewiesen werden. Außerdem sank die Konzentration der frühen proinflammatorischen Zytokine über die Zeit in den Überständen der infizierten DCs ab, sodass sie nach $72 \mathrm{~h}$ teilweise nicht mehr nachzuweisen waren.

\subsubsection{Replikation des FSME-Virus in den DC-Subtypen}

Wie in den Kapiteln 3.1.3 und 3.1.4 gezeigt werden konnte, aktiviert das FSME-Virus beide DC-Subtypen, wobei die Aktivierung der mDCs allerdings nur unvollständig war. In vivo führt diese Aktivierung zu einer Migration der DCs in die Lymphknoten, um dort den T-Zellen die prozessierten Fremdantigene zu präsentieren, wodurch die T-Zellen aktiviert werden. Andererseits stellt diese Migration der DCs eine Möglichkeit für das 
Virus dar sich im Wirtsorganismus schnell auszubreiten. Dies setzt allerdings voraus, dass eine Replikation in den DCs möglich ist.

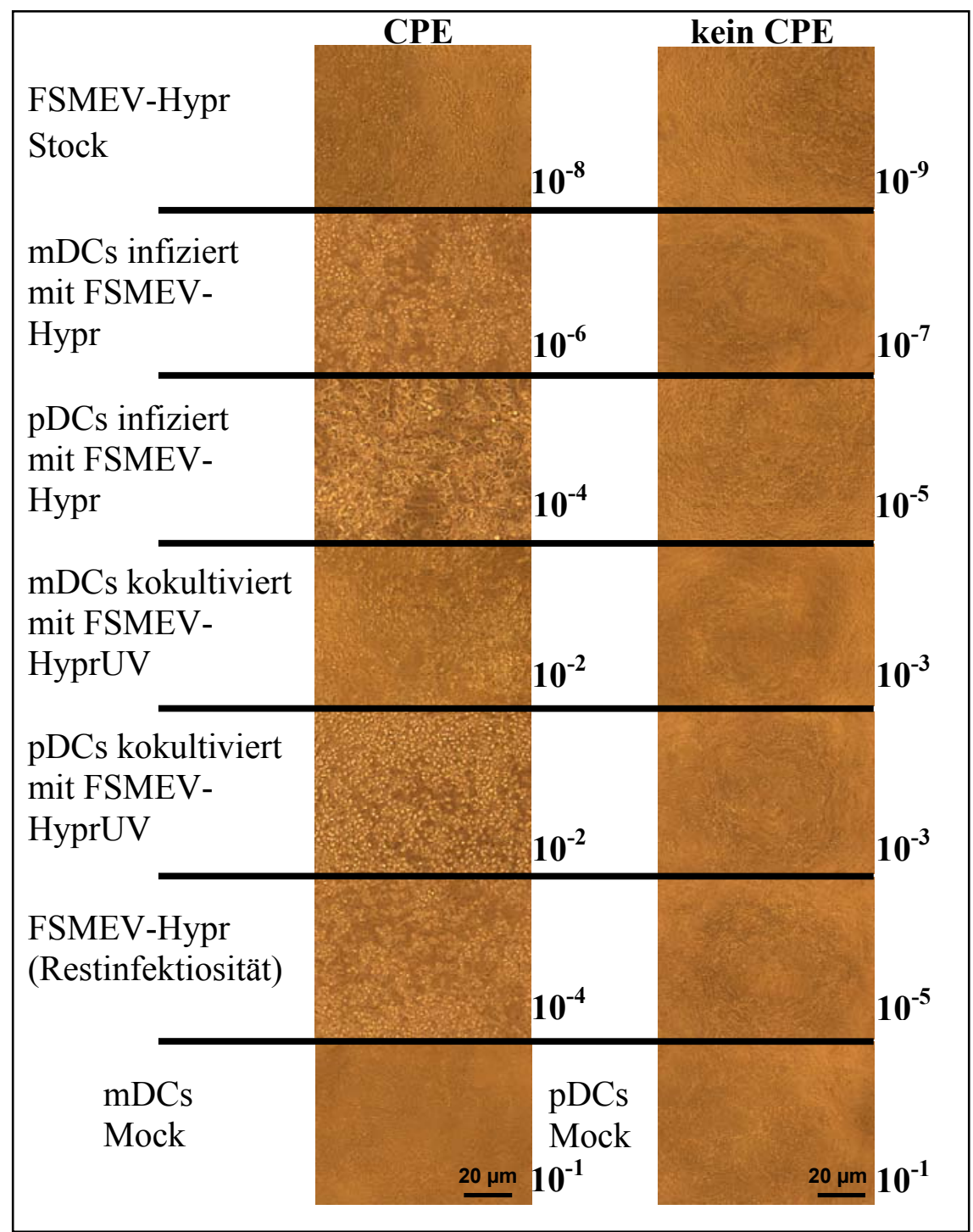

Abbildung 3.12: Mikroskopische Fotos der TCID $_{50}$-Analysen der mDC- und pDC-
Zellkulturüberstände auf Vero-B4-Indikatorzellen.

Auf der linken Seite sind die Verdünnungsstufen abgebildet, bei denen noch bei den Vero-B4 Indikatorzellen ein CPE zu erkennen ist und rechts die jeweiligen Verdünnungsstufen, bei denen kein CPE bei den Vero-B4 Zellen erkennbar ist. Die jeweiligen Verdünnungsstufen sind den Bildern rechts unten zugewiesen. In der Abbildung sind der Reihenfolge nach von oben bis unten folgende Bilder aufgeführt: Titration des Virusstocks als Positivkontrolle (FSMEV-Hypr Stock), Titration der Überstände der mDCs, die mit dem FSMEV-Stamm Hypr infiziert wurden (mDCs infiziert mit FSMEV-Hypr), Titration der Überstände der pDCs, die mit dem FSMEV-Stamm Hypr infiziert wurden (pDCs infiziert mit FSMEVHypr), Titration der Überstände der mDCs, die mit dem UV-inaktivierten FSMEV-Stamm Hypr kokultiviert wurden (mDCs kokultiviert mit FSMEV-HyprUV), Titration der Überstände der pDCs, die mit dem UV-inaktivierten FSMEV-Stamm Hypr kokultiviert wurden (pDCs kokultiviert mit FSMEV-HyprUV) und die Titration des Inputvirus zur Darstellung der Restinfektiosität (FSMEV-Hypr (Restinfektiosität)). Auf den unteren beiden Bildern sind die jeweiligen Mock-Kontrollen abgebildet (mDCs (mDCs Mock) links und pDCs (pDCs Mock) rechts). 
Um zu untersuchen, ob das FSME-Virus in den DC-Subtypen repliziert, wurden die Virustiter der Zellkulturüberstände der DCs, die mit dem FSME-Virus mit einer MOI von 10 infiziert wurden, bestimmt. Als Kontrolle wurden DCs mit UV-inaktiviertem Virus und Virus-freiem Medium kokultiviert. Zusätzlich wurde die Restinfektiosität nach $72 \mathrm{~h}$ bei $37^{\circ} \mathrm{C}$ der zur Infektion eingesetzten Virussuspensionen bestimmt („Inputvirus“). Die Bestimmung der Virustiter erfolgte wie unter 2.2.2.3 beschrieben.

In der Abbildung 3.12 sind die jeweiligen Verdünnungsstufen des TCID $_{50}$ mit den $\mathrm{mDC}$ und pDC-Zellkulturüberständen sowie der Ausgangssuspension des Virus, dem Inputvirus und der Mock-Kontrolle dargestellt, bei denen bei den Vero-B4 Indikatorzellen noch ein CPE sichtbar war (linke Seite) und bei denen kein CPE mehr bei den Vero-B4Indikatorzellen mehr sichtbar war (rechte Seite). Zur besseren Veranschaulichung sind die berechneten Titer (s. Kapitel 2.2.2.3) der TCID $_{50}$-Analyse der DC-Zellkulturüberstände zusätzlich in einer Graphik zusammenfassend aufgeführt, die in der Abbildung 3.13 dargestellt ist.

Anhand der Abbildung 3.13 kann man sehen, dass der Virustiter in der Ausgangssuspension des FSME-Virus (Zellkulturüberstand FSME-Virus infizierter Vero-B4 Zellen) am höchsten ist. In den Zellkulturüberständen der mDCs, die mit dem FSME-Virus infiziert wurden, liegt der gemessene Titer bei $6,8 \times 10^{6} \mathrm{TCID}_{50} / \mathrm{ml}$. 1,5 log-Stufen darunter liegen die Virustiter der Zellkulturüberstände der pDCs, die mit dem FSME-Virus infiziert wurden, und der Titer des Inputvirus, das in einer zellfreien Umgebung unter den gleichen Bedingungen inkubiert wurde und die Restinfektiösität der Virussuspension nach $72 \mathrm{~h}$ bei $37^{\circ} \mathrm{C}$ aufzeigt. Aufgrund des um 1,5 log-Stufen höheren Virustiters der mDCs im Vergleich zur Restinfektösität des FSME-Virus, kann davon ausgegangen werden, dass sich das FSME-Virus in den mDCs vermehrt hat. Hingegen liegt der Virustiter der pDC-Überstände knapp unter dem Wert des Inputvirus, sodass hier keine effektive Vermehrung des Virus stattgefunden hat. Bei den Überständen der DCs, die mit dem UV-inaktiverten FSME-Virus kokultiviert wurden, wurde ein Titer von 1,3 x $10 \mathrm{TCID}_{50} / \mathrm{ml}$ ermittelt. In den Mock-Kontrollen war erwartungsgemäß kein Virus enthalten.

Somit konnte gezeigt werden, dass das FSME-Virus sehr viel effizienter in den mDCs als in den pDCs repliziert. 


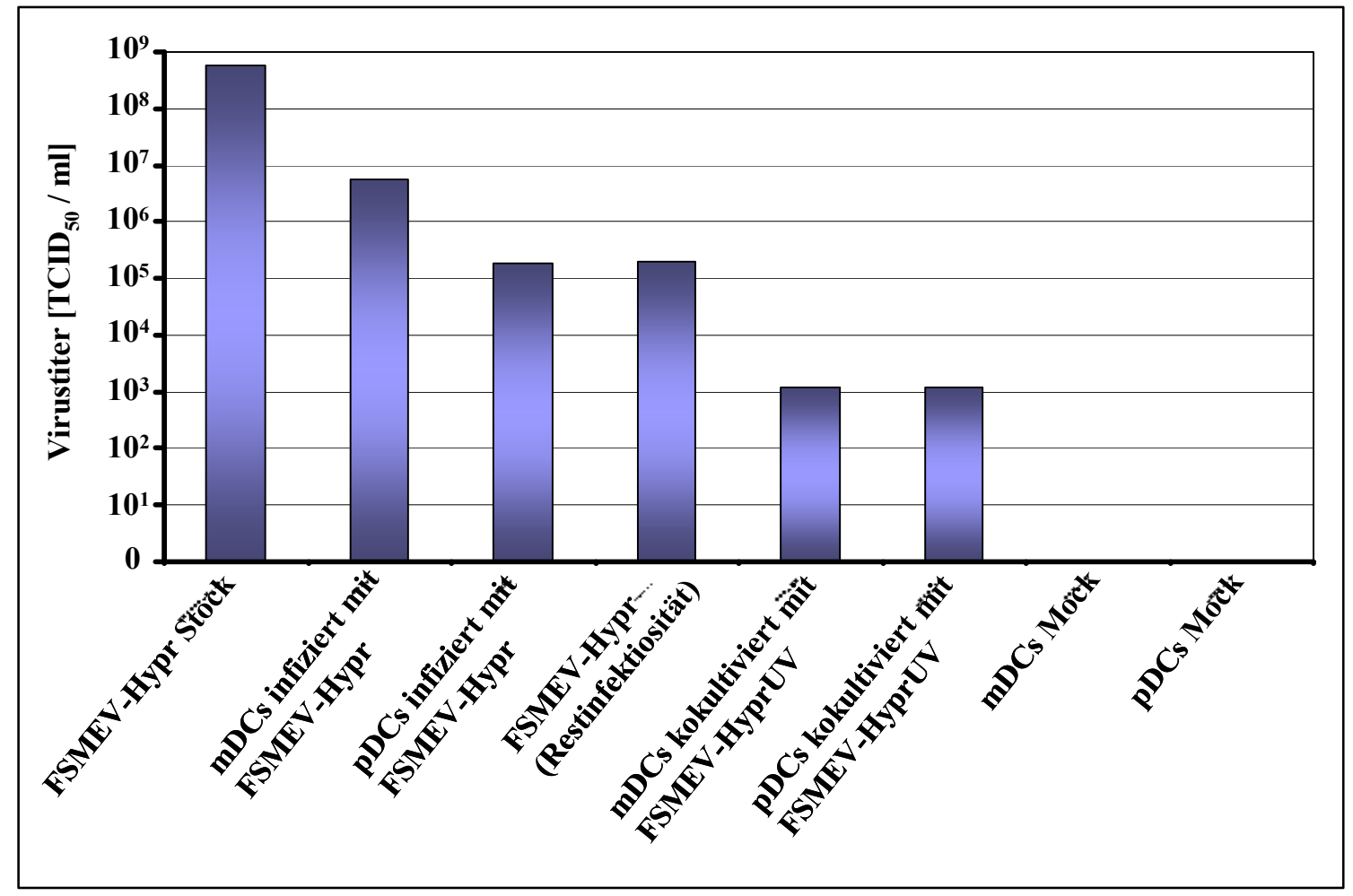

Abbildung 3.13: Darstellung der Ergebnisse der TCID ${ }_{50}$-Anaylsen von den mDC- und pDC Zellkulturüberständen.

In der Abbildung sind die Titer der einzelnen Zellkulturüberstände und des FSMEV-Hypr Stocks aufgeführt. Der Reihenfolge nach von links nach rechts sind die Titer des Virusstocks als Positivkontrolle (FSMEV-Hypr Stock), die Titer der Überstände der mDCs, die mit dem FSMEV-Stamm Hypr infiziert wurden (mDCs infiziert mit FSMEV-Hypr), die Titer der Überstände der pDCs, die mit dem FSMEVStamm Hypr infiziert wurden (pDCs infiziert mit FSMEV-Hypr), die Titer der Überstände der mDCs, die mit dem UV-inaktivierten FSMEV-Stamm Hypr kokultiviert wurden (mDCs kokultiviert mit FSMEVHyprUV), die Titer der Überstände der pDCs, die mit dem UV-inaktivierten FSMEV-Stamm Hypr kokultiviert wurden (pDCs kokultiviert mit FSMEV-HyprUV), und die Titer des Inputvirus zur Darstellung der Restinfektiosität (FSMEV-Hypr (Restinfektiosität)) dargestellt. Bei den beiden rechten Balken handelt es sich um die Titer der jeweiligen Mock-Kontrollen (mDCs links (mDCs Mock) und pDCs rechts (pDCs Mock)).

\subsubsection{Replikation des FSME-Virus in mit IFNAR-Antikörper behandelten pDCs}

Der Typ I Interferon-Signalweg, wird über den IFNAR aktiviert und führt zur Aktivierung der Expression von antiviral wirksamen ISGs. In dieser Arbeit konnte gezeigt werden, dass das FSME-Virus zum einen die Produktion von hohen Mengen von IFN- $\alpha$ in den pDCs induziert und zum anderen, dass eine effiziente FSMEVirusrepliaktion in den pDCs nicht stattfindet.

Um zu untersuchen, inwieweit die starke Interferon-Produktion in pDCs eine Rolle bei der Prävention der FSME-Virusreplikation spielt, wurde der IFNAR durch einen Antikörper blockiert und so die der Typ I IFN-Signalweg unterbrochen. Den Nachweis 
über eine mögliche Replikation des FSME-Virus wurde mittels TCID $_{50}$-Analysen der Zellkulturüberstände der pDCs auf Vero-B4 Indikatorzellen durchgeführt. Einige TCID $_{50^{-}}$ Analysen mit den Zellkulturüberständen wurden mit Hilfe des Mikroskops ausgewertet (s. Kapitel 2.2.8) und andere $\mathrm{TCID}_{50}$-Analysen mit den Zellkulturüberständen wurden anhand des MTT-Assays (s. Kapitel 2.2.7) untersucht. Dabei wurde die Zellviabilität der Vero-B4 Indikatorzellen untersucht. Zusätzlich wurden aus den pDCs und den Zellkulturüberständen der pDCs die gesamt RNA-isoliert und mittels der RT-PCR die Mengen an FSME-Virus RNA in den einzelnen Proben bestimmt (s. Kapitel 2.2.11.6 und Kapitel 2.2.11.7).

\subsubsection{Das FSME-Virus repliziert in den mit IFNAR-Antikörper behandelten pDCs}

Um die Replikation des FSME-Virus nachzuweisen, wurden pDCs mit und ohne IFNARAntikörper inkubiert und jeweils mit FSME-Virus infiziert, mit UV-inaktivierten FSMEVirus oder mit Medium als Mock-Kontrolle für 3 Tage kokultiviert. Mit den Zellkulturüberständen wurden $\mathrm{TCID}_{50}$-Analysen zur Virustiterbestimmung durchgeführt (s. Kapitel 2.2.2.3). Zusätzlich wurden die Virustiter der für die Infektionen verwendete Virussuspension als Positivkontrolle und die Restinfektiosität der verwendeten Virussuspension („Inputvirus“, s. Kapitel 2.2.2.5) bestimmt. Die Bilder der einzelnen Verdünnungstufen, bei denen noch ein CPE zu erkennen war und kein CPE mehr sichtbar war, sind in der Abbildung 3.14 dargestellt. In der Abbildung 3.14 sind die jeweiligen Verdünnungsstufen des TCID $_{50}$ mit den IFNAR-Antikörper behandelten pDC- und ohne Antikörper behandelten pDC-Zellkulturüberständen sowie der Ausgangssuspension des Virus, dem Inputvirus und der Mock-Kontrolle dargestellt, bei denen bei den Vero-B4 Indikatorzellen noch ein CPE sichtbar war (linke Seite) und bei denen kein CPE mehr bei den Vero-B4-Indikatorzellen sichtbar war (rechte Seite). Zur besseren Veranschaulichung sind die aus den $\mathrm{TCID}_{50}$-Analysen berechneten Titer (s. 2.2.2.3) zusammenfassend in der Abbildung 3.15 dargestellt. 


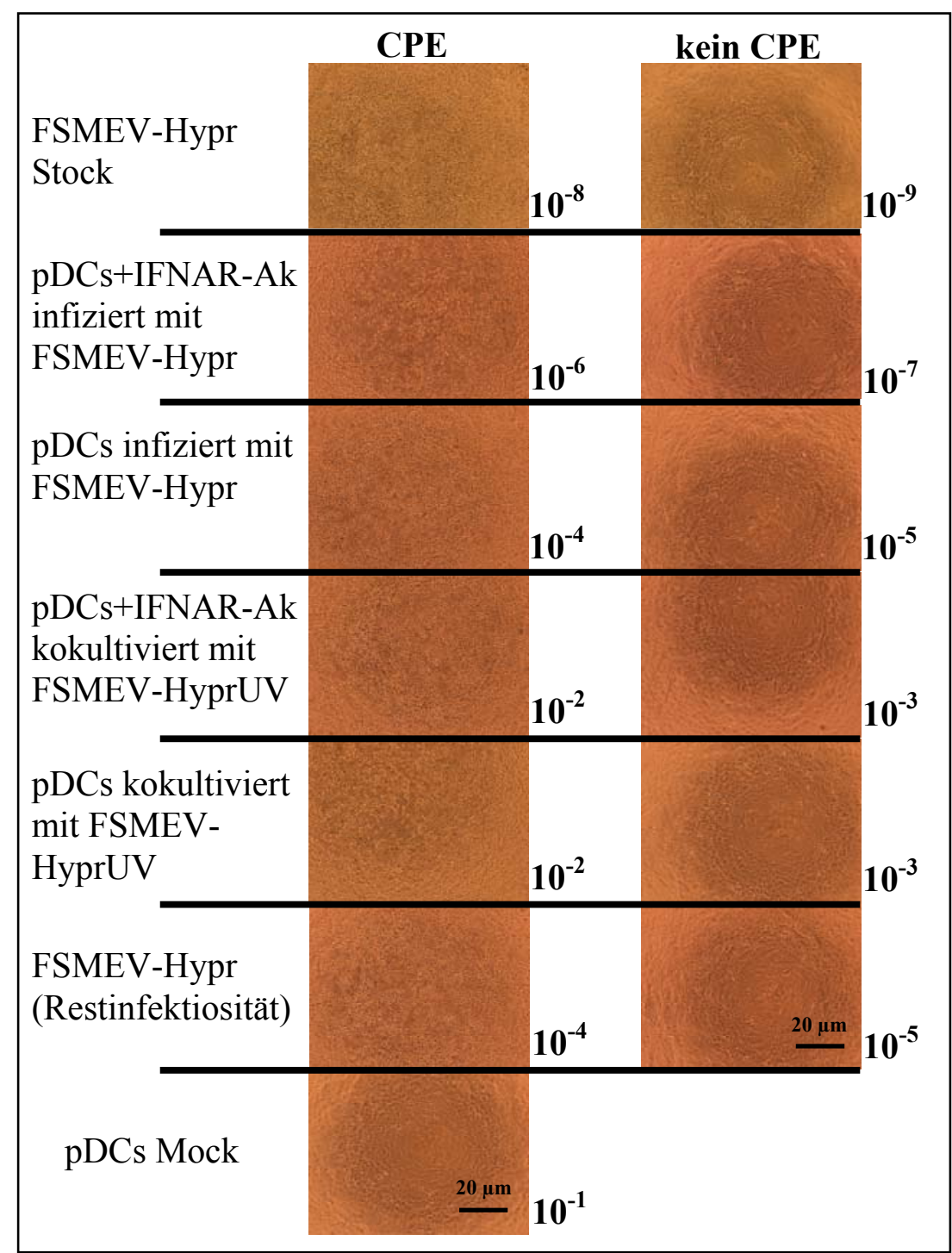

Abbildung 3.14: Darstellung der mikroskopischen Fotos der TCID $_{50}$-Analysen der pDC Zellkulturüberstände und der Überstände der IFNAR-Antikörper behandelten pDCs auf Vero-B4Indikatorzellen.

Auf der linken Seite sind die Verdünnungsstufen abgebildet, bei denen noch bei den Vero-B4 Indikatorzellen ein CPE zu erkennen ist und rechts die jeweiligen Verdünnungsstufen, bei denen kein CPE bei den Vero-B4 Zellen erkennbar ist. Die jeweiligen Verdünnungsstufen sind den Bildern rechts unten zugewiesen. In der Abbildung sind der Reihenfolge nach von oben bis unten folgende Bilder aufgeführt: Titration des Virusstocks als Positivkontrolle (FSMEV-Hypr Stock), Titration der Überstände der pDCs, die mit dem IFNAR-Antikörper vorinkubiert und mit dem FSMEV-Stamm Hypr infiziert wurden (pDCs+IFNAR-Ak infiziert mit FSMEV-Hypr), Titration der Überstände der pDCs, die mit dem FSMEVStamm Hypr infiziert wurden (pDCs infiziert mit FSMEV-Hypr), Titration des Inputvirus zur Darstellung der Restinfektiosität (FSMEV-Hypr (Restinfektiosität)), Titration der Überstände der pDCs, die mit dem IFNAR-Antikörper vorinkubiert und mit dem FSMEV-Stamm Hypr infiziert wurden (pDCs+IFNAR-Ak kokultiviert mit FSMEV-HyprUV), Titration der Überstände der pDCs, die mit dem UV-inaktivierten FSMEV-Stamm Hypr kokultiviert wurden (pDCs kokultiviert mit FSMEV-HyprUV), und die Titration der Überstände der pDCs, die mit dem UV-inaktivierten FSMEV-Stamm Hypr kokultiviert wurden (pDCs kokultiviert mit FSMEV-HyprUV). Auf dem unteren Bild ist die Mock-Kontrolle abgebildet (pDCs Mock). 


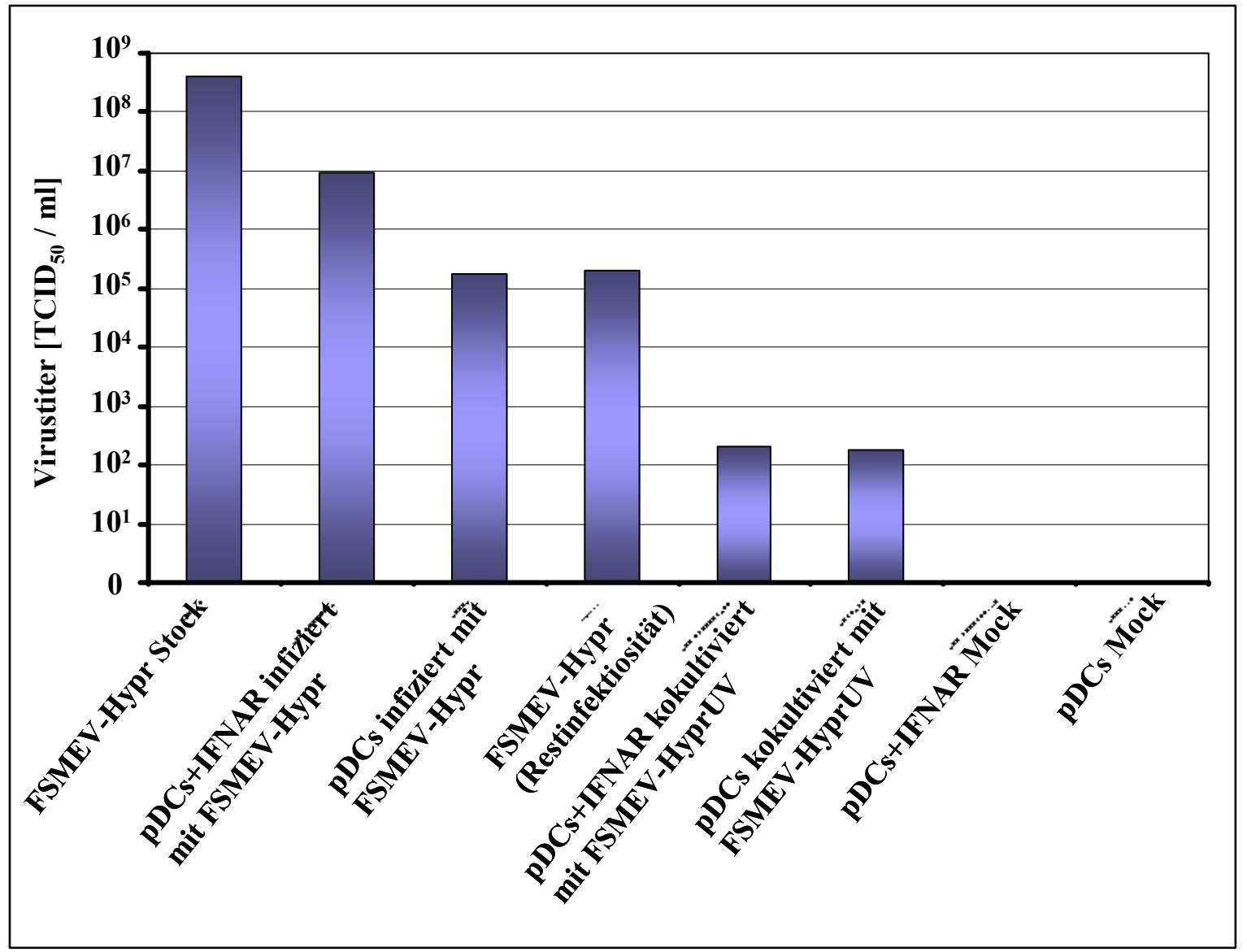

Abbildung 3.15: Darstellung der Ergebnisse der TCID $_{50}$-Analysen der pDC Zellkulturüberstände und der Überstände der IFNAR-Antikörper behandelten pDCs.

In der Abbildung sind die Titer der einzelnen Zellkulturüberstände und des FSMEV-Hypr Stocks aufgeführt. Der Reihenfolge nach von links nach rechts sind die Titer des Virusstocks als Positivkontrolle (FSMEV-Hypr Stock), die Titer der Überstände der pDCs, die mit dem IFNAR-Antikörper vorinkubiert und mit dem FSMEV-Stamm Hypr infiziert wurden (pDCs+IFNAR-Ak infiziert mit FSMEV-Hypr), die Titer der Überstände der pDCs, die mit dem FSMEV-Stamm Hypr infiziert wurden (pDCs infiziert mit FSMEV-Hypr), die Titer des Inputvirus zur Darstellung der Restinfektiosität (FSMEV-Hypr (Restinfektiosität)), die Titer der Überstände der pDCs, die mit dem IFNAR-Antikörper vorinkubiert und mit dem FSMEV-Stamm Hypr infiziert wurden (pDCs+IFNAR-Ak kokultiviert mit FSMEV-HyprUV), die Titer der Überstände der pDCs und die Titer der Überstände, die mit dem UV-inaktivierten FSMEV-Stamm Hypr kokultiviert wurden (pDCs kokultiviert mit FSMEV-HyprUV) dargestellt. Bei den beiden rechten Balken handelt es sich um die Titer der Mock-Kontrollen der pDCs, die mit dem IFNAR-Ak behandelt wurden (pDC+IFNAR Mock), und der pDCs ohne Antikörperbehandlung (pDC Mock).

Der Titer in der Ausgangsvirussuspension beläuft sich auf 4,1 x $10^{8} \mathrm{TCID}_{50} / \mathrm{ml}$. Der Virustiter der Zellkulturüberstände der Zellkulturüberstände der pDCs, die mit dem IFNAR-Antikörper behandelt wurden und darauf mit dem FSME-Virus infiziert wurden, beläuft sich auf 9,4 x $10^{6}$ TCID $_{50} / \mathrm{ml}$ und der Virustiter der Zellkulturüberstände der pDCs, die nicht mit dem IFNAR-Antikörper behandelt wurden und nur mit dem FSMEVirus infiziert wurden, beträgt $1,8 \times 10^{5} \mathrm{TCID}_{50} / \mathrm{ml}$ und liegt damit knapp unter dem 
Virustiter, der noch in der Inputvirus-Kontrolle als Restinfektiosität enthalten ist. Die Virustiter der Zellkulturüberstände der pDCs, die sowohl mit dem IFNAR-Antikörper behandelt wurden als auch ohne Antikörperbehandlung anschließend mit dem UVinaktivierten FSME-Virus kokultiviert wurden, liegen 3 log-Stufen unter den Titern der Überstände der Zellen, die mit dem aktiven Virus infiziert wurden. Das bedeutet, dass das durch die UV-Behandlung replikationsinkompetente FSME-Virus sich erwartungsgemäß nicht weiter in den Zellen vervielfältigt hat. In den Mock-Kontrollen konnte kein CPE der Vero-B4 Indikatorzellen nachgewiesen werden, sodass in den Zellkulturüberständen der Mock-Kontrollen (mit und ohne IFNAR-Antikörper Behandlung) erwartungsgemäß kein Virus vorhanden ist.

Damit lag der Virustiter der Zellkulturüberstände der pDCs, die mit dem IFNARAntikörper behandelt wurden und anschließend mit dem FSME-Virus infiziert wurden, um fast 2 log-Stufen über dem Virustiter der Zellkulturüberstände der pDCs, die mit dem FSME-Virus infiziert, aber nicht mit dem IFNAR-Antikörper inkubiert wurden. Dieser wiederum liegt noch knapp unter dem Wert, der für die Restinfektiosität ermittelt wurde, d. h. eine effiziente Replikation des FSME-Virus findet in unbehandelten pDCs nicht statt. Aus den Ergebnissen lässt sich ableiten, dass durch Blockierung des IFNAR eine Replikation des FSME-Virus in pDCs ermöglicht wird, was darauf schließen lässt, dass die starke IFN- $\alpha$-Produktion nach FSME-Virusinfektion für die Hemmung der Virusreplikation verantwortlich ist.

\subsubsection{Bestimmung der Zellviabilität nach FSME-Virusinfektion mittels MTT-}

\section{Assay}

Zusätzlich zur mikroskopischen Untersuchung der TCID $_{50}$-Analysen wurde eine Zellviabilitätsbestimmung der Vero-B4 Indikatorzellen durchgeführt, die mit den Zellkulturüberständen sowie dem Ausgangsstock des Virus und dem Inputvirus kokultiviert wurden. Die Viabilität der Zellen wurde mittels des MTT-Assays analysiert (s. Kapitel 2.2.7). Die Ergebnisse der Zellviabilitätsanalyse mittels des MTT-Assays sind in der Abbildung 3.16 dargestellt. 


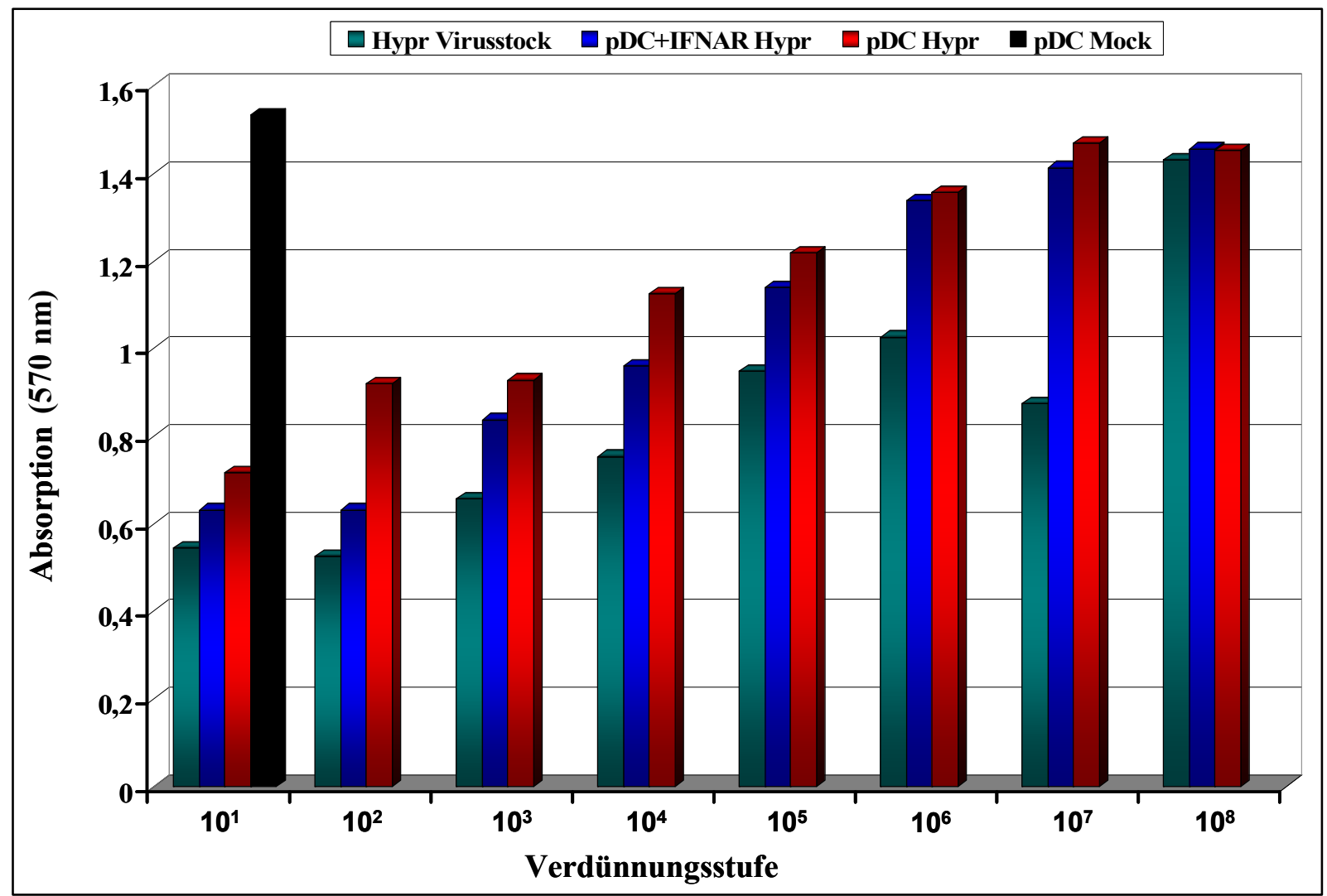

Abbildung 3.16: Ergebnisse des TCID T0 $_{50}$ des MTT-Assays mit den Zellkulturüberständen der pDCs. Auf der Abszisse sind die einzelnen Verdünnungsstufen der Überstände dargestellt und auf der Ordinate die Absorptionswerte bei einer Wellenlänge von $570 \mathrm{~nm}$. Die grünen Balken stellen den Virussuspension des Ausgangsstocks als Positivkontrolle dar, die blauen Balken die Zellkulturüberstände der pDCs, die mit dem FSME-Virus infiziert wurden, die roten Balken die Zellkulturüberstände der pDCs, die zusätzlich mit dem IFNAR-Antikörper behandelt wurden, und der schwarze Balken den Zellkulturüberstand der MockKontrolle.

In der Abbildung 3.16 kann man erkennen, dass die Absorption des solubilisierten Farbstoffs in den Proben mit den Vero-B4 Indikatorzellen, die direkt mit dem FSMEVirus infiziert wurden bis zu der Verdünnungsstufe $10^{7}$ sehr gering ist (grüne Balken). Das liegt daran, dass das FSME-Virus die suszeptiblen Vero-B4-Indikatorzellen infiziert und zerstört, sodass die Zellviabilität und demzufolge die gemessene Absorption abnimmt. In der Mock-Kontrolle ist erwatungsgemäß kein Virus vorhanden, sodass die Vero-B4 Indikatorzellen eine hohe Zellviabilitätsrate aufweisen, was sich in den hohen Absorptionswerten widerspiegelt (schwarzer Balken). Die Absorptionswerte und damit die Zellviabilität der Vero-B4 Indikatorzellen, die mit den Überständen der IFNARAntikörper behandelten und mit dem FSME-Virus infizierten pDCs inkubiert (blaue Balken) wurden, liegt bis zu einer Verdünnungsstufe von $10^{5}$ deutlich unter den 
Werten der nicht mit dem IFNAR-Antikörper inkubierten pDCs (rote Balken). Daraus lässt sich schließen, dass in den IFNAR-Antikörper vorbehandelten pDCs eine verstärkte Replikation des FSME-Virus stattgefunden hat, die zu einem entsprechend stärkeren CPE führt als in unbehandelten pDCs. Dieser Befund deckt sich mit den unter 3.1.7.1 beschriebenen Ergebnissen der $\mathrm{TCID}_{50}$-Bestimmungen, und lässt ebenfalls den Schluss $\mathrm{zu}$, dass eine Hemmung des Typ I IFN-Signalwegs in pDCs eine Replikation von FSMEVirus erlaubt.

\subsubsection{Der Nachweis von FSME-Virus RNA in infizierten DCs}

Um zum einen zu zeigen, dass das FSME-Virus die pDCs infiziert und zum anderen um nachzuweisen, dass das FSME-Virus in den pDCs repliziert, bei denen der IFNARSignalweg blockiert ist und dementsprechend die Induktion der Expression von antiviral wirksamen ISGs verhindert wird, wurde aus pDCs, die mit und ohne dem IFNARAntikörper koinkubiert wurden, sowie aus deren Überständen virale RNA isoliert und eine Quantifizierung mittels der RT-PCR durchgeführt. Sollte das FSME-Virus in den Zellen replizieren, die mit dem IFNAR-Antikörper behandelt wurden, so müsste folglich auch der Gehalt an viraler RNA in den Zellen und Zellkulturüberständen zunehmen.

Um einen negativen Einfluss des DNA-Anteils in der RNA-Probe, der in den Zellen ebenfalls vorhanden ist und unter Umständen bei der RNA-Isolation zu einem gewissen Grad mit aufgereinigt wurde, bei der RT-PCR der mRNA auszuschließen, erfolgte eine Aufreinigung der isolierten RNA-Proben mittels dem TURBO DNA-free Kit der Firma AB Applied Biosystems. Um die Reinheit der isolierten und aufgereinigten RNA-Proben zu überprüfen, wurde eine PCR mit diesen Proben durchgeführt. Da bei einer PCR keine RNA amplifiziert werden kann, sollten keine PCR-Produkte in den PCR-Ansätzen vorhanden sein, in denen die RNA-Proben eingesetzt wurden. Als spezifische Primer wurden die GAPDH-Primer und die GAPDH-Sonde benutzt, da es sich bei dem Gen der GAPDH um ein so genanntes housekeeping-Gen handelt, das unter jedem Zellstatus und Umstand in der lebenden Zelle repliziert wird. Das zu erwartende Amplikon der GAPDHPCR weist eine Fragmentgröße von 70 bp auf. Mit den PCR-Produkten wurde anschließend eine Agarose-Gelelektrophorese mit einem 2\%igen Agarose-Gel durchgeführt. In Abbildung 3.17 ist die elektrophoretische Auftrennung der Amplifikationsprodukte dargestellt. 
Es ergab sich, dass nach DNase-Behandlung (Spur 5) kein GAPDH-spezifisches Amplifikat mehr nachzuweisen ist. Bei dem zu detektierenden Signal handelt es sich um nicht umgesetzte Primer bzw. Sonde, die auch in der Wasserkontrolle (Spur 1) sichtbar sind. Im Gegensatz hierzu ist in den DNA-haltigen Proben (Spur 3 und 4) ein Amplifikat sichtbar. Damit erfüllen die DNase-behandelten RNA-Proben die für den RNA-Nachweis notwendige Voraussetzung, dass keine DNA-Kontaminationen mehr vorhanden sind, die zu einem falsch positiven Ergebnis führen könnten.

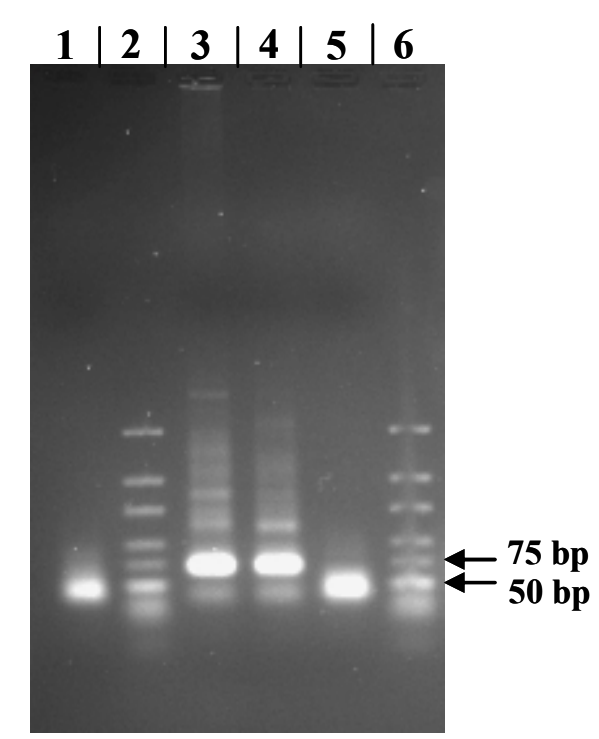

Spur 1: Negativkontrolle

Spur 2: GeneRuler ${ }^{\mathrm{TM}}$ Ultra Low Range DNA Ladder $(0.5 \mu \mathrm{g} / \mu \mathrm{l})$

Spur 3: DNA-Kontrolle 1 (aus pDCs isolierte gesamt-DNA)

Spur 4: DNA-Kontrolle 2 (aus pDCs isolierte gesamt-DNA)

Spur 5: RNA isoliert aus uninfizierten und mit IFNAR-Antikörper behandelten pDCs (behandelt mit Ambion TURBO DNA-free Kit)

Spur 6: Marker (GeneRuler Ultra Low Range DNA Ladder $(0.5 \mu \mathrm{g})$ )

Abbildung 3.17: Foto des 2\%igen Agarosegels mit den aufgetragenen GAPDH-RT-PCR Produkten. 


\subsubsection{FSMEV-RT-PCR der pDCs}

Um den Gehalt an FSME-Virus-RNA in der aus FSME-Virus infizierten pDCs bzw. aus deren Überständen isolierten gesamt-RNA zu quantifizieren, wurde eine real time FSMEV-RT-PCR wie unter 2.2.11.7. beschrieben durchgeführt.

Neben den eigentlichen Proben, wurde bei der FSMEV-RT-PCR zusätzlich eine Negativkontrolle (dabei wurde die RNA durch Wasser ersetzt) und ein FSME-Virus-RNA Standardreihe mitgeführt. Bei der FSME-Virus-Standardreihe handelte es sich um in vitro transkribierte FSME-Virus RNA, die in 7 verschiedenen definierten Konzentrationen $\left(1 \times 10^{7}\right.$ Molekülen $/ \mathrm{ml}$ in Verdünnungsschritten um den Faktor 10 bis $1 \times 10^{1}$ Molekülen / ml) verdünnt war. Durch die Bildung des Verhältnisses von Cp-Wert zur enthaltenen viralen Kopienzahl der einzelnen Verdünnungen des Standards konnte eine Standardkurve erstellt werden, mit der die Kopienzahl / $\mu 1$ in den einzelnen RNAProben bestimmt werden konnten. Die einzelnen Cp-Werte der FSMEV-RT-PCR sowie die anhand des FSME-Virus-RNA-Standards berechneten RNA-Konzentration von den RNA-Proben aus den pDCs und den Zellkulturüberständen sind in der Tabelle 3.1 aufgeführt.

Aus der Abbildung 3.18 sowie der Tabelle 3.1 geht hervor, dass der Gehalt an RNA in den pDCs, die mit dem IFNAR-Antikörper inkubiert wurden, um etwa den Faktor 2 höher war, als in den Überständen der unbehandelten pDCs. Demzufolge sind die Konzentrationen an viraler RNA in den mit dem IFNAR-Antikörper behandelten, wie auch in den unbehandelten pDCs ähnlich. Daraus lässt sich schließen, dass das FSMEVirus in die pDCs gelangt und virale RNA unabhängig von dem Typ I IFN-Signalweg und den daher induzierten antiviral wirkenden Faktoren in den pDCs vorhanden ist. Dagegen fällt der Unterschied bei den RNA-Konzentrationen der Zellkulturüberstände deutlicher aus. So ist der Tabelle 3.1 und der Abbildung $3.18 \mathrm{zu}$ entnehmen, dass die Konzentration an FSME-Virus-RNA in den Überständen der pDCs, die mit dem IFNARAntikörper inkubiert wurden, um etwa den Faktor 20 größer ist, als die FSME-VirusRNA-Konzentration in den Überständen der unbehandelten pDCs. Demzufolge ist in den Überständen der pDCs, die mit dem IFNAR-Antikörper inkubiert wurden, erheblich mehr Virus vorhanden, als in den Überständen der unbehandelten pDCs. Daraus lässt sich schließen, dass sich das FSME-Virus in den pDCs vermehrt hat, bei denen der Typ I IFNSignalweg gehemmt ist. 
Tabelle 3.1: Aufführung der Cp-Werte und RNA-Konzentrationen der FSMEV-RT-PCR der RNAProben aus den pDC-Überständen sowie aus den pDCs und des FSME-Virus-RNA Standards.

\begin{tabular}{|c|c|c|}
\hline $\begin{array}{c}\text { RNA-Standard- } \\
\text { Probe }\end{array}$ & $\begin{array}{c}\text { Cp-Wert der } \\
\text { FSMEV-RT-PCR }\end{array}$ & $\begin{array}{c}\text { Konzentration } \\
{[\text { Kopien / } \mu \mathrm{l}]}\end{array}$ \\
\hline FSME-Virus-Standard $\left(10^{1}\right.$ Kopien $\left./ \mu \mathrm{l}\right)$ & 37,75 & $10^{1}$ \\
\hline FSME-Virus-Standard $\left(10^{2}\right.$ Kopien $\left./ \mu \mathrm{l}\right)$ & 35,90 & $10^{2}$ \\
\hline FSME-Virus-Standard $\left(10^{3}\right.$ Kopien $\left./ \mu \mathrm{l}\right)$ & 34,11 & $10^{3}$ \\
\hline FSME-Virus-Standard $\left(10^{4}\right.$ Kopien $\left./ \mu \mathrm{l}\right)$ & 31,26 & $10^{4}$ \\
\hline FSME-Virus-Standard $\left(10^{5}\right.$ Kopien $\left./ \mu \mathrm{l}\right)$ & 28,27 & $10^{5}$ \\
\hline FSME-Virus-Standard $\left(10^{6}\right.$ Kopien $\left./ \mu 1\right)$ & 24,75 & $10^{6}$ \\
\hline FSME-Virus-Standard $\left(10^{7}\right.$ Kopien $\left./ \mu \mathrm{l}\right)$ & 21,22 & $10^{7}$ \\
\hline RNA-Probe & $\begin{array}{c}\text { Cp-Wert der } \\
\text { FSMEV-RT-PCR }\end{array}$ & $\begin{array}{c}\text { Konzentrationen } \\
\text { [Kopien / } \mu \mathrm{l}]\end{array}$ \\
\hline pDCs+IFNAR-Ak, Mock, Zellen (1 ng) & - & 0 \\
\hline pDCs+IFNAR-Ak, Mock, Überstand ( $1 \mu \mathrm{l})$ & - & 0 \\
\hline pDCs+IFNAR-Ak, Hypr, Zellen (1 ng) & 26,51 & $2,89 \times 10^{5}$ \\
\hline pDCs+IFNAR-Ak, Hypr, Überstand $(1 \mu \mathrm{l})$ & 23,15 & $2,86 \times 10^{6}$ \\
\hline pDCs, Mock, Zellen (1 ng) & - & 0 \\
\hline pDCs, Mock, Überstand ( $1 \mu 1)$ & - & 0 \\
\hline pDCs, Hypr, Zellen (1 ng) & 27,15 & $1,87 \times 10^{5}$ \\
\hline pDCs, Hypr, Überstand $(1 \mu \mathrm{l})$ & 27,80 & $1,26 \times 10^{5}$ \\
\hline
\end{tabular}

Dieser Befund geht einher mit den unter 3.1.7.1 und der unter 3.1.7.2. beschriebenen Ergebnissen der TCID $_{50}$-Bestimmungen bzw. der MTT-Analysen. Damit lässt sich schlußfolgern, dass durch die Hemmung des Typ I IFN-Signalwegs in den pDCs die Replikation von FSME-Virus ermöglicht wird. 


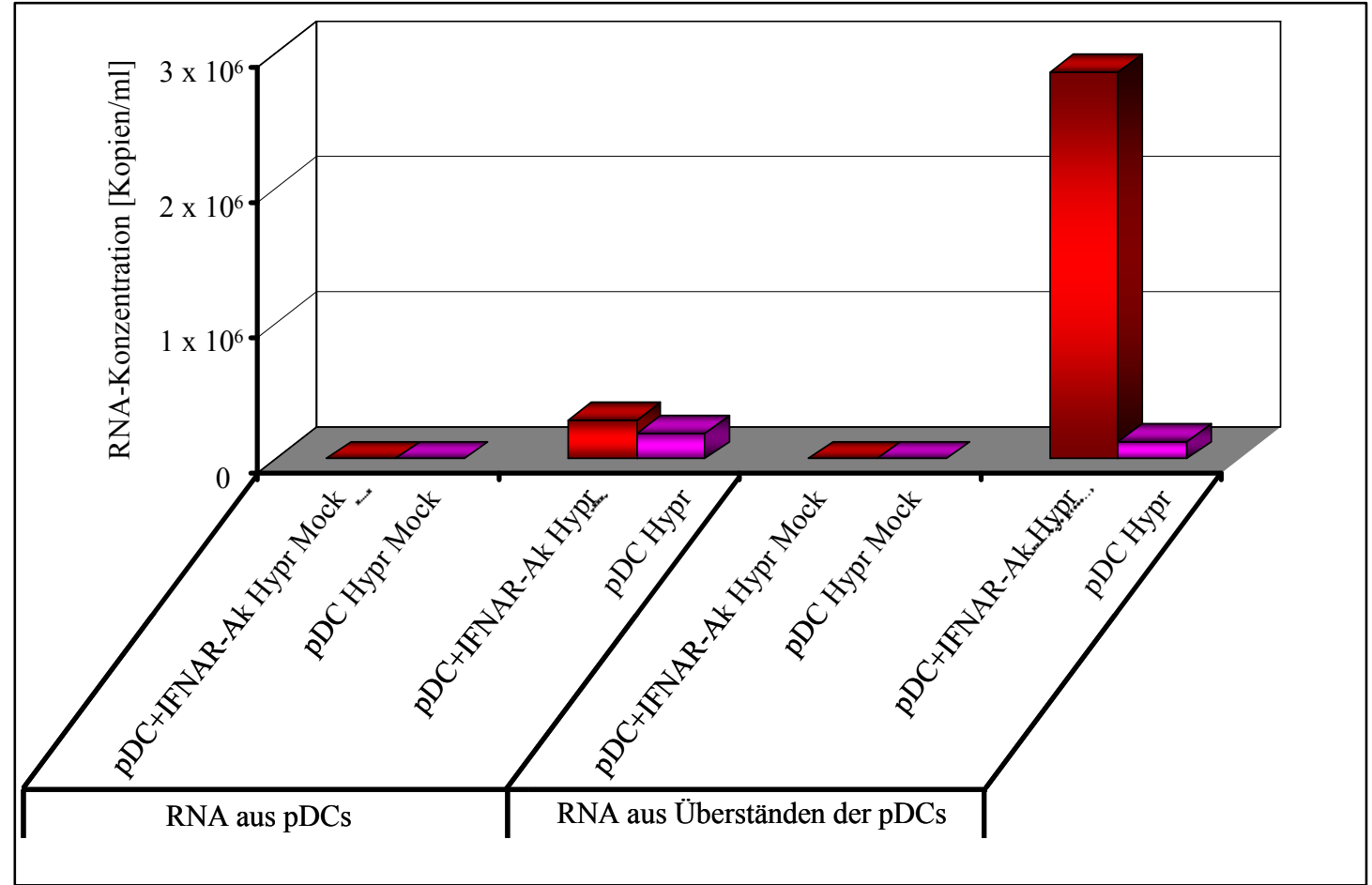

Abbildung 3.18: Darstellung der berechneten RNA-Konzentrationen der RNA-Proben aus den pDCs und den Zellkulturüberständen.

Die roten Balken stellen die RNA-Konzentrationen der RNA-Proben dar, die aus den pDCs bzw. Zellkulturüberstäden der pDCs isoliert wurden, die mit dem IFNAR-Antikörper vorinkubiert wurden. Die blauen Balken stellen die RNA-Konzentrationen der RNA-Proben dar, die aus den pDCs bzw. Zellkulturüberstäden der pDCs isoliert wurden. Auf der linken Seite sind die RNA-Proben aufgeführt, die aus den pDCs isoliert wurden und auf der rechten Seite die RNA-Proben, die aus den Zellkulturüberständen der pDCs isoliert wurden.

\subsection{Die T-Zell-Antwort auf die FSME-Virusinfektion}

Die T-Zellen stellen eine wichtige Komponente der adaptiven Immunantwort bei der Bekämpfung von viralen Eindringlingen dar. Aus diesem Grund wäre es naheliegend, dass das FSME-Virus die Antwort der T-Zellen beeinflusst, um Mechanismen oder Komponenten der adaptiven Immunantwort zu umgehen.

Um den Einfluss des FSME-Virus auf die Expression verschiedener Oberflächenmoleküle der T-Zellen zu untersuchen, wurden T-Zellen aus humanen Buffy-Coats isoliert und mit dem FSME-Virus infiziert oder mit UV-inaktivertem Virus sowie Medium als MockKontrolle kokultiviert. Die Zellen wurden $72 \mathrm{~h}$ nach der Infektion geerntet und mittels Fluorochrom-gekoppelten Antikörper und der Durchflußzytometrie auf die Expression verschiedener Oberflächenmoleküle untersucht (s. Kapitel 3.2.2). Weiterhin wurden von den kultivierten T-Zellen nach 12 h, 24 h, 48 h und 72 h die Überstände abgenommen, um 
die Zytokinantwort der T-Zellen auf das FSME-Virus zu analysieren. Die Zytokinantwort der T-Zellen ist in Kapitel 3.2.3 aufgeführt. Darüber hinaus kommen die T-Zellen auch als möglicher Verbreitungsfaktor des FSME-Virus im menschlichen Körper in Frage. Um zu untersuchen, ob das FSME-Virus in den T-Zellen repliziert wurden $\mathrm{TCID}_{50}$-Analysen durchgeführt, die mittels Mikroskop oder MTT-Assay analysiert wurden. Die Ergebnisse der Replikationsanalysen sind in dem Kapitel 3.2.4 dargestellt.

Zur Untersuchung der Proliferation von $\mathrm{CD}^{+}-$und $\mathrm{CD}^{+}$T-Zellen wurde eine Proliferationsanalyse der T-Zellen in einer PBMC-Kultur durchgeführt (3.3.3. Proliferationstest der T-Zellen). Dazu wurden aus humanen Buffy-Coats isolierte PBMCs mit CFSE gefärbt und nach 3 und 5 Tagen mittels des Durchflußzytometers auf eine erfolgte Proliferation analysiert. Die Ergebnisse der Proliferationsanalyse sind in dem Kapitel 3.2.5 aufgeführt.

\subsubsection{Reinheitsbestimmung der isolierten T-Zellen}

Um die Reinheit der aus humanen Buffy-Coats isolierten T-Zellen zu kontrollieren und damit mögliche Kontaminationen mit anderen Zellpopulation auszuschließen, wurden die T-Zellen direkt nach der Isolation mit spezifischen Fluorochrom-gekoppelten Antikörpern behandelt und anschließend mit Hilfe des Durchflußzytometers analysiert. Als spezifische Marker der T-Zellen wurden die Oberflächenmoleküle CD2 und CD3 herangezogen. Die T-Zellen wurden mit entsprechenden Fluorochrom-gekoppelten Antikörpern (PE für antiCD2, Pacific Blue für anti-CD3), die gegen diese Oberflächenmoleküle gerichtet waren, behandelt und durchflußzytometrisch untersucht. Die Ergebnisse der Reinheitsanalyse sind in der Abbildung 3.19 dargestellt.

Unter dem Punkt A der Abbildung 3.19 sind auf der linken Seite die isolierten T-Zellen als Dot-Plot-Diagramm in der SSC-FSC-Auftragung dargestellt. Die rechte Graphik zeigt die Gegenüberstellung der CD3 (Abszisse) und CD2 (Ordinate)-Marker. Es wurden T-Zellen für die durchflußzytometrischen Analysen benutzt, deren Reinheit nach der Isolation über 90 \% lag, d. h. die eine Expression der beiden Oberflächenmarker CD2 und CD3 aufwiesen (s. Abbildung 3.19 A, rechtes Diagramm, rechter oberer Quadrant). Unter Punkt B der Abbildung 3.19 ist in den Histogrammen die Expression der beiden spezifischen Marker CD2 (Punkt B, links, blaue Linie) und CD3 (Punkt B, rechts, blaue Linie) im Vergleich zur Isotypenkontrolle (Negativkontrolle, schwarze Linien) gezeigt. 


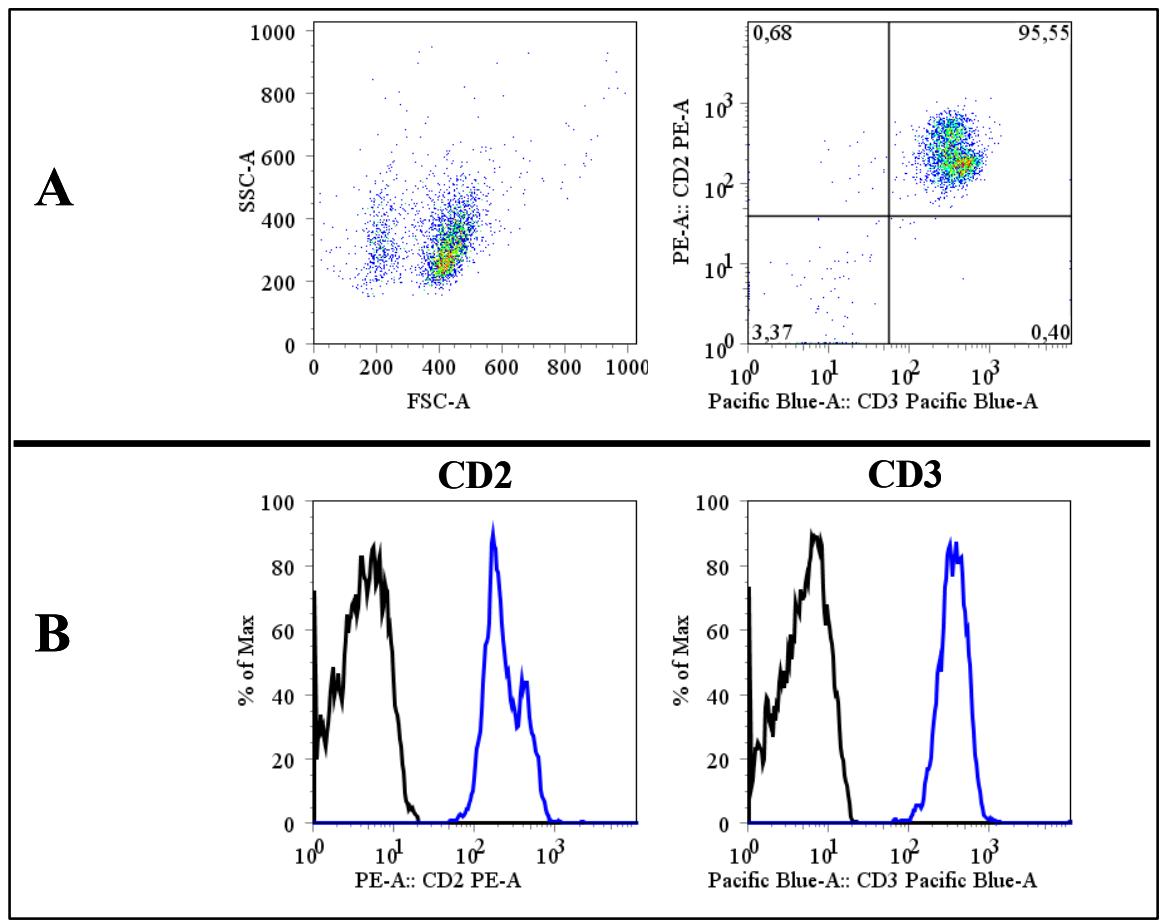

Abbildung 3.19: Reinheitsanalyse der isolierten T-Zellen.

Unter Punkt A sind die T-Zellen als Dot-Plot-Diagramme dargestellt. Die linke Graphik zeigt die T-Zellen in der FSC (Abszisse)-SSC (Ordinate)-Darstellung und die rechte Graphik die Auftragung der Fluoreszenzen der spezifischen Marker CD3 (Abszisse)- zu den CD2 (Ordinate). Unter Punkt B sind die Histogramme der Fluoreszenzintensität bezüglich der Markierung mit den spezifischen Antikörpern gegen CD2 (links) und CD3 (rechts) dargestellt. Die Isotypenkontrollen sind als schwarze Linien und die jeweiligen Marker als blaue Linien aufgeführt.

\subsubsection{Das FSME-Virus beeinflusst die Expression von Oberflächenmolekülen der T-Zellen}

Um die Expression einiger Oberflächenmolekülen bei den T-Zellen über drei Tagen hinweg zu analysieren, wurden nach 12 h, 24 h, $48 \mathrm{~h}$ und $72 \mathrm{~h}$ die T-Zellen geerntet, die vorher mit FSME-Virus infiziert worden waren bzw. mit UV-inaktivierten FSME-Virus oder Medium als Mock-Kontrolle kokultiviert wurden. Die T-Zellen wurden mit spezifischen Fluorochrom-gekoppelten Antikörpern gegen die entsprechenden Oberflächenmoleküle behandelt und mittels der durchflußzytomertrischen Analyse untersucht. Bei den T-Zellen wurde die Expression der spezifischen Oberflächenmoleküle CD3, CD4 und CD8, um die T-Zellpopulationen differenzieren zu können, sowie die Aktivierungsmarker CD69, CD25 und MHC-II analysiert. Die Ergebnisse der durchflußzytometrischen Analyse der T-Zellen sind in den Abbildung 3.20 für die CD4 ${ }^{+}$und Abbildung 3.21 für die $\mathrm{CD}^{+} \mathrm{T}$-Zellen dargestellt. Vergleicht man die Expression der 
Oberflächenmoleküle der $\mathrm{CD} 4^{+}-$und $\mathrm{CD} 8^{+} \mathrm{T}$-Zellen miteinander, so kann man bis auf den für die jeweiligen Subtypen spezifischen Marker CD4 bzw. CD8 keine Unterschiede erkennen. Dabei kann man in beiden Abbildungen beobachten, dass bei beiden T-ZellSubtypen über die Zeit von $72 \mathrm{~h}$ nur der Aktivierungsmarker CD69 bei den T-Zellen, die mit dem FSME-Virus infiziert wurden, verstärkt exprimiert wird. Die T-Zellen, die mit dem UV-inaktivierten FSME-Virus koinkubiert wurden, zeigen dabei bezüglich der Expression des Aktivierungsmarkers ein ähnliches Bild wie die Mock-Kontrolle. Bei den beiden anderen Aktivierungsmarker CD25 und MHC-II dagegen konnte kein Unterschied zwischen den T-Zellen, die mit inaktiviertem und aktivem FSME-Virus koinkubiert wurden, beobachtet werden. Dagegen wurde der Aktivierungsmarker CD25 auf den T-Zellen, die lediglich mit dem Medium als Mock-Kontrolle koinkubiert wurden, nach $24 \mathrm{~h}$ und $72 \mathrm{~h}$ stärker exprimiert als bei den mit dem FSME-Virus infizierten T-Zellen. Bei der Expression des späten Aktivierungsmarkers MHC-II konnten zwischen der MockKontrolle und den T-Zellen, die mit inaktiviertem oder aktivem FSME-Virus koinkubiert wurden, keine Unterschiede festgestellt werden. Demnach scheint es, dass die beiden T-Zellsubtypen im Rahmen der Infektion mit dem FSME-Virus nur zu einer unvollständigen Aktivierung kommt, da lediglich eine verzögerte und transiente Verstärkung der Expression des frühen Aktivierungsmarkers CD69 zu beobachten war, während für CD25 teilweise sogar eine verminderte Expression nach Kontakt mit FSMEVirus beobachtet wurde. 


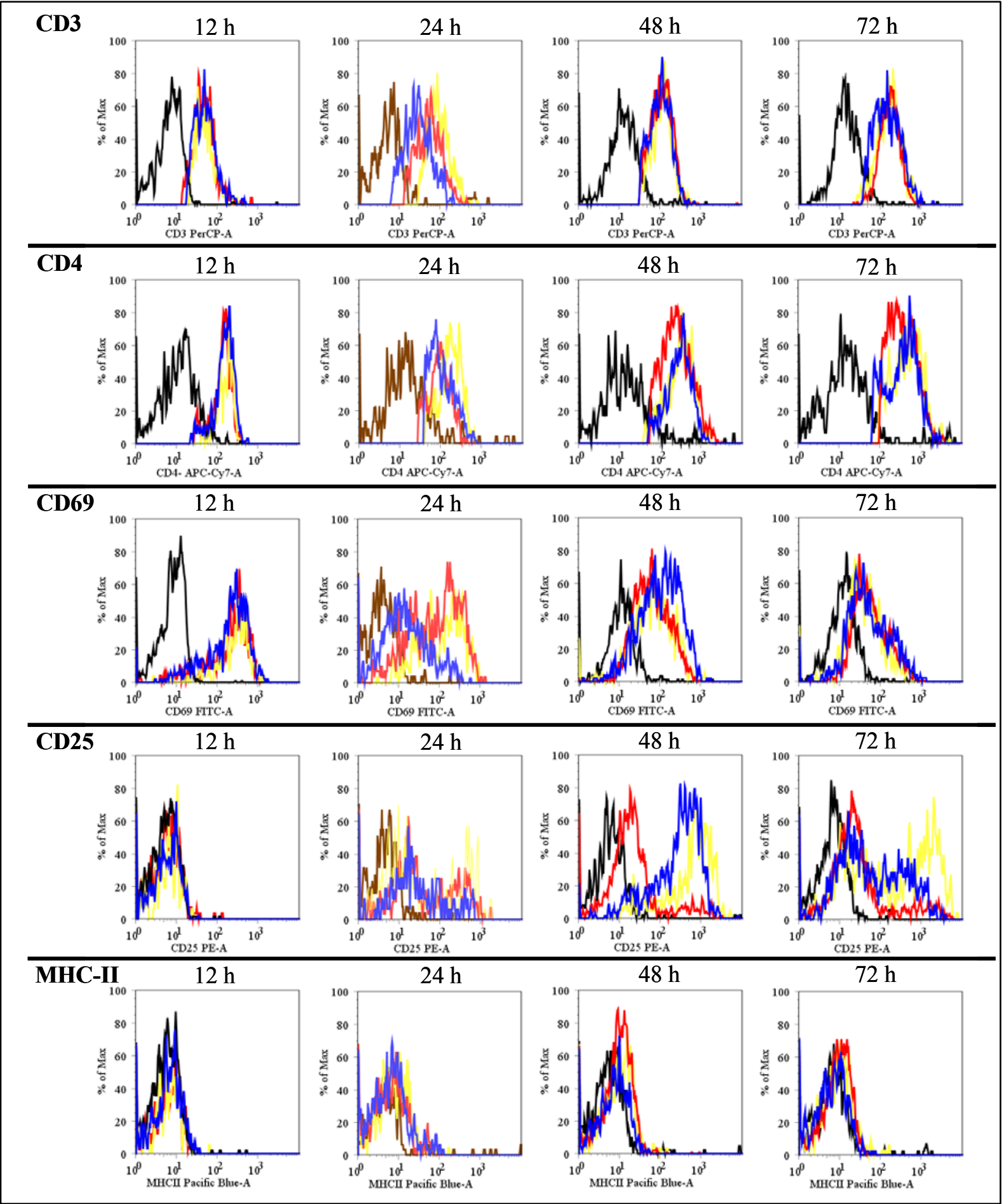

Abbildung 3.20: Durchflußzytometrische Analyse der Expression von Aktivierungsmarkern auf CD4 ${ }^{+}$T-Zellen.

In der Abbildung sind die Expressionsmuster des für T-Zellen spezifischen Markers CD3 und des für T-Helferzellen spezifische Markers CD4 sowie die Expressionsmuster der Aktivierungsmarker CD69, CD25 und MHC-II im Zeitraum von $12 \mathrm{~h}, 24 \mathrm{~h}, 48 \mathrm{~h}$ und $72 \mathrm{~h}$ nach Infektion aufgeführt. Die Expressionsmuster der T-Zellen, die mit dem aktiven FSME-Virus infiziert wurden, sind als blaue Linie, die der T-Zellen, die mit dem UV-inaktivierten Virus kokultiviert wurden, sind als rote Linie, die der MockKontrolle ist als gelbe Linie und die Isotypenkontrolle ist als schwarze bzw. braune Linie dargestellt. 


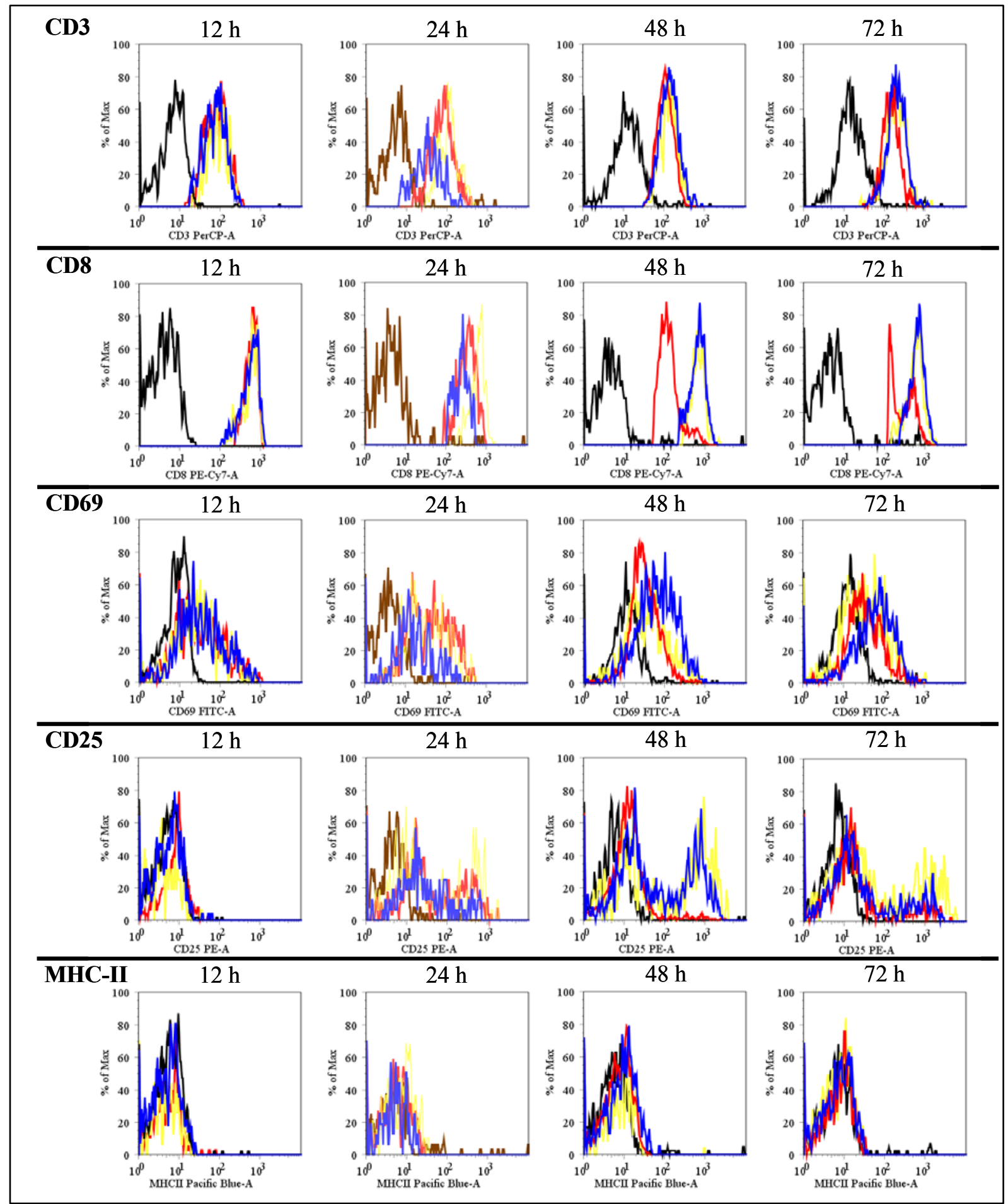

Abbildung 3.21: Durchflußzytometrische Analyse der Expression von Aktivierungsmarkern auf $\mathrm{CD8}^{+} \mathrm{T}$-Zellen.

In der Abbildung sind die Expressionsmuster der spezifischen T-Zellmarker CD3 sowie der Subtypenspezifische Marker CD8, die Aktivierungsmarker CD69, CD25 und MHC-II im Zeitraum von 12 h, 24 h, $48 \mathrm{~h}$ und $72 \mathrm{~h}$ nach Infektion aufgeführt. Die Expressionsmuster der T-Zellen, die mit dem aktiven FSMEVirus infiziert wurden, sind als blaue Linie, die der T-Zellen, die mit dem UV-inaktivierten Virus kokultiviert wurden, sind als rote Linie, die der Mock-Kontrolle ist als gelbe Linie und die Isotypenkontrolle ist als schwarze bzw. braune Linie dargestellt. 


\subsubsection{Zytokinantwort der T-Zellen nach FSME-Virusinfektion}

Die T-Zellen produzieren im Rahmen der Aktivierung Zytokine, die unterschiedliche Funktionen haben, wobei die einzelnen Subtypen der T-Zellen gemäß ihrer unterschiedlichen Funktion entsprechend verschiedene Zytokine produzieren. Um die Zytokinantwort der T-Zellen zu untersuchen, wurden isolierte T-Zellen mit dem FSMEVirus infiziert oder mit UV-inaktiviertem Virus oder mit Medium als Mock-Kontrolle kokultiviert. Die Zytokinantwort der T-Zellen wurde nach einem frühen $(24 \mathrm{~h}$ nach Infektion) und einem späten (72 h nach Infektion) Zeitpunkt analysiert. Aus den jeweiligen Zellkulturüberständen wurden die Konzentrationen der Zytokine IL-4, IL-5, IL-10, TNF- $\alpha$ und IFN- $\gamma$ mittels des CBA untersucht (s. Kapitel 2.2.5). Die Ergebnisse der Zytokinanalyse der T-Zellen sind in der Abbildung 3.22 dargestellt.

Dabei konnte gezeigt werden, dass die T-Zellen in Antwort auf das FSME-Virus das proinflammatorische Zytokin TNF- $\alpha$ und das IFN- $\gamma$ in Konzentrationen über 200 pg / ml (TNF- $\alpha)$ bzw. $300 \mathrm{pg} / \mathrm{ml}$ (IFN- $\gamma$ ) produzieren. Während nach $24 \mathrm{~h}$ schon über $180 \mathrm{pg} / \mathrm{ml}$ des TNF- $\alpha$ gemessen wurden, lag die Konzentration des IFN- $\gamma$ unter $20 \mathrm{pg} / \mathrm{ml}$. Erst nach $72 \mathrm{~h}$ konnten auch bei dem IFN- $\gamma$ eine erhöhte Konzentration festgestellt werden. Neben dem antiinflammatorischen Zytokin IL-10 konnten auch die Zytokine IL-4 und IL-5 in den Zellkulturüberständen der T-Zellen, die mit dem aktiven FSME-Virus koinkubiert wurden, nachgewiesen werden. Allerdings waren die Konzentrationen dieser Zytokine gering und lagen im Falle des IL-10 nach $72 \mathrm{~h}$ bei über $70 \mathrm{pg} / \mathrm{ml}$ und bei den anderen Zytokinen deutlich unter der $50 \mathrm{pg} / \mathrm{ml}$-Marke. Die Koinkubation mit dem UV-inaktivierten Virus führt auch zur Induktion der Zytokine, die allerdings bis auf das IL-10 deutlich geringer als bei dem aktiven Virus ausfällt. Aber auch beim IL-10 ist die Konzentration nur minimal höher. 


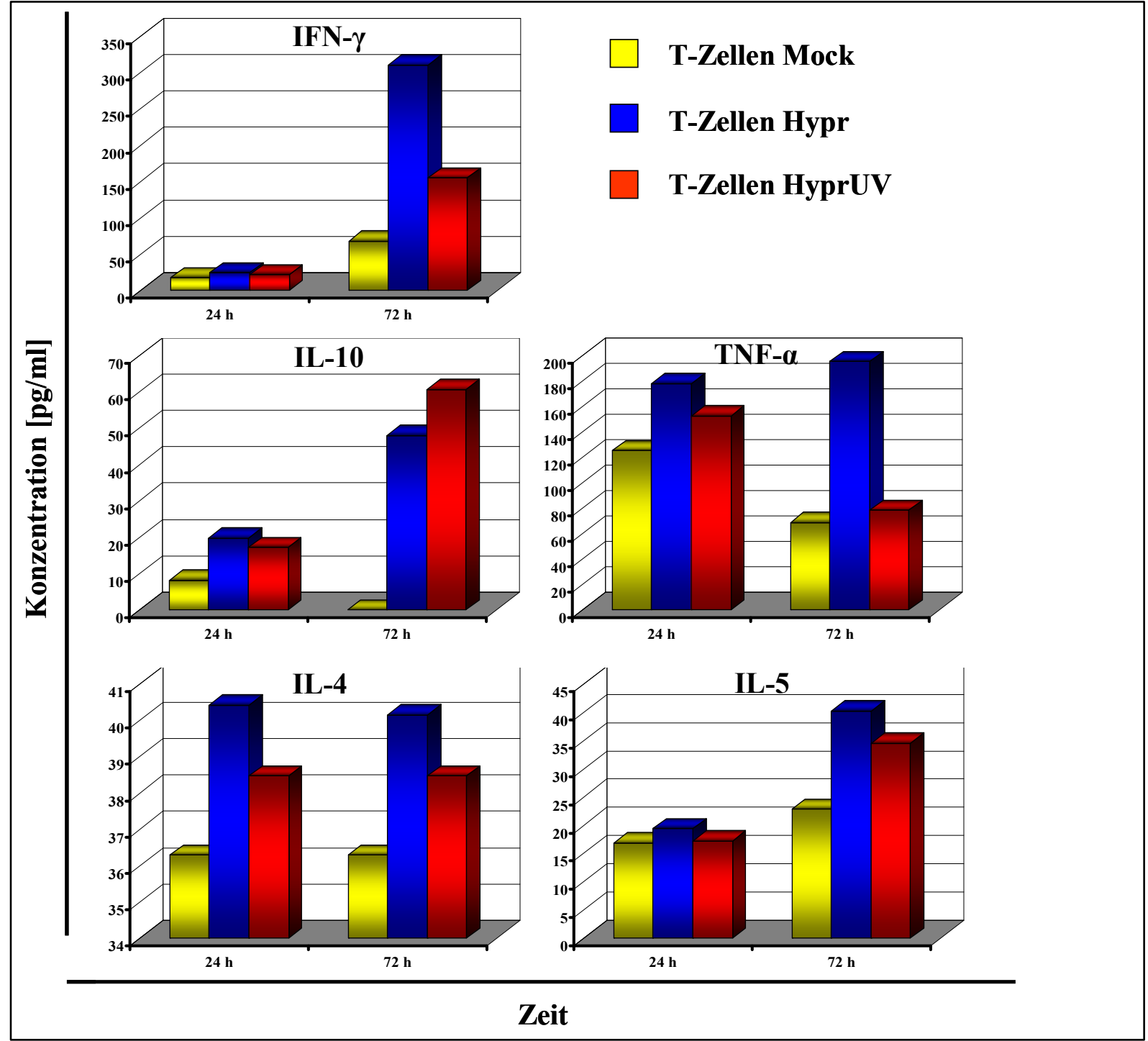

Abbildung 3.22: Zytokinantwort der T-Zellen auf die Infektion mit dem FSME-Virus.

Die Konzentrationen der Zytokine IL-4, IL-5, IL-10, IFN- $\gamma$ und TNF- $\alpha$ wurden $24 \mathrm{~h}$ und $72 \mathrm{~h}$ nach der Infektion mit dem FSME-Virus (blaue Balken), Kokultivierung mit dem UV-inaktivierten FSME-Virus (rote Balken) oder mit Medium als Mock-Kontrolle (gelbe Balken) mittels CBA gemessen. Auf den Abszissen der einzelnen Graphen ist die Zeit und auf den Ordinaten die Konzentration angegeben.

\subsubsection{Das FSME-Virus repliziert nicht effizient in T-Zellen}

Neben den DC-Subtypen können auch die T-Zellen einen möglicherweise wichtigen Faktor bei der Verbreitung des FSME-Virus im menschlichen Wirt darstellen. Dabei könnten die T-Zellen sogar als Shuttle bzw. als Art „Trojanisches Pferd“ für das FSMEVirus bei der Passage der Blut-Hirn-Schranke fungieren. Sie könnten aber auch von dem FSME-Virus zur Replikation benutzt werden und sich somit weiter im menschlichen 
Körper zu verbreiten. Ob das FSME-Virus auch in den T-Zellen repliziert, wurde anhand einer Replikationsanalyse untersucht. Dabei wurde der Virustiter der Zellkulturüberstände mittels $\mathrm{TCID}_{50}$ und einer zusätzlichen Zellviabilitätsanalyse der Vero-B4 Indikatorzellen anhand des MTT-Assays durchgeführt.

\subsubsection{Replikationsanalyse}

Um zu untersuchen, ob das FSME-Virus in den T-Zellen repliziert und diese somit als Verbreitungsfaktor in Frage kommen, wurden die Titer der Zellkulturüberstände der T-Zellen, die mit dem FSME-Virus infiziert wurden, von T-Zellen, die mit UVinaktivierten FSME-Virus kokultiviert wurden, mittels TCID 50 -Analyse (s. Kapitel 2.2.2.3) bestimmt. Neben der Virustiterbestimmung der Zellkulturüberstände wurde zusätzlich der Virustiter des Inputvirus bestimmt, um die Restinfektiosität dieser Virussuspension nach $72 \mathrm{~h}$ bei $37^{\circ} \mathrm{C}$ in zellfreier Umgebung zu ermitteln. Die Bilder der TCID $_{50}$-Analysen von den einzelnen Verdünnungstufen, bei denen noch ein $\mathrm{CPE}$ zu erkennen war und kein CPE mehr sichtbar war, sind in der Abbildung 3.23 dargestellt. Die Ergebnisse der $\mathrm{TCID}_{50}$-Analysen der T-Zellkulturüberstände sind zusammenfassend in der Abbildung 3.24 aufgeführt.

In der Abbildung 3.23 sind die jeweiligen Verdünnungsstufen des $\mathrm{TCID}_{50}$ mit den T-Zellüberständen sowie der Ausgangssuspension des Virus, dem Inputvirus und der Mock-Kontrolle dargestellt, bei denen bei den Vero-B4 Indikatorzellen noch ein CPE sichtbar war (linke Seite) und bei denen kein CPE mehr bei den Vero-B4-Indikatorzellen mehr sichtbar war (rechte Seite). Zur besseren Veranschaulichung sind die aus den TCID $_{50}$-Analysen berechneten Virustiter (s. Kapitel 2.2.2.3) zusammenfassend in der Abbildung 3.24 dargestellt. 


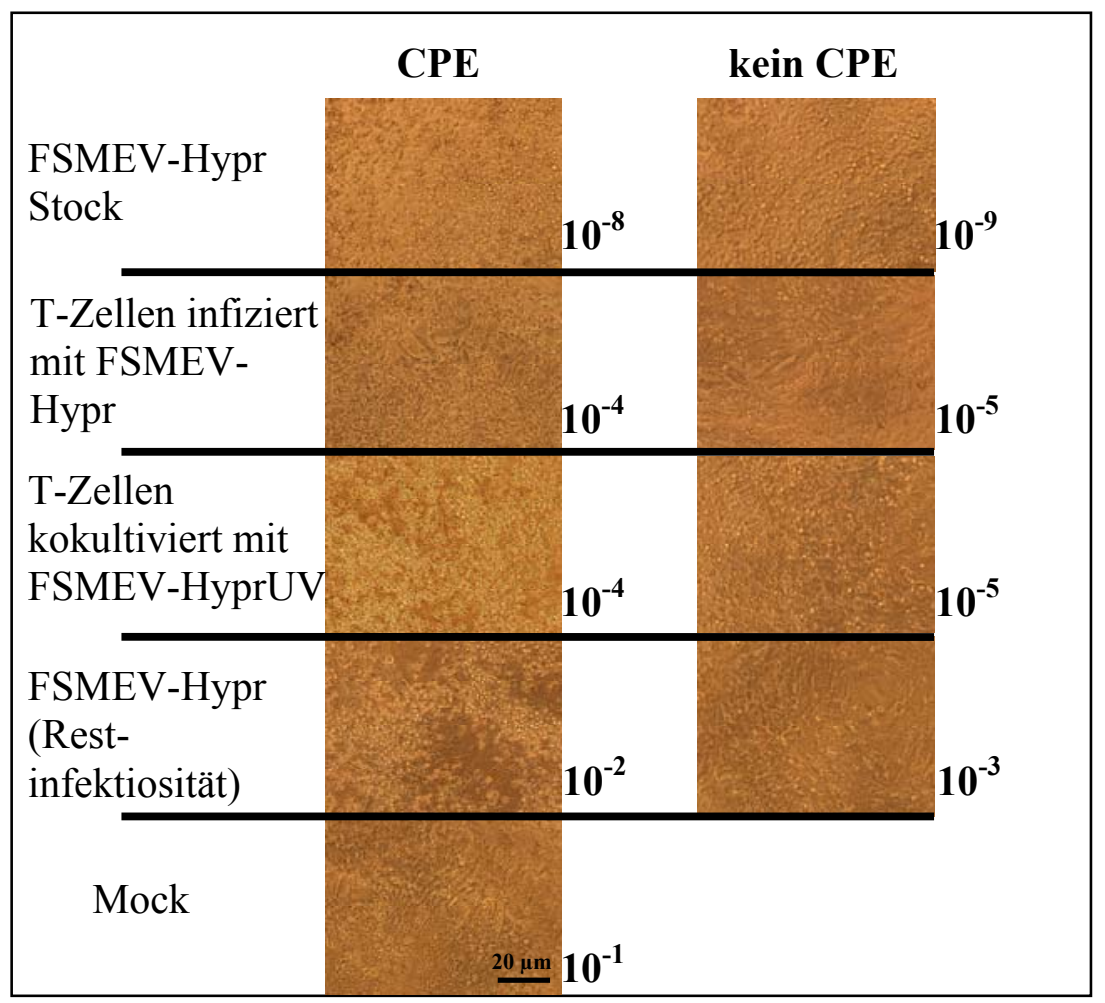

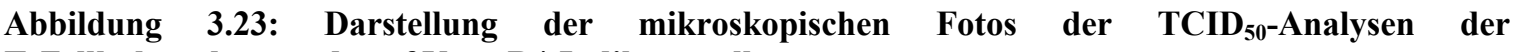
T-Zellkulturüberstände auf Vero-B4-Indikatorzellen.

Auf der linken Seite sind die Verdünnungsstufen abgebildet, bei denen bei den Vero-B4 Indikatorzellen noch ein CPE zu erkennen war und rechts die jeweiligen Verdünnungsstufen, bei denen kein CPE mehr erkennbar war. Die jeweiligen Verdünnungsstufen sind den Bildern rechts unten zugewiesen. In der Abbildung sind der Reihenfolge nach von oben bis unten folgende Bilder aufgeführt: Titration des Virusstocks als Positivkontrolle (FSMEV-Hypr Stock), Titration der Überstände der T-Zellen, die mit dem FSMEV-Stamm Hypr infiziert wurden, (T-Zellen infiziert mit FSMEV-Hypr), Titration der Überstände der T-Zellen, die mit dem UV-inaktivierten FSMEV-Stamm Hypr kokultiviert wurden (T-Zellen kokultiviert mit FSMEV-HyprUV), und die Titration des Inputvirus als Nachweis für die Restinfektiosität (FSMEVHypr (Restinfektiosität). Auf dem unteren Bild ist die Mock-Kontrolle abgebildet (pDCs Mock).
\end{abstract}

Aus der Abbildung 3.24 wird ersichtlich, dass der Virustiter in den Zellkulturüberständen der T-Zellen, die mit den FSME-Virus infiziert wurden, knapp unter dem Titer liegt, der noch in der Inputvirus-Kontrolle vorhanden ist. Der Titer der T-Zellüberstände beläuft sich auf $1,8 \times 10^{5} \mathrm{TCID}_{50} / \mathrm{ml}$ und der Titer des Inputvirus auf $3,61 \times 10^{5} \mathrm{TCID}_{50} / \mathrm{ml}$. Das bedeutet, dass die Restinfektiösität des FSME-Virus fast gleich mit der Infektiösität des Virus in den Überständen der infizierten T-Zellen ist und es scheint somit, dass sich das FSME-Virus nicht wesentlich in den T-Zellen vermehrt hat. Der Titer der Ausgangssuspension des FSME-Virus, die als Positivkontrolle mitgeführt wurde, liegt fast 3 log-Stufen über den Virustitern des Inputvirus und des T-Zellüberstandes. 


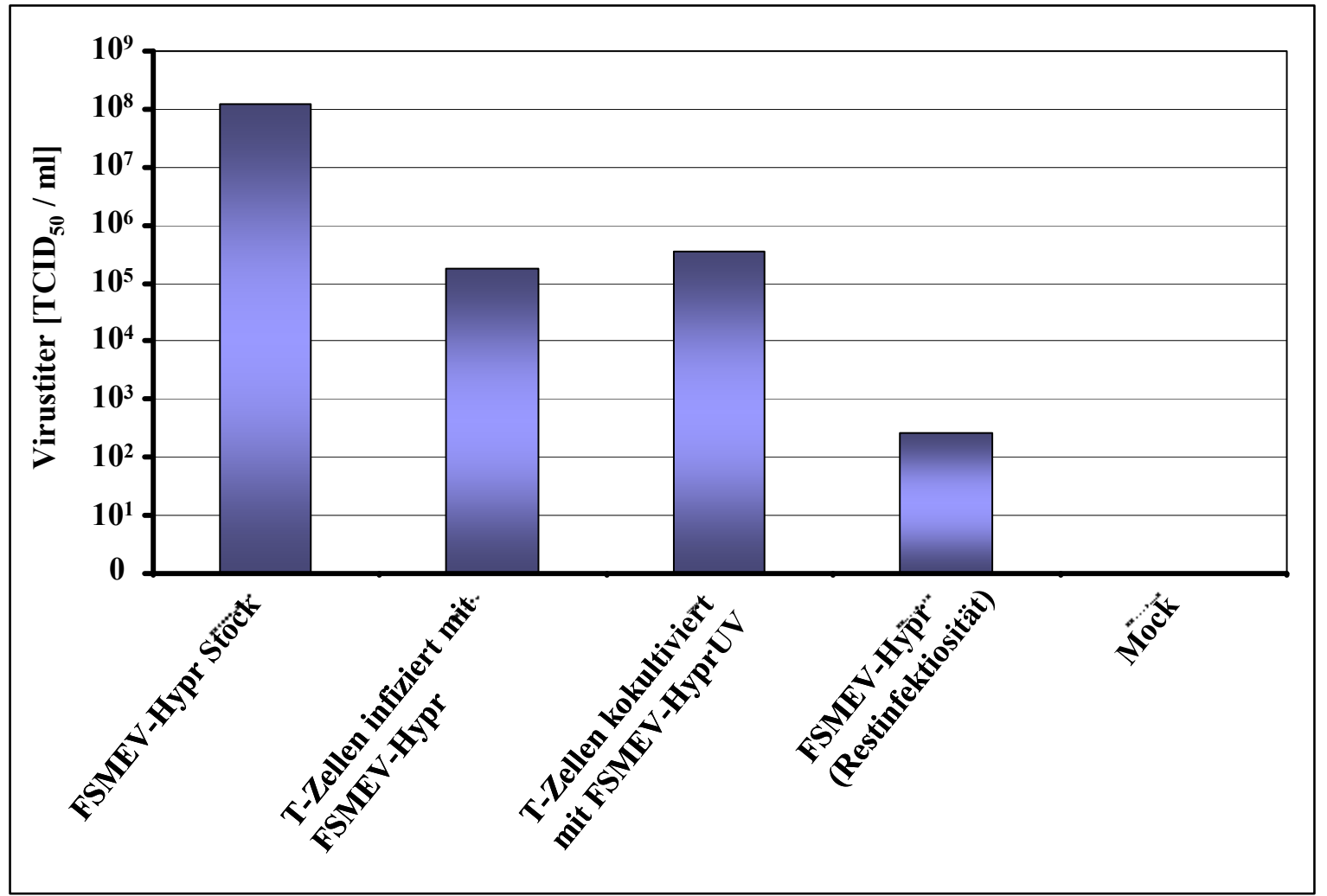

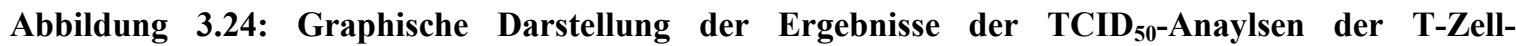
Kulturüberstände.

In der Abbildung sind die Titer der einzelnen T-Zellkulturüberstände und des FSMEV-Hypr Stock aufgeführt. Der Reihenfolge nach von links nach rechts sind die Titer des Virusstocks als Positivkontrolle (FSMEV-Hypr Stock), die Titer der Überstände der T-Zellen, die mit dem FSMEV-Stamm Hypr infiziert wurden (T-Zellen infiziert mit FSMEV-Hypr), die Titer des Inputvirus zur Darstellung der Restinfektiosität (FSMEV-Hypr (Restinfektiosität)) und die Titer der Überstände der T-Zellen, die mit dem UV-inaktivierten FSMEV-Stamm Hypr kokultiviert wurden (T-Zellen kokultiviert mit FSMEV-HyprUV), dargestellt. Bei dem rechten Balken handelt es sich um die Titer der Mock-Kontrolle.

Bei den Überständen der T-Zellen, die mit dem UV-inaktiverten FSME-Virus kokultiviert wurden, war ein niedriger Titer von um die $5 \times 10^{3} \mathrm{TCID}_{50} / \mathrm{ml}$ vorhanden. Somit konnte gezeigt werden, dass das FSME-Virus wohl nicht effektiv in den T-Zellen repliziert. In den Mock-Kontrollen konnte kein CPE der Vero-B4 Indikatorzellen festgestellt werden, sodass hier erwartungsgemäß kein messbarer Virustiter bestimmt werden konnte.

\subsubsection{Zellviabilitätsanalyse mittels MTT-Assay}

Durch den MTT-Assay sollte zusätzlich die Viabilität der Indikatorzellen, die mit den Zellkulturüberständen der mit FSME-Virus infizierten T-Zellen inkubiert wurden, 
überprüft werden (s. Kapitel 2.2.7). Die Ergebnisse der TCID $_{50}$-Analysen mit verschiedenen T-Zell-Überständen sind in der Abbildung 3.25 graphisch aufgeführt.

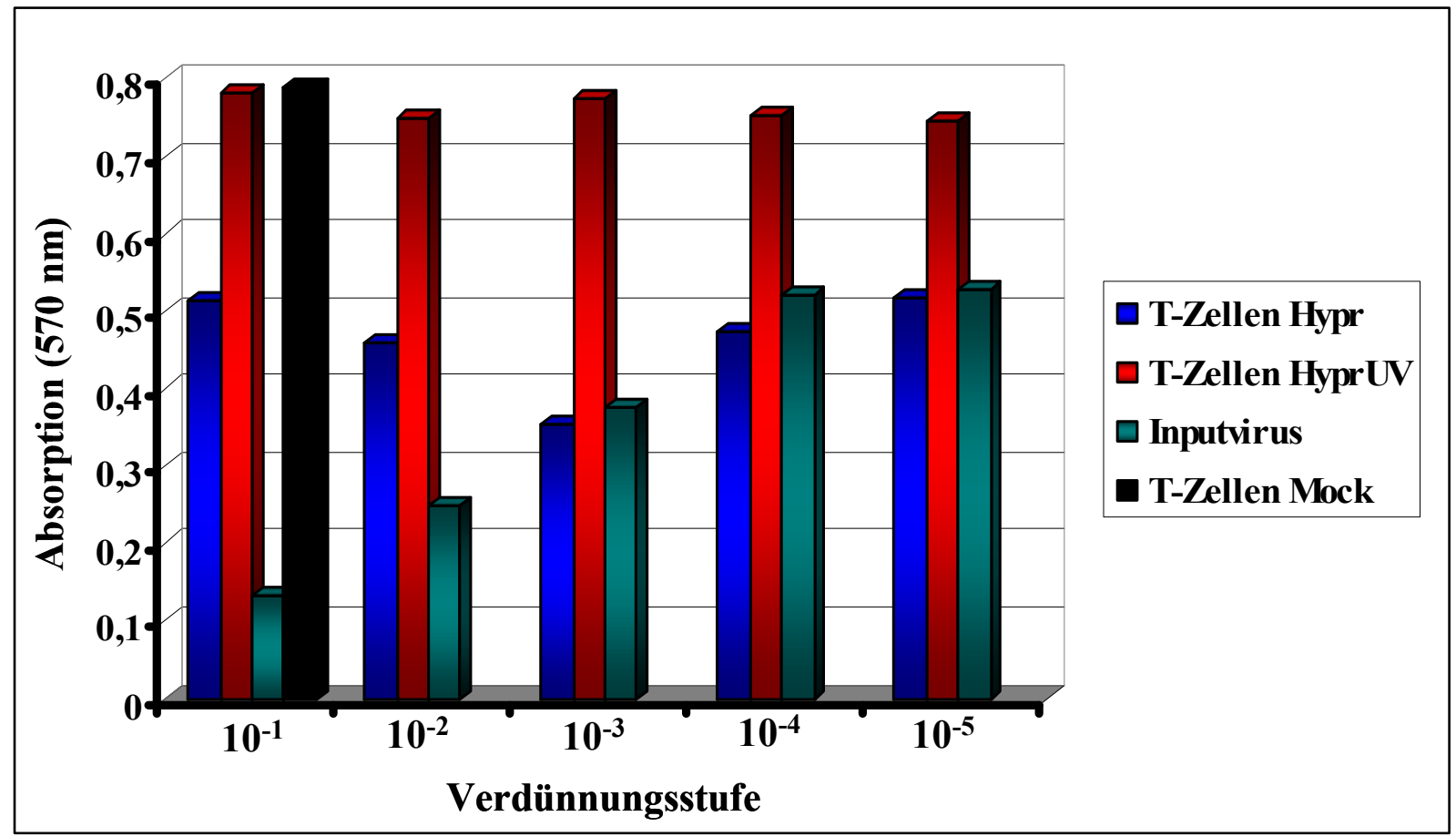

Abbildung 3.25: Ergebnisse des TCID 50 des MTT-Assays mit Zellkulturüberständen der T-Zellen. Auf der Abszisse sind die einzelnen Verdünnungsstufen der Überstände dargestellt und auf der Ordinate die Absorptionswerte bei einer Wellenlänge von $570 \mathrm{~nm}$. Die grauen Balken stellen das Inputvirus dar und der schwarze Balken den Zellkulturüberstand der Mock-Kontrolle. Die blauen Balken stehen für die Zellkulturüberstände der T-Zellen, die mit dem FSME-Virus infiziert wurden, und die roten Balken für die Überstände der T-Zellen, die mit dem UV-inaktivierten Virus kokultiviert wurden.

Wie in der Abbildung 3.25 dargestellt, war die Viabilitätsrate der Vero-B4 Indikatorzellen, die mit den infizierten T-Zellüberständen inkubiert wurden (blaue Balken), höher als bei der Kontrolle der Restinfektiosität (grüne Balken). Dagegen waren bei der Mock-Kontrolle und bei den Indikatorzellen, die mit dem replikationsinkompetenten Virus inkubiert wurden, die Absorptionswerte und damit die Zellviabilität sehr hoch (schwarzer Balken bzw. rote Balken).

In insgesamt sechs Versuchsreihen mit T-Zellen verschiedener Spender ergab sich mit einer Ausnahme, bei der eine FSME-Virusreplikation nachgewiesen wurde, ein ähnliches Bild. In humanen T-Zellen scheint daher in der Regel keine effiziente Replikation des FSME-Virus stattzufinden. 


\subsubsection{Proliferation der T-Zellen nach FSME-Virusinfektion}

Um die Immunantwort der T-Zellen auf das FSME-Virus genauer zu analysieren, wurde ein Proliferationstest der T-Zellen innerhalb einer Kultur mit PBMCs durchgeführt. Dazu wurden PBMCs isoliert und mit CFSE gefärbt. Anschließend wurden die Proben mit FSME-Virus infiziert oder mit UV-inaktivierten FSME-Virus, Medium als MockKontrolle oder PHA als Stimulanz und Proliferationskontrolle kokultiviert. Nach 3- und 5 Tagen wurden die PBMCs geerntet und mit den T-Zellspezifischen spezifischen Fluorochrom-gekoppelten Antikörpern gegen CD3, CD4, CD8 angefärbt und die Proliferation der T-Zellen in den PBMC-Kulturen mit Hilfe des Durchflußzytometers untersucht. Das CFSE bindet an die Proteine, die sich durch die Zellteilung auf die Tochterzellen aufteilen, sodass die Menge an CFSE in der einzelnen Zelle abnimmt. Durch den Verdünnungseffekt nimmt die Fluoreszenz des CFSE ab. Damit ist eine abnehmende Fluoreszenz des CFSE gleichbedeutend mit der Proliferation der T-Zellen. Die Abnahme der Fluoreszenz kann mittels des Durchflußzytometers untersucht werden. Um zu zeigen, ob es unter den T-Zell-Subtypen Unterschiede in der Proliferation in Folge einer Infektion mit dem FSME-Virus gibt, wurden die T-Zellen zusätzlich mit Fluorochrom-gekoppelten Antikörpern gegen CD4 und CD8 markiert. Die Ergebnisse des CFSE-Proliferationstest der T-Zellen sind in der Abbildung 3.26 dargestellt.

Dabei ist in der Abbildung $3.26 \mathrm{zu}$ erkennen, dass sich die T-Zellen, die als Proliferationskontrolle mit dem PHA-stimuliert wurden, im Zuge der Proliferation weiter teilen und sich durch den Verdünnungseffekt des CFSE distinkte Generationen der T-Zellen bestimmen lassen können. Bei den T-Zellen, die mit dem PHA stimuliert wurden, lassen sich 5 Generationen bestimmen, die im Zuge der Proliferation aus der parentalen Generation 0 entstanden sind. Demzufolge ist auch der Anteil der stimulierten Zellen in der parentalen sowie ersten Generation im Vergleich zur Mock-Kontrolle geringer. Bei der Mock-Kontrolle sowie bei den T-Zellen der PBMCs, die mit dem aktiven oder inaktivierten Virus koinkubiert wurden, kann man allerdings erkennen, das der prozentuale Anteil der T-Zellen in der parentalen Generation und in der ersten Generation am höchsten sind. Dagegen war der prozentuale Anteil bei den darauf folgenden Generationen sehr gering oder es waren keine Zellen in der jeweiligen Generation vorhanden. Dabei gab es auch zwischen den beiden Subtypen der T-Zellen 
keinen Unterschied. Demzufolge induziert das FSME-Virus keine Proliferation der T-Zellen, die über die der Mock-Kontrolle hinausgeht.

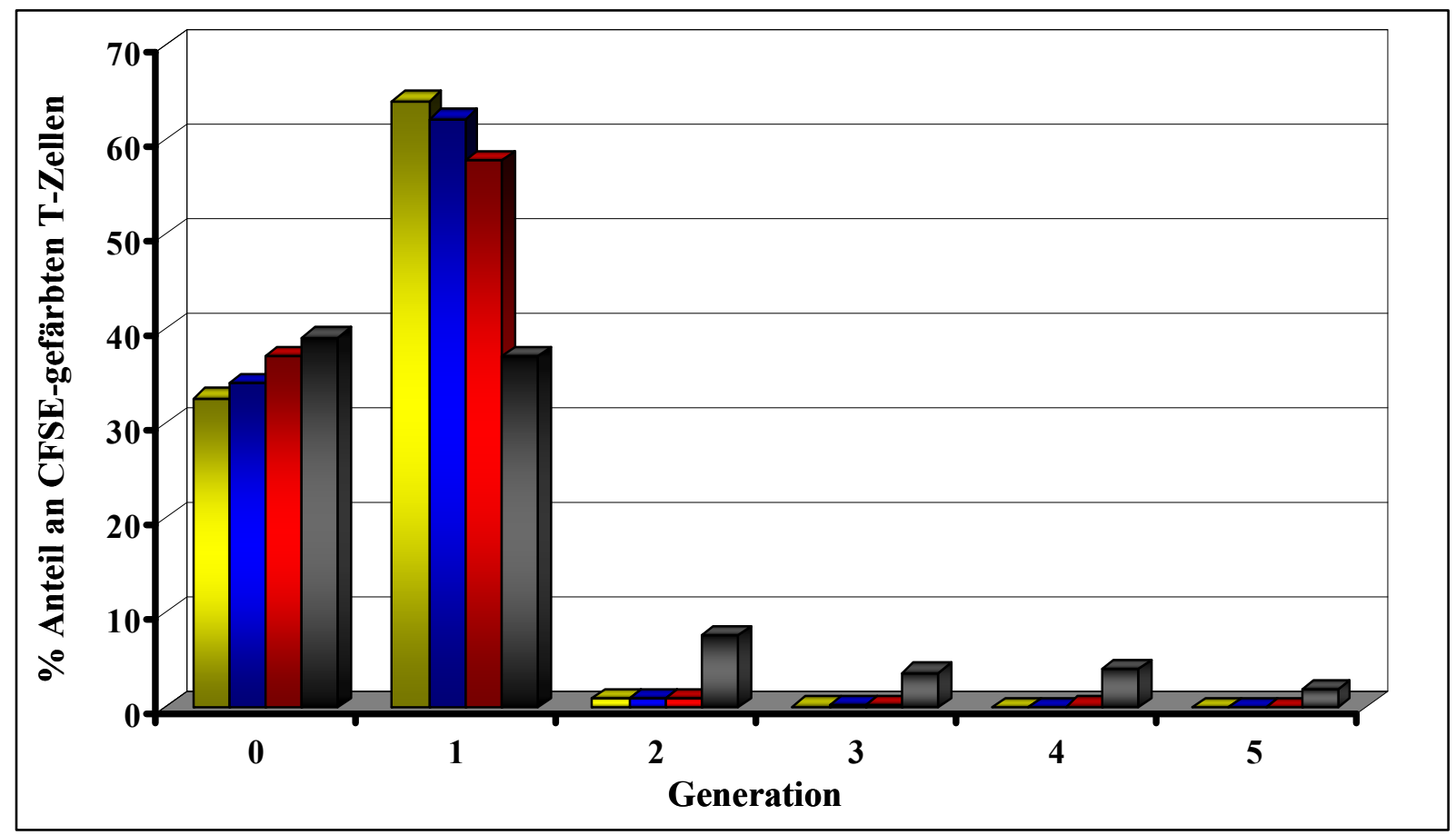

Abbildung 3.26: Ergebnisse des Proliferationstest der T-Zellen in der PBMC-Kultur mittels CFSE 5 Tage nach der Infektion.

Auf der Abszisse sind die einzelnen Generationen der T-Zellen $\left(\mathrm{CD}^{+}\right)$, die durch die Zellteilung bei der Proliferation zustande kommen, dargestellt und auf der Ordinate der prozentuale Anteil an der Gesamtzellzahl der T-Zellen. Die schwarzen Balken stellen die mit PHA-stimulierten T-Zellen dar und die gelben Balken die T-Zellen der Mock-Kontrolle. Die blauen- Balken stehen für die T-Zellen, die mit dem FSME-Virus infiziert wurden, und die roten Balken für die T-Zellen, die mit dem UV-inaktivierten Virus kokultiviert wurden.

\subsection{Infektion von Kokulturen aus pDCs und T-Zellen mit FSME-Virus}

Um zu zeigen in wie weit die pDCs die $\mathrm{CD}^{+}-$und $\mathrm{CD}^{+} \mathrm{T}-$ Zellen in einer Kokultur aktivieren und deren Differenzierung beeinflussen können, wurden aus humanen Buffy Coat sowohl pDCs als auch T-Zellen isoliert und in einem Verhältnis von $1: 10$ kokultiviert (s. Kapitel 2.2.1.5.4). Die jeweiligen pDC-T-Zell-Kokulturen wurden mit FSME-Virus infiziert oder mit UV-inaktivierten FSME-Virus oder Medium als MockKontrolle kokultiviert. Nach $72 \mathrm{~h}$ wurden die Zellen geerntet und die Expression einiger Oberflächenmoleküle mittels Durchflußzytometer analysiert (s. Kapitel 3.3.1). Außerdem 
wurde anhand der Zellkulturüberstände die Konzentration der Zytokine zu einem frühen (24 h nach Infektion) und $\mathrm{zu}$ einem späten (72 h nach Infektion) Zeitpunkt bestimmt (s. Kapitel 3.3.2).

\subsubsection{Das FSME-Virus beeinflusst die Expression von Oberflächenmolekülen der pDCs und T-Zellen in der gemeinsamen Kokultur}

In Kapitel 3.1.3 konnte bereits gezeigt werden, dass die pDCs durch das FSME-Virus transient aktiviert werden und neben den Aktivierungs- und Reifungsmarkern auch die Adhäsions-, Kostimulations- und Antigenpräsentationsmoleküle, mit denen die T-Zellen in Kombination interagieren, aktiviert werden können. Um zu untersuchen, ob die pDCs die T-Zellen aktivieren und welche T-Zellantwort die pDCs induzieren, wurden die Expressionsmuster diverser Oberflächenmoleküle bei den pDCs sowie bei den $\mathrm{CD} 4^{+}-$und $\mathrm{CD}^{+}$T-Zellen $72 \mathrm{~h}$ nach der Infektion mit dem FSME-Virus oder nach der Kokultivierung mit dem UV-inaktivierten FSME-Virus sowie mit dem Medium als Mock-Kontrolle mittels der Durchflußzytometrie analysiert.

Auf Seiten der pDCs wurde die Expression der Aktivierungs- und Kostimulierungsmoleküle CD40, CD80 und CD86 sowie der antigenpräsentierenden Moleküle MHC-I und MHC-II untersucht. Bei den T-Zellen wurde Subtypen-spezifisch die Expression der Aktivierungsmarker CD25, CD69 und MHC-II analysiert. Die Ergebnisse der durchflußzytometrischen Analyse der Oberflächenmoleküle in der pDCT-Zell-Kokultur sind in der Abbildung 3.28 dargestellt. Dabei ist in der Abbildung 3.28 zu erkennen, dass bei der Expression der Aktivierungs- und Kostimulierungsmoleküle CD40, CD80 und CD86 sowie der antigenpräsentierenden Moleküle MHC-I und MHC-II der pDCs in der Kokultur, die mit dem aktiven FSME-Virus kokultiviert wurden, keine Unterschiede zu den pDCs zu erkennen sind, die innerhalb der Kokultur mit dem UVinaktiverten Virus oder als Mock-Kontrolle mit Medium koinkubiert wurden. Vielmehr ist die Expression der Moleküle im Vergleich mit der Mock-Kontrolle auf Seiten der pDCs, die mit dem inaktivierten oder aktiven Virus kokultiviert wurden ähnlich der Mock-Kontrolle. Dies ist im Einklang mit den in Kapitel 3.1.3 dargestellten Ergebnissen, die ergaben, dass es nach FSME-Virusinfektion $\mathrm{zu}$ einer transienten Aktivierung der pDCs kommt, die aber $72 \mathrm{~h}$ nach Infektion nicht mehr sichtbar ist. Bei den T-Zellen gibt es im Vergleich der beiden T-Zell-Subtypen keine Unterschiede bei der Expression der 
Aktivierungsmarker CD69 und CD25. Während CD69 auf den T-Zellen in der Kokultur, die mit dem replikationskompetenten FSME-Virus infiziert wurden, verstärkt exprimiert wurde, war die Expression des Aktivierungsmarker CD25 nach Kontakt mit FSME-Virus im Vergleich zur Mock-Kontrolle erniedrigt. Zusätzlich konnte bei den CD8 ${ }^{+}$T-Zellen, die in der Kokultur mit dem FSME-Virus inkubiert wurden, eine erhöhte Expression des späten Aktivierungsmarkers MHC-II beobachtet werden.

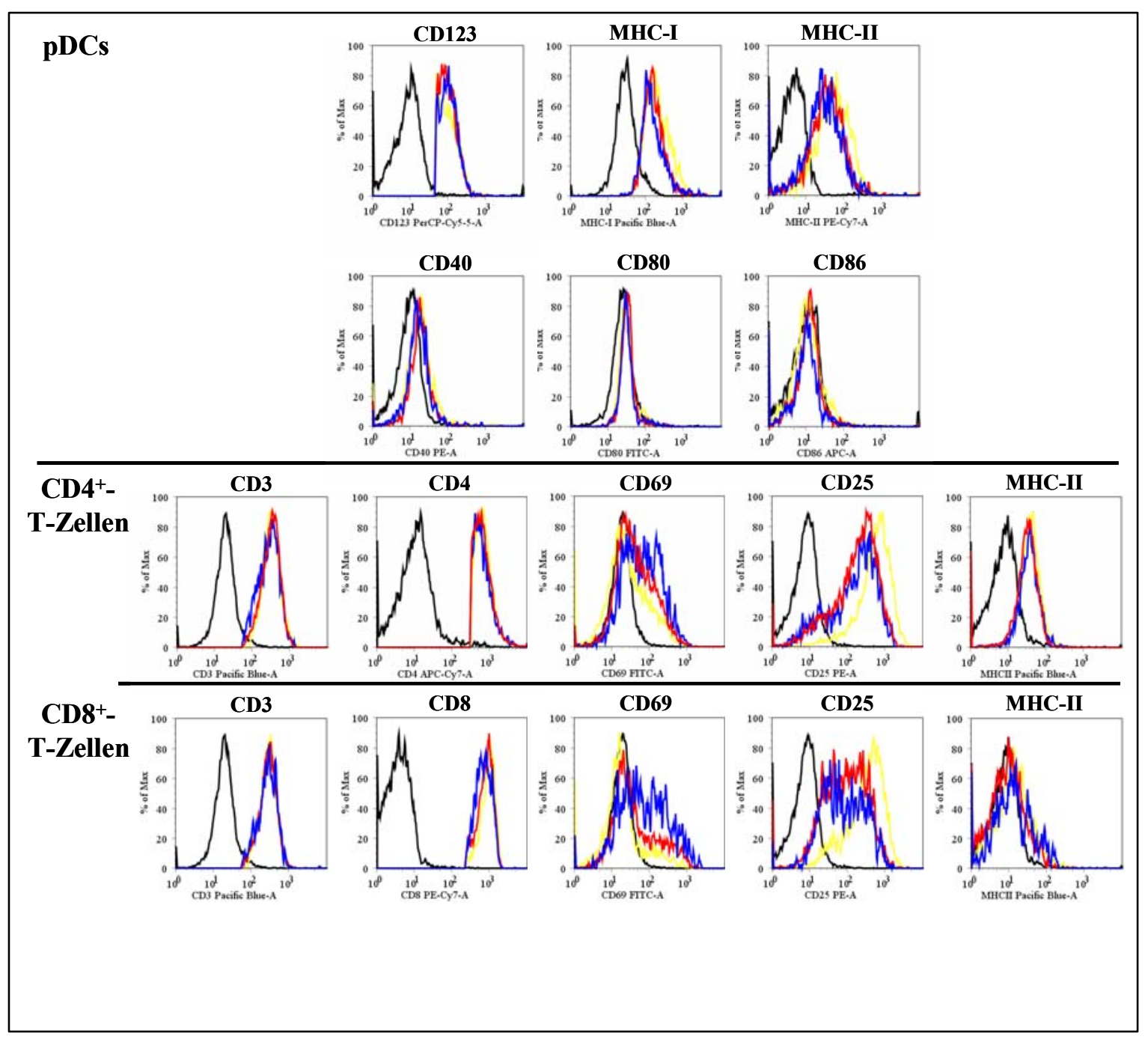

Abbildung 3.27: Durchflußzytometrische Analyse der Expression von Aktivierungsmarkern auf kokultivierten pDCs und T-Zellen nach FSME-Virusinfektion.

In der oberen Hälfte der Abbildung sind die Expressionsmuster des spezifischen pDC-Zellmarker CD123, der Aktivierungs- und Kostimulationsmarker CD40, CD80 und CD86 sowie der beiden Antigenpräsentationsmolekülen MHC-I und MHC-II dargestellt. In der unteren Hälfte ist die Expression der Aktivierungsmarker CD69, CD25 und MHC-II für die beiden Subtypen CD4 ${ }^{+}$und CD8 ${ }^{+}$T-Zellen dargestellt. Die Zellen, die mit dem aktiven FSME-Virus infiziert wurden sind als blaue Linie, die mit dem UV-inaktivierten Virus kokultivierten Zellen sind als rote Linie, die Mock-Kontrolle ist als gelbe Linie und die Isotypenkontrolle ist als schwarze Linie dargestellt 
Nach 72 h konnte in der Kokultur keine Aktivierung der pDCs nachgewiesen werden, aber auf Seiten der T-Zellen war eine verstärkte Expression des Aktivierungsmarkers CD69 zu erkennen. Bei den CD8 ${ }^{+}$T-Zellen war darüber hinaus auch die Expression des späten Aktivierungsmarkers MHC-II leicht erhöht. Somit scheinen die pDCs die T-Zellen in der Kokultur nach FSME-Virusinfektion zumindest teilweise zu aktivieren.

\subsubsection{Die Zytokinantwort in der pDC-T-Zell-Kokultur}

Zusätzlich zu den Oberflächenmolekülen wurde auch die Zytokinantwort der T-Zellen in der pDC-T-Zell-Kokultur auf das FSME-Virus untersucht. Im Rahmen der Aktivierung der T-Zellen durch die pDCs produzieren die T-Zellen je nach Subtyp unterschiedliche Zytokine und induzieren somit eine unterschiedliche Immunantwort. Durch die Analyse diverser Zytokine sollte die Immunantwort zum einen auf den jeweiligen T-Zell-Subtyp zurückgeführt werden und zum anderen sollte die Zytokinantwort einen Anhaltspunkt für den weiteren Verlauf der adaptiven Immunantwort, die durch die T-Zellen induziert wird, geben. Um die Zytokinantwort der T-Zellen in der pDC-T-Zell-Kokultur zu untersuchen, wurden die Zellen mit dem FSME-Virus infiziert oder mit UV-inaktiviertem Virus sowie Medium als Mock-Kontrolle kokultiviert. Nach $24 \mathrm{~h}$ und $72 \mathrm{~h}$ wurden die Überstände der Kokulturen abgenommen und mittels CBA auf das Vorhandensein der Zytokine IL-4, IL-5, IL-10 TNF- $\alpha$ und IFN- $\gamma$ untersucht. Die Ergebnisse des CBAs der pDC-T-ZellKokulturen sind in der Abbildung 3.28 aufgeführt.

In den Zellkulturüberständen der Kokultur, die mit dem FSME-Virus koinkubiert wurden, konnten erhöhte Konzentrationen der Zytokine IFN- $\gamma$ und TNF- $\alpha$ nachgewiesen werden. Dabei stieg die Konzentration des IFN- $\gamma$ von ca. $3500 \mathrm{pg} / \mathrm{ml}$ nach $24 \mathrm{~h}$ auf über $6000 \mathrm{pg} / \mathrm{ml}$ nach $72 \mathrm{~h}$ an. Auch die Konzentration des proinflammatorischen Zytokins TNF- $\alpha$ stieg über die Zeit von $3500 \mathrm{pg} / \mathrm{ml}$ auf deutlich über $600 \mathrm{pg} / \mathrm{ml}$. Auch das UVinaktivierte FSME-Virus induzierte die Produktion der beiden Zytokine, wobei die Konzentrationen unter denen des aktiven FSME-Virus lagen. Weiterhin scheinen die T-Zellen aufgrund der Stimulation durch die pDCs große Mengen des antiinflammatorischen Zytokins IL-10 über die Zeit hinweg zu produzieren, wobei die Konzentrationen nach $24 \mathrm{~h}$ und $72 \mathrm{~h}$ um die $2500 \mathrm{pg} / \mathrm{ml}$ Marke lagen. Auch bei der Kokultur, die mit dem UV-inaktivierten FSME-Virus kokultiviert wurde, konnte das IL-10 nachgewiesen werden, allerdings war nach $24 \mathrm{~h}$ die IL-10-Konzentration um etwa 
die Hälfte gegenüber der mit dem aktiven Virus herabgesetzt und erst nach $72 \mathrm{~h}$ war die Konzentration auf der gleichen Ebene, wie bei dem aktiven Virus.

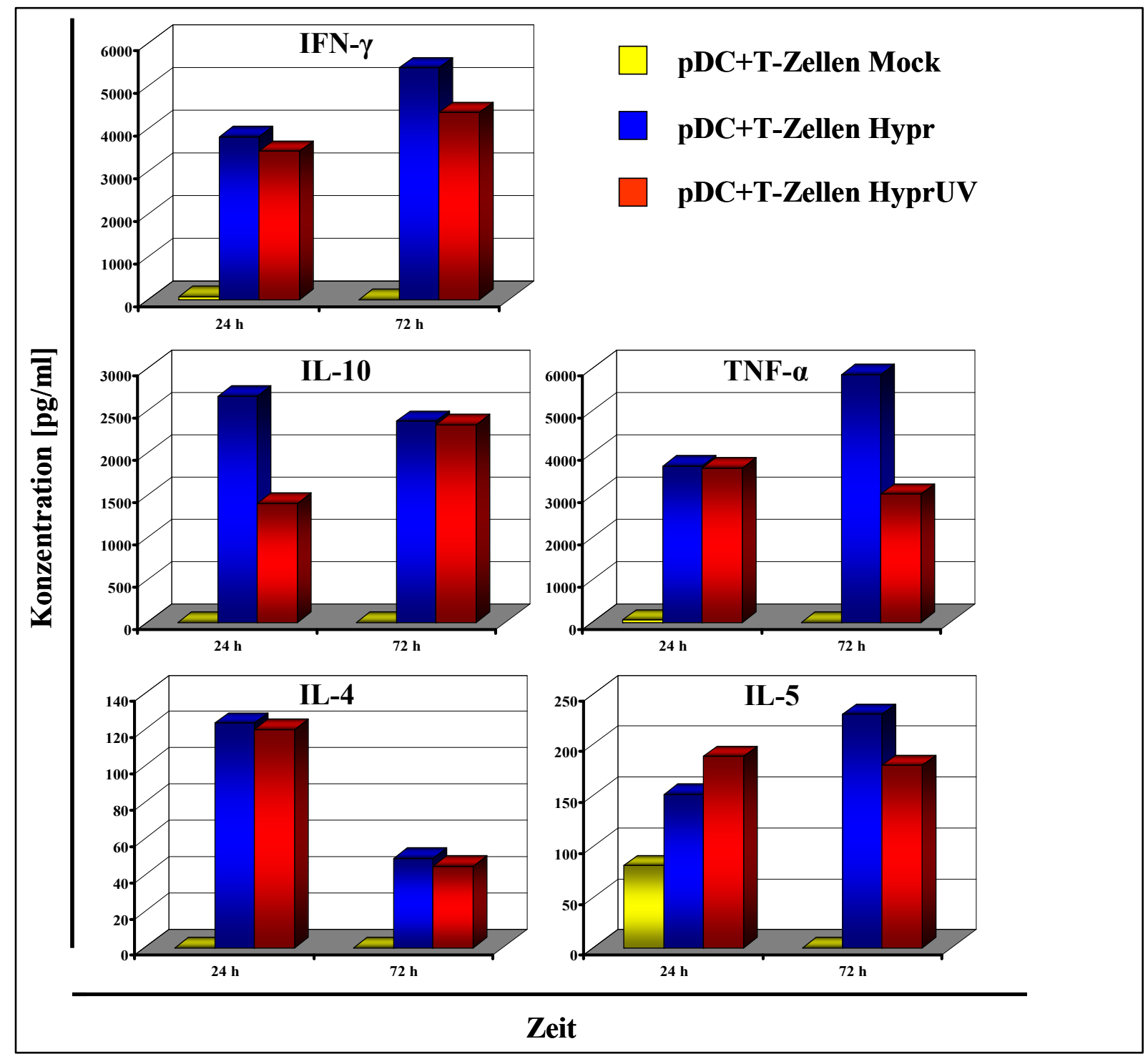

Abbildung 3.28: Zytokinantwort der Kokultur von pDCs und T-Zellen auf die Infektion mit dem FSME-Virus.

Die Konzentrationen der Zytokine IL-4, IL-5, IL-10, IFN- $\gamma$ und TNF- $\alpha$ wurden $24 \mathrm{~h}$ und $72 \mathrm{~h}$ nach der Infektion mit dem FSME-Virus (blaue Balken), Kokultivierung mit dem UV-inaktivierten FSME-Virus (rote Balken) oder mit Medium als Mock-Kontrolle (gelbe Balken) mittels CBA gemessen. Auf den Abszissen der einzelnen Graphen ist die Zeit und auf den Ordinaten die Konzentration angegeben.

Darüber hinaus konnten auch niedrigere Konzentrationen der Zytokine IL-4 und IL-5 in den Zellkulturüberständen nachgewiesen werden. Während die Konzentrationen des IL-4 von ca. $120 \mathrm{pg} / \mathrm{ml}$ nach $24 \mathrm{~h}$ unter die $50 \mathrm{pg} / \mathrm{ml}$ nach $72 \mathrm{~h}$ sank, stiegen die Konzentrationen von IL-5 von ca. $150 \mathrm{pg} / \mathrm{ml}$ auf über $200 \mathrm{pg} / \mathrm{ml}$ an. Bei den 
Zellkulturüberständen der Kokulturen, die mit Medium als Mock-Kontrolle für die jeweilige Zeit inkubiert wurden, konnten keine der angegebenen Zytokine nachgewiesen werden, lediglich bei der Mock-Kontrolle, die nach $24 \mathrm{~h}$ untersucht wurde, konnte eine Konzentration von etwa 75 pg / $\mathrm{ml}$ an IL-5 nachgewiesen werden.

Es konnte gezeigt werden, dass das FSME-Virus in einer Kokultur aus pDCs und T-Zellen eine starke Zytokinantwort hervorruft, die sowohl pro- wie auch antiinflammatorische Zytokine beinhaltet. Demzufolge scheinen die pDCs die T-Zellen $\mathrm{zu}$ aktivieren und so die adaptive Immunantwort nach Infektion mit dem FSME-Virus induzieren. 


\section{Diskussion}

Das FSME-Virus ist ein in Europa und vielen Teilen Asiens prävalentes Arbovirus, das sich aufgrund verschiedener Faktoren immer weiter ausbreitet und somit $\mathrm{zu}$ einem potentiellen Infektionsrisiko für immer mehr Menschen wird $(55,184)$. Der Mensch stellt im Übertragungszyklus des FSME-Virus einen Fehlwirt dar, da er nicht als Überträger des Virus fungiert. Dennoch kann der Mensch von dem FSME-Virus durch den Stich einer FSME-Virus infizierten Zecke, durch den Konsum FSME-Virus enthaltener Milchprodukte infizierter Tiere oder durch das Einatmen FSME-Virus enthaltener Aerosole infiziert werden. Im Zuge der Infektion mit dem FSME-Virus stellen die DCs ein potentielles und frühes Ziel für das Virus dar. Die DCs sind eine zentrale Komponente des Immunsystems, da sie zum einen als Schnittstelle der angeborenen- und erworbenen Immunität fungieren und zum anderen im Rahmen der spezifischen Immunantwort T-Zellen und B-Zellen aktivieren. In dieser Arbeit wurde untersucht, ob das FSME-Virus mit der Aktivierung von DCs und T-Zellen interferiert. Die DC-Subtypen und T-Zellen wurden dazu aus humanen Buffy-Coat isoliert, kultiviert und mit dem FSME-Virus infiziert. Anschließend wurde die Expression von Aktivierungsmarkern sowie die Produktion von proinflammatorischen Zytokinen und antiviral wirksamen IFN- $\alpha$ untersucht. Darüber hinaus wurden mit FSME-Virus infizierten T-Zellen Proliferationstests durchgeführt. Außerdem wurde untersucht, ob das FSME-Virus in DCs und T-Zellen repliziert und diese Zellen somit als Verbreitungsfaktor für das Virus im Wirt fungieren können.

\subsection{Reaktion der DCs auf das FSME-Virus}

Die DCs sind wichtige Aktivatoren und Regulatoren des angeborenen- und erworbenen Immunsystems. Sie sind in der Lage innerhalb kurzer Zeit virale- oder bakterielle Eindringlinge $\mathrm{zu}$ erkennen und eine Abwehrantwort $\mathrm{zu}$ initiieren. Aufgrund der Morphologie, der Expression verschiedener PRRs sowie ihrer Funktion können die DCs in zwei Subtypen eingeteilt werden, myeloide- und plasmazytoide DCs (32). Während plasmazytoide DCs wegen ihrer Fähigkeit große Mengen an IFN- $\alpha$ zu produzieren eine wichtige Rolle bei der angeborenen Immunantwort spielen, sind die myeloiden DCs 
aufgrund ihrer Fähigkeit zur effizienten Antigenpräsentation entscheidend für die Aktivierung der adaptiven Immunantwort (84). Die Aktivierung der angeborenen Immunität beginnt durch die Erkennung von so genannten PAMPS durch entsprechende Rezeptoren, den PRRs. Neben den membranständigen TLRs als PRRs besitzen die DCs auch die zytoplasmatischen Sensoren RIG-I und MDA-5. Allen PRRs ist gemeinsam, dass sie die Produktion von Typ I IFN und Zytokinen sowie die Expression verschiedener Oberflächenmoleküle einleiten können.

Für die in dieser Arbeit durchgeführten Untersuchungen wurden pDCs und mDCs aus humanen Buffy-Coats isoliert und anschließend die Infektionsversuche durchgeführt. In den meisten Studien zur Untersuchung der Interaktionen von mDCs mit Pathogenen werden aus Monozyten generierte DCs benutzt. Da in dieser Arbeit keine aus Monozyten gereiften DCs sondern primäre mDCs benutzt wurden, konnte sichergestellt werden, dass die Fähigkeit der Antigenpräsentation nicht durch den Reifungsprozess negativ beeinträchtigt wird, so wie es für aus Monozyten generierten DCs gezeigt wurde (75). Darüber hinaus sind die funktionellen Eigenschaften von in vitro generierten mDCs zumindest teilweise von der gewählten Selektionsmethode abhängig $(72,144)$. Durch die Verwendung primärer mDCs konnte daher diese Fehlerquelle ausgeschlossen werden.

\subsubsection{Aktivierung der DCs}

Um zu untersuchen, ob eine FSME-Virusinfektion DCs aktiviert, wurden die DCs mit dem FSME-Virus infiziert, mit UV-inaktivierten Virus oder als Mock-Kontrolle mit Medium koinkubiert und mittels Durchflußzytometrie die Expression von Reifungs-, Kostimulations-, Antigenpräsentations-, Adhäsions- und Apoptosemolekülen analysiert. Um Aussagen über den zeitlichen Verlauf der Markerexpression machen zu können, wurden die infizierten DCs 12 h, 24 h, 48 h und 72 h nach Infektion untersucht (s. Kapitel 3.1.2 (mDCs) und 3.1.3 (pDCs)).

Durch die Erkennung von Viren über die PRRs kann neben der Produktion von Typ I IFNs auch die Expression von verschiedenen Oberflächenmolekülen induziert werden. Die durch die TLRs induzierte Signaltransduktion führt neben der IFN- $\alpha$ vermittelten Etablierung eines antiviralen Zustands und der Expression proinflammatorischer Zytokine auch zur Reifung und Aktivierung der DCs, was durch die erhöhte Expression des Reifungsmarkers CD83 sowie der Aktivierungs- und 
kostimulatorischen Marker CD40, CD80 und CD86, die für die Aktivierung der T-Zellen benötigt werden, gekennzeichnet ist $(14,78,84)$. Durch die Aktivierung der DCs wird sowohl die endozytotische Aufnahme der Antigene als auch die Expression von antigenpräsentierenden Molekülen gesteigert und damit die Fähigkeit Fremdantigene an ihrer Zelloberfläche zu präsentieren verstärkt (3, 32). In Kombination mit kostimulatorischen Molekülen führt die Antigenpräsentation zur Aktivierung der T-Zellen und damit zum Aufbau der adaptiven Immunantwort (32).

In dieser Arbeit konnte gezeigt werden, dass es in mDCs im Zuge der Infektion mit replikationskompetentem FSME-Virus nur zu einer geringen Verstärkung der Expression des antigenpräsentierenden Moleküls MHC-I kommt (s. Kapitel 3.1.2). Die pDCs zeigten in Antwort auf das FSME-Virus eine deutlich verstärkte Expression von MHC-I und MHC-II 12 h nach Infektion, die aber zu späteren Zeitpunkten nach Infektion nicht mehr zu beobachten war. Die Aktivierung der MHC-Expression in pDCs wird nur von replikationskompetentem FSME-Virus induziert, da UV-inaktiviertes Virus keinen Einfluss auf die MHC-Expression hatte. Auffällig war, dass bei den mDCs ein solcher Unterschied nicht $\mathrm{zu}$ beobachten war, hier konnte in keinem Fall eine effiziente Aktivierung der MHC-Expression beobachtet werden. Die deutliche aber transiente Erhöhung der MHC-Expression bei pDCs durch replikationskompetentes FSME-Virus deutet darauf hin, dass eine initiale FSME-Virusreplikation stattfindet, die dann aber durch die pDCs erfolgreich restringiert wird. Dagegen scheint in $\mathrm{mDCs}$ eine Infektion mit FSME-Virus mit der Aktivierung der MHC-Expression zu interferieren.

Auch die Expression des Reifungsmarkers CD83 (111) war in FSME-Virus infizierten mDCs und pDCs unterschiedlich (s. Kapitel 3.1.3 und 3.1.2). Die verstärkte Expression von CD83 trat bei den infizierten mDCs erst zu späten Zeitpunkten nach Infektion ein ( $48 \mathrm{~h}$ und $72 \mathrm{~h}$ ), während bei den pDCs bereits $12 \mathrm{~h}$ nach der Infektion eine gesteigerte, aber wiederum transiente Expression von CD83 zu beobachten war. Die Koinkubation der DCs mit UV-inaktiviertem FSME-Virus hatte keinen Einfluß auf die Expression von CD83 und führte demnach nicht zu einer Reifung der Zellen.

Weiterhin konnte für $\mathrm{pDCs}$, nicht aber für $\mathrm{mDCs}$, gezeigt werden, dass es zu einer verstärkten Expression der Aktivierungs- bzw. kostimulatorischen Marker CD40, CD80 und CD86 kommt (s. Kapitel 3.1.3, Abbildung 3.7), die wiederum transient und nur nach Infektion mit repliaktionskompetentem Virus zu beobachten war. 
Neben den Aktivierungs- und Kostimulationsmarkern wird im Zuge der Aktivierung von DCs auch die Expression der Adhäsionsmoleküle CD54 und CD58 verstärkt, die für die Interaktion von DCs und T-Zellen eine wichtige Rolle spielen (14). Bei den infizierten mDCs konnte lediglich eine leichte Hochregulation der Expression des Adhäsionsmoleküls CD54 im Zeitraum von $24 \mathrm{~h}$ bis $48 \mathrm{~h}$ nach Infektion beobachtet werden (s. Kapitel 3.1.2, Abbildung 3.5), während bei pDCs eine deutlich erhöhte Expression $12 \mathrm{~h}$ nach der Infektion beobachtet wurde (s. Kapitel 3.1.3, Abbildung 3.8). Bei dem Adhäsionsmolekül CD58 waren die Unterschiede bezüglich der Expression zwischen Mock-Kontrolle und infizierten DCs nur gering.

Als Apoptosemarker wurde CD95 (FAS) untersucht, welches durch die Stimulation mit CD95L (FAS-Ligand) den programmierten Zelltod einleitet (197). Bei den mit FSMEVirus infizierten mDCs und pDCs wurde im Vergleich zu den nicht-infizierten- oder mit UV-inaktivierten Virus kokultivierten DCs keine verstärkte CD95-Expression beobachtet (s. Kapitel 3.1.2, Abbildung 3.5 (mDCs) und Kapitel 3.1.3, Abbildung 3.8 (pDCs)). Die CD95-vermittelte Einleitung der Apoptose scheint bei den DCs nach FSMEVirusinfektion somit keine Rolle zu spielen.

Zusammenfassend ergibt sich, dass die FSME-Virusinfektion nur zu einer inkompletten Aktivierung der mDCs führt, da zum einen die Expression der untersuchten Marker nur teilweise verstärkt wird und zum anderen die verstärkte Expression dieser Marker nur wenig ausgeprägt oder verzögert ist. Im Gegensatz dazu kommt es bei den pDCs zu einer transienten aber deutlichen Aktivierung. Damit unterscheidet sich das FSME-Virus von anderen Flaviviren, die auch mDCs aktivieren. So kommt es nach Infektion von DCs mit WNV (mDCs), LGTV (mDCs) und DENV (pDCs und mDCs) zur verstärkten Expression von Aktivierungsmarkern, kostimulatorischen Molekülen und antigenpräsentierenden $\operatorname{MHCs}(23,44,163,181)$.

\subsubsection{Interferonantwort der DCs auf die Infektion mit dem FSME-Virus}

In verschiedenen Studien konnte gezeigt werden, dass Flaviviren, einschließlich dem FSME-Virus, sensitiv gegenüber den antiviralen Wirkungen der Typ I IFNs sind (FSMEVirus (150), DENV (65); (50), JEV (44) und LGTV (23) (49)). Für LGTV konnte gezeigt 
werden, dass die Vorinkubation von Zellen mit Typ I IFN zu einem um den Faktor 1000 verminderten Virustiter im Vergleich zu unbehandelten Zellen führt (23).

Die DCs und speziell die pDCs sind in der Lage, Typ I IFN in großen Mengen zu produzieren, dabei können die pDCs im Vergleich zu anderen Zellen das 100-1000fache an Typ I IFN bilden (70). Vor diesem Hintergrund wurde untersucht, ob die DC-Subtypen in Antwort auf die Infektion mit dem FSME-Virus in der Lage sind IFN- $\alpha$ zu produzieren oder ob das FSME-Virus die IFN-Produktion beeinflusst. Dazu wurden die beiden DCSubtypen mit FSME-Virus, UV-inaktiviertem FSME-Virus und Medium als MockKontrolle kokultiviert und die IFN- $\alpha$-Konzentrationen in den Zellkulturüberständen mittels ELISA quantifiziert. Dabei konnte gezeigt werden, dass das FSME-Virus bei den pDCs bereits $12 \mathrm{~h}$ nach der Infektion eine starke IFN- $\alpha$-Antwort induziert und die IFN- $\alpha$ Konzentration von $1500 \mathrm{pg} / \mathrm{ml} 12 \mathrm{~h}$ nach Infektion auf über $3500 \mathrm{pg} / \mathrm{ml}$ nach $24 \mathrm{~h}$ ansteigt (s. Kapitel 3.1.4). Auch nach $72 \mathrm{~h}$ waren noch IFN- $\alpha$-Konzentrationen über $3000 \mathrm{pg} / \mathrm{ml}$ in den Zellkulturüberständen der pDCs, die mit dem FSME-Virus infiziert wurden, vorhanden (s. Kapitel 3.1.4 und Abbildung 3.8 B). Im Gegensatz zu replikationskompetentem FSME-Virus war die IFN- $\alpha$-Antwort, die durch das UVinaktivierte Virus induziert wurde, über den Beobachtungszeitraum von $72 \mathrm{~h}$ um den Faktor 10 vermindert.

Auch für die mDCs konnte gezeigt werden, dass das FSME-Virus eine frühe IFN- $\alpha$ Antwort induziert, die allerdings um den Faktor 10 geringer ausfällt als bei den pDCs (s. Kapitel 3.1.4 und Abbildung 3.8 A). Außerdem sanken die Konzentrationen in den Zellkulturüberständen der mDCs, die mit dem FSME-Virus infiziert wurden, nach $48 \mathrm{~h}$ auf Werte knapp über die 100 pg / ml-Marke ab. Im Gegensatz zu den pDCs konnte aber gezeigt werden, dass das UV-inaktivierte Virus ähnliche IFN- $\alpha$ Mengen wie das replikationskompetente FSME-Virus in den mDCs induziert.

Die Interferonantwort der pDCs auf das FSME-Virus ist somit stärker ausgeprägt als die der mDCs, wobei dies die unterschiedlichen Funktionen der DC-Subtypen widerspiegelt. Die Fähigkeit der pDCs im Zuge einer viralen Stimulation in kurzer Zeit große Mengen der Typ IIFNs zu produzieren ist auf die konstitutive Expression des Transkriptionsfaktors IRF7 zurückzuführen, der die Induktion der IFN- $\alpha$-Subtypen ermöglicht, während die IRF7-Expression in anderen Zelltypen einschließlich den mDCs einer transkriptionellen Regulation unterliegt und erst nach einer Virusinfektion 
Typ I IFN-vermittelt induziert wird $(9,70,113,171)$. Die mDCs exprimieren den Transkriptionsfaktor IRF-3 konstitutiv, der nach Virusinfektion die IFN- $\beta$ Expression induziert und dessen Expression aber nicht gesteigert wird $(9,171)$. Die Expression von IRF7 bzw. IFN- $\alpha$ ist in den mDCs der IFN- $\beta$ Expression nachgeschaltet und von dieser abhängig.

Es konnte auch für weitere Flaviviren (DENV, LGTV und WNV) gezeigt werden, dass bei einer Infektion der DCs eine Typ I IFN-Antwort hervorgerufen wird (23, 44, 163, 181). In diesem Zusammenhang sind speziell die Ergebnisse der Untersuchungen mit DENV hervorzuheben, da in dieser Studie auch direkt isolierte mDCs und nicht aus Monozyten generierte mDCs benutzt wurden (181). Im Gegensatz zu den Beobachtungen mit FSME-Virus wurde dabei allerdings nachgewiesen, dass die IFN- $\alpha$-Antwort der mDCs erst 48 h nach Infektion mit dem DENV einsetzt. Die Ergebnisse, die mit DENV infizierten pDCs bezüglich der IFN- $\alpha$-Induktion erzielt wurden, stimmen dagegen im zeitlichen Verlauf und in der Größenordnung der IFN- $\alpha$-Konzentrationen in etwa mit den Ergebnissen, die in dieser Arbeit nach FSME-Virusinfektionen von pDCs erzielt wurden, überein.

Die Tatsache, dass das FSME-Virus bei den mDCs eine IFN- $\alpha$-Antwort induziert, die über die Zeit von $72 \mathrm{~h}$ nach der Infektion wieder abfällt, kann in den Zusammenhang mit einer Hemmung des Typ I IFN-Signalwegs durch das FSME-Virus gebracht werden. Dazu konnte in bisherigen Studien gezeigt werden, dass verschiedene Flaviviren die IFNSignaltransduktion über den JAK-STAT-Signalweg durch antagonistische Wirkung von bestimmten Nichtstrukturproteinen verhindern, um der durch Typ I IFN induzierten antiviralen Wirkung entgegenzuwirken. So blockiert das DENV NS4B Protein die Aktivierung von STAT1 und damit die Aktivierung von ISRE Promotoren in IFNstimulierten Zellen (140). Darüber hinaus bindet das DENV NS5-Protein an STAT2 und inhibiert ebenfalls den JAK-STAT-Signalweg (6). Das JEV NS5-Protein inhibiert den durch IFN- $\alpha$ induzierten JAK-STAT-Signalweg durch die Hemmung der Phosphorylierung von Tyk2 (114). Bei dem mit dem FSME-Virus nahe verwandten LGTV konnte gezeigt werden, dass das NS5 Protein als Interferon Antagonist agiert, indem es mit dem IFN- $\alpha / \beta$ Rezeptor interagiert und die Phosphorylierung von STAT1 in inhibiert, wodurch die Produktion von IFN- $\alpha$ verhindert wird (23). Es konnte auch gezeigt werden, dass das FSME-Virus mittels des NS5 Proteins und dem Membranprotein 
Scribble die von den Typ I IFNs stimulierte JAK-STAT Interaktion und somit die Produktion von IFN- $\alpha$ inhibiert (200). Die Ergebnisse, die mit UV-inaktivierten Viren erhalten wurden, unterscheiden sich von Studie zu Studie. Während in einigen Versuchen gezeigt werden konnte, dass eine Inkubation mit UV-inaktivierten Flaviviren zum kompletten Ausfall der Typ I IFN-Produktion bei den pDCs führen kann, konnte in einer anderen Versuchsreihe die Produktion von IFN- $\alpha$ in Antwort auf replikationsinkompetente, UV-inaktivierte Flaviviren durch pDCs nachgewiesen werden (181). Dabei können unterschiedliche Vorgehensweisen bei der UV-Inaktivierung (variierende Bestrahlungszeit, unterschiedliche Dosierungen des UV-Lichts, Variationen in der Entfernung der UV-Lichtquelle) eine Rolle spielen. In dieser Arbeit konnte gezeigt werden, dass das UV-inaktivierte FSME-Virus in den mDCs eine ähnliche IFN- $\alpha$ Antwort induziert wie das replikationskompetente Virus (s. Kapitel 3.1.4 Abbildung 3.9 A). In den pDCs hingegen ist die IFN- $\alpha$-Antwort, die durch das UV-inaktivierte FSME-Virus ausgelöst wird, um den Faktor 10 geringer als nach Infektion mit dem replikationskompetenten Virus und liegt auf dem Niveau der IFN- $\alpha$-Antwort der mDCs nach Kontakt mit FSME-Virus (s. Kapitel 3.1.4, Abbildung 3.9). Der Grund für die Unterschiede kann auf die unterschiedlichen Aktivierungswege der pDCs und mDCs bezüglich der Typ I IFN-Synthese zurückgeführt werden. In den mDCs wird virale RNA im Zytosol vorwiegend durch die Rezeptoren RIG-I und MDA-5 bzw. Membranassoziiert durch TLR3 und TLR8 erkannt und so IRF3-vermittelt die Typ I IFN-Synthese induziert. In den pDCs wird die starke und schnelle IFN- $\alpha$-Antwort durch die Erkennung und Signalweiterleitung der endosomal lokalisierten TLRs 7 und 9 vorangetrieben, die IRF7 aktivieren, welches die Synthese der IFN- $\alpha$-Subtypen induziert. Der TLR7 erkennt einzelsträngige RNA und RNA-Zwischenprodukte der viralen Replikation. Für die effiziente TLR7-vermittelte Aktivierung scheint im Falle des FSME-Virus die virale Replikation notwendig zu sein, da die IFN- $\alpha$-Induktion der pDCs nach Kontakt mit dem replikationsinkompetenten FSME-Virus sehr viel weniger ausgeprägt ist und der von mDCs ähnelt. Andererseits konnte gezeigt werden, dass nicht unbedingt replikationskompetentes Virus für die effiziente Induktion von Typ I IFN in pDCs benötigt wird, sofern die Virushülle intakt ist (205). So induziert im Falle von WNV und DENV UV-inaktiviertes Virus ebenso effizient die IFN- $\alpha$-Synthese in den pDCs, wie repliaktionskompetentes Virus $(175,181)$. 


\subsubsection{Zytokinantwort der DCs auf das FSME-Virus}

Im Zuge der Aktivierung kommt es bei den DCs nicht nur zur Produktion von Typ I IFN sondern auch zur Bildung proinflammatorischer Zytokine, wie TNF- $\alpha$ und IL-6 sowie IL-8 $(33,203)$. Speziell pDCs produzieren dabei große Mengen an TNF- $\alpha$ und IL-6 (33).

Um die inflammatorische Zytokinantwort der einzelnen DC-Subtypen auf die Infektion mit dem FSME-Virus über ein Intervall von $72 \mathrm{~h} \mathrm{zu}$ untersuchen, wurden die Zellkulturüberstände der DCs, die mit FSME-Virus infiziert, mit UV-inaktiviertem FSME-Virus oder Medium als Mock-Kontrolle kokultiviert wurden, nach 12 h, 24 h, 48 h und $72 \mathrm{~h}$ mittels eines CBA auf die Zytokine IL-1 $\beta$, TNF- $\alpha$, IL-6, IL-8, IL-10 und IL-12p40 untersucht. Dabei konnte gezeigt werden, dass durch die Infektion mit replikationskompetentem FSME-Virus bei den mDCs und pDCs eine starke Produktion der proinflammatorischen Zytokine IL-6 und IL-8 über die Zeit von $72 \mathrm{~h}$ hervorgerufen wird, wobei die Konzentrationen der beiden Zytokine in den Überständen der pDCs um den Faktor 10 gegenüber den mDCs erhöht waren und im Falle des IL-8 teilweise dicht unter der $200000 \mathrm{pg} / \mathrm{ml}$-Marke lagen. Auch die beiden frühen Zytokine IL-1 $\beta$ und TNF- $\alpha$ konnten in den Zellkulturüberständen der mDCs nachgewiesen werden, wobei die Konzentrationen mit Werten unter 5 pg / ml (IL-1 $\beta)$ und unter 20 pg / ml (TNF- $\alpha)$ sehr niedrig waren und über die Zeit hinweg abnahmen, sodass sie nach $72 \mathrm{~h}$ unter der Nachweisgrenze lagen (s. Kapitel 3.1.5). Bei den pDCs konnte dagegen lediglich TNF- $\alpha$ in den Zellkulturüberständen nachgewiesen werden, jedoch war die TNF- $\alpha$-Antwort der pDCs um den Faktor 20 gegenüber den mDCs erhöht. Aber auch in den pDCÜberständen sank die Konzentration des TNF- $\alpha$ deutlich ab und lag nach $48 \mathrm{~h}$ bereits deutlich unter der $100 \mathrm{pg} / \mathrm{ml}-$ Marke.

UV-inaktiviertes FSME-Virus induzierte bei den DCs eine ähnliche Zytokinantwort, wie das replikationskompetente Virus. Bei den pDCs induzierte das UV-inaktiverte Virus jedoch deutlich weniger TNF- $\alpha$ als replikationskompetentes Virus.

Die beiden Zytokine TNF- $\alpha$ und IL-1 induzieren die Kaskade der inflammatorischen Mediatoren (53) und damit auch die Produktion von IL-6 (94), und IL-8 (10). Aber auch das IFN- $\alpha$ induziert die Produktion von IL-6 in humanen PBMCs in vivo und in vitro (40, 165). Das IL-6 wiederum induziert u. a. IL-1- und TNF- $\alpha$-Antagonisten (IL-1Ra bzw. TNFsRp55) (94, 190). Das könnte der Grund für den Rückgang der Konzentrationen der 
beiden frühen Zytokine IL-1 $\beta$ und TNF- $\alpha$ erklären, der bei beiden DC-Subtypen zu späteren Zeitpunkten nach der Infektion mit dem FSME-Virus zu erkennen war. Zudem inhibiert Typ I IFN ebenfalls die Produktion des frühen proinflammatorischen Zytokins TNF- $\alpha$ (39). Da in beiden DC-Subtypen nach FSME-Virusinfektion Typ I IFN gebildet wird, könnte auch dieses zur Hemmung der TNF- $\alpha$ Produktion beitragen.

Auch bei FSME-Patienten wurden erhöhte Konzentrationen an proinflammatorischen Zytokinen im Serum nachgewiesen $(8,191)$. Mit zunehmender Zeit sanken die Konzentrationen der proinflammatorischen Zytokine im Serum, während der Gehalt des antiinflammatorischen Zytokins IL-10 zunahm (8). Demzufolge könnten die mDCs und pDCs eine wichtige Rolle als Produzenten des proinflammatorischen Zytokins IL-6, das im Verlauf der FSME-Virusinfektion gebildet wird, spielen. Die Rolle von IL-6 für den Krankheitsverlauf ist unklar, da keine Korrelation zwischen der Höhe der IL-6 Konzentrationen und der Ausprägung und Schwere der Krankheit festgestellt werden konnte (191). In bisher veröffentlichten Studien wurde nicht die Produktion des Chemokins IL-8 nach FSME-Virusinfektion untersucht $(8,191)$. In dieser Arbeit konnte gezeigt werden, dass in den Zellkulturüberständen der FSME-Virus infizierten mDCs und pDCs großen Mengen an IL-8 vorhanden sind. IL-8 ist ein chemotaktisches Protein, das z. B. die Rekrutierung von neutrophilen Granulozyten hervorruft, die die Immunantwort an der Stelle der Inflammation verstärken $(24,86)$. Weiterhin führt es zur Aktivierung und Degranulation der Neutrophilen, die dadurch teilweise Gewebeschäden verursachen können (53). Im Serum von Patienten, die mit dem mit FSME-Virus nahe verwandten JEV infiziert waren, konnten hohe Konzentrationen des inflammatorischen Zytokins IL-8 nachgewiesen werden (176). Bei diesen Patienten konnte gezeigt werden, dass sich durch den Anstieg der IL-8 Konzentration auch die Anzahl der neutrophilen Granulozyten erhöhte (176). Welche Rolle die neutrophilen Granulozyten im Rahmen der FSME-VirusInfektion und von FSME spielen ist noch unklar. Es liegt nahe, dass sie die Zytokin- und Chemokinantwort komplementieren, wie es auch für das WNV beschrieben wurde (71). Außerdem konnte in in vitro Studien gezeigt werden, dass IL-8 das Wachstum von Astrozyten und Mikroglia-Zellen im ZNS erhöht (4). Somit könnte das IL-8 eine wichtige Rolle bei der Immunantwort im ZNS im Zuge der FSME-Virus-Infektion spielen.

In den Zellkulturüberständen der FSME-Virus infizierten pDCs konnte kein IL-1 $\beta$, IL-10 oder IL-12p40 nachgewiesen werden. Diese Beobachtung geht teilweise mit der Literatur 
einher, in der beschrieben wird, dass die pDCs nicht in der Lage sind, IL- $1 \alpha / \beta$, IL-10 oder signifikante Mengen an IL-12 zu produzieren. Auch in den Zellkulturüberständen der infizierten mDCs konnte in dieser Arbeit kein IL-10 oder IL-12p40 nachgewiesen werden. Die mDCs sind zwar prinzipiell in der Lage IL-12 zu produzieren, doch wird die Produktion des IL-12 durch IFN- $\alpha$ gehemmt (41).

Das antiinflammatorische IL-10 konnte dagegen nicht in den Zellkulturüberständen der mDCs und pDCs nachgewiesen werden, sodass die Konzentrationen des IL-10, die im Serum von FSME-Patienten nachgewiesen wurden (8), auf andere Zellen, wahrscheinlich die T-Zellen, zurückzuführen sind, worauf auch die Ergebnisse dieser Arbeit deuten. Inwieweit die pDCs in der Lage sind das antiinflammatorische IL-10 zu produzieren kann allerdings nicht eindeutig beantwortet werden. In der Literatur wird häufig beschrieben, dass die pDCs selbst unfähig sind IL-10 zu produzieren und gemessene Mengen an IL-10 eher auf Kontamination mit anderen Zellen zurückzuführen ist (120). Damit wären die pDCs nicht in der Lage, mittels der Produktion des IL-10 als antiinflammatorisches Zytokin die inflammatorische Immunantwort autokrin zu inhibieren. Allerdings konnte in einer anderen Versuchsreihe gezeigt werden, dass die pDCs im Rahmen der lokalen Immuntoleranz fähig sind IL-10 konstitutiv zu exprimieren (151). Für T-Zellen konnte in dieser Arbeit die Sekretion von IL-10 nach FSME-Virusinfektion nachgewiesen werden. Interessanterweise konnte in pDC-T-Zell-Kokulturen eine stärkere IL-10-Synthese nachgewiesen werden als in reinen T-Zell-Kulturen. Die stärkere Produktion an IL-10 in der Kokultur legt den Schluss nahe, dass hier eine Aktivierung der T-Zellen durch die pDCs stattgefunden hat. Auch wenn eine Studie bei Mäusen gezeigt hat, dass die pDCs eher eine Rolle als auf Abruf stehende APCs spielen, als effektiv die Aktivierung naiver T-Zellen $\mathrm{zu}$ induzieren (104). So konnte doch gezeigt werden, dass die pDCs die intrinsische Fähigkeit besitzen, eine IL-10 Produktion in den T-Zellen zu induzieren (107).

\subsubsection{Hilft die Zytokinantwort der DCs dem Wirt oder dem FSME-Virus?}

In dieser Arbeit konnte gezeigt werden, dass es nach Infektion von DCs mit dem FSMEVirus $\mathrm{zu}$ einer ausgeprägten Produktion proinflammatorischer Zytokine kommt (s. Kapitel 3.1.5). In Kapitel 4.3 wurde aufgezeigt, dass diese Zytokinantwort mit dem in der Literatur beschriebenen Krankheitsverlauf von FSME teilweise korreliert. Allerdings 
können diese proinflammatorischen Zytokine auch unter Umständen andere Wirkungen haben, die nicht unbedingt die Immunantwort in Bezug auf die Bekämpfung des Virus unterstützen, sondern eher dem FSME-Virus bei der Ausbreitung behilflich sein könnten.

TNF- $\alpha$ und IL-1 $\beta$ führen zur Migration der DCs in die Lymphgefäße, wo sie in den T-Zellzonen den T-Zellen Antigene präsentieren (43). Durch die Infektion der mDCs in denen das FSME-Virus repliziert, kann das Virus im Zuge der Migration, die durch das TNF- $\alpha$ oder IL- $1 \beta$ hervorgerufen wird, sich im Körper des Wirts ausbreiten und in die Lymphgefäße gelangen. Darüber hinaus konnte gezeigt werden, dass das TNF- $\alpha$ die Permeabilität der Blut-Hirn-Schranke beeinflusst und sogar zu Schäden der Blut-HirnSchranke führen kann (172) (15). Wie in dieser Arbeit gezeigt werden konnte, werden in einer pDC-T-Zell-Kokultur in Antwort auf eine Infektion mit dem FSME-Virus hohe Mengen an TNF- $\alpha$ produziert (s. Kapitel 3.3.2). Dadurch könnte es für das FSME-Virus möglich sein die Blut-Hirn-Schranke zu überwinden und in das ZNS vorzudringen.

Neben TNF- $\alpha$ beeinflusst auch IL-6 die Permeabilität der Endothelzellen und trägt so zur Überwindung der Blut-Hirn-Schranke bei, wie es für das WNV schon gezeigt wurde (198). Darüber hinaus konnte auch in Maus- und Rattenmodellen gezeigt werden, dass das IL-6 zu Schäden in der Blut-Hirn-Schranke führen kann $(29,31)$. Demnach könnte auch das IL-6 eine Rolle bei der Überwindung der Blut-Hirn-Schranke durch das FSMEVirus spielen.

Auch IL-8 wurde in großen Mengen von den DCs als Antwort auf die Infektion mit dem FSME-Virus gebildet. Das IL-8 führt zur Rekrutierung von weiteren Immunzellen an den Ort der Inflammation. Durch diese Rekrutierung anderer Immunzellen kann auf der einen Seite die Immunantwort verstärkt werden, allerdings kann es aber auch dazu kommen, dass zusätzliche Zellen an den Ort der Infektion gelangen, die durch FSME-Virus infizierbar sind und in denen das FSME-Virus replizieren kann. Außerdem konnte gezeigt werden, dass das IL-8 in vivo und in vitro die IFN- $\alpha$ vermittelte Induktion eines antiviralen Status inhibieren kann $(100,154)$. Das IL-8 kann die Replikation des Zytomegalievirus sowie von positivsträngigen RNA-Viren verstärken (100, 143). Die Mengen an IL-8, die durch die DCs in Antwort auf das FSME-Virus produziert wurden, waren im Vergleich zum IFN- $\alpha$ oder TNF- $\alpha$ oder IL-1 $\beta$ sehr hoch. Demnach könnte es möglich sein, dass die Taktik des FSME-Virus darin liegt, eine starke IL-8-Antwort zu 
induzieren, um so den durch das IFN- $\alpha$ induzierten antiviralen Status zu umgehen und damit in suszeptiblen Zellen replizieren zu können.

\subsection{Einfluss der FSME-Virus-Infektion auf die T-Zellen}

Um direkte Interaktionen zwischen dem FSME-Virus und T-Zellen zu untersuchen, wurden isolierte T-Zellen mit dem FSME-Virus, UV-inaktivierten FSME-Virus oder Medium als Mock-Kontrolle koinkubiert und die Expression der Aktivierungsmarker CD69, CD25, MHC-II für CD4 ${ }^{+}$- und $\mathrm{CD}^{+}$T-Zellen zu verschiedenen Zeitpunkten nach Infektion untersucht. Die Expression dieser Marker verläuft zeitlich gestaffelt und beginnt mit der Expression von CD69. Der Aktivierungsmarker CD25 wird auf Zellen verstärkt exprimiert, bei denen der IL-2-Rezeptor ausgebildet wird, der neben der Zellproliferation auch die Differenzierung der T-Zellen induziert. Dabei wird das CD25 im Rahmen der Aktivierung von T-Lymphozyten später als CD69 exprimiert, aber nach $12 \mathrm{~h}$ bis $24 \mathrm{~h}$ ist im Falle einer Aktivierung eine erhöhte Expression erkennbar (160). Der MHC-IIKomplex ist ein später Aktivierungsmarker der T-Zellen, der erst $48 \mathrm{~h}$ bis $60 \mathrm{~h}$ nach einer Stimulation verstärkt exprimiert wird (160). Beide T-Zellpopulationen reagierten auf die FSME-Virus-Infektion nur mit einer verstärkten Expression des frühen Aktivierungsmarkers CD69, wobei auffällig war, dass diese erst 48h nach Infektion und damit verzögert erfolgte. Ein weiterer Ablauf der Aktivierungskaskade in Form der verstärkten Expression von CD25 und MHC-II konnte nicht nachgewiesen werden. FSME-Virus bewirkt also nur eine Teilaktivierung der $\mathrm{CD} 4^{+}$- und $\mathrm{CD} 8^{+} \mathrm{T}-$ Zellen.

Die Infektion von T-Zellen mit dem FSME-Virus bewirkt eine gering ausgeprägte Zytokinantwort dieser Zellen (s. Kapitel 3.2.3). Es konnte lediglich nach $72 \mathrm{~h}$ eine größere Menge an IFN- $\gamma$ und bereits nach $24 \mathrm{~h}$ eine erhöhte Menge an TNF- $\alpha$ bestimmt werden, wobei die Werte um 300 pg / ml bzw. 200 pg / ml lagen. Die Konzentrationen der Zytokine IL-4, IL-5 und IL-10 waren relativ gering und erreichten mit Ausnahme des IL-4 erst nach $72 \mathrm{~h}$ Werte um die 50-60 pg / ml. Die Produktion der Zytokine in den T-Zellen wurde auch durch das UV-inaktivierte Virus stimuliert, wobei mit Ausnahme von IL-10 diese weniger stark ausfiel als nach Infektion mit replikationskompetentem Virus. 
Die fehlende Verstärkung der Expression von CD25 und MHC-II sowie die geringe Produktion von Zytokinen zeigen, dass die T-Zellen nach direkten Kontakt mit dem FSME-Virus nur unvollständig aktiviert werden.

Die Aktivierung der T-Zellen durch DCs beginnt mit der Interaktion von Adhäsionsmolekülen, mit deren Hilfe ein Kontakt zu den T-Zellen hergestellt wird. Dabei interagieren die Adhäsionsmoleküle CD11c (mDCs), CD54 sowie CD58 auf Seiten der DCs mit den Molekülen CD18, CD11 (LFA-1) und CD2 auf den T-Zellen. Die MHCMoleküle präsentieren Fremdantigene an die T-Zellrezeptoren, wodurch eine spezifische Bindung erfolgt. Die DCs sind dabei in der Lage sowohl naive $\mathrm{CD}^{+}-$als auch naive $\mathrm{CD}^{+}$T-Zellen zu aktivieren (130). Dabei interagieren die mit einem Antigen beladenen MHC-I Moleküle auf den DCs mit dem T-Zellrezeptor der naiven $\mathrm{CD}^{+} \mathrm{T}$-Zellen, während die beladenen MHC-II-Moleküle mit dem T-Zellrezeptor der naiven $\mathrm{CD}^{+} \mathrm{T}$-Zellen interagieren. Durch die Interaktion wird die Bindung der Adhäsionsmoleküle verstärkt $(58,59)$. Zur Aktivierung der T-Zellen kommt es allerdings erst durch eine weitere Interaktion der kostimulatorischen Rezeptoren CD40, CD80 und CD86 auf Seiten der DCs mit den entsprechenden Liganden CD40L und CD28 auf Seiten der T-Zellen. Im Zuge der Aktivierung kommt es bei den T-Zellen wie bereits beschreiben zu einer vermehrten Expression der Aktivierungsmarker CD25, CD69 und MHC-II (35). Im Kapitel 3.1.3 konnte gezeigt werden, dass die pDCs als Antwort auf die Infektion mit dem FSME-Virus die Expression von Adhäsionsmarkern, Aktivierungsund Kostimulationsmolekülen sowie der antigenpräsentierenden MHCs erhöhen. Darüber hinaus produzieren die pDCs durch die Aktivierung mit dem FSME-Virus proinflammatorische Zytokine sowie das IFN- $\alpha$, die ebenfalls an der Aktivierung der T-Zellen beteiligt sind. Typ I Interferone, wie das IFN- $\alpha$, das als Antwort auf eine FSMEVirusinfektion in den pDCs produziert wird, verstärken die Expression der MHCs und der kostimulatorischen Moleküle CD40, CD80 und CD86 (189). Die Typ I IFNs sind zudem ein zentraler Überlebensfaktor von $\mathrm{CD}^{+}$- und $\mathrm{CD}^{+} \mathrm{T}$-Zellen $(128,182)$. Um die Aktivierung von T-Zellen durch DCs nach Infektion mit dem FSME-Virus zu untersuchen, wurden aus humanen Buffy-Coat isolierte pDCs und T-Zellen im Verhältnis 1:10 kokultiviert und mit dem FSME-Virus, UV-inaktiviertem FSME-Virus oder Medium als Mock-Kontrolle koinkubiert und die Expression der Aktivierungsmarker CD25, CD69 und MHC-II, sowie die für die T-Zell-Subtypen spezifischen Marker CD4 und CD8 
untersucht. Außerdem wurde die Zytokinantwort der T-Zellen in der Kokultur zu einem frühen (24 h nach Infektion) und späten (72 h nach Infektion) Zeitpunkt mittels des CBAs analysiert. Bei den pDCs wurde die Expression der Kostimulationsmarker CD40, CD80 und CD86 sowie der antigenpräsentierenden Moleküle MHC-I und MHC-II untersucht (s. Kapitel 3.3.1).

Während bei den T-Zellen nachgewiesen werden konnte, dass sowohl die CD4 ${ }^{+}$- als auch die $\mathrm{CD}^{+} \mathrm{T}$-Zellen in der Kokultur nach Infektion mit dem FSME-Virus den Aktivierungsmarker CD69 verstärkt exprimieren, konnte bei den pDCs keine erhöhte Expression der kostimulatorischen Marker bzw. der Antigenpräsentationsmoleküle nachgewiesen werden. Das stimmt mit der Beobachtung überein, dass bei den isolierten pDCs $72 \mathrm{~h}$ nach FSME-Virusinfektion keine verstärkte Expression von Aktivierungs- und Antigenpräsentationsmarkern im Vergleich zur Mock-Kontrolle mehr festgestellt werden konnte. Es ist denkbar, dass die antiinflammatorische Zytokinantwort der T-Zellen in der Kokultur zur Aufhebung der Aktivierung der pDCs beiträgt. Bei den T-Zellen konnte wie auch schon bei der Einzelkultur keine verstärkte Expression der Aktivierungsmarker CD25 oder MHC-II beobachtet werden. Im Verlauf der T-Zellaktivierung sollte eine verstärkte Expression der späteren Aktivierungsmarker CD25 (12-24 h) und MHC-II (48$60 \mathrm{~h}$ ) auftreten (160). Warum diese nach FSME-Virusinfektion ausbleibt ist unklar, Auch in der Literatur finden sich nur sehr wenig Hinweise bezüglich der Immunmodulation von T-Zellen nach Flavivirusinfektion. Die verzögerte Expression des eigentlich frühen Aktivierungsmarkers CD69 sowie die fehlenden Aktivierung der CD25- und MHC-IIExpression lassen auf eine unvollständige Aktivierung von T-Zellen durch pDCs nach FSME-Virus-Infektion schließen.

In den Zellkulturüberständen der pDC-T-Zell-Kokultur, die mit dem FSME-Virus koinkubiert wurde, konnte nachgewiesen werden, dass im Gegensatz $\mathrm{zu}$ reinen T-Zellkulturen, die mit FSME-Virus infiziert worden waren, bereits nach $24 \mathrm{~h}$ größere Mengen an TNF- $\alpha$ (ca. $3500 \mathrm{pg} / \mathrm{ml}$ ), IFN- $\gamma$ (ca. $4000 \mathrm{pg} / \mathrm{ml}$ ) und IL-10 (ca. $2500 \mathrm{pg} / \mathrm{ml}$ ) sowie geringere Mengen an IL-4 und IL-5 (bis $150 \mathrm{pg} / \mathrm{ml}$ ) vorhanden waren. Abgesehen von IL-4 und IL-10 stiegen die Mengen bis $72 \mathrm{~h}$ nach Infektion noch weiter an (s. Kapitel 3.3.2). Neben den pDCs kommen auch die T-Zellen als Mitproduzenten des TNF- $\alpha$ in Frage, zumindest war die TNF- $\alpha$-Antwort sehr stark und erreichte nach $72 \mathrm{~h}$ Konzentrationen bis 6000 pg / ml. Aber auch die IFN- $\gamma$-Konzentration 
war über die Zeit sehr hoch. IFN- $\gamma$ aktiviert Makrophagen und stimuliert die Antigenpräsentation. Des Weiteren induziert es die Differenzierung der Th1-Zellen und reprimiert die Th2-Zellantwort (27) und wird hauptsächlich von Th1-Zellen selbst und von $\mathrm{CD}^{+} \mathrm{T}$-Zellen produziert. Demzufolge scheint die Aktivität der Th1-Zellen und $\mathrm{CD}^{+} \mathrm{T}$ Zellen in den FSME-Virus infizierten Kokulturen relativ hoch zu sein.

In den Zellkulturüberständen der FSME-Virus infizierten Kokulturen konnten auch die Zytokine IL-4 und IL-5 nachgewiesen werden. IL-4 und IL-5 werden hauptsächlich von den Th2-Zellen produziert und fördern die Differenzierung von naiven CD4 ${ }^{+}$-Zellen zu Th2-Zellen. Dadurch kommt es zur Verstärkung der humoralen Immunantwort und zur Hemmung der inflammatorischen Aktivitäten der Th1-Zellen. Die Konzentration an IL-4 und IL-5 in den Zellkulturüberständen war allerdings relativ gering und belief sich im Falle des IL-4 über die Zeit auf ca. 40 pg / ml, während die Konzentration des IL-5 von $20 \mathrm{pg} / \mathrm{ml}$ auf annähernd $40 \mathrm{pg} / \mathrm{ml}$ anstieg. Das Zytokinprofil der infizierten Kokultur lässt daher auf eine Th1-dominierte Immunantwort nach FSME-Virusinfektion schließen.

Nach FSME-Virusinfektion der pDC-T-Zell-Kokultur kam es zu einer ausgeprägten Produktion vom antiinflammatorischen IL-10. Das IL-10 inhibiert die Expression von antigenpräsentierenden- sowie kostimulatorischen Molekülen (MHC-I, MHC-II, CD80 und CD86) bei den DCs und Makrophagen, zudem inhibiert es die Aktivierung von T-Zellen (34, 67, 68, 136, 138, 179). Dabei supprimiert das IL-10 hauptsächlich die Aktivierung der $\mathrm{CD}^{+} \mathrm{T}$-Zellen, die Wirkung auf $\mathrm{CD}^{+}$T-Zellen dagegen ist unterschiedlich und kann je nach Situation und äußeren Umständen supprimierend oder aktivierend sein (136). Bereits $24 \mathrm{~h}$ nach Infektion der Kokulturen mit FSME-Virus betrug die IL-10 Konzentration mehr als 2500 pg / ml. Auch bei FSME-Patienten konnte gezeigt werden, dass die IL-10-Konzentrationen im Serum im Laufe der Zeit zunehmen, während die Konzentrationen der proinflammatorischen Zytokine abnehmen (8, 191). Die T-Zellen und speziell die Th2-Zellen stellen dabei eine wichtige Quelle von IL-10 dar und tragen so zur Verminderung der DC-Aktivität und zur Inhibierung der Produktion von proinflammatorischen Zytokinen bei (138). Eine Infektion mit WNV führt zur verstärkten Expression des antiinflammatorischen Zytokins IL-10 durch Makrophagen und $\mathrm{CD}^{+}$T-Zellen (11). Durch die immunsupprimierende Wirkung des IL-10 wird die Immunreaktion abgeschwächt, sodass das Virus besser im Wirt replizieren kann (11). Ob 
das IL-10 auch bei der FSME-Virusinfektion eine ähnliche Rolle spielt, ist bisher noch ungeklärt.

Für die T-Zellen in einer PBMC-Kultur konnte im Rahmen dieser Arbeit nachgewiesen werden, dass sich die Proliferation von $\mathrm{CD}^{+}$- und $\mathrm{CD} 8^{+} \mathrm{T}$-Zellen nach FSME-VirusInfektion nicht von der Proliferation Mock-infizierter T-Zellen unterscheidet. Grund hierfür könnte sein, dass es nach FSME-Virusinfektion von T-Zellen nicht zu einer effizienten Replikation des Virus kommt (s. Kapitel 3.2.4.1) und die Vermehrung der T-Zellen nicht durch die Virusvermehrung gebremst wird.

In dieser Arbeit konnte damit gezeigt werden, dass die T-Zellen durch die pDCs nach FSME-Virusinfektion zumindest teilweise aktiviert werden und neben einer singulär verstärkten Expression des Aktivierungsmarkers CD69 eine ausgeprägte Zytokinantwort induziert wird. Weiterhin scheinen beide Subtypen der T-Zellen (CD4 ${ }^{+}$- und $\mathrm{CD}^{+} \mathrm{T}-Z$ ellen) von den pDCs im gleichen Maße aktiviert zu werden. Eine verstärkte Proliferation der beiden Subtypen in Antwort auf das FSME-Virus konnte nicht beobachtet werden, jedoch lässt das Zytokinprofil den Schluss zu, dass die Th1-Antwort dominiert.

Es konnte gezeigt werden, dass athymische Nacktmäuse, denen die T-Zellen fehlen, eine erhöhte Empfänglichkeit für eine Infektion mit JEV haben und ein adoptiver Transfer von Virus-spezifischen zytotoxischen T-Zellen die Mäuse vor einem letalen Krankheitsverlauf durch das JEV schützt $(109,142)$. Auch für das WNV konnte in Mausmodellen gezeigt werden, dass die Mortalität durch das Fehlen von $\mathrm{CD} 8^{+} \mathrm{T}-$ Zellen erhöht ist und eine T-Zelldepletion zur einer verstärkten Enzephalitis führt (51). Die unvollständige Aktivierung der T-Zellen in Folge der FSME-Virus-Infektion könnte daher einen viralen Immunescape-Mechanismus darstellen, der durch eine Behinderung der T-Zellaktivierung dem FSME-Virus einen Replikationsvorteil im Wirt verschafft.

\subsection{FSME-Virusreplikation in DCs oder T-Zellen als Ausbreitungsfaktor}

Für die Ausbreitung der Flaviviren und deren Passage durch die Blut-Hirn-Schranke gibt es verschiedene Hypothesen. Eine Hypothese besagt, dass sich das FSME-Virus in 
immunkompetenten Zellen vermehrt und ausbreitet und diese Zellen als eine Art „Trojanisches Pferd“ für die Passage durch die Blut-Hirn-Schranke in das ZNS nutzt. Als mögliche immunkompetente Zellen kommen die DCs in Frage, die ein frühes Ziel während der Infektion mit dem FSME-Virus darstellen, während die T-Zellen erst nach Kontakt mit den DCs infiziert werden. Um zu untersuchen, ob sich das FSME-Virus in diesen Zelltypen vermehrt und ob diese Zellen als möglicher Ausbreitungsfaktor geeignet sind, wurde in dieser Arbeit die Fähigkeit des FSME-Virus in mDCs, pDCs und T-Zellen zu replizieren analysiert.

Dabei wurde der Virustiter aus den Zellkulturüberständen von mDCs, pDCs und T-Zellen, die mit dem FSME-Virus, UV-inaktivierten FSME-Virus mittels TCID $_{50^{-}}$ Analysen sowie die Zellviabilität der Vero-B4 Indikatorzellen anhand des MTT-Assays analysiert (s. Kapitel 3.1.6 (mDCs), 3.1.7 (pDCs), 3.2.4 (T-Zellen)).

Bei der Virustitration der Zellkulturüberstände der pDCs, die mit dem FSME-Virus infiziert wurden, konnte kein signifikanter Unterschied zur Restinfektiosität der verwendeten Virussuspension festgestellt werden (s. Kapitel 3.1.6 und 3.1.7). Damit ergibt sich, dass das FSME-Virus sich in den pDCs nicht effizient vermehren kann. Die Vermutung liegt nahe, dass die starke IFN- $\alpha$-Produktion der pDCs Ursache für die beobachtete Replikationshemmung ist. Dass der Typ I IFN-Signalweg eine wichtige Rolle bei der Flavivirusinfektion spielt, wurde schon in Mausmodellen gezeigt, bei denen Typ I IFN- oder IFNAR-defiziente Mäuse eine erhöhte Letalität nach der Infektion mit dem WNV zeigten $(121,170)$. Darüber hinaus wurde bei anderen Studien gezeigt, dass NS-Proteine der Flaviviren den JAK-STAT-Signalweg außer Funktion setzen und so eine IFN-Antwort sowie die Etablierung eines antiviralen Status verhindern.

In dieser Arbeit konnte gezeigt werden, dass die pDCs in Antwort auf die FSMEVirusinfektion die IFN- $\alpha$-Produktion induzieren und IFN- $\alpha$ sezernieren. Vor dem Hintergrund, dass die Replikation verschiedener Flaviviren durch Typ I IFN inhibiert wird (TBEV (150), DENV (65); (50), JEV (44) und LGTV(23)), wurde durch die Behandlung der pDCs mit einem IFNAR-Antikörper, der an den IFNAR bindet und so eine Aktivierung durch Typ I IFN verhindert, der Typ I IFN-Signalweg außer Funktion gesetzt. Dabei konnte gezeigt werden, dass der Gehalt an Virus-RNA in den pDCs mit und ohne Vorbehandlung der pDCs mit dem IFNAR-Antikörper ähnlich ist. Demnach kann man davon ausgehen, dass das Virus unabhängig von der IFN- $\alpha$-Wirkung in die 
pDCs gelangt und dort anfängt zu replizieren. In den Zellkulturüberständen der infizierten und mit dem IFNAR-Antikörper behandelten pDCs dagegen konnte ein um den Faktor 20 erhöhter Gehalt an viraler RNA gegenüber den Zellkulturüberständen der infizierten und nicht IFNAR-Antikörper behandelten pDCs festgestellt werden. Das bedeutet, dass neues infektiöses FSME-Virus nur aus den pDCs freigesetzt wird, die mit dem IFNARAntikörper inkubiert wurden. Es konnte somit gezeigt werden, dass das FSME-Virus in den pDCs repliziert, sofern der Typ I IFN-Signalweg, der durch die Interaktion von Typ I IFN und dem IFNAR induziert wird, außer Funktion gesetzt wird (s. Kapitel 3.1.6 und 3.1.7) und damit die Expression antiviral aktiver Proteine unterdrückt wird, die von den Interferon-stimulierten Genen (ISGs) kodiert werden. Zu den von ISGs kodierten antiviral aktiven Proteinen, die auch als antivirale Effektoren bezeichnet werden, gehören z. B. die dsRNA bindende PKR, die die Translation hemmt, ADAR1, die die RNAEditierung antreibt, die GTPase Mx1, die virale Nukleoproteine sequestriert, die RNaseL, die den Abbau der RNA fördert sowie das ISG15 und APOBEC (168, 169). Die Expression solcher Faktoren scheint für das Verhindern einer effektiven Replikation des FSME-Virus notwendig zu sein, allerdings ist bisher nicht geklärt, welche Typ I IFNinduzierten antiviral aktiven Proteine die FSME-Virusreplikation in pDCs verhindern. Für PKR konnte gezeigt werden, dass es die FSME-Virus-Replikation zwar nicht vollständig unterdrücken kann, aber zumindest teilweise für die Typ I IFN Sensitivität des FSMEVirus verantwortlich ist (150).

Im Gegensatz zu den pDCs erfolgt in mDCs eine produktive Replikation des FSMEVirus. Auch mDCs produzieren in Antwort auf eine Infektion mit dem FSME-Virus IFN- $\alpha$, jedoch nur ca. $10 \%$ der Menge, die von pDCs produziert wird (Kapitel 3.1.4); zudem war ein Absinken der IFN- $\alpha$ Konzentration zu späteren Infektionszeitpunkten zu beobachten. Hierfür sind vermutlich sowohl zelluläre als auch virale Faktoren verantwortlich: Zum einen erfolgt die Induktion der Typ I IFN-Synthese in mDCs und pDCs unterschiedlich. Während in pDCs konstitutiv exprimiertes IRF7 nach Aktivierung die Synthese aller IFN- $\alpha$-Subtypen induziert und so eine schnelle und starke Typ I IFNProduktion ermöglicht wird, wird in mDCs IRF3-vermittelt zunächst nur IFN- $\beta$ gebildet. Dieses wiederum induziert u. a. die Synthese von IRF7, welches dann wiederum die Produktion der IFN- $\alpha$-Subtypen induziert, die dann IRF7-vermittelt ihre eigene Expression verstärken (IFN-Amplifikationsschleife). Daraus resultiert eine zeitlich 
verzögerte, aber auch geringere Synthese von Typ I IFN in mDCs im Vergleich zu pDCs. Zum anderen gibt es, wie schon in Kapitel 4.1.2 beschrieben, bereits verschiedene Studien, in denen gezeigt werden konnte, dass NS-Proteine der Flaviviren mit der Funktion von Komponenten der IFN-Signalkaskade interferieren. So wurde für das FSME-Virus gezeigt, dass das NS5 Protein die von den Typ I IFNs stimulierte JAKSTAT-Interaktion und somit die Produktion von Typ I IFNs negativ beeinflussen kann (200). Für das eng verwandte LGTV konnte gezeigt werden, dass das NS5 Protein mit der IFNAR2-Untereinheit des IFNAR interagiert und die Funktion des IFNARs, sowie die Aktivierung des JAK-STAT-Signaltransduktionswegs in aus Monozyten generierten mDCs inhibiert (23). Damit ergibt sich folgendes Bild für die Replikation des FSMEVirus in pDCs und mDCs: Beide Subtypen sind durch FSME-Virus infizierbar. In pDCs werden aber infolge der Infektion schnell große Mengen an IFN- $\alpha$ gebildet, die einen antiviralen Status etablieren, der zu einer Hemmung der FSME-Virusreplikation führt. Da das FSME-Virus nach derzeitigem Kenntnisstand nur mit der Typ I IFN-Signalkaskade nicht aber mit der Typ I IFN-Induktion interferieren kann, ist das Virus nicht in der Lage die antivirale Wirkung des Typ I IFN schnell genug $\mathrm{zu}$ unterlaufen, um die Virusreplikation aufrecht zu erhalten. In mDCs dagegen verläuft die Typ I IFN-Induktion langsamer und weniger ausgeprägt, sodass hier wohl die NS5-vermittelte Hemmung der JAK/STAT-Signalkaskade greift und zu einer Unterbrechung der IFNAmplifikationsschleife bzw. der Synthese der IFN-induzierten antiviral aktiven Proteine führt und damit zu einer dauerhaften Virusreplikation führt.

Wie in Kapitel 3.2.4 gezeigt werden konnte, repliziert das FSME-Virus nicht in den T-Zellen oder die Replikation unterliegt einer nicht zuzuordnenden Spenderabhängigkeit. In 5 von 6 Versuchsansätzen konnte kein signifikanter Unterschied zwischen den Titern der Zellkulturüberstände der infizierten T-Zellen und der Restinfektiosität der verwendeten Virussuspension beobachtet werden. Damit scheinen die T-Zellen nicht als geeigneter Verbreitungsfaktor in Frage zu kommen. Allerdings wurde in den T-Zellen eines Spenders Virusvermehrung mit Hilfe des TCID $_{50}$ Assays nachgewiesen. So könnte umgekehrt auch der Schluss gezogen werden, dass unter bestimmten allerdings noch ungeklärten Umständen die Replikation des FSME-Virus in den T-Zellen möglich sein kann und die T-Zellen somit unter diesen Umständen auch als Verbreitungsfaktor im Wirt 
eine Rolle spielen könnten. Was das für Umstände sind oder welche Voraussetzungen die T-Zellen des jeweiligen Spenders haben müssen ist allerdings unklar.

\subsection{Mögliche Mechanismen der Immunmodulation durch das FSME-Virus}

Basierend auf bereits veröffentlichten Ergebnissen sowie auf den Ergebnissen dieser Arbeit können einige Hypothesen formuliert werden, wie das FSME-Virus das Immunsystem moduliert und die Immunantwort beeinflusst oder umgeht:

Durch die immunsupprimierende Wirkung des Zeckenspeichels kann das FSME-Virus bei der Übertragung auch DCs in der Haut infizieren und in ihnen replizieren und sich so vermehren. Durch den Zeckenspeichel wird die Migration der infizierten und aktivierten DCs unterbunden, sodass sie an der Stelle der Infektion bleiben und dort als Vermehrungsquelle für das FSME-Virus agieren können (66). Darüber hinaus wird die Produktion der proinflammatorischen Zytokine TNF- $\alpha$ und IL-6 durch die DCs von Zeckenspeichel herabgesetzt (66). Bei der Modulation der angeborenen Immunität spielt das NS5 Protein des FSME-Virus eine wichtige Rolle, da es die Typ I IFN-Signalkaskade inhibiert $(23,201)$. Auch das von den T-Zellen gebildete antiinflammatorische Zytokin IL-10 ist möglicherweise an der Modulation der angeborenen Immunität beteiligt. Für WNV konnte gezeigt werden, dass in IL-10-defizienten Mäusen mehr IFN- $\alpha$ nach WNVInfektion gebildet wird als in Wildtyp-Mäusen und gleichzeitig die WNV-Replikation vermindert ist, was auf eine IL-10 vermittelte Hemmung des Typ I IFN-Systems schließen lässt (11).

In der frühen Phase nach Infektion mit dem FSME-Virus kommt es zunächst jedoch zur Induktion einer starken proinflammatorischen Zytokinantwort. Die Zytokinantwort der DCs könnte dabei dazu führen, dass das FSME-Virus viele rekrutierte Immunzellen infizieren kann (Rekrutierung von Immunzellen durch IL-8 $(24,86))$ und in ihnen repliziert (Inhibierung der Induktion des durch das IFN- $\alpha$ vermittelten antiviralen Status durch IL-8 (100, 154)). In dieser Arbeit wurde gezeigt, dass das FSME-Virus in den mDCs repliziert, darüber hinaus gibt es Hinweise, dass sich das FSME-Virus auch in Makrophagen vermehren kann (1). Durch die Migration der infizierten mDCs kann sich das FSME-Virus im Körper ausbreiten und wenn es nicht durch die neutralisierenden 
Antikörper, die durch die B-Zellen produziert werden, effektiv neutralisiert wird, kann es möglicherweise Zytokin-vermittelt die Blut-Hirn-Schranke überwinden (Schädigung der Blut-Hirn-Schranke durch das TNF- $\alpha$ oder IL-6 (15, 29, 31, 172); T-Zellen, DCs oder Makrophagen als Shuttle (101)) und so in das ZNS gelangen, wo es die Neuronen als Zielzellen infizieren kann. Die Ausbreitung des FSME-Virus erfolgt im ZNS zwischen den Neuronen von Zelle zu Zelle (98); damit ist das Virus weitgehend der humoralen Immunantwort entzogen. Die Beseitigung des FSME-Virusinfektion erfolgt ab diesem Zeitpunkt hauptsächlich durch die zytotoxischen $\mathrm{CD}^{+} \mathrm{T}-$ Zellen (98). Auch das verwandte JEV persistiert in den Neuronen für eine längere Zeit, um der Immunantwort zu umgehen (49).

\subsection{Einordnung der Ergebnisse und Ansatzpunkte für zukünftige Projekte}

In dieser Arbeit konnte gezeigt werden, dass das FSME-Virus humane mDCs unvollständig und pDCs vollständig aber transient aktiviert. Durch die Aktivierung der pDCs und die Induktion einer potenten IFN- und Zytokinantwort, sind die Voraussetzungen zur Initiation der adaptiven Immunantwort durch die DCs gegeben. Wie in der pDC-T-Zell-Kokultur gezeigt werden konnte, aktivieren die pDCs, wenn auch nur unvollständig, die T-Zellen, was sich in einer verstärkten Expression des Aktivierungsmarker CD69 und der induzierten Zytokinantwort widerspiegelte. Anhand von pDC-T-Zell-Kokulturen konnte gezeigt werden, dass erhöhte Mengen an antiinflammatorischen IL-10 im Vergleich zu FSME-Virus-infizierten T-Zellkulturen produziert werden. Weiterhin konnte in dieser Arbeit gezeigt werden, dass die mDCs ein potentieller Ausbreitungsfaktor des FSME-Virus sind, da das Virus in den mDCs repliziert, wohingegen die Replikation des Virus in den pDCs gehemmt war. Diese Replikationshemmung ist IFN- $\alpha$-abhängig, da eine Blockierung des IFNAR in pDCs zur produktiven FSME-Virusreplikation führt. Für die Replikationshemmung scheint die Menge an gebildeten IFN- $\alpha$ entscheidend zu sein, da mDCs ebenfalls IFN- $\alpha$ nach FSMEVirusinfektion bilden, aber nur ca. $10 \%$ der in pDCs gebildeten Menge, die überdies zu späteren Zeitpunkten nach Infektion weiter zurückging. Ob dieser Rückgang der IFNKonzentrationen durch das FSME-Virus hervorgerufen wird und die Replikation des 
Virus damit positiv beeinflusst, muss allerdings noch untersucht werden. Jedoch liegt die Vermutung nahe, dass hier die IFN-antagonistische Funktion des FSME-Virus NS5Proteins zum Tragen kommt. Weiterhin kann auch die Kinetik der IFN- $\alpha$-Synthese eine Rolle spielen. In pDCs werden nach einer Virusinfektion sofort alle IFN- $\alpha$-Subtypen gebildet, die dann die Synthese antiviral aktiver Proteine induzieren. In allen anderen Zellen einschließlich der mDCs wird primär nach Infektion IFN- $\beta$ gebildet, das dann die Synthese der IFN- $\alpha$-Subtypen induziert (positive Amplifikationsschleife). Zwar kann IFN- $\beta$ auch selbst die Synthese antiviral aktiver Proteine induzieren, für die Etablierung des antiviralen Zustandes in der infizierten Zelle reicht dies aber nicht aus, hierfür wird auch IFN- $\alpha$ benötigt.

In beiden DC-Subtypen erfolgt als Reaktion auf das FSME-Virus eine starke proinflammatorische Zytokinantwort. Inwieweit das IL-8 die Funktion des IFN- $\alpha$ in den mDCs inhibiert und unter Umständen die Replikation des FSME-Virus fördert kann, wie es für andere positivsträngige RNA-Viren in gezeigt werden konnte $(100,143)$, ist unklar. In den pDCs scheint die inhibierende Wirkung des IL-8 auf das IFN- $\alpha$ zumindest keine Rolle zu spielen, da in den pDCs die FSME-Virusreplikation durch IFN- $\alpha$ gehemmt wird.

T-Zellen scheinen kein geeigneter Faktor für die Ausbreitung des FSME-Virus im Wirt zu sein. Hierbei muss ein anderer Mechanismus als das Typ I IFN-System die Replikation verhindern, da T-Zellen bezüglich dieses Systems sich von mDCs nicht wesentlich unterscheiden. Möglich wäre beispielsweise, dass T-Zellen den bisher nicht charakterisierten FSME-Virus Rezeptor nicht exprimieren und daher das Virus überhaupt nicht in T-Zellen aufgenommen wird.

Bisher ungeklärt ist der Mechanismus, mit dem das FSME-Virus die Blut-Hirn-Schranke überwindet und in das Gehirn vordringt. In dieser Arbeit konnte gezeigt werden, dass das FSME-Virus bei den DCs die Produktion proinflammatorischer Zytokine induziert, die in der Lage sind, die Permeabilität der Blut-Hirn-Schranke herabzusetzen und so das Eindringen des FSME-Virus in das Gehirn fördern könnten. Die Ergebnisse dieser Arbeit deuten weiter darauf hin, dass die mDCs als Shuttle für das FSME-Virus dienen können. Eine weitere Möglichkeit zur Passage der Blut-Hirn-Schranke wäre, dass freies FSMEVirus in der virämischen Phase die Blut-Hirn-Schranke aufgrund des in hohen 
Konzentrationen produzierten IL-6 und dessen Fähigkeit die Permeabilität der Blut-HirnSchranke zu erhöhen, überwinden kann.

Im Rahmen dieser Arbeit wurde die Interaktion von DCs mit FSME-Virus untersucht, da diese sowohl für die angeborene- als auch adaptive Immunantwort eine wichtige Rolle spielen. Eine weitere Schnittstelle von angeborener- und adaptiver Immunität stellen die Makrophagen dar. In Mausmodellen konnte bereits gezeigt werden, dass das FSME-Virus die Makrophagen infiziert und in ihnen repliziert, sodass sie eine Rolle als Ausbreitungsfaktor im Organismus spielen können (1). Inwieweit humane Makrophagen auch eine Rolle bei der viralen Ausbreitung des FSME-Virus im menschlichen Körper spielen oder ob sie die produktive FSME-Virusreplikation unterdrücken können, ist noch ungeklärt. Für Mausmakrophagen konnte gezeigt werden, dass es nach FSMEVirusinfektion zur verstärkten Produktion des für die virale Replikation inhibitorisch wirkenden Stickstoffmonoxids (NO) kommt (152). Ob dies auch für humane Makrophagen gilt, muss noch untersucht werden, weiterhin ist nicht klar, ob das FSMEVirus die Induktion antiviraler- und proinflammatorischer Zytokine in den Makrophagen modulieren kann. 



\section{Literaturverzeichnis}

1. Ahantarig, A., D. Ruzek, M. Vancova, A. Janowitz, H. St'astna, M. Tesarova, and L. Grubhoffer. 2009. Tick-borne encephalitis virus infection of cultured mouse macrophages. Intervirology 52:283-90.

2. Alekseev, A. N., and S. P. Chunikhin. 1990. Transmission of the Tick-Borne Encephalitis-Virus by Ixodid Ticks in the Experiment (Mechanisms, Terms, Species and Sexual Distinctions). Parazitologiya 24:177-185.

3. Alvarez, D., E. H. Vollmann, and U. H. von Andrian. 2008. Mechanisms and consequences of dendritic cell migration. Immunity 29:325-42.

4. Araujo, D. M., and C. W. Cotman. 1993. Trophic effects of interleukin-4, -7 and -8 on hippocampal neuronal cultures: potential involvement of glial-derived factors. Brain Res 600:49-55.

5. Arnez, M., and T. Avsic-Zupanc. 2009. Tick-borne encephalitis in children: an update on epidemiology and diagnosis. Expert Rev Anti Infect Ther 7:1251-60.

6. Ashour, J., M. Laurent-Rolle, P. Y. Shi, and A. Garcia-Sastre. 2009. NS5 of Dengue Virus Mediates STAT2 Binding and Degradation. Journal of Virology 83:5408-5418.

7. Asselin-Paturel, C., G. Brizard, K. Chemin, A. Boonstra, A. O'Garra, A. Vicari, and G. Trinchieri. 2005. Type I interferon dependence of plasmacytoid dendritic cell activation and migration. J Exp Med 201:1157-67.

8. Atrasheuskaya, A. V., T. M. Fredeking, and G. M. Ignatyev. 2003. Changes in immune parameters and their correction in human cases of tick-borne encephalitis. Clin Exp Immunol 131:148-54.

9. Au, W. C., P. A. Moore, W. Lowther, Y. T. Juang, and P. M. Pitha. 1995. Identification of a member of the interferon regulatory factor family that binds to the interferon-stimulated response element and activates expression of interferoninduced genes. Proc Natl Acad Sci U S A 92:11657-61.

10. Baggiolini, M., and I. Clark-Lewis. 1992. Interleukin-8, a chemotactic and inflammatory cytokine. FEBS Lett 307:97-101.

11. Bai, F., T. Town, F. Qian, P. Wang, M. Kamanaka, T. M. Connolly, D. Gate, R. R. Montgomery, R. A. Flavell, and E. Fikrig. 2009. IL-10 signaling blockade controls murine West Nile virus infection. PLoS Pathog 5:e1000610.

12. Balachandran, S., C. N. Kim, W. C. Yeh, T. W. Mak, K. Bhalla, and G. N. Barber. 1998. Activation of the dsRNA-dependent protein kinase, PKR, induces apoptosis through FADD-mediated death signaling. Embo J 17:6888-902.

13. Banchereau, J., F. Briere, C. Caux, J. Davoust, S. Lebecque, Y. J. Liu, B. Pulendran, and K. Palucka. 2000. Immunobiology of dendritic cells. Annu Rev Immunol 18:767-811.

14. Banchereau, J., and R. M. Steinman. 1998. Dendritic cells and the control of immunity. Nature 392:245-52.

15. Banks, W. A., and M. A. Erickson. 2010. The blood-brain barrier and immune function and dysfunction. Neurobiol Dis 37:26-32. 
16. Banzhoff, A., M. Broker, and O. Zent. 2008. Protection against tick-borne encephalitis (TBE) for people living in and travelling to TBE-endemic areas. Travel Med Infect Dis 6:331-41.

17. Barchet, W., M. Cella, and M. Colonna. 2005. Plasmacytoid dendritic cells-virus experts of innate immunity. Semin Immunol 17:253-61.

18. Barrett, A. D. T., and L. R. Stanberry. 2008. Vaccines for Biodefense and Emerging and Neglected Diseases, vol. 1. Academic Press.

19. Bauer, J., U. Ganter, T. Geiger, U. Jacobshagen, T. Hirano, T. Matsuda, T. Kishimoto, T. Andus, G. Acs, W. Gerok, and et al. 1988. Regulation of interleukin-6 expression in cultured human blood monocytes and monocytederived macrophages. Blood 72:1134-40.

20. Becker, Y. 2003. Milestones in the research on skin epidermal Langerhans/dendritic cells (LCs/DCs) from the discovery of Paul Langerhans 1868-1989. Virus Genes 26:131-4.

21. Bekisz, J., H. Schmeisser, J. Hernandez, N. D. Goldman, and K. C. Zoon. 2004. Human interferons alpha, beta and omega. Growth Factors 22:243-51.

22. Bender, A., G. Jager, W. Scheuerer, B. Feddersen, R. Kaiser, and H. W. Pfister. 2004. Two severe cases of tick-borne encephalitis despite complete active vaccination--the significance of neutralizing antibodies. J Neurol 251:353-4.

23. Best, S. M., K. L. Morris, J. G. Shannon, S. J. Robertson, D. N. Mitzel, G. S. Park, E. Boer, J. B. Wolfinbarger, and M. E. Bloom. 2005. Inhibition of interferon-stimulated JAK-STAT signaling by a tick-borne flavivirus and identification of NS5 as an interferon antagonist. J Virol 79:12828-39.

24. Bickel, M. 1993. The role of interleukin-8 in inflammation and mechanisms of regulation. J Periodontol 64:456-60.

25. Blanchet, F. P., and V. Piguet. 2010. Immunoamphisomes in dendritic cells amplify TLR signaling and enhance exogenous antigen presentation on MHC-II. Autophagy 6:816-8.

26. Bocci, V., A. Pacini, M. Muscettola, L. Paulesu, G. P. Pessina, M. Santiano, and I. Viano. 1981. Renal filtration, absorption and catabolism of human alpha interferon. J Interferon Res 1:347-52.

27. Boehm, U., T. Klamp, M. Groot, and J. C. Howard. 1997. Cellular responses to interferon-gamma. Annu Rev Immunol 15:749-95.

28. Bogovic, P., S. Lotric-Furlan, and F. Strle. 2010. What tick-borne encephalitis may look like: clinical signs and symptoms. Travel Med Infect Dis 8:246-50.

29. Brett, F. M., A. P. Mizisin, H. C. Powell, and I. L. Campbell. 1995. Evolution of neuropathologic abnormalities associated with blood-brain barrier breakdown in transgenic mice expressing interleukin-6 in astrocytes. J Neuropathol Exp Neurol 54:766-75.

30. Burke, D. S., and T. P. Monath. 2001. Flaviviruses, 4th ed. ed, vol. 1. Lippincott, Williams \& Wilkins, Philadelphia.

31. Campbell, I. L., C. R. Abraham, E. Masliah, P. Kemper, J. D. Inglis, M. B. Oldstone, and L. Mucke. 1993. Neurologic disease induced in transgenic mice by cerebral overexpression of interleukin 6. Proc Natl Acad Sci U S A 90:100615 .

32. Cao, W. 2009. Molecular Characterization of Human Plasmacytoid Dendritic Cells. Journal of Clinical Immunology 29:257-264. 
33. Cao, W., and Y. J. Liu. 2007. Innate immune functions of plasmacytoid dendritic cells. Current Opinion in Immunology 19:24-30.

34. Carbonneil, C., H. Saidi, V. Donkova-Petrini, and L. Weiss. 2004. Dendritic cells generated in the presence of interferon-alpha stimulate allogeneic CD4+ Tcell proliferation: modulation by autocrine IL-10, enhanced T-cell apoptosis and T regulatory type 1 cells. Int Immunol 16:1037-52.

35. Caruso, A., S. Licenziati, M. Corulli, A. D. Canaris, M. A. De Francesco, S. Fiorentini, L. Peroni, F. Fallacara, F. Dima, A. Balsari, and A. Turano. 1997. Flow cytometric analysis of activation markers on stimulated $\mathrm{T}$ cells and their correlation with cell proliferation. Cytometry 27:71-6.

36. Cella, M., D. Jarrossay, F. Facchetti, O. Alebardi, H. Nakajima, A. Lanzavecchia, and M. Colonna. 1999. Plasmacytoid monocytes migrate to inflamed lymph nodes and produce large amounts of type I interferon. Nat Med 5:919-23.

37. Chambers, T. J., C. S. Hahn, R. Galler, and C. M. Rice. 1990. Flavivirus Genome Organization, Expression, and Replication. Annual Review of Microbiology 44:649-688.

38. Colamonici, O. R., and P. Domanski. 1993. Identification of a novel subunit of the type I interferon receptor localized to human chromosome 21. J Biol Chem 268:10895-9.

39. Corssmit, E. P., J. de Metz, H. P. Sauerwein, and J. A. Romijn. 2000. Biologic responses to IFN-alpha administration in humans. J Interferon Cytokine Res 20:1039-47.

40. Corssmit, E. P., R. Heijligenberg, C. E. Hack, E. Endert, H. P. Sauerwein, and J. A. Romijn. 1997. Effects of interferon-alpha (IFN-alpha) administration on leucocytes in healthy humans. Clin Exp Immunol 107:359-63.

41. Cousens, L. P., J. S. Orange, H. C. Su, and C. A. Biron. 1997. Interferonalpha/beta inhibition of interleukin 12 and interferon-gamma production in vitro and endogenously during viral infection. Proc Natl Acad Sci U S A 94:634-9.

42. Crawford, K., A. Stark, B. Kitchens, K. Sternheim, V. Pantazopoulos, E. Triantafellow, Z. Wang, B. Vasir, C. E. Larsen, D. Gabuzda, E. Reinherz, and C. A. Alper. 2003. CD2 engagement induces dendritic cell activation: implications for immune surveillance and T-cell activation. Blood 102:1745-52.

43. Cumberbatch, M., R. J. Dearman, and I. Kimber. 1997. Langerhans cells require signals from both tumour necrosis factor-alpha and interleukin-1 beta for migration. Immunology 92:388-95.

44. Daffis, S., M. A. Samuel, M. S. Suthar, B. C. Keller, M. Gale, Jr., and M. S. Diamond. 2008. Interferon regulatory factor IRF-7 induces the antiviral alpha interferon response and protects against lethal West Nile virus infection. J Virol 82:8465-75.

45. de Metz, J., J. A. Romijn, E. Endert, E. P. Corssmit, and H. P. Sauerwein. 2000. Administration of interferon-gamma in healthy subjects does not modulate thyroid hormone metabolism. Thyroid 10:87-91.

46. Delves, P. J., and I. M. Roitt. 2000. The immune system. First of two parts. N Engl J Med 343:37-49.

47. Der, S. D., A. Zhou, B. R. Williams, and R. H. Silverman. 1998. Identification of genes differentially regulated by interferon alpha, beta, or gamma using oligonucleotide arrays. Proc Natl Acad Sci U S A 95:15623-8. 
48. Deutsche Sammlung von Mikroorganismen und Zellkulturen GmbH. 2004. VERO-B4. Deutschen Sammlung von Mikroorganismen und Zellkulturen GmbH, Braunschweig. http://www.dsmz.de/human and animal_cell_lines/info.php?dsmz nr=33\&term= Vero\&highlight $=$.

49. Diamond, M. S. 2003. Evasion of innate and adaptive immunity by flaviviruses. Immunol Cell Biol 81:196-206.

50. Diamond, M. S., and E. Harris. 2001. Interferon inhibits dengue virus infection by preventing translation of viral RNA through a PKR-independent mechanism. Virology 289:297-311.

51. Diamond, M. S., B. Shrestha, E. Mehlhop, E. Sitati, and M. Engle. 2003. Innate and adaptive immune responses determine protection against disseminated infection by West Nile encephalitis virus. Viral Immunol 16:259-78.

52. Diebold, S. S. 2008. Determination of T-cell fate by dendritic cells. Immunol Cell Biol 86:389-97.

53. Dinarello, C. A. 2000. Proinflammatory cytokines. Chest 118:503-8.

54. Donoso Mantke, O., R. Schadler, and M. Niedrig. 2008. A survey on cases of tick-borne encephalitis in European countries. Euro Surveill 13.

55. Dorrbecker, B., G. Dobler, M. Spiegel, and F. T. Hufert. 2010. Tick-borne encephalitis virus and the immune response of the mammalian host. Travel Med Infect Dis 8:213-22.

56. Dougherty, R. 1964. Animal virus titration techniques. In: Harris RJC, ed. Techniques in experimental virology New York: Academic Press, Inc.:183-186.

57. Dumpis, U., D. Crook, and J. Oksi. 1999. Tick-borne encephalitis. Clin Infect Dis 28:882-90.

58. Dustin, M. L., J. Garcia-Aguilar, M. L. Hibbs, R. S. Larson, S. A. Stacker, D. E. Staunton, A. J. Wardlaw, and T. A. Springer. 1989. Structure and regulation of the leukocyte adhesion receptor LFA-1 and its counterreceptors, ICAM-1 and ICAM-2. Cold Spring Harb Symp Quant Biol 54 Pt 2:753-65.

59. Dustin, M. L., and T. A. Springer. 1989. T-cell receptor cross-linking transiently stimulates adhesiveness through LFA-1. Nature 341:619-24.

60. Dzionek, A., A. Fuchs, P. Schmidt, S. Cremer, M. Zysk, S. Miltenyi, D. W. Buck, and J. Schmitz. 2000. BDCA-2, BDCA-3, and BDCA-4: three markers for distinct subsets of dendritic cells in human peripheral blood. J Immunol 165:603746.

61. Dzionek, A., Y. Inagaki, K. Okawa, J. Nagafune, J. Rock, Y. Sohma, G. Winkels, M. Zysk, Y. Yamaguchi, and J. Schmitz. 2002. Plasmacytoid dendritic cells: from specific surface markers to specific cellular functions. Hum Immunol 63:1133-48.

62. Ecker, M., S. L. Allison, T. Meixner, and F. X. Heinz. 1999. Sequence analysis and genetic classification of tick-borne encephalitis viruses from Europe and Asia. J Gen Virol 80 ( Pt 1):179-85.

63. Facchetti, F., E. Candiago, and W. Vermi. 1999. Plasmacytoid monocytes express IL3-receptor alpha and differentiate into dendritic cells. Histopathology 35:88-9.

64. Facchetti, F., C. de Wolf-Peeters, D. Y. Mason, K. Pulford, J. J. van den Oord, and V. J. Desmet. 1988. Plasmacytoid T cells. Immunohistochemical evidence for their monocyte/macrophage origin. Am J Pathol 133:15-21. 
65. Fernandez-Sesma, A., D. Bernal-Rubio, D. Kaminski, K. Boyd, H. PhippsYonas, T. M. Moran, A. Garcia-Sastre, and J. Munoz-Jordan. 2008. Lack of Type I Ifn in Dengue Virus (Denv) Infected Human Blood Cells May Account for Inefficient Immune Responses during Denv Infection. American Journal of Tropical Medicine and Hygiene 79:14-14.

66. Fialova, A., Z. Cimburek, G. Iezzi, and J. Kopecky. 2010. Ixodes ricinus tick saliva modulates tick-borne encephalitis virus infection of dendritic cells. Microbes Infect 12:580-5.

67. Fiorentino, D. F., A. Zlotnik, T. R. Mosmann, M. Howard, and A. O'Garra. 1991. IL-10 inhibits cytokine production by activated macrophages. J Immunol 147:3815-22.

68. Fiorentino, D. F., A. Zlotnik, P. Vieira, T. R. Mosmann, M. Howard, K. W. Moore, and A. O'Garra. 1991. IL-10 acts on the antigen-presenting cell to inhibit cytokine production by Th1 cells. J Immunol 146:3444-51.

69. Fitzgerald-Bocarsly, P. 2002. Natural interferon-alpha producing cells: The plasmacytoid dendritic cells. Biotechniques:16-+.

70. Fitzgerald-Bocarsly, P., J. H. Dai, and S. Singh. 2008. Plasmacytoid dendritic cells and type I IFN: 50 years of convergent history. Cytokine \& Growth Factor Reviews 19:3-19.

71. Fredericksen, B. L., and M. Gale, Jr. 2006. West Nile virus evades activation of interferon regulatory factor 3 through RIG-I-dependent and -independent pathways without antagonizing host defense signaling. J Virol 80:2913-23.

72. Freer, G., and D. Matteucci. 2009. Influence of dendritic cells on viral pathogenicity. PLoS Pathog 5:e1000384.

73. Freudenthal, P. S., and R. M. Steinman. 1990. The distinct surface of human blood dendritic cells, as observed after an improved isolation method. Proc Natl Acad Sci U S A 87:7698-702.

74. Garcia-Sastre, A. 2011. 2 methylate or not 2 methylate: viral evasion of the type I interferon response. Nat Immunol 12:114-5.

75. Gauzzi, M. C., I. Canini, P. Eid, F. Belardelli, and S. Gessani. 2002. Loss of type IIFN receptors and impaired IFN responsiveness during terminal maturation of monocyte-derived human dendritic cells. Journal of Immunology 169:30383045.

76. Gelpi, E., M. Preusser, F. Garzuly, H. Holzmann, F. X. Heinz, and H. Budka. 2005. Visualization of Central European tick-borne encephalitis infection in fatal human cases. J Neuropathol Exp Neurol 64:506-12.

77. Gelpi, E., M. Preusser, U. Laggner, F. Garzuly, H. Holzmann, F. X. Heinz, and H. Budka. 2006. Inflammatory response in human tick-borne encephalitis: analysis of postmortem brain tissue. J Neurovirol 12:322-7.

78. Gilliet, M., W. Cao, and Y. J. Liu. 2008. Plasmacytoid dendritic cells: sensing nucleic acids in viral infection and autoimmune diseases. Nat Rev Immunol 8:594-606.

79. Grard, G., G. Moureau, R. N. Charrel, J. J. Lemasson, J. P. Gonzalez, P. Gallian, T. S. Gritsun, E. C. Holmes, E. A. Gould, and X. de Lamballerie. 2007. Genetic characterization of tick-borne flaviviruses: New insights into evolution, pathogenetic determinants and taxonomy. Virology 361:80-92.

80. Gritsun, T. S., V. A. Lashkevich, and E. A. Gould. 2003. Tick-borne encephalitis. Antiviral Res 57:129-46. 
81. Grouard, G., M. C. Rissoan, L. Filgueira, I. Durand, J. Banchereau, and Y. J. Liu. 1997. The enigmatic plasmacytoid T cells develop into dendritic cells with interleukin (IL)-3 and CD40-ligand. J Exp Med 185:1101-11.

82. Gunther, G., M. Haglund, L. Lindquist, B. Skoldenberg, and M. Forsgren. 1997. Intrathecal IgM, IgA and IgG antibody response in tick-borne encephalitis. Long-term follow-up related to clinical course and outcome. Clin Diagn Virol 8:17-29.

83. Gunther, G., M. Haglund, L. Lindquist, B. Skoldenberg, and M. Forsgren. 1996. Intrathecal production of neopterin and beta 2 microglobulin in tick-borne encephalitis (TBE) compared to meningoencephalitis of other etiology. Scand J Infect Dis 28:131-8.

84. Haeryfar, S. M. 2005. The importance of being a pDC in antiviral immunity: the IFN mission versus Ag presentation? Trends Immunol 26:311-7.

85. Haglund, M., and G. Gunther. 2003. Tick-borne encephalitis--pathogenesis, clinical course and long-term follow-up. Vaccine 21 Suppl 1:S11-8.

86. Harada, A., N. Sekido, T. Akahoshi, T. Wada, N. Mukaida, and K. Matsushima. 1994. Essential involvement of interleukin-8 (IL-8) in acute inflammation. J Leukoc Biol 56:559-64.

87. Hart, D. N. J., and J. W. Fabre. 1981. Demonstration and Characterization of IaPositive Dendritic Cells in the Interstitial Connective Tissues of Rat-Heart and Other Tissues, but Not Brain. Journal of Experimental Medicine 154:347-361.

88. Heinz, F. X. 2003. Molecular aspects of TBE virus research. Vaccine 21 Suppl 1:S3-S10.

89. Heinz, F. X., and S. L. Allison. 2003. Flavivirus structure and membrane fusion. Flaviviruses: Structure, Replication and Evolution 59:63-+.

90. Heinz, F. X., and C. W. Mandl. 1993. The molecular biology of tick-borne encephalitis virus. Review article. Apmis 101:735-45.

91. Holzmann, H. 2003. Diagnosis of tick-borne encephalitis. Vaccine 21:S36-S40.

92. Hulo, C., E. de Castro, P. Masson, L. Bougueleret, A. Bairoch, I. Xenarios, and P. Le Mercier. 2010. ViralZone: a knowledge resource to understand virus diversity. Nucleic Acids Res. source of picture: ViralZone: http://www.expasy.org/viralzone, SIB Swiss Institute of Bioinformatics

93. International Committee on Taxonomy of Viruses (ICTV). 2002. ICTV Taxonomy and Index to Virus Classification and NomenclatureTaxonomic lists and Catalogue of viruses. Source: http://www.ictvdb.org/Ictv/index.htm. Web Page last updated: 25 May 2004.

94. Jones, S. A., P. J. Richards, J. Scheller, and S. Rose-John. 2005. IL-6 transsignaling: the in vivo consequences. J Interferon Cytokine Res 25:241-53.

95. Kabelitz, D., T. Pohl, and K. Pechhold. 1993. Activation-induced cell death (apoptosis) of mature peripheral T lymphocytes. Immunol Today 14:338-9.

96. Kadowaki, N., S. Ho, S. Antonenko, R. W. Malefyt, R. A. Kastelein, F. Bazan, and Y. J. Liu. 2001. Subsets of human dendritic cell precursors express different toll-like receptors and respond to different microbial antigens. J Exp Med 194:863-9.

97. Kaiser, R. 1999. The clinical and epidemiological profile of tick-borne encephalitis in southern Germany 1994-98: a prospective study of 656 patients. Brain 122 ( Pt 11):2067-78. 
98. Kaiser, R., and H. Holzmann. 2000. Laboratory findings in tick-borne encephalitis - Correlation with clinical outcome. Infection 28:78-84.

99. Keller, R. 2001. Dendritic cells: their significance in health and disease. Immunol Lett 78:113-22.

100. Khabar, K. S., F. Al-Zoghaibi, M. N. Al-Ahdal, T. Murayama, M. Dhalla, N. Mukaida, M. Taha, S. T. Al-Sedairy, Y. Siddiqui, G. Kessie, and K. Matsushima. 1997. The alpha chemokine, interleukin 8, inhibits the antiviral action of interferon alpha. J Exp Med 186:1077-85.

101. Kindberg, E., A. Mickiene, C. Ax, B. Akerlind, S. Vene, L. Lindquist, A. Lundkvist, and L. Svensson. 2008. A deletion in the chemokine receptor 5 (CCR5) gene is associated with tickborne encephalitis. J Infect Dis 197:266-9.

102. Kirchhoff, H. 1968. [Studies of the effectiveness of disinfectants on viruses on surfaces]. Berl Munch Tierarztl Wochenschr 81:54-7.

103. Kreil, T. R., I. Burger, M. Bachmann, S. Fraiss, and M. M. Eibl. 1997. Antibodies protect mice against challenge with tick-borne encephalitis virus (TBEV)-infected macrophages. Clin Exp Immunol 110:358-61.

104. Krug, A., R. Veeraswamy, A. Pekosz, O. Kanagawa, E. R. Unanue, M. Colonna, and M. Cella. 2003. Interferon-producing cells fail to induce proliferation of naive $\mathrm{T}$ cells but can promote expansion and $\mathrm{T}$ helper 1 differentiation of antigen-experienced unpolarized T cells. J Exp Med 197:899906.

105. Kunz, C. 2003. TBE vaccination and the Austrian experience. Vaccine 21 Suppl 1:S50-5.

106. Kunze, U., L. Asokliene, T. Bektimirov, A. Busse, V. Chmelik, F. X. Heinz, V. Hingst, F. Kadar, R. Kaiser, P. Kimmig, A. Kraigher, T. Krech, L. Linquist, I. Lucenko, V. Rosenfeldt, M. Ruscio, B. Sandell, H. Salzer, F. Strle, J. Suss, K. Zilmer, and I. Mutz. 2004. Tick-borne encephalitis in childhood--consensus 2004. Wien Med Wochenschr 154:242-5.

107. Kvale, E. O., Y. Floisand, F. Lund-Johansen, H. Rollag, L. Farkas, S. Ghanekar, P. Brandtzaeg, F. L. Jahnsen, and J. Olweus. 2007. Plasmacytoid DCs regulate recall responses by rapid induction of IL-10 in memory $\mathrm{T}$ cells. Blood 109:3369-76.

108. Labuda, M., J. M. Austyn, E. Zuffova, O. Kozuch, N. Fuchsberger, J. Lysy, and P. A. Nuttall. 1996. Importance of localized skin infection in tick-borne encephalitis virus transmission. Virology 219:357-66.

109. Lad, V. J., A. K. Gupta, M. K. Goverdhan, V. L. Ayachit, J. J. Rodrigues, and L. V. Hungund. 1993. Susceptibility of BL6 nude (congenitally athymic) mice to Japanese encephalitis virus by the peripheral route. Acta Virol 37:232-40.

110. Langerhans, P. 1868. Über die Nerven der menschlichen Haut. Virchows Arch 44:325-337.

111. Lechmann, M., S. Berchtold, J. Hauber, and A. Steinkasserer. 2002. CD83 on dendritic cells: more than just a marker for maturation. Trends Immunol 23:273-5.

112. Lee, H. K., L. M. Mattei, B. E. Steinberg, P. Alberts, Y. H. Lee, A. Chervonsky, N. Mizushima, S. Grinstein, and A. Iwasaki. 2010. In Vivo Requirement for Atg5 in Antigen Presentation by Dendritic Cells. Immunity 32:227-239. 
113. Levy, D. E., I. Marie, and A. Prakash. 2003. Ringing the interferon alarm: differential regulation of gene expression at the interface between innate and adaptive immunity. Curr Opin Immunol 15:52-8.

114. Lin, R. J., B. L. Chang, H. P. Yu, C. L. Liao, and Y. L. Lin. 2006. Blocking of interferon-induced Jak-Stat signaling by Japanese encephalitis virus NS5 through a protein tyrosine phosphatase-mediated mechanism. J Virol 80:5908-18.

115. Lin, Y. L., Y. L. Huang, S. H. Ma, C. T. Yeh, S. Y. Chiou, L. K. Chen, and C. L. Liao. 1997. Inhibition of Japanese encephalitis virus infection by nitric oxide: antiviral effect of nitric oxide on RNA virus replication. J Virol 71:5227-35.

116. Lindenbach, B. D., and C. M. Rice. 1999. Genetic interaction of flavivirus nonstructural proteins NS1 and NS4A as a determinant of replicase function. J Virol 73:4611-21.

117. Lindenbach, B. D., and C. M. Rice. 2003. Molecular biology of flaviviruses. Adv Virus Res 59:23-61.

118. Lindquist, L., and O. Vapalahti. 2008. Tick-borne encephalitis. Lancet 371:1861-71.

119. Lipscomb, M. F., and B. J. Masten. 2002. Dendritic cells: immune regulators in health and disease. Physiol Rev 82:97-130.

120. Liu, Y. J. 2005. IPC: professional type 1 interferon-producing cells and plasmacytoid dendritic cell precursors. Annu Rev Immunol 23:275-306.

121. Lobigs, M., A. Mullbacher, Y. Wang, M. Pavy, and E. Lee. 2003. Role of type I and type II interferon responses in recovery from infection with an encephalitic flavivirus. J Gen Virol 84:567-72.

122. Loo, Y. M., J. Fornek, N. Crochet, G. Bajwa, O. Perwitasari, L. MartinezSobrido, S. Akira, M. A. Gill, A. Garcia-Sastre, M. G. Katze, and M. Gale, Jr. 2008. Distinct RIG-I and MDA5 signaling by RNA viruses in innate immunity. J Virol 82:335-45.

123. Mackenzie, J. M., M. K. Jones, and P. R. Young. 1996. Immunolocalization of the dengue virus nonstructural glycoprotein NS1 suggests a role in viral RNA replication. Virology 220:232-40.

124. Maloy, K. J., C. Burkhart, T. M. Junt, B. Odermatt, A. Oxenius, L. Piali, R. M. Zinkernagel, and H. Hengartner. 2000. CD4(+) T cell subsets during virus infection. Protective capacity depends on effector cytokine secretion and on migratory capability. J Exp Med 191:2159-70.

125. Mandl, C. W. 2005. Steps of the tick-borne encephalitis virus replication cycle that affect neuropathogenesis. Virus Res 111:161-74.

126. Mandl, C. W., M. Ecker, H. Holzmann, C. Kunz, and F. X. Heinz. 1997. Infectious cDNA clones of tick-borne encephalitis virus European subtype prototypic strain Neudoerfl and high virulence strain Hypr. J Gen Virol 78 ( Pt 5):1049-57.

127. Mansfield, K. L., N. Johnson, L. P. Phipps, J. R. Stephenson, A. R. Fooks, and T. Solomon. 2009. Tick-borne encephalitis virus - a review of an emerging zoonosis. J Gen Virol 90:1781-94.

128. Marrack, P., J. Kappler, and T. Mitchell. 1999. Type I interferons keep activated T cells alive. J Exp Med 189:521-30.

129. Maximova, O. A., J. M. Ward, D. M. Asher, M. St Claire, B. W. Finneyfrock, J. M. Speicher, B. R. Murphy, and A. G. Pletnev. 2008. Comparative 
neuropathogenesis and neurovirulence of attenuated flaviviruses in nonhuman primates. J Virol 82:5255-68.

130. McKenna, K., A. S. Beignon, and N. Bhardwaj. 2005. Plasmacytoid dendritic cells: linking innate and adaptive immunity. J Virol 79:17-27.

131. McMinn, P. C. 1997. The molecular basis of virulence of the encephalitogenic flaviviruses. Journal of General Virology 78:2711-2722.

132. Medhurst, A. D., D. C. Harrison, S. J. Read, C. A. Campbell, M. J. Robbins, and M. N. Pangalos. 2000. The use of TaqMan RT-PCR assays for semiquantitative analysis of gene expression in CNS tissues and disease models. J Neurosci Methods 98:9-20.

133. Mellman, I., and R. M. Steinman. 2001. Dendritic cells: specialized and regulated antigen processing machines. Cell 106:255-8.

134. Miltenyi, S., W. Muller, W. Weichel, and A. Radbruch. 1990. High-Gradient Magnetic Cell-Separation with Macs. Cytometry 11:231-238.

135. Moldenhauer, D. 1984. Quantitative evaluation of the effects of disinfectants against viruses in suspension experiments. Zentralbl Bakteriol Mikrobiol Hyg B 179:544-54.

136. Moore, K. W., R. de Waal Malefyt, R. L. Coffman, and A. O'Garra. 2001. Interleukin-10 and the interleukin-10 receptor. Annu Rev Immunol 19:683-765.

137. Morgan, E., R. Varro, H. Sepulveda, J. A. Ember, J. Apgar, J. Wilson, L. Lowe, R. Chen, L. Shivraj, A. Agadir, R. Campos, D. Ernst, and A. Gaur. 2004. Cytometric bead array: a multiplexed assay platform with applications in various areas of biology. Clin Immunol 110:252-66.

138. Mosser, D. M., and X. Zhang. 2008. Interleukin-10: new perspectives on an old cytokine. Immunol Rev 226:205-18.

139. Mukhopadhyay, S., R. J. Kuhn, and M. G. Rossmann. 2005. A structural perspective of the flavivirus life cycle. Nat Rev Microbiol 3:13-22.

140. Munoz-Jordan, J. L., M. Laurent-Rolle, J. Ashour, L. Martinez-Sobrido, M. Ashok, W. I. Lipkin, and A. Garcia-Sastre. 2005. Inhibition of alpha/beta interferon signaling by the NS4B protein of flaviviruses. Journal of Virology 79:8004-8013.

141. Munteanu, L. S., and A. Dinu. 2004. Fraction of Granulocytes from whole human blood by centrifugation. practical hints. Romanian J. Biophys. 14:53-58.

142. Murali-Krishna, K., V. Ravi, and R. Manjunath. 1996. Protection of adult but not newborn mice against lethal intracerebral challenge with Japanese encephalitis virus by adoptively transferred virus-specific cytotoxic $\mathrm{T}$ lymphocytes: requirement for L3T4+ T cells. J Gen Virol 77 ( Pt 4):705-14.

143. Murayama, T., K. Kuno, F. Jisaki, M. Obuchi, D. Sakamuro, T. Furukawa, N. Mukaida, and K. Matsushima. 1994. Enhancement human cytomegalovirus replication in a human lung fibroblast cell line by interleukin-8. J Virol 68:7582-5.

144. Naik, S. H., P. Sathe, H. Y. Park, D. Metcalf, A. I. Proietto, A. Dakic, S. Carotta, M. O'Keeffe, M. Bahlo, A. Papenfuss, J. Y. Kwak, L. Wu, and K. Shortman. 2007. Development of plasmacytoid and conventional dendritic cell subtypes from single precursor cells derived in vitro and in vivo. Nat Immunol 8:1217-26.

145. Noble, P. B., and J. H. Cutts. 1967. Separation of blood leukocytes by Ficoll gradient. Can Vet J 8:110-1. 
146. Noble, P. B., J. H. Cutts, and K. K. Carroll. 1968. Ficoll flotation for the separation of blood leukocyte types. Blood 31:66-73.

147. Nuttall, P. A., and M. Labuda. 2005. Tick-Borne Encephalitis. American Society of Microbiology (ASM) Press, Herndon USA Tick-borne diseases of humans edited by Jesse L. Goodman,David Tappen Dennis,Daniel E. Sonenshine: $150-163$.

148. Nuttall, P. A., and M. Labuda. 2004. Tick-host interactions: saliva-activated transmission. Parasitology 129:S177-S189.

149. O'Doherty, U., M. Peng, S. Gezelter, W. J. Swiggard, M. Betjes, N. Bhardwaj, and R. M. Steinman. 1994. Human blood contains two subsets of dendritic cells, one immunologically mature and the other immature. Immunology 82:487-93.

150. Overby, A. K., and F. Weber. 2008. The interferon sensitivity of tick-borne encephalitis virus is partially mediated by double-stranded RNA-dependent protein kinase. Cytokine 43:307-307.

151. Parcina, M., M. Schiller, A. Gierschke, K. Heeg, and I. Bekeredjian-Ding. 2009. PDC expressing CD36, CD61 and IL-10 may contribute to propagation of immune tolerance. Autoimmunity 42:353-5.

152. Plekhova, N. G., L. M. Somova, D. V. Zavorueva, N. V. Krylova, and G. N. Leonova. 2008. NO-producing activity of macrophages infected with tick-borne encephalitis virus. Bull Exp Biol Med 145:344-7.

153. Pogodina, V. V. 1958. [Resistance of tick-borne encephalitis virus to gastric juice.]. Vopr Virusol 3:271-5.

154. Polyak, S. J., K. S. Khabar, M. Rezeiq, and D. R. Gretch. 2001. Elevated levels of interleukin-8 in serum are associated with hepatitis $\mathrm{C}$ virus infection and resistance to interferon therapy. J Virol 75:6209-11.

155. Pospisil, L., L. Jandasek, and J. Pesek. 1954. [Isolation of new strains of meningoencephalitis virus in the Brno region during the summer of 1953.]. Lek List 9:3-5.

156. Prickett, T. C. R., J. L. Mckenzie, and D. N. J. Hart. 1988. Characterization of Interstitial Dendritic Cells in Human-Liver. Transplantation 46:754-761.

157. Proksch, E., J. M. Brandner, and J. M. Jensen. 2008. The skin: an indispensable barrier. Exp Dermatol 17:1063-72.

158. Puchhammer-Stockl, E., C. Kunz, C. W. Mandl, and F. X. Heinz. 1995. Identification of tick-borne encephalitis virus ribonucleic acid in tick suspensions and in clinical specimens by a reverse transcription-nested polymerase chain reaction assay. Clin Diagn Virol 4:321-6.

159. Randall, R. E., and S. Goodbourn. 2008. Interferons and viruses: an interplay between induction, signalling, antiviral responses and virus countermeasures. J Gen Virol 89:1-47.

160. Rea, I. M., S. E. McNerlan, and H. D. Alexander. 1999. CD69, CD25, and HLA-DR activation antigen expression on CD3+ lymphocytes and relationship to serum TNF-alpha, IFN-gamma, and sIL-2R levels in aging. Exp Gerontol 34:7993.

161. Rehwinkel, J., C. P. Tan, D. Goubau, O. Schulz, A. Pichlmair, K. Bier, N. Robb, F. Vreede, W. Barclay, E. Fodor, and E. S. C. Reis. 2010. RIG-I detects viral genomic RNA during negative-strand RNA virus infection. Cell 140:397408. 
162. Roberts, R. M., L. Liu, Q. Guo, D. Leaman, and J. Bixby. 1998. The evolution of the type I interferons. J Interferon Cytokine Res 18:805-16.

163. Robertson, S. J., D. N. Mitzel, R. T. Taylor, S. M. Best, and M. E. Bloom. 2009. Tick-borne flaviviruses: dissecting host immune responses and virus countermeasures. Immunol Res 43:172-86.

164. Robinson, S. P., S. Patterson, N. English, D. Davies, S. C. Knight, and C. D. Reid. 1999. Human peripheral blood contains two distinct lineages of dendritic cells. Eur J Immunol 29:2769-78.

165. Rosztoczy, I., and J. Content. 1990. The effects of various cytokines on interleukin-6 and interferon-alpha synthesis in human peripheral blood mononuclear cells. J Interferon Res 10:637-45.

166. Ruzek, D., G. Dobler, and O. D. Mantke. 2010. Tick-borne encephalitis: Pathogenesis and clinical implications. Travel Medicine and Infectious Disease in press.

167. Ruzek, D., J. Salat, M. Palus, T. S. Gritsun, E. A. Gould, I. Dykova, A. Skallova, J. Jelinek, J. Kopecky, and L. Grubhoffer. 2009. CD8+ T-cells mediate immunopathology in tick-borne encephalitis. Virology 384:1-6.

168. Sadler, A. J., and B. R. Williams. 2008. Interferon-inducible antiviral effectors. Nat Rev Immunol 8:559-68.

169. Samuel, C. E. 2001. Antiviral actions of interferons. Clin Microbiol Rev 14:778809 , table of contents.

170. Samuel, M. A., and M. S. Diamond. 2005. Alpha/beta interferon protects against lethal West Nile virus infection by restricting cellular tropism and enhancing neuronal survival. J Virol 79:13350-61.

171. Sato, M., H. Suemori, N. Hata, M. Asagiri, K. Ogasawara, K. Nakao, T. Nakaya, M. Katsuki, S. Noguchi, N. Tanaka, and T. Taniguchi. 2000. Distinct and essential roles of transcription factors IRF-3 and IRF-7 in response to viruses for IFN-alpha/beta gene induction. Immunity 13:539-48.

172. Sharief, M. K., M. Ciardi, E. J. Thompson, F. Sorice, F. Rossi, V. Vullo, and A. Cirelli. 1992. Tumour necrosis factor-alpha mediates blood-brain barrier damage in HIV-1 infection of the central nervous system. Mediators Inflamm 1:191-6.

173. Shortman, K., and Y. J. Liu. 2002. Mouse and human dendritic cell subtypes. Nat Rev Immunol 2:151-61.

174. Siegal, F. P., N. Kadowaki, M. Shodell, P. A. Fitzgerald-Bocarsly, K. Shah, S. Ho, S. Antonenko, and Y. J. Liu. 1999. The nature of the principal type 1 interferon-producing cells in human blood. Science 284:1835-7.

175. Silva, M. C., A. Guerrero-Plata, F. D. Gilfoy, R. P. Garofalo, and P. W. Mason. 2007. Differential activation of human monocyte-derived and plasmacytoid dendritic cells by West Nile virus generated in different host cells. J Virol 81:13640-8.

176. Singh, A., R. Kulshreshtha, and A. Mathur. 2000. Secretion of the chemokine interleukin-8 during Japanese encephalitis virus infection. J Med Microbiol 49:607-12.

177. Sporkenbach-Hoffler, J., K. J. Wiegers, and R. Dernick. 1983. [Mechanism of virus inactivation by peracids]. Zentralbl Bakteriol Mikrobiol Hyg B 177:469-81.

178. Stadler, K., S. L. Allison, J. Schalich, and F. X. Heinz. 1997. Proteolytic activation of tick-borne encephalitis virus by furin. J Virol 71:8475-81. 
179. Steinbrink, K., M. Wolfl, H. Jonuleit, J. Knop, and A. H. Enk. 1997. Induction of tolerance by IL-10-treated dendritic cells. J Immunol 159:4772-80.

180. Strobl, H., C. Scheinecker, E. Riedl, B. Csmarits, C. Bello-Fernandez, W. F. Pickl, O. Majdic, and W. Knapp. 1998. Identification of CD68+lin- peripheral blood cells with dendritic precursor characteristics. J Immunol 161:740-8.

181. Sun, P., S. Fernandez, M. A. Marovich, D. R. Palmer, C. M. Celluzzi, K. Boonnak, Z. Liang, H. Subramanian, K. R. Porter, W. Sun, and T. H. Burgess. 2009. Functional characterization of ex vivo blood myeloid and plasmacytoid dendritic cells after infection with dengue virus. Virology 383:20715.

182. Sun, S., X. Zhang, D. F. Tough, and J. Sprent. 1998. Type I interferonmediated stimulation of T cells by CpG DNA. J Exp Med 188:2335-42.

183. Suss, J. 2003. Epidemiology and ecology of TBE relevant to the production of effective vaccines. Vaccine 21:S19-S35.

184. Suss, J. 2008. Tick-borne encephalitis in Europe and beyond--the epidemiological situation as of 2007. Euro Surveill 13.

185. Swiecki, M., and M. Colonna. 2010. Unraveling the functions of plasmacytoid dendritic cells during viral infections, autoimmunity, and tolerance. Immunol Rev 234:142-62.

186. Takeda, K., and S. Akira. 2005. Toll-like receptors in innate immunity. Int Immunol 17:1-14.

187. Tarnok, A., J. Hambsch, R. Chen, and R. Varro. 2003. Cytometric bead array to measure six cytokines in twenty-five microliters of serum. Clin Chem 49:10002.

188. Tautz, N., A. Kaiser, and H. J. Thiel. 2000. NS3 serine protease of bovine viral diarrhea virus: characterization of active site residues, NS4A cofactor domain, and protease-cofactor interactions. Virology 273:351-63.

189. Theofilopoulos, A. N., R. Baccala, B. Beutler, and D. H. Kono. 2005. Type I interferons (alpha/beta) in immunity and autoimmunity. Annu Rev Immunol 23:307-36.

190. Tilg, H., E. Trehu, M. B. Atkins, C. A. Dinarello, and J. W. Mier. 1994. Interleukin-6 (IL-6) as an anti-inflammatory cytokine: induction of circulating IL1 receptor antagonist and soluble tumor necrosis factor receptor p55. Blood 83:113-8.

191. Toporkova, M. G., S. E. Aleshin, S. V. Ozherelkov, M. V. Nadezhdina, J. R. Stephenson, and A. V. Timofeev. 2008. Serum levels of interleukin 6 in recently hospitalized tick-borne encephalitis patients correlate with age, but not with disease outcome. Clinical and Experimental Immunology 152:517-521.

192. Turvey, S. E., and D. H. Broide. 2010. Innate immunity. J Allergy Clin Immunol 125:S24-32.

193. Ueno, H., N. Schmitt, A. K. Palucka, and J. Banchereau. 2010. Dendritic cells and humoral immunity in humans. Immunol Cell Biol 4:376-380.

194. Vargin, V. V., and B. F. Semenov. 1986. Changes of natural killer cell activity in different mouse lines by acute and asymptomatic flavivirus infections. Acta Virol 30:303-8.

195. Villadangos, J. A., and L. Young. 2008. Antigen-presentation properties of plasmacytoid dendritic cells. Immunity 29:352-61. 
196. Vyas, J. M., A. G. Van der Veen, and H. L. Ploegh. 2008. The known unknowns of antigen processing and presentation. Nat Rev Immunol 8:607-18.

197. Wajant, H. 2002. The Fas signaling pathway: more than a paradigm. Science 296:1635-6.

198. Wang, T., T. Town, L. Alexopoulou, J. F. Anderson, E. Fikrig, and R. A. Flavell. 2004. Toll-like receptor 3 mediates West Nile virus entry into the brain causing lethal encephalitis. Nat Med 10:1366-73.

199. Wengler, G., and G. Wengler. 1989. Cell-associated West Nile flavivirus is covered with $\mathrm{E}+$ pre-M protein heterodimers which are destroyed and reorganized by proteolytic cleavage during virus release. J Virol 63:2521-6.

200. Werme, K., M. Wigerius, and M. Johansson. 2008. Tick-borne encephalitis virus NS5 associates with membrane protein scribble and impairs interferonstimulated JAK-STAT signalling. Cellular Microbiology 10:696-712.

201. Werme, K., M. Wigerius, and M. Johansson. 2008. Tick-borne encephalitis virus NS5 associates with membrane protein scribble and impairs interferonstimulated JAK-STAT signalling. Cell Microbiol 10:696-712.

202. Yasumura, Y., and Y. Kawakita. 1963. Studies on SV40 in tissue culture preliminary step for cancer research in vitro. Nippon Rinsho 21:201-1215.

203. Yoneyama, M., and T. Fujita. 2010. Recognition of viral nucleic acids in innate immunity. Rev Med Virol 20:4-22.

204. Zhang, M., S. Daniel, Y. Huang, C. Chancey, Q. Huang, Y. F. Lei, A. Grinev, H. Mostowski, M. Rios, and A. Dayton. 2010. Anti-West Nile virus activity of in vitro expanded human primary natural killer cells. BMC Immunol 11:3.

205. Zhang, Z., and F. S. Wang. 2005. Plasmacytoid dendritic cells act as the most competent cell type in linking antiviral innate and adaptive immune responses. Cell Mol Immunol 2:411-7.

206. Zhou, L. J., and T. F. Tedder. 1996. CD14+ blood monocytes can differentiate into functionally mature CD83+ dendritic cells. Proc Natl Acad Sci U S A 93:2588-92. 



\section{Anhang}

\subsection{Abbildungsverzeichnis}

Abbildung 1.1: Schema zum Ursprung und der Entwicklung sowie zum ausgebildeten Phänotyp von humanen DCs (modifiziert nach (119))................. 5

Abbildung 1.2: Schema zur Erkennung von PAMPs und Signalweiterleitung durch die PRRs sowie zur autokrinen Typ I IFN-Schleife.

Abbildung 1.3: Aufbau des Genoms und Polyproteins der Flaviviren.

Abbildung 1.4.: Replikationszyklus der Flaviviren (Abbildung modifiziert nach (139)).

Abbildung 1.5: Viraler Übertragungszyklus des FSME-Virus (Abbildung modifiziert nach (127)).

Abbildung 1.6: Interaktion von FSME-Virus mit dem Immunsystem der Säugetiere (Abbildung modifiziert nach (55)).

Abbildung 3.1: Reinheitsanalyse der isolierten mDCs.

Abbildung 3.2: Reinheitsanalyse der isolierten pDCs.

Abbildung 3.3: Durchflußzytometrische Analyse der Expression von spezifischen und antigenpräsentierenden Molekülen der mDCs.

Abbildung 3.4: Durchflußzytometrische Analyse der Expression von kostimulatorischen-, Aktivierungs- und Maturierungsmarken der mDCs.

Abbildung 3.5: Durchflußzytometrische Analyse der Expression von Adhäsions- und Apoptose-Markern der mDCs.

Abbildung 3.6: Durchflußzytometrische Analyse der Expression von spezifischen und antigenpräsentierenden Molekülen der pDCs.

Abbildung 3.7: Durchflußzytometrische Analyse der Expression von kostimulatorischen-, Aktivierungs- und Maturierungsmarken der pDCs........ 96

Abbildung 3.8: Durchflußzytometrische Analyse der Expression von Adhäsions- und Apoptose-Markern der pDCs.

Abbildung 3.9: Darstellung des zeitlichen Verlaufs der IFN-a-Produktion der mDCs und pDCs.

Abbildung 3.10: Messung der inflammatorischen Zytokine der mDCs mittels CBA.

Abbildung 3.11: Messung der inflammatorischen Zytokine der pDCs mittels CBA.

Abbildung 3.12: Mikroskopische Fotos der TCID $_{50}$-Analysen der mDC- und pDC-Zellkulturüberstände auf Vero-B4-Indikatorzellen. 
Abbildung 3.13: Darstellung der Ergebnisse der TCID $_{50}$-Anaylsen von den mDC- und pDC Zellkulturüberständen.

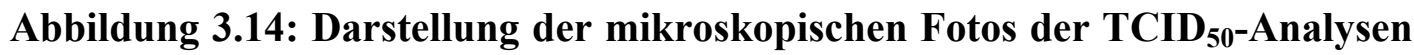
der pDC Zellkulturüberstände und der Überstände der IFNARAntikörper behandelten pDCs auf Vero-B4-Indikatorzellen.

Abbildung 3.15: Darstellung der Ergebnisse der TCID $_{50}$-Analysen der pDC Zellkulturüberstände und der Überstände der IFNAR-Antikörper behandelten pDCs.

Abbildung 3.16: Ergebnisse des TCID $_{50}$ des MTT-Assays mit den Zellkulturüberständen der pDCs.

Abbildung 3.17: Foto des 2\%igen Agarosegels mit den aufgetragenen GAPDHRT-PCR Produkten.

Abbildung 3.18: Darstellung der berechneten RNA Konzentrationen der RNAProben aus den pDCs und den Zellkulturüberständen.

Abbildung 3.19: Reinheitsanalyse der isolierten T-Zellen.

Abbildung 3.20: Durchflußzytometrische Analyse der Expression von Aktivierungsmarkern auf $\mathrm{CD4}^{+} \mathrm{T}$-Zellen.

Abbildung 3.21: Durchflußzytometrische Analyse der Expression von Aktivierungsmarkern auf $\mathrm{CD8}^{+} \mathrm{T}$-Zellen.

Abbildung 3.22: Zytokinantwort der T-Zellen auf die Infektion mit dem FSME-Virus.

Abbildung 3.23: Darstellung der mikroskopischen Fotos der TCID 50-Analysen der T-Zellkulturüberstände auf Vero-B4-Indikatorzellen.

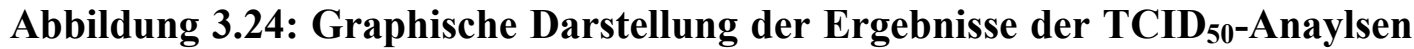
der T-Zell-Kulturüberstände.

Abbildung 3.25: Ergebnisse des TCID $_{50}$ des MTT-Assays mit Zellkulturüberständen der T-Zellen.

Abbildung 3.26: Ergebnisse des Proliferationstest der T-Zellen in der PBMCKultur mittels CFSE 5 Tage nach der Infektion.

Abbildung 3.27: Durchflußzytometrische Analyse der Expression von Aktivierungsmarkern auf kokultivierten pDCs und T-Zellen nach FSMEVirusinfektion.

Abbildung 3.28: Zytokinantwort der Kokultur von pDCs und T-Zellen auf die Infektion mit dem FSME-Virus. 


\subsection{Tabellenverzeichnis}

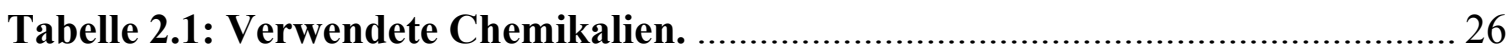

Tabelle 2.2: Verwendete Materialien für die Zellkultur und Verbrauchswaren...... 28

Tabelle 2.3: Verwendete Gerätschaften. .................................................................. 32

Tabelle 2.4: Verwendete Puffer, Medien und Lösungen. ............................................. 36

Tabelle 2.5: Verwendete Antikörper und Fluoreszenzfarbstoffe............................. 38

Tabelle 2.6: Verwendete Oligonukleotidprimer und Sonden. .................................. 41

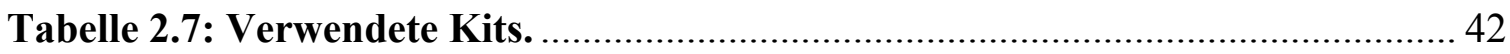

Tabelle 2.8: Verwendete Programme zur Datenanalyse, Literaturrecherche und Textverarbeitung. 43

Tabelle 2.9: Reaktionsansatz für die GAPDH RT-PCR mittels dem LightCycler 480 RNA Master Hydrolysis Probes Kit. ........................................................... 79

Tabelle 2.10: Programm für die GAPDH-RT-PCR .................................................... 79

Tabelle 2.11: Reaktionsansatz für die FSMEV-RT-PCR mittels dem LightCycler 480 RNA Master Hydrolysis Probes Kit...................................................... 82

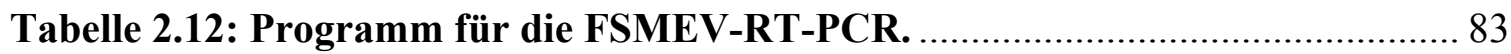

Tabelle 3.1: Aufführung der Cp-Werte und RNA-Konzentrationen der FSMEVRT-PCR der RNA-Proben aus den pDC-Überständen sowie aus den pDCs und des FSME-Virus-RNA Standards. 


\subsection{Publikationsverzeichnis}

Teile dieser Arbeit sowie verwandte Themen wurden wie folgt veröffentlicht:

\subsubsection{Publikationen mit persönlicher Beteiligung}

\section{Bastian Dörrbecker, Gerhard Dobler, Martin Spiegel and Frank T. Hufert}

"Tick-borne encephalitis virus and the immune response of the mammalian host" Travel Medicine and Infectious Disease (2010); (8), p.213-222.

Bastian Dörrbecker, Thorsten Volgmann, Gerhard Dobler, Martin Pfeffer, Martin Spiegel and Frank T. Hufert

"Tick-borne encephalitis virus and the interaction with dendritic cells"

In Vorbereitung.

\subsubsection{Aufführung der Präsentationen}

\subsubsection{Vorträge}

Bastian Dörrbecker, Martin Spiegel, Gerhard Dobler, Martin Pfeffer, Frank T. Hufert „Interaction of tick-borne encephalitis virus strains with plasmacytoid dendritic cells“ German Arbovirus Research Network Symposium, Berlin 18.-21.März 2008

Bastian Dörrbecker, Martin Spiegel, Gerhard Dobler, Martin Pfeffer, Frank T. Hufert „Interaction of tick-borne encephalitis virus strains with plasmacytoid dendritic cells and T cells"

7th Workshop of the Society for Virology; Study group "Immunobiology of Viral Infections", Deidesheim 8.-10.Oktober 2008

Bastian Dörrbecker, Martin Spiegel, Gerhard Dobler, Martin Pfeffer, Frank T. Hufert „Interaction of tick-borne encephalitis virus strains with plasmacytoid dendritic cells and $\mathrm{T}$ cells" X International Jena Symposium on Tick-Borne Diseases, Weimar 18.-21.März 2009 


\subsubsection{Posterpräsentationen}

Bastian Dörrbecker, Gerhard Dobler, Martin Pfeffer, Frank T. Hufert, Martin Spiegel "Interaction of tick-borne encephalitis virus strains with plasmacytoid dendritic cells and T-cells"

19th Annual Meeting of the Society for Virology (GfV), Leipzig 18.-21.März 2009

Bastian Dörrbecker, Thorsten Voglmann, Gerhard Dobler, Martin Pfeffer, Martin Spiegel, Frank T. Hufert

„Interaction of tick-borne encephalitis virus with human myeloid- and plasmacytoid dendritic cells“"

GfV Jahrestagung 23.-26.03.2011 in Freiburg

Martin Spiegel, Bastian Dörrbecker, Gerhard Dobler, Martin Pfeffer, Frank T. Hufert „Interaction of tick-borne encephalitis virus with human plasmacytoid- and myeloid dendritic cells"

Nationales Symposium zur Zoonosenforschung, Berlin, 07.-08.10.2009 


\subsection{Danksagung}

Als erstes möchte ich mich bei Prof. Dr. Frank Hufert bedanken, dass ich meine Doktorarbeit in seiner Abteilung anfertigen durfte und weiterhin für die wissenschaftliche Betreuung, für die aufschlussreichen Diskussionen und die freundliche Aufnahme in die Arbeitsgruppe.

Bei Dr. Martin Spiegel möchte ich mich für die Betreuung während der Phase meiner Doktorarbeit und darüber hinaus für die wertvollen und sachkundigen Tipps, die fachlichen und menschlichen Gespräche sowie für die angenehme Atmosphäre bedanken.

Bei PD Dr. Michael Hoppert möchte ich mich für die engagierte Betreuung meiner Doktorarbeit, für die tatkräftige organisatorische Unterstützung und die wissenschaftlichen Diskussionen bedanken.

Des Weiteren bedanke ich mich bei Prof. Dr. Gerhard Hunsmann für die Betreuung meiner Doktorarbeit und für die tollen wissenschaftlichen sowie sportwissenschaftlichen Diskussionen.

Weiterhin möchte ich mich herzlich bei allen Mitgliedern des Deutschen Arbovirus Netzwerkes (AVN) für die informativen Tagungen, Fachgespräche und der tollen freundschaftlichen Atmosphäre bedanken. Insbesondere danke ich dabei Herrn Dr. Gerhard Dobler für die aufschlussreichen und interessanten Gespräche.

Bei Dr. Manfred Weidmann möchte ich mich für die zahlreichen Tipps und informativen sowie anregenden Unterhaltungen und der konstruktiven Kritik bedanken.

Ein ganz besonderer Dank geht an Dr. Meik Dilcher für die vielen hilfreichen und interessanten Gespräche, die wissenschaftlichen Ratschläge und die tolle Zusammenarbeit rund um das S3-Labor.

Für die sehr freundliche Betreuung und die tolle Atmosphäre während meines Aufenthaltes in der Abteilung Virologie des Universitätsklinikums Freiburg möchte ich mich ganz herzlich bei PD Dr. Ursula Meyer-König, Dr. Kerstin Schneider, Sabine Zidane und Babara Günzel bedanken.

Ein großes Dankeschön geht auch an den DRK-Blutspendedienst NSTOB in Springe, die uns immer sehr zuverlässig mit Buffy-Coats versorgt haben und speziell an den Herrn Dr. Thorsten Volgmann für das Zustandekommen des hervorragenden Services, den 
sehr netten Kontakt und für den informationsreichen Besuch des DRK-Blutspendedienst in Springe.

Mein Dank gilt an dieser Stelle auch an ein tolles und schlagkräftiges Team, bestehend aus Andrea Paluschkiwitz, Andrea Koch, Doris Heidenreich, Susanne BöhlkenFascher und Udo Goldmann, das mich während der Zeit meiner Doktorarbeit freundschaftlich aufgenommen hat und mir mit Rat und Tat beiseite gestanden hat: Dankbar anerkennen will ich auch die vielen Diskussionen und all die schönen Momente, die den Laboralltag verschönert haben.

Ein großes Dankeschön geht auch an die Frau Erika Pitz für die tatkräftige und sehr freundliche Unterstützung sowie für die tollen Ratschläge.

Ganz besonders möchte ich mich bei Tanja Gall für die wertvollen Tipps und vielen wissenschaftlichen- und zwischenmenschlichen Unterhaltungen sowie für die mitfühlende und moralische Unterstützung bedanken.

Bei meinen „Mitdoktoranden“ Dora Finkeisen, Katharina Schnülle, Milena Euler, Tom Essien und Mathias Besse, möchte ich mich für das angenehme Betriebsklima in unserem Büro, den vielen Diskussionen und medizinischen- wie auch biologischen Auseinandersetzungen bedanken. Außerdem möchte ich mich bei meinem Mitstreiter Ahmed Abdel Wahed für die zahlreichen wissenschaftlichen- und kulturellen Unterhaltungen bedanken.

Bei meinen Freunden Katrin Gunka, Eva Rietkötter, Denise Lüttmann, Christoph Wrede, Henning Seemann und Markus Mientus möchte ich für die moralische Unterstützung, die zahlreichen wissenschaftlichen Diskussionen, die schönen Stunden neben dem Laboralltag sowie der tollen Studienzeit in Göttingen bedanken.

Bei meinem Bruder Sven möchte ich mich für die wichtigen Ratschläge und die konstruktive Kritik bedanken.

Ein ganz besonderer Dank gilt meinen Eltern, die mich während meines Studiums gefördert und unterstützt haben. 


\subsection{Lebenslauf}

\section{Bastian Dörrbecker}

\section{Geboren am 01. August 1981 in Kassel}

\section{Diplom Biologe}

\section{Nationalität: deutsch}

$12 / 2007-03 / 2011$

Doktorand im Institut für Virologie der Universitätsmedizin Göttingen der Georg-August Universität Göttingen in der Arbeitsgruppe Hufert;

Thema der Doktorarbeit: „Interaktion des Frühsommer-Meningoenzephalitis-Virus mit antigenpräsentierenden Zellen“"

02/2007-10/2007 Diplomarbeit in der Abteilung allgemeine Mikrobiologie im Institut für Mikrobiologie und Genetik an der Georg-August Universität Göttingen in der Arbeitsgruppe Stülke;

Thema der Diplomarbeit: „Der Einfluss der Temperatur auf die Aktivität von RNA-Schaltern der Transkription in Bacilli“

10/2002-02/2007 Diplomstudiengang Biologie an der Georg-August Universität zu Göttingen

08/2001-06/2002 Ableistung des Zivildienstes bei der Kasseler Werkstatt e. V.

08/1992-05/2001 Besuch der Georg-Christoph-Lichtenberg-Schule in KasselOberzwehren

Abschluss: Abitur

09/1988-06/1992 Besuch der Grundschule Niedervellmar 
